\title{
MODELLING SHARED VEHICLE SYSTEM DESIGN AND OPERATION \\ USING DISCRETE-EVENT SIMULATION TECHNIQUE
}

By

Md. Akhtar Hossain

M.Eng. (Transportation Engineering), Asian Institute of Technology, 1996

B.Sc. (Civil), Bangladesh University of Engineering \& Technology, 1989

\author{
A thesis submitted to the \\ Faculty of Graduate Studies and Research \\ In Partial Fulfillment of the Requirements \\ For the Degree of \\ Doctor of Philosophy \\ Department of Civil and Environmental Engineering \\ Carleton University \\ Ottawa, Ontario
}

May 2006

(C) Md. Akhtar Hossain, Ottawa, Canada, 2006

The Doctor of Philosophy in the Civil and Environmental Engineering Program is a joint program with the University of Ottawa, administered by the Ottawa-Carleton Institute for Civil Engineering 


$\begin{array}{ll}\begin{array}{l}\text { Library and } \\ \text { Archives Canada }\end{array} & \begin{array}{l}\text { Bibliothèque et } \\ \text { Archives Canada }\end{array} \\ \begin{array}{l}\text { Published Heritage } \\ \text { Branch }\end{array} & \begin{array}{l}\text { Direction du } \\ \text { Patrimoine de l'édition }\end{array} \\ \begin{array}{l}\text { 395 Wellington Street } \\ \text { Ottawa ON K1A 0N4 }\end{array} & \begin{array}{l}\text { 395, rue Wellington } \\ \text { Ottana ON K1A ON4 } \\ \text { Canada }\end{array}\end{array}$

Your file Votre référence ISBN: 978-0-494-16668-0 Our file Notre référence ISBN: 978-0-494-16668-0

NOTICE:

The author has granted a nonexclusive license allowing Library and Archives Canada to reproduce, publish, archive, preserve, conserve, communicate to the public by telecommunication or on the Internet, loan, distribute and sell theses worldwide, for commercial or noncommercial purposes, in microform, paper, electronic and/or any other formats.

The author retains copyright ownership and moral rights in this thesis. Neither the thesis nor substantial extracts from it may be printed or otherwise reproduced without the author's permission.
AVIS:

L'auteur a accordé une licence non exclusive permettant à la Bibliothèque et Archives Canada de reproduire, publier, archiver, sauvegarder, conserver, transmettre au public par télécommunication ou par l'Internet, prêter, distribuer et vendre des thèses partout dans le monde, à des fins commerciales ou autres, sur support microforme, papier, électronique et/ou autres formats.

L'auteur conserve la propriété du droit d'auteur et des droits moraux qui protège cette thèse. $\mathrm{Ni}$ la thèse ni des extraits substantiels de celle-ci ne doivent être imprimés ou autrement reproduits sans son autorisation.
In compliance with the Canadian

Privacy Act some supporting forms may have been removed from this thesis.

While these forms may be included in the document page count, their removal does not represent any loss of content from the thesis.
Conformément à la loi canadienne sur la protection de la vie privée, quelques formulaires secondaires ont été enlevés de cette thèse.

Bien que ces formulaires aient inclus dans la pagination, il n'y aura aucun contenu manquant. 


\begin{abstract}
As an alternative transportation paradigm, shared vehicle systems (SVS) have been implemented in recent years in Europe, North America, Japan, and other countries of the world. SVS systems consist of a fleet of vehicles that are used several times each day by different users. As compared with private automobile, the SVS systems offer a number of advantages. They reduce the number of vehicles, hence parking demand, required to meet total travel demand. Additionally, energy and environmental benefits materialize when low-polluting e.g., electric vehicles (EV) are used.
\end{abstract}

To date, a number of SVS systems have been implemented and evaluated in North America and around the world. The evaluation findings of these projects revealed the effects of SVS systems on user travel behaviors (i.e., mode choice, commuting habit). These findings and the state-of-the-art of modelling efforts suggest research need to enhance the design and operations of SVS systems with a complete set of design variables. Therefore, the objective of this study is to develop an improved simulation model for the design and operations of SVS systems focused on multiple station and station car. For achieving this objective, discrete-event simulation technique within the application of queuing theory to network framework is adopted. Within this framework, a powerful simulation model has been developed and is implemented in Microsoft Visual C++ environment using CSIM 19. Based on an iterative approach, an efficient and effective design configuration is identified which satisfies a set of measures of performance including user waiting time and number of vehicle relocations. 
Analyses showed that SVS systems performance is highly sensitive to vehicle-to-trip ratio and parking-to-vehicle ratio. User waiting time and number of vehicle relocations is found as direct function of vehicle-to-trip and parking-to-vehicle ratios. The SVS systems capacity was found to increase with vehicle-to-trip ratio. Systems with higher demand proved to be served with lower vehicle-to-trip ratio and more economically. The test case study shows that electric vehicles are suitable for serving travel demand requirement of SVS systems with respect to existing battery range.

Analysis with Bayesian probabilistic technique in estimating travel time showed that in the absence of incident related congestion and delay, the SVS systems operation is insensitive to the accuracy gain in travel time for customer wait time and number of relocations. Results showed that the system performance was not significantly affected, at $5 \%$ or $10 \%$ level, until travel times were 1.75 times the base travel times. A preliminary cost analysis showed that SVS systems could compete with private car and taxi.

This thesis research contributes knowledge to the field of public transportation. The philosophical basis for the SVS systems is highlighted in terms of serving a niche travel market. The scientific basis for system planning and design is advanced by developing and illustrating a simulation model that is more advanced than models reported in the literature. The Ottawa case study serves the purpose of showing how the simulation model works and can be used to find efficient and effective design configuration. For applications elsewhere, the suggested stated preference (SP) approach can be used to obtain travel demand inputs required by the simulation model. 


\section{ACKNOWLEDGEMENTS}

The author wishes to extend his heartiest thanks to Prof. Ata M. Khan, the thesis Supervisor, for his constant encouragement, guidance, and advice throughout the course of this research study.

Special thanks are extended to the members of the Ph.D. Advisory committee, especially to Prof A.K.M. Ehsan Saleh and Prof. Juan J. Salinas for their constructive comments and suggestions throughout this research.

The author would like to convey his sincere appreciation to Mr. Siddhartha Bishnu and Anuj Nijhawan for their help in developing the algorithm and computer code.

The author also would like to extend his sincere and deep appreciation to his fellow friends, at Carleton University, for their moral supports during the course of study.

Finally, the author would like to express sincere gratitude to his beloved wife, Monami, and twin sons, Tauheed and Tamjeed, who inspired and encouraged him at every stage of this research study. 
This thesis work is dedicated to Almighty Allah and my Parents to whom I am grateful for my life, and to my Teachers to whom for my knowledge. 


\section{TABLE OF CONTENTS}

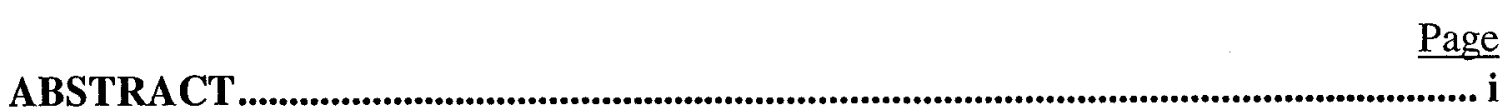

ACKNOWLEDGEMENTS ..................................................................................................... iii

TABLE OF CONTENTS ...........................................................................................................v

LIST OF TABLES ...............................................................................................................

LIST OF FIGURES ................................................................................................... xiv

\section{CHAPTER I}

PROBLEM IDENTIFICATION AND RESEARCH FRAMEWORK..............1

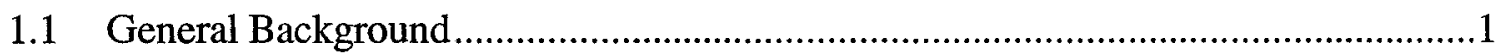

1.2 Shared Vehicle Systems: Different Forms and Concepts.........................................9

1.3 Shared Vehicle Systems Operations......................................................................16

1.4 Shared Vehicle Systems: Design and Operation Problems .......................................21

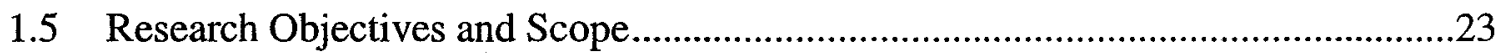

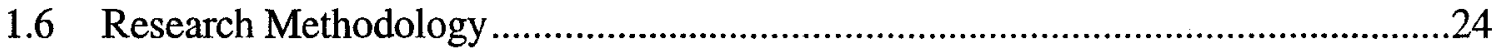

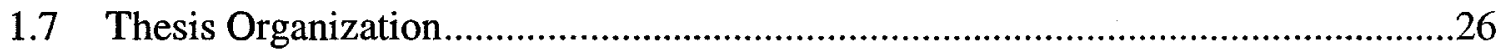

\section{CHAPTER II}

SHARED VEHICLE SYSTEMS EXPERIMENTAL RESEARCH: LITERATURE

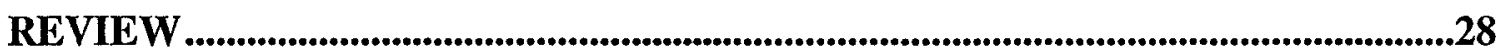

2.1 History of Carsharing or Shared Vehicle Systems ……….....................................28

2.1.1 Carsharing in Europe ....................................................................................28

2.1.2 Carsharing in North America..........................................................................31

2.1.3 Carsharing in Asia ........................................................................................3

2.1.4 Carsharing in Latin America........................................................................34

2.2 Effects of Carsharing on Travel Behavior ...............................................................35

2.2.1 Effects on Vehicle Ownership and Mode Choice...........................................36

2.2.2 Mobility Effect................................................................................................ 
2.3 Role of ITS Technologies in Shared Vehicle Systems Management

2.4 Shared Vehicle System Demonstration Projects ...................................................41

2.5 State-of-the-Art of Shared Vehicle Systems Programs in North America ...............42

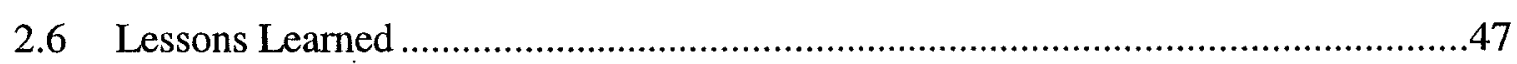

\section{CHAPTER III}

\section{RECENT MODELLING EFFORTS AND APPROACHES: LITERATURE

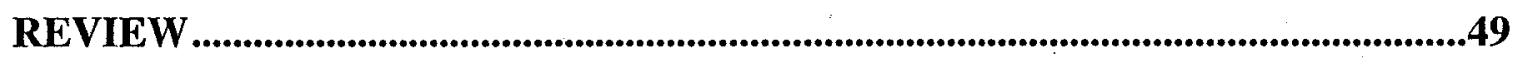

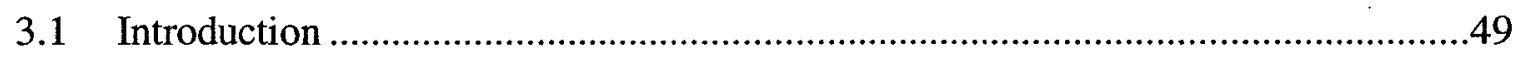

3.2 Barth and Todd's Multiple Station Shared Vehicle System Simulation Model.......50

3.3 The Kyoto Public-Car System's Simulation Model ..............................................56

3.4 Simulation Models For French Praxitele Trial Project ......................................62

3.5 A Model of Car Availability in Car-Sharing Scheme of Different Sizes ................65

3.6 Simulation Analysis of A Mobility Enterprise System's Operation-Purdue

University, Indiana, USA

3.7 The Use of Electric Vehicles (EVs) in CFB Ottawa's Base Taxi Fleet-A

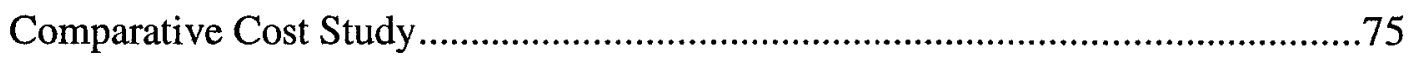

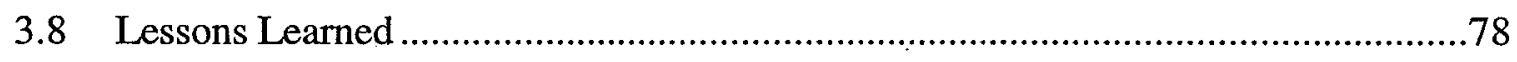

\section{CHAPTER IV}

A FRAMEWORK FOR MODELLING SHARED VEHICLE SYSTEMS ...............80

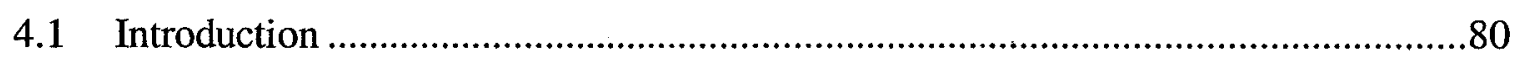

4.2 Structuring the New Modelling Framework...................................................82

4.2.1 Demand-Supply Interaction in Shared Vehicle Systems Operations..............86

4.2.1.1 Methodology for Design Variables Selection................................89

4.2.1.2 Formulation of Dynamic Database and Travel Demand Profile .......92

4.2.1.3 Selection of Complete Set of Design Variables and Development of

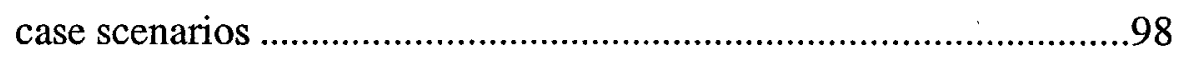

4.3 Shared Vehicle Systems Simulation Model Development.....................................105

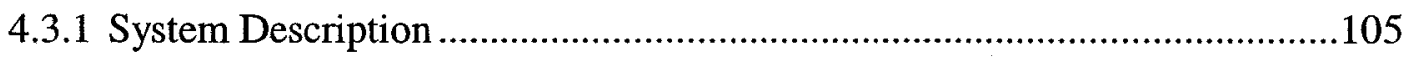


4.3.2 Data Requirement.

4.3.3 Simulation Model Development Strategy.....

4.3.3.1 Stochastic Trip Generator

4.3.3.2 Traffic Simulator

4.3.3.3 Modelling Shared Vehicle System's other Dynamic Characteristics 126

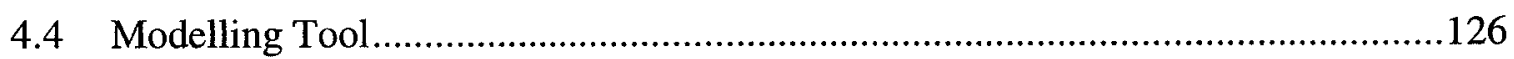

4.5 Evaluation of the Simulation Model Results..................................................127

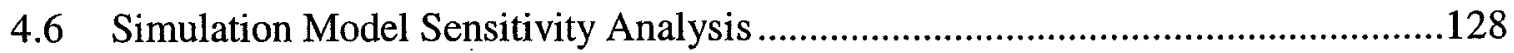

4.7 Energy Savings Estimation and Cost Analysis of Shared Vehicle Systems...........129

4.7.1 Methodology for Petroleum Energy Savings Estimation ...........................130

4.7.2 Methodology for Economic Analysis .......................................................130

\section{CHAPTER V}

DISCRETE EVENT SIMULATION TECHNIQUE...............................................133

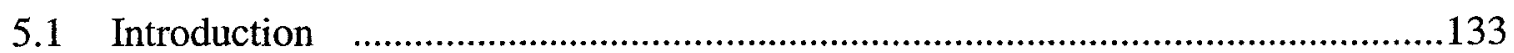

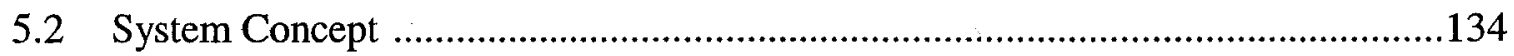

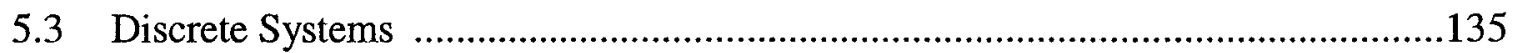

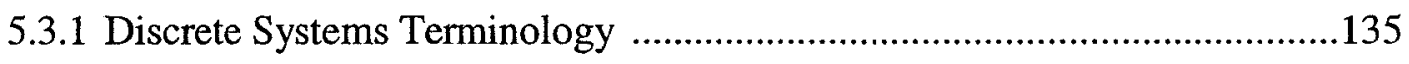

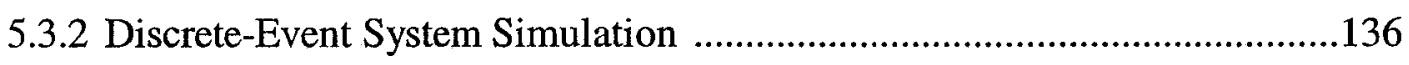

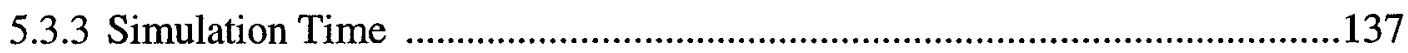

5.3.3.1 Time Management Techniques in Discrete System Simulation .....138

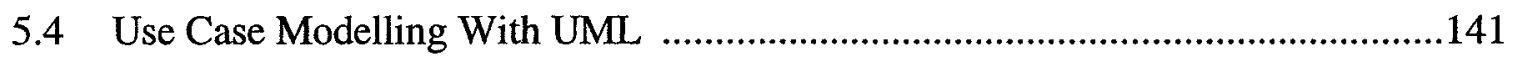

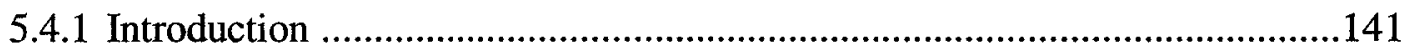

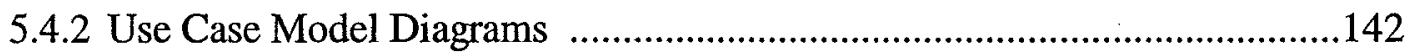

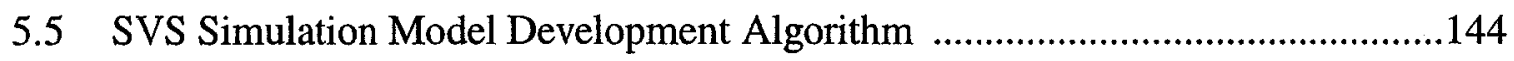

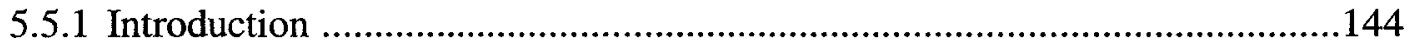

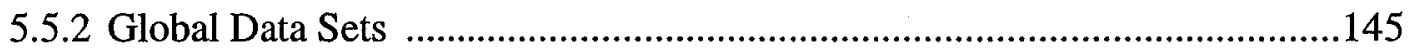

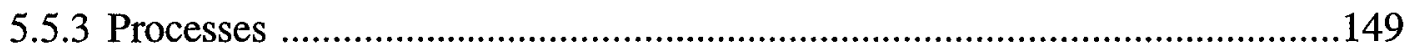

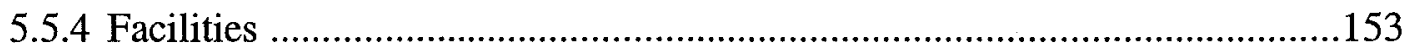

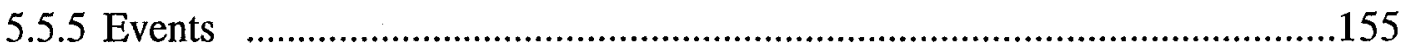

vii 


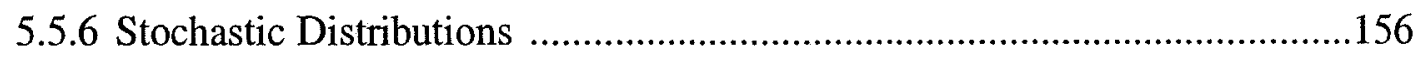

5.6 UML Architecture of Shared Vehicle System Model ...........................................158

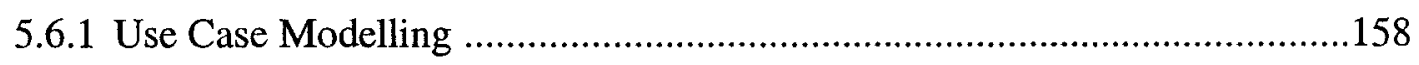

5.6.1.1 Documenting Use Cases ............................................................158

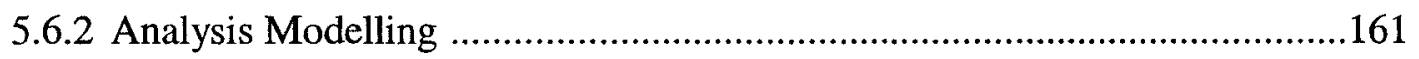

\section{CHAPTER VI}

MODEL IMPLEMENTATION, VALIDATION, TEST RESULTS..........................164

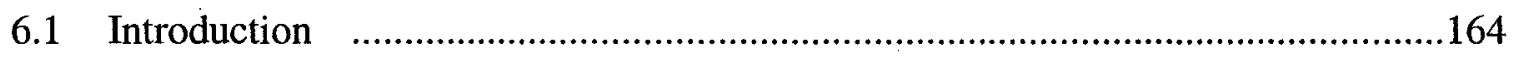

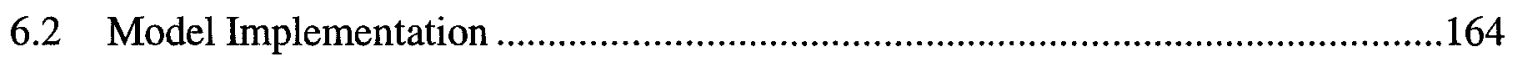

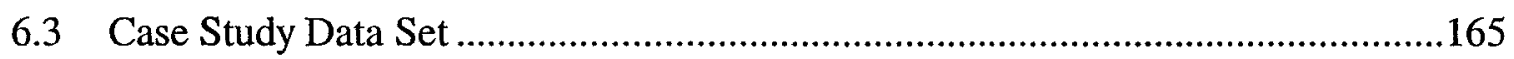

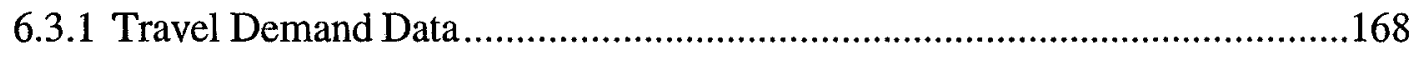

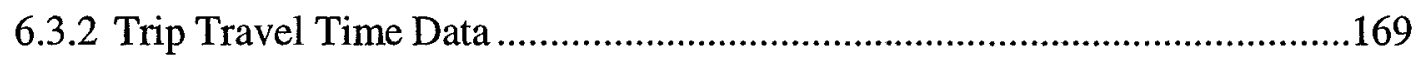

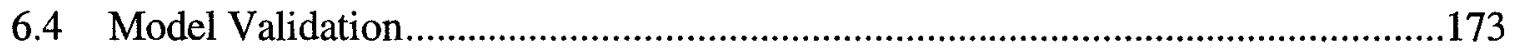

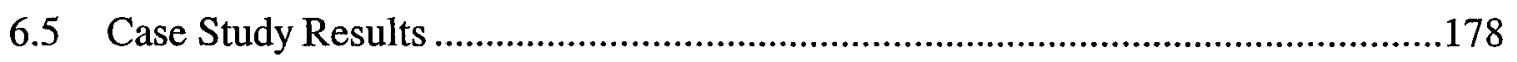

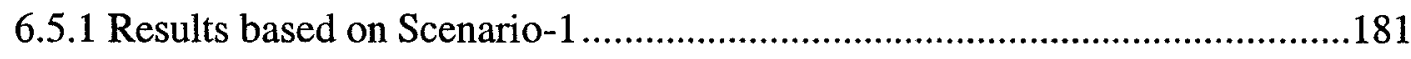

6.5.1.1 User Waiting Time and Number of Relocations Analysis ...............181

6.5.1.2 Analysis of Trips Served and Queue Length ....................................187

6.5.1.3 Analysis for Parking-to-Vehicle Ratio for a 5-Station SVS .............188

6.5.1.4 Capacity Sensitivity with Fleet Size ................................................191

6.5.1.5 Response of the System to Miscellaneous Variables .......................195

6.5.1.5.1 Trip Travel Time.............................................................195

6.5.1.5.2 Number of Stations .......................................................199

6.5.1.5.3 Higher Travel Demand.......................................................200

6.5.1.5.4 Vehicle State-of-Charge (SOC) ........................................208

6.5.2 Results based on Scenario-2 ………………………………………….......210

6.5.2.1 Wait Time and Relocation Analysis .................................................211

6.5.2.2 Analysis of Trips Served and Queue Length ....................................213

6.5.3 Results based on Scenario-3 ………………………………………….....214

6.6 Comparison of Energy Consumption: Petroleum Fuel Saving ...............................217 


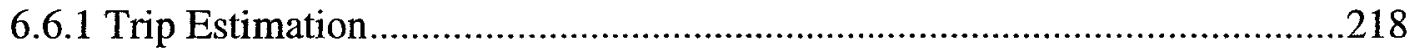

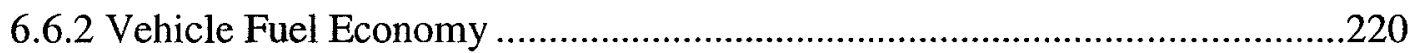

6.6.3 Fuel Consumption of Displaced Vehicles ...................................................222

6.6.4 Shared Vehicle System's EV and Relocation Trip Energy Consumption.....222

6.6.5 Petroleum Fuel Saving .................................................................................226

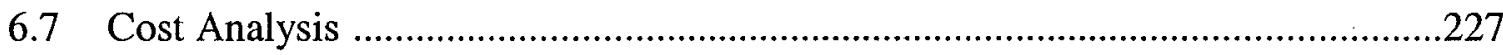

6.7.1 Cost Estimation .........................................................................................229

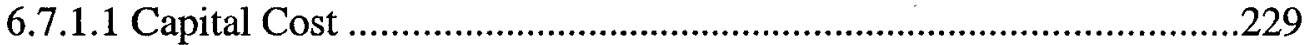

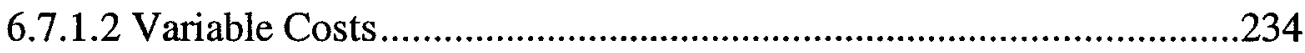

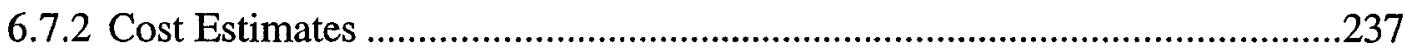

\section{CHAPTER VII}

CONCLUSIONS AND RECOMMENDATIONS...........................................................249

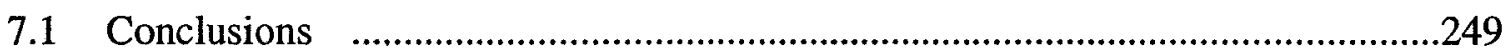

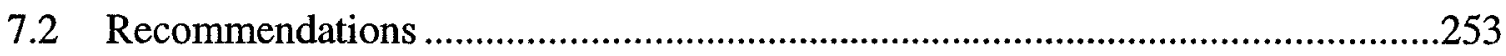

GLOSSARY OF TERMS......................................................................................

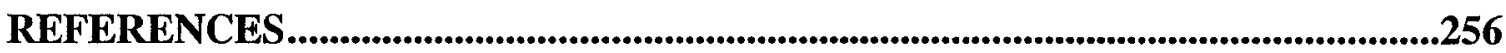

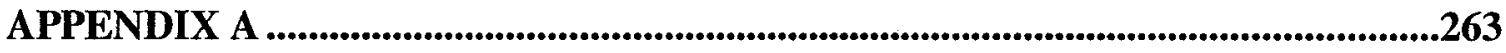

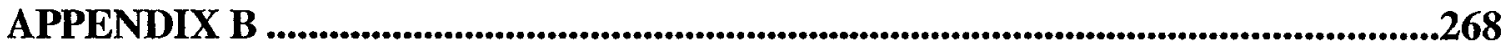

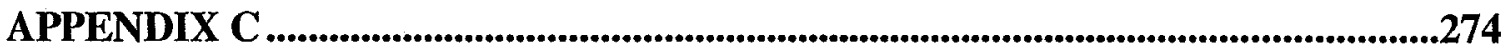

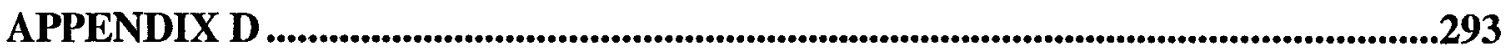

APPENDIX E ..................................................................................................................................302 


\section{LIST OF TABLES}

$\underline{\text { Tables }}$

Description of Tables

$\underline{\text { Page }}$

2.1 U.S. Cooperative Type Shared Vehicle Systems Programs ......................................43

2.2 U.S. Station Car Type Shared Vehicle Systems Programs........................................45

2.3 Canadian Shared Vehicle Systems Programs ..........................................................

3.1 Vehicle-to-trip ratios for wait time inflection point, and maximum and minimum number of vehicle relocations for different peak travel demand...............................53

3.2 Vehicle characteristics of mobility enterprise's fleet ..............................................72

3.3 Travel Demand of the Mobility Enterprise by trip purposes.....................................73

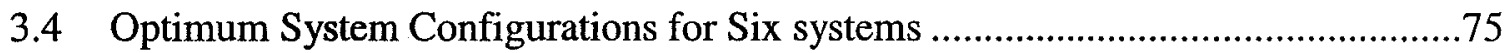

4.1 Typical travel demand matrix with ODs of $\mathrm{k}^{\text {th }}$ operation hour that includes trips

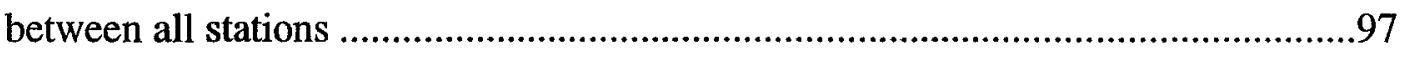

4.2 Variables and measures of performance (MOP) indicators selection ….................102

4.3 Sample OD pattern of Station \#1 .....................................................................117

4.4 Determination of trip destination in stochastic trip generation process .................117

4.5 Party size distribution observed in collected data set ............................................118

4.6 Sample party size modelling in stochastic trip generation process ........................119

5.1 Global data sets and their respective data fields...............................................145

5.2 Persistent and Temporary processes and their corresponding purpose ..................149

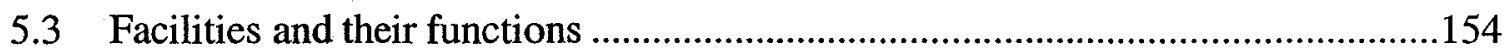

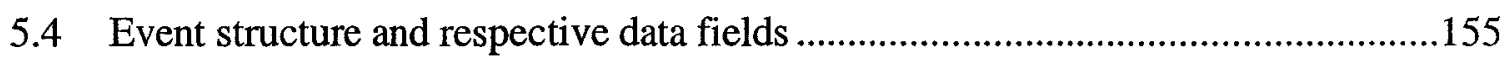

5.5 Stochastic distributions used in SVS simulation..............................................157 


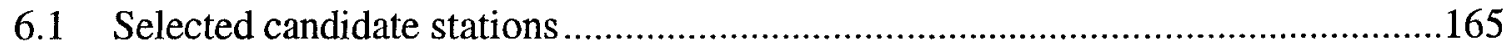

6.2 Travel demand for five stations case study system ….......................................169

6.3 Estimated travel times in minutes of trips among five stations..............................170

6.4 Sample prior probabilities for station \#1 ........................................................172

6.5 Conditional probabilities estimated by Riley (2002)..........................................172

6.6 MOP indicators values in model validation ..................................................175

6.7 Descriptive Statistics of MOP indicators ..........................................................176

6.8 Analysis of vehicle-to-trip ratio for a 5-station SVS system.................................184

6.9 Sample simulation model relocation activity output.......................................................186

6.10 Analysis of parking-to-vehicle ratio for a 5-station SVS system ...........................189

6.11 SVS capacity gains with respect to vehicle-to-trip ratio .......................................194

6.12 Comparison of optimal values of user average waiting time, number of relocations, trip served (\%), and vehicle SOC for three demand scenarios .................................204

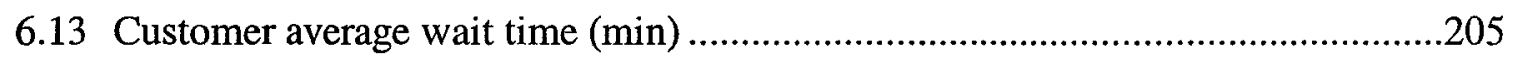

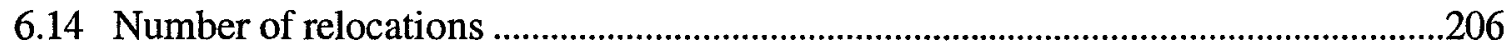

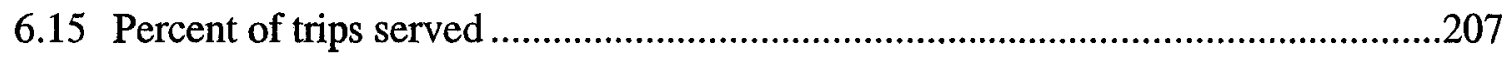

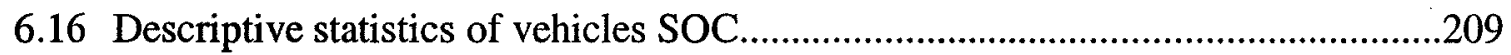

6.17 Comparison of normal average travel times with travel times estimated using

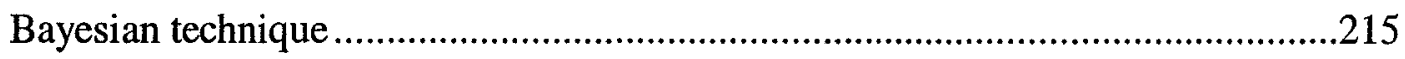

6.18 Fuel consumption of three types of vehicles, Final Report, Honda (1997)...........220

6.19 Average fuel consumption of standard ICE vehicles, from Garcia (2004) ............221

6.20 Average fuel consumption of standard ICE vehicles from Internet sources ..........221

6.21 Inter-station relocation trip distribution in percent............................................225 
6.22 Comparison of energy consumption.

6.23 Estimated cost of scenarios with different analysis period. .246

B.1 Origin-destination matrix of CFB Ottawa base taxi for selected stations, October 1979 .269

B.2 Candidate station selection analysis .270

B.3 Selected candidate stations .270

B.4 5-Station SVS system travel demand .271

B.5 5-Station SVS System travel demand 1.5 times of original .271

B.6 Modified travel time in minute data for 5-station system .272

B.7 Prior probability of three travel time states T1, T2, and T3 for 3-station SVS .....272

B.8 Conditional probabilities 272

B.9 Base/original travel time in minute .273

B.10 Bayesian Estimated Travel Times with Advisory R1 .273

B.11 Bayesian Estimated Travel Times with Advisory R3 .273

E.1 Analysis for Optimum Vehicle-to-Trip Ratio for a 5-Station SVS System . .302

E.2 Analysis for Optimal Parking-to-Vehicle Ratio for a 5-Station SVS System........303

E.3 Travel Time Sensitivity Analysis Results of Shared Vehicle System using registration KIOSK Statistics 303

E.4 Travel Time Sensitivity Analysis Results of Shared Vehicle System using ..........304

E.5 Shared vehicle system capacity gain w.r.t. vehicle-to-trip ratio . .304

E.6 Analysis for Optimum Vehicle-to-Trip Ratio for a 5-Station SVS System with travel demand 1.5 times of original 307 
E.7 Comparison of average wait time, number of relocations, and trip served (\%)

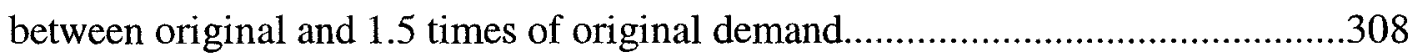

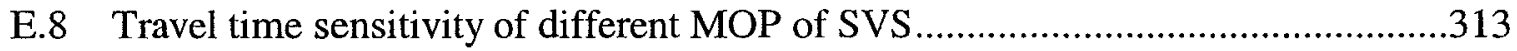

E.9 Number of relocations as a function of number of stations in the shared vehicle system network 316 


\section{LIST OF FIGURES}

Figures

Description of Figures

$\underline{\text { Page }}$

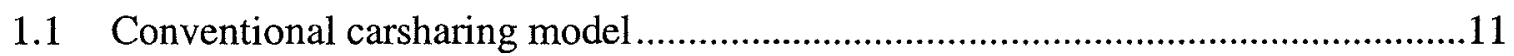

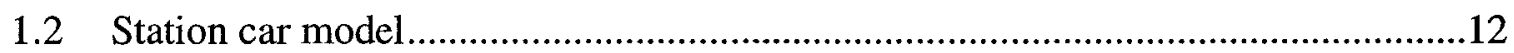

1.3 Multiple station shared vehicle system model....................................................14

1.4 Multiple station shared vehicle system operation and user interaction flowchart ...20

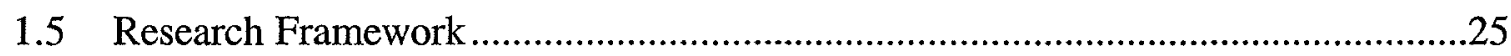

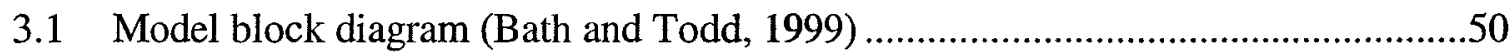

3.2 Simulation model flow chart, Kyoto Public-Car system...........................................60

3.3 Simulation model flow chart, Liu et al (1983) .......................................................

3.4 Number of vehicles needed to serve 100 trips in self-drive taxi system, CFB,

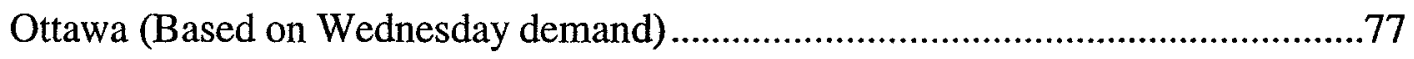

4.1 Conceptual framework for modeling shared vehicle systems ..................................85

4.2 Steps in demand-supply interaction modelling process ..........................................8

4.3 Real-time travel demand and vehicle distribution at stations....................................94

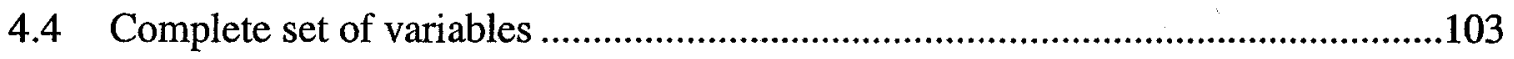

4.5 Multi-station intelligent shared vehicle system architecture ….............................106

4.6 Model Electric Vehicles ....................................................................................107

4.7 Shared vehicle system stations with hypothetical travel route .................................108

4.8 OCC with possible interfaces with vehicle fleet and users .....................................109

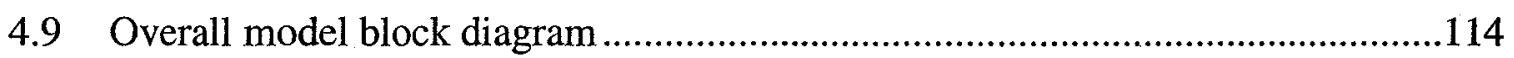

4.10 Exponential probability distribution function (qualitative) ……….........................115

xiv 
4.11 Flow chart of stochastic trip generator process

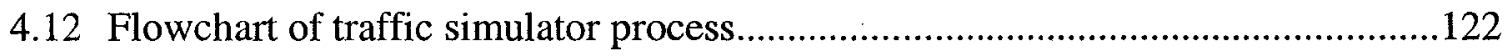

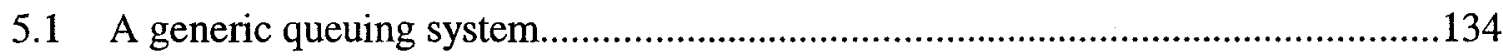

5.2 Time management techniques in simulation ...........................................140

5.3 Use Case diagram: Project management system ............................................143

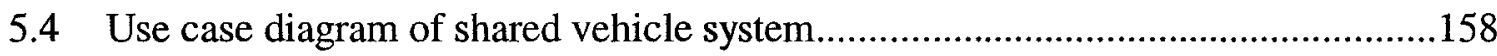

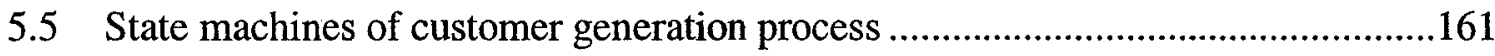

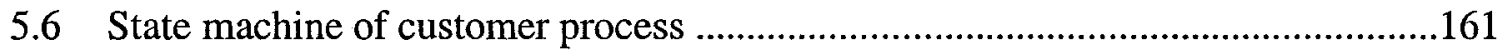

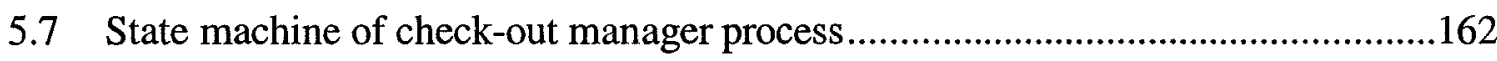

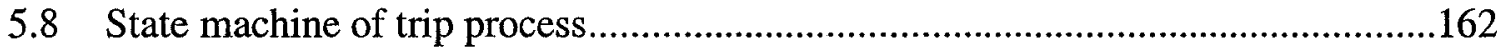

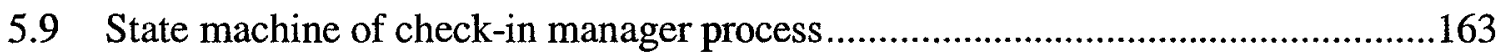

6.1 Case study area CFB Ottawa's departmental locations with potential stations (red

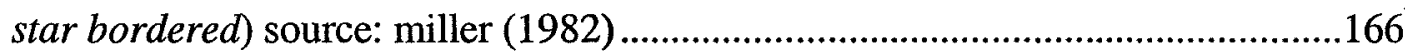

6.2 Detailed of selected five stations and surrounding road network..........................167

6.3 Diurnal variation of travel demand of selected stations ..................................168

6.4 Performance indicators variability level during model validation .......................174

6.5 Number of relocations and its $95 \%$ confidence interval in 20 runs .....................176

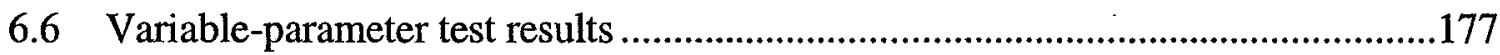

6.7 Average wait time and number of relocations as a function of vehicle-to-trip ratio183

6.8 Vehicle fleet size and number of relocations as a function of vehicle-to-trip ratio 185

6.9 Trips served and queue length as a function of vehicle-to-trip ratio ....................187

6.10 Number of relocations and trips served in percent as a function of parking-tovehicle ratio 
6.11 Number of relocations and user average waiting time as a function of parking-tovehicle ratio 190

6.12 Relationship of total trips served and vehicle-to-trip ratio 192

6.13 Effect of vehicle-to-trip ratio on system capacity 193

6.14 Effect of travel time on user wait time .195

6.15 Effect of travel time on number of relocations

6.16 Effect of travel time on trips served

6.17 Combined plot of trips served, queue length, number of relocations, and user average wait time for different travel time scenarios .198

6.18 Effect of number of stations on number of relocations 199

6.18 Trip served and customer average wait time as a function of vehicle-to-trip ratio at 1.5 times of original modelled demand .201

6.20 User wait time and number of relocations as a function of vehicle-to-trip ratio at demand 1.5 times of the original .202

6.21 Comparison of trips served (\%), number of relocations, and user average wait time between original and 1.5 times the original travel demand. .203

6.22 User average wait time ( $\mathrm{min}$ ) as a function of vehicle-to-trip ratio for base demand and 1.5 and 2.0 times of base demand .205

6.23 Number of relocations as a function of vehicle-to-trip ratio for base demand and 1.5 and 2.0 times of base demand. .206

6.24 Percent of trips served as a function of vehicle-to-trip ratio for base demand and 1.5 and 2.0 times of base demand. .207

6.25 Distribution of the vehicle's battery state-of-charge (SOC) .210

xvi 
6.26 User average wait time, and number of relocations as a function of vehicle-to-trip ratio in scenario-2

6.27 Total trips served (\%) and queue length (in trips) as a function of vehicle-to-trip ratio in scenario-2

6.28 User average wait time, and number of relocations as a function of vehicle-to-trip ratio in scenario-3 .216

6.29 Trips served and queue length as a function of vehicle-to-trip ratio in scenario-3 216

6.30 Estimated cost of scenarios with different analysis periods .247

6.31 Share $(\%)$ of individual cost items within total cost for 3-year analysis period.....248

6.32 Share (\%) of individual cost items in total cost for 10-year analysis period .248

E.1 Vehicle fleet size and number of relocations as a function of vehicle-to-trip ratio305

E.2 Average customer wait time and number of relocations as a function of vehicle-totrip ratio 305

E.3 Number of relocations and trips served in percent as a function of Relationship Parking-to-Vehicle Ratio 306

E.4 Estimated trips served and SVS capacity gain as a function of vehicle-to-trip ratio306

E.5 Average customer wait time and number of relocations as a function of vehicle-totrip ratio .309

E.6 Vehicle fleet size and customer average wait time as a function of vehicle-to-trip ratio 309

E.7 Trips served in percent and average queue length as a function of Relationship Parking-to-Vehicle Ratio 310 
E.8 Trips served in percent and average queue length as a function of relationship vehicle-to-trip Ratio

E.9 Comparison of average wait time, number of relocations, and trip served (\%) between original and 1.5 times of original demand.

E.10 Customer average wait time versus vehicle-to-trip ratio

E.11 Number of relocations versus vehicle-to-trip ratio plot

E.12 Total trips served in percent versus vehicle-to-trip ratio relationship

E.13 Customer average wait time and percent of change under different travel time scenarios

E.14 Number of relocations and percent of change in different travel time scenarios ...314

E.15 Total trips served in $\%$ and percent of change in different travel time scenarios...315

E.16 Queue length and percent of change under different travel time scenarios.

E.17 Number of relocations as a function of number of station in SVS system with linearly increased number of stations and demand at vehicle-to-trip ratio 10.5 percent and parking-to-vehicle ratio $2: 1$

E.18 Customer or user average wait time and its $95 \%$ C.I. for 20 simulation runs 319

E.19 Number of trips served in percent of total and its $95 \%$ C.I. for 20 simulation runs 319

E.20 Number of relocations and its $95 \%$ C.I. for 20 simulation runs .320

E.21 Average queue length and its $95 \%$ C.I. for 20 simulation runs 320

xviii 


\section{GLOSSARY OF TERMS}

ATL Average Trip Length

ARTL Average Relocation Trip Length

AVL Automatic Vehicle Location

CBD Central Business District

CFB Canadian Force Base

CI Confidence Interval

COV Coefficient of Variation

CTCC City Traffic Control Center

DND Department of National Defence

EV Electric Vehicle

FC Fuel Consumption

FCFS First Come First Serve

GIS Geographic Information System

GPS Global Positioning System

ICE Internal Combustion Engine

ITS Intelligent Transportation System

kWh Kilowatt Hour

MSSVS Multiple Station Shared Vehicle System

MOE Measure of Effectiveness 


$\begin{array}{ll}\text { MOP } & \text { Measure of Performance } \\ \text { NDT } & \text { Number of Displaced Trips } \\ \text { NR } & \text { Number of Relocations } \\ \text { OCC } & \text { Operation Control Center } \\ \text { OMG } & \text { Object Modeling Group } \\ \text { OPP } & \text { Object Oriented Programming } \\ \text { SOC } & \text { State-of-Charge } \\ \text { SVS } & \text { Shared Vehicle System } \\ \text { TM } & \text { Time Management } \\ \text { TMC } & \text { Transportation Management Center } \\ \text { UML } & \text { Unified Modeling Language } \\ \text { w.r.t. } & \text { with respect to }\end{array}$




\section{CHAPTER I}

\section{PROBLEM IDENTIFICATION AND RESEARCH FRAMEWORK}

\subsection{General Background}

Three major system innovations have transformed transportation in the past two centuries with profound and far-reaching impacts (Shaheen, 1999). First came the widespread adoption of interurban rail in the mid 1800s, several decades later came the introduction of electric urban rail, and then automobiles in the early 1900s. Railroads transformed the nature of business, electric-rail transformed collection of neighborhoods into metropolitan regions, and finally the automobile transformed lifestyle with maximum comfort and convenience in personal mobility. These innovations not only shaped transportation but also much more of our economy and society (Shaheen, 1999).

In the modern world of rapid change, it is remarkable how profoundly the motor vehicle (automobile) has revolutionized society, and economy (Shaheen, 1999). Providing large mobility benefits, private automobiles have become deeply entrenched, continuing to increase their share of travel, even in countries with high fuel and vehicle taxes, dense land use pattern, and high quality transit services. Indeed, private vehicles, cars and light trucks, now account for almost 80 percent (on average) of all motorized passenger travel in virtually all OECD (Organization for Economic Cooperation and Development) countries (Shaheen et al, 1998). Automobiles are becoming more dominant in many other countries around the world. Most travelers no longer reflect on their mode choice, using private automobiles for all metropolitan trips. 
This sweeping transformation of travel from collective conveyance to private vehicle generates large benefit on mobility and flexibility but also large costs, higher energy consumption, severe congestion, air pollution, noise pollution, accident, and other related stresses (Shaheen, et al, 1998). The impact of increasing traffic on the infrastructures (i.e., roads, highways, parking lots, intersections, interchanges, entrance and exit ramps, toll booths, etc) and the quality of urban life endangers the effective social and economic functioning of the cities. Not only does traffic create pollution and danger, the subject of much concern and attention, but it also makes ever-increasing demand on space need to construct more highways and parking lots, widening intersections, ramps, and toll booths, which results in unsustainable urban transportation development for the future. Public space in cities is increasingly dominated by cars, both in moving and parked, which are preventing other activities that are the lifeblood of the city from taking place. These spatial problems cannot really be solved by technical fixes (Shaheen, et al, 1998).

Shaheen, et al (1999), in their paper mentioned, it is axiomatic that transportation services and activities can be conducted more efficiently than they usually do now. Certainly travelers can be fully informed of options, services can be priced more correctly, and transaction costs can be reduced so that travelers will satisfy their travel desires economically and efficiently. But they are not, information about alternative modes and services (i.e., public transportation systems and services) is not well matched to travelers needs, public transit is either unavailable or inconvenient, and private vehicles are not the economic match to all mobility needs. The result is an uneconomical use of resources to move individuals using private vehicle extensively. In order to encourage a 
change, a reduction in ownership and use of private vehicle, and improve quality of urban life, a 'new form of urban mobility' called carsharing or shared vehicle system has recently evolved in many cities and communities in Europe, North America, and around the world (Bernard and Collins, 1998). By definition, shared vehicle systems can take many forms, but the underlying concept is that individual vehicles are not privately owned but are shared by several users making different trips throughout the day (Barth and Todd, 1999).

The vast majority of trips in North American metropolitan areas are drive-alone trips, about 90 percent (Salon, Sperling, Shaheen, and Sturges, 1999). This form of transportation is expensive and requires large amount of resources including vehicle, infrastructure, energy, and land. Today, commuters are more likely to spend longer time in commute than they did in the past (Shaheen, 1999). In contrast, attitudes toward commuting have become more negative in almost all communities. Despite these trends, in the $1990 \mathrm{~s}$, public transit accounted for less than five percent of the total passenger travel, on average, in North America (Vincent, et al., 1994; mentioned in Shaheen, 1999). A more efficient but less convenient alternative to private automobile use would allow drivers to share cars. By deploying "smart" transportation system technologies (i.e., ITS technologies) in connection with alternative vehicle usage arrangements, shared use vehicle, the opportunity now exists to enhance transit services, thereby improving their competitiveness with private, individually owned automobile that may significantly change travelers commuting and/or travel behavior (Shaheen, 1999). 
Demographic changes, energy consumption trend in transportation sector, concern about the future of transportation infrastructure, and growing interest in alternative mode of travel generate large thought, discussion, and research needs for sustainable transportation development in North American cities and around the world (Bernard and Collins, 2001). In his book "The Age of Access: The New Culture of Hypercapitalism, Where All of Life Is a Paid-For Experience," Rifkin (2000) demonstrates how commerce is evolving from sellers and buyers to suppliers and users; how society (both individuals and corporations) wants access to goods and services rather than ownership. Rifkin explains that we are now moving to an economy in which possessions are not nearly as important as access. The philosophies and concepts that are developed and used to explain the future likely form of our commerce, economy, and society raise realistic questions as the following:

Why own a van with capacity much larger than we need most of the time when, at less cost, we can have access to a van at the time we need it and use of an appropriate small car or a shared vehicle for running about town when we need to?

Why own a summer home when every year we can have use of a place in a different part of the world at less cost through time-shared services?

And many more

Examples of service replacing property and equipment ownership include buying into time-shared condominiums, leasing vehicles, leasing office and construction equipment and space, and outsourcing everything except the firm's core business. A lot more 
alternatives to ownership are found in the world. Philosopher Aristotle mentioned, "On the whole, you find wealth much more in use than in ownership" (www.carsharing.org).

Issues related to land use and urban development, that are becoming popular discussions among planners, politicians, and academicians often include such term as "new urbanism", "urban sprawl", "smart growth etc." (Bernard and Collins, 2001). These discussions bring together the problems of traffic congestion, air pollution, lack of affordable housing, and rapid loss of open space often proposing that an ideal solution would be to create livable cities, making use of existing infrastructure and revitalizing mixed-use neighborhood. Indeed, some North American cities seem to indicate that young professionals are flocking to renewed warehouse areas, restoring grand old Victorians, and creating urban start-up companies (Fishman, 1999). A recent study found that "the growth rates in some North American downtown areas are quite dramatic, primarily due to a small current population base" (Sohmer, et al, 1999). The study also implied that downtown areas are the home to an increasing number of young professionals, corporate executives, young married couples, and empty nesters, driving the central business district in America's largest cities in 24-hour center of commercial, cultural, entertainment, and residential life (Sohmer, et al, 1999). Fishman speculating about the future for the 32 million Americans who will be 75 years or older in 2030 , suggested that "if crime rates continue to decline in large cities, empty nesters might increasingly sell their suburban tract homes to move to urban apartments where a full range of services can be found within walking distance" (Fishman, 1999). 
Should increasing numbers of people choose to live in downtown urban areas, however, they will necessarily need to address such realities as limited parking space and higher cost of owning their cars. As a whole, the movement to new urbanism, or whatever it is finally called, means denser living, more walking, cycling, and transit trips, and less demand for that always-ready-to-go, expensive, and/or difficult-to-park household car. Shared, small, battery-powered electric, or other suitable technology cars (fuel cell, hybrid) used in carsharing and/or station cars, known as shared vehicle systems, application could be a better/realistic solution for such residential and/or mixed-use neighborhoods (Bernard and Collins, 2001). Station cars are normally electric vehicles (EVs) driven to and from mass transit stations by transit riders. They are usually an extension of mass transit, providing the same instant, yet more convenient and less hassled, mobility as conventional privately owned vehicles. These can, therefore, positively contribute to a city's clean air efforts and sustainable development (Bernard and Collins, 2001).

Carsharing is popular in many European countries for leisure and shopping trips (Reutter and Bohler, 2000). Several studies explained potential niche market for carsharing in other trips i.e., business, work, school, and mid-day activity (errand trips). Two pilot projects "Car Sharing for Companies in the Aachen Region, Germany" were carried out in two cities, Duren and Huchelhoven. The objectives of those projects were to find out (Reutter and Bohler, 2000):

1) how to design a carsharing scheme for the catering needs of companies, 
2) how carsharing for private and business use can be combined to run efficiently, and

3) what possibilities exist for its sustainable establishment (implementation) and spatial expansion.

The project, approved by the Ministries for Economic Affairs and Technology and Transport of the State and funded by the European Union, was scientifically analyzed by the Wuppertal Institute for Climate, Environment, and Energy. The oldest and biggest carsharing service provider in Germany, StadttAuto, took care of the marketing, vehicle pool/fleet management, and all services related to carsharing. A number of conclusions drawn from these pilot projects include the following:

1) In large towns, the chances of success for the introduction of carsharing are relatively good; a highly educated workforce, good public transport, a suitable railway connection and an organized carsharing offer have a favorable effect,

2) Carsharing stations should be planned to be within easy walking distance (10 minutes maximum) of as many different companies as possible in urban locations with dense, mixed residential and business land use. The more employees who travel to work by non-car modes, the better chances are of success.

From pricing perspective, the study (Reutter and Bohler, 2000) concluded that rates are particularly attractive for companies for their short and medium types urban mobility 
demands, and when long distance urban travel demands are fulfilled by other form of service i.e., combined use of carsharing, traditional car rental firms, and taxis. The majority of the companies, who took part in this innovative mobility service (i.e., carsharing) option, were satisfied with it and decided to stay with the service. Finally two substantial conclusions were derived from the results of the pilot projects. Business transport represents a tremendous opportunity for carsharing providers. When the recommendations for a promising carsharing offer are followed, growth rate can be increased remarkably as compared to the growth rates normally achieved for private households. Also, the degree of professionalism of the mobility suppliers can be enhanced. Companies as carsharing customers improve fleet utilization, and thereby support and complement the traditional core business of mobility suppliers, which traditionally, meet the needs of private households. As part of the modern mobility management for companies, carsharing can, together with other measures, contribute to the efficient organization of a company's mobility.

From the foregoing discussion, it is obvious that there is potential for the success of these innovative shared vehicle systems including station car and multiple station shared vehicle system. Therefore, these deserve research attention. Improved methodologies and models are required that could be used to explore the demand-supply interaction and critical systems performance issues. Some of these are vehicle availability and system imbalance, vehicle relocation need, average user wait time, portion or percentage of demand served, vehicle-to-user or vehicle-to-trip ratio, and parking-to-vehicle ratio. 


\subsection{Shared Vehicle Systems: Different Forms and Concepts}

\section{The Conventional Carsharing Concept}

The conventional carsharing concept originated in Europe about fifteen years ago (Barth and Shaheen 2002). Carsharing efforts mostly emerged from individuals who wanted the mobility benefits of automobiles but could not justify the cost of ownership and parking (Barth and Shaheen, 2002). As a result, several carsharing organizations (CSOs) were initiated consisting of a few vehicles used by a group of individuals. It is based on the premise that individuals/households do not need to own or lease cars on a long term basis in order to maintain access to goods, services, jobs, etc., thereby allowing individuals to more freely make transportation mode choice decisions (Cousins, 1998). This should also reduce the bias toward the automobile and induce its efficient use. Most of the North American carsharing programs are community based and designed to fulfill the social trips and cars are located at neighborhoods (specially at or nearby residential apartments). For example, in San Francisco, it is called the "Short Term Auto Rental" (STAR) program, which was designed and implemented to serve travel/mobility needs of residents in two apartment buildings. In this concept, it is the car itself that is shared rather than the car journey or ride (Cousins, 1998).

Most carsharing enterprises/systems started at the grassroots level with one or two conventional automobile(s) and developed locally as car co-operatives (Cousins, 1998). Recently, government sponsorship of carsharing has become more common, as has private sector involvement. In Europe, carsharing has become so prevalent that profit- 
making corporations often run it. In North America, some carsharing organizations are approaching toward profitability (e.g., Boston Zipcar).

Carsharing is an innovative urban mobility system with several cars and subscribers (Barth and Todd, 1999). Today's carsharing organization (CSO) places a network of shared-use vehicles at strategic parking locations throughout a dense city as shown in Figure 1.1. Members of the CSO can reserve the vehicles in advance; on the actual date and time of the rental, the user gains access to the vehicle, carries out their trip, then returns the vehicle back to the same location (station) they originally accessed the vehicle from (Barth and Shaheen, 2002). This kind of trip is known as "two-way" or "round" trip and the system known as round trip shared vehicle system (RTSVS). Members pay a usage fee typically based on time and mileage and a small monthly membership fee. The $\mathrm{CSO}$ as a whole maintains the fleet of vehicles. Vrtucar, Ottawa, ON, Canada; Car Share Co-op, Victoria, BC, Canada; Flexcar, Washington, DC, USA are the examples conventional or co-op type neighborhood carsharing or shared vehicle systems. 


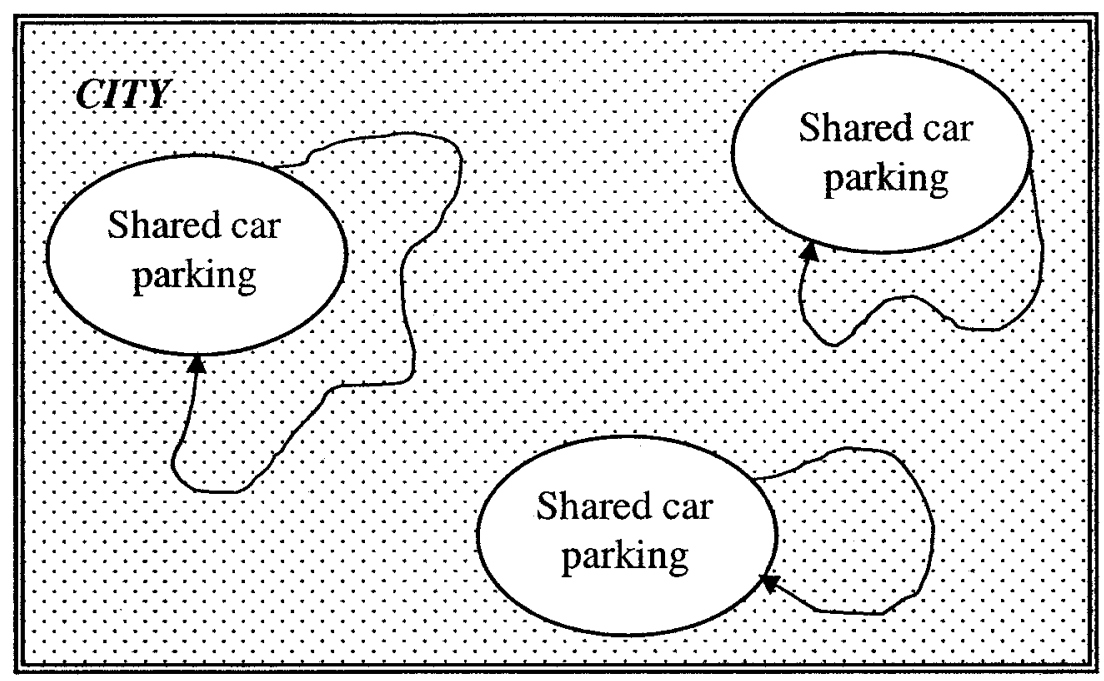

Figure 1.1 Conventional carsharing model (adapted from Barth and Shaheen, 2002)

\section{The Station Car Concept}

The station car concept is another new form of shared vehicle urban mobility system (Bernard and Nerenberg, 1998). Station cars are normally electric vehicles (EVs) driven to and from mass transit stations by transit riders. They are usually an extension of mass transit, providing the same instant, yet more convenient and less hassled, of mobility as conventional privately owned vehicles as shown in Figure 1.2. While away from the transit station, they can be used for any type of short trip (Bernard et al, 1998, 1999). Therefore, by definition, station car system is another form of short-term-auto-rental system similar to conventional carsharing or shared vehicle system but usually consists of multiple stations. The concept of station car system originated in the United States and some programs have been implemented in Europe (Barth and Shaheen, 2002). 


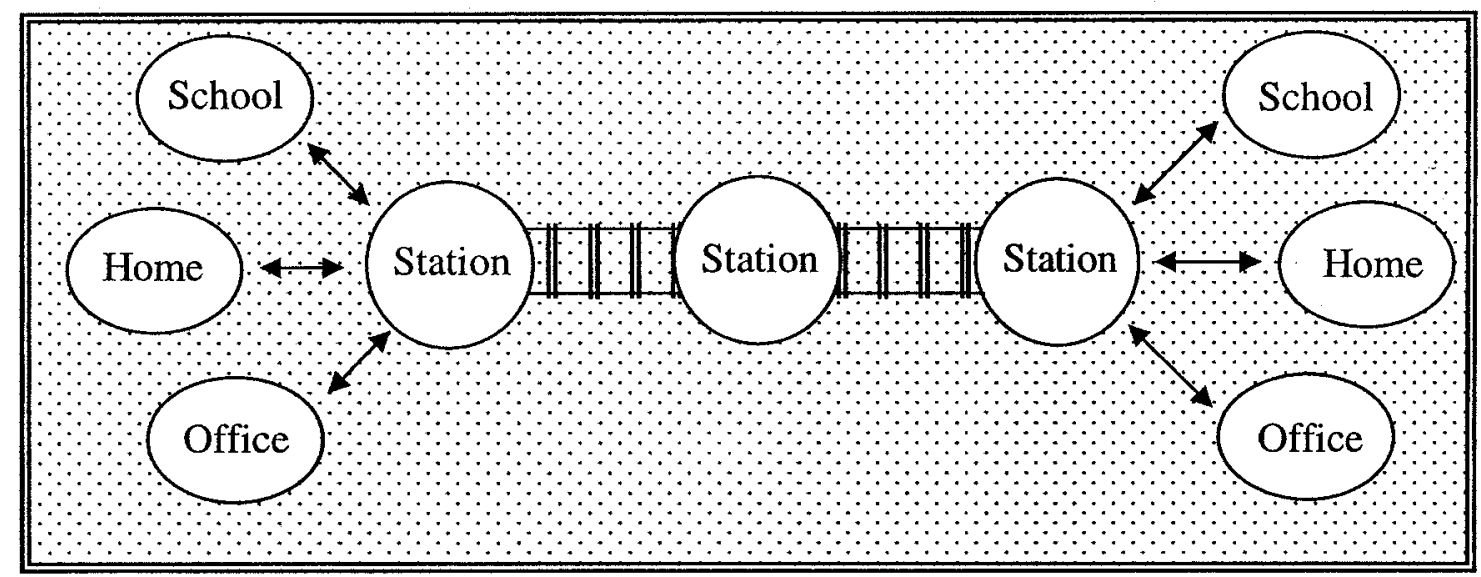

Figure 1.2 Station car model (adapted from Barth and Shaheen, 2002)

According to the National Station Car Association (NSCA), USA, when fully implemented, station car system will become a mobility system, as ubiquitous as a utility, changing the transportation paradigm of many metropolitan area households (Bernard and Nerenberg, NSCA, 1998). Each mobility system will be designed to support the specific transportation needs of each community and the following features are likely to be applicable.

- A typical station car in the future will be battery-powered, have two seats, be freeway capable, but will have a more limited range and fewer amenities than the electric vehicles (EVs) in the mass market. Station cars will be able to serve essentially all local trips away from the station. Some station cars may be larger depending on the trip attributes (e.g., party size).

- Station cars will be rented more than once a day by different users and can be called multiple uses. 
- A station is a place for quickly renting and returning a station car, for charging and storing station cars, and for cleaning and performing some level of maintenance on the cars. Initially stations are likely to be located at transit stations, but eventually stations could be located at places that require high regular access, i.e., university campuses, convention centers, airports, and residential and commercial complexes.

- Station car will be kept and charged in queues to minimize space requirements and maximize use (first in first out)

- Station car system's intelligent electronics will be the computer-based system for managing reservations, access, user accounts, queues, and station car fleets.

- Station cars will require unique hardware for queuing, charging, and cleaning.

- Station car service would be provided by a private sector vendor, even though some stations might be on public land, i.e., transit station parking lots and college campuses.

- Station cars will provide the ultimate flexibility in selection of exact vehicle to suit the requirement of the trip.

Hence, from the National Station Car Association's proposed definition of a matured station car system, as noted above, it is obvious that the final form of a station car system will be "multiple station" in nature and be similar in characteristics to that of the multiple station shared vehicle system (MSSVS), the ultimate form of shared vehicle systems, described in detail in the following section. 


\section{Multiple Station Shared Vehicle System Concept}

It has been envisioned that the ultimate development or future matured form of the carsharing or shared vehicle system is the one in which the cars are used between stations, major activity centers, where the system consists of more than two stations and called multiple station shared vehicle system (MSSVS) as shown in Figure 1.3. Therefore, in an MSSVS, a car can be taken from one station/depot and returned to the same or another station (Barth and Shaheen, 2002). Hence the system will experience both one-way and round trips. The underlying concept of vehicle use, fleet management, and usage cost is similar to conventional carsharing system.

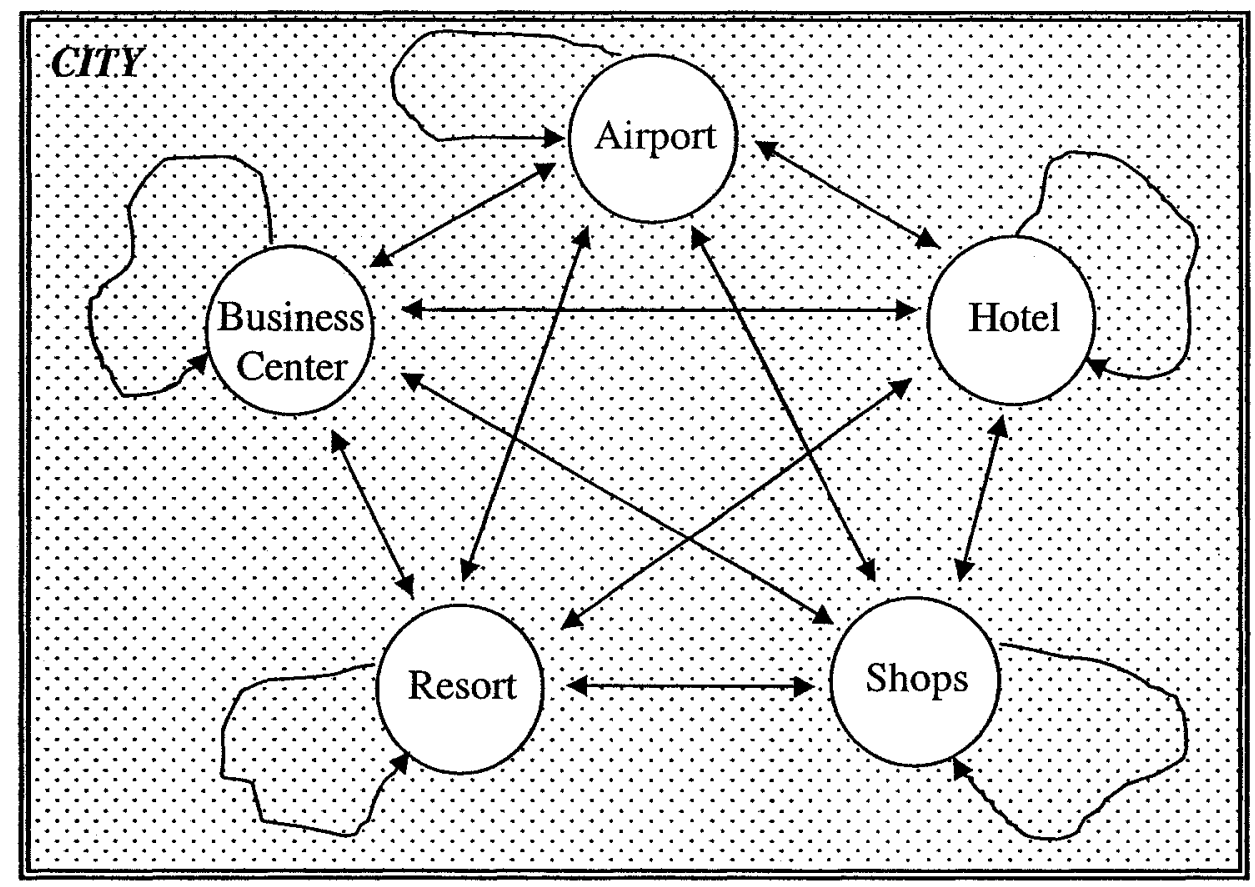

Figure 1.3 Multiple station shared vehicle system model (adapted from Barth and

Shaheen, 2002) 
It is envisioned that a multiple station shared vehicle system (MSSVS) would be the future ultimate form of carsharing system in terms of flexibility (Bernard, M. and Nerenberg, V., 1998). This system would serve a special segment of mobility/travel needs of a sub-area or community of a metropolis and would use intelligent transportation system (ITS) technologies and low emission vehicles (i.e., electric and hybrid vehicles, small vehicles) to achieve traffic, environmental, and energy benefits. These systems potentially fit well in resort communities and large national parks where there are a number of attractions and visitors can travel between them (Barth and Shaheen, 2002). Barth and Shaheen also mentioned that these multiple station systems are also good option for campus settings, either corporate or academic. These multiple station systems allow large scale of inter-nodal oneway trips and are more complicated to manage, since there is the possibility of vehicle imbalance; i.e., too many vehicles may end up at one station and not enough vehicles at another (Barth and Shaheen, 2002). The system would employ an appropriate ITS technology bundle to achieve its major system operations objectives including efficiency, user-friendliness, vehicle availability, and vehicle stateof-charge (SOC) management (Barth and Todd, 2000).

Recently, in Europe, a program was launched to assess the market potential of "carsharing for business" such as "Car Sharing for Companies in the Aachen Region", Aachen, Germany (Reutter and Bohler, 2000). In this system, automobiles are supplied at different locations, called station or depot; within the business area to serve the business trips among different offices. This is an example of multiple station/depot carsharing or 
shared vehicle system in Europe. University of California at Riverside's IntelliShare is an example of multiple station shared vehicle system (MSSVS) in North America.

Most of the carsharing services, including station cars, are priced in similar way (Katzev, 1999). The subscribers or members pay a monthly/annual subscription to the host CSO, and a charge for each trip by hour and/or distance (Cousins, 1998). This means that all the fixed costs of car ownership and use are transformed to variable or perceived costs. The mobility service providers are usually responsible for parking, maintenance, licensing, insurance, and other infrastructure (i.e., charging facilities, ITS technologies) costs (Bernard and Collins, 1999). Therefore, the users are completely free from all hassles of automobile ownership and use (Katzev, 1999).

\subsection{Shared Vehicle Systems Operations}

From the definition and classification of shared vehicle systems in the previous sections, it is observed that three categories of such system are presently in operation in North America, Europe, and Asia. The three classes, identified and defined in the previous sections include; 1) conventional carsharing model, 2) station car model, and 3) multiple station shared vehicle system model. The degree of complexity of the operations of these three different forms of shared vehicle systems is not same. Review of the literature shows that the operations of shared vehicle systems could be best characterized by the following system components:

1. Trip registration procedure,

2. Vehicle access procedure, 
3. User trip procedure (if applicable), and

4. Vehicle relocation procedure (if applicable).

In conventional or co-op type carsharing system, the service providing organization owns fleets of vehicles that their user pool can access throughout the day. Vehicles are placed in neighborhoods, apartment buildings, etc. A user either reserves a vehicle in advance or simply walks up to an available vehicle. Reservations are generally made by telephone to a system control center or through Internet (Cousins, 1998). The keys are typically obtained through a common lock box, and then the vehicle can be used for a period of time as set by the CSO. At the end of the trip, the vehicle is returned, typically to the original location/station and hence the trips are round trips, and the mileage is recorded. At the end of the month, each user is billed a small user fee plus a mileage and trip time based charged (Walb and London, 1986). In this form of shared vehicle system the user trip procedure and vehicle relocation components are not required in system operations. Therefore, the system operation is simple and fewer ITS technologies are required for efficient system operations and management.

The second form of carsharing system is the station car, which is usually associated with a long haul transportation mode, such as urban rail transit, commuter rail, and transit buses (Shaheen, Susan, 1999 and 2000), as shown in Figure 1.2. In this case, users can access station cars at both ends of their commuting route(s). At each end, a car could be used for trips throughout the day. For registration and vehicle access, various types of techniques are presently in use, ranging from access to key through common lock-box to 
smartcard technology (Shaheen, 1999). In this form of shared vehicle system, vehicles are usually received at the time of trip. The vehicles are mostly electric and/or hybrid type. CarLink I, and CarLink II of the University of California at Davis, USA, are smart intelligent station car type shared vehicle systems (Shaheen, et al., 1998, 1999). Although the operation of station car system is similar to that of conventional carsharing system, all four system operation components are present in the station car operations.

The most generalized or ultimate form of shared vehicle system is the multiple depot/station shared vehicle system (Barth and Shaheen, 2002). In this form of shared vehicle system, vehicles are used among multiple stations to go from one activity center to another. Such system may be set up in any sub-area of a metropolis i.e., resort communities, recreational areas, high regular access zones including university campuses, malls, employment centers (i.e., CBD), and airports.

In this form of shared vehicle system, the trips are more likely to be oneway each time (Barth and Todd, 1999). This is in contrast to the typical roundtrips made in commutebased station car type shared vehicle system and community-based co-op type shared vehicle system. Because there are many more oneway trips, as compared to two-way or round trips, in a multiple station scenario the number of vehicles can quickly become disproportionately distributed among the stations with respect to the station demand at a particular time of the day (Barth and Todd, 1999). As a result, the system may become imbalanced and its operations become interrupted and inefficient. Consequently, it is indeed necessary to relocate vehicles periodically during operation to bring balance in 
vehicle distribution or at the end of operation to meet the next day demand at each station (Barth and Todd, 1999). Otherwise, the system would suffer from inefficiency and user demand could not be satisfied with the given standard level of service. Therefore, a dynamic database system and its management is extremely necessary to keep track of all vehicles in the system and their battery state-of-charge (SOC). For these reasons, a multiple station shared vehicle system operations comprise of trip registration, vehicle access, user trip procedure, and vehicle relocation processes. These components should be analyzed and designed consistently and enriched with appropriate ITS technologies to make the system efficient, user-friendly, and manageable (Barth, and Todd, 1999). A prototype multiple station shared vehicle system is currently in operation at the University of California at Riverside (UCR) campus, called UCR Intelligent Shared Vehicle system (UCR IntelliShare) or Intelligent Community Shared Vehicle System (ICVS) (Barth and Todd, 1999). The system is equipped with an appropriate bundle of ITS technology (Barth and Todd, 2000) to better manage the various components of shared vehicle system operation. Figure 1.4 illustrates the system and user interaction flowchart of a multiple station intelligent shared vehicle system, comprised of trip registration, vehicle access, and user trip procedure. The monitoring of vehicle distribution and vehicle stateof-charge and relocation activity are not included in Figure 1.4. 


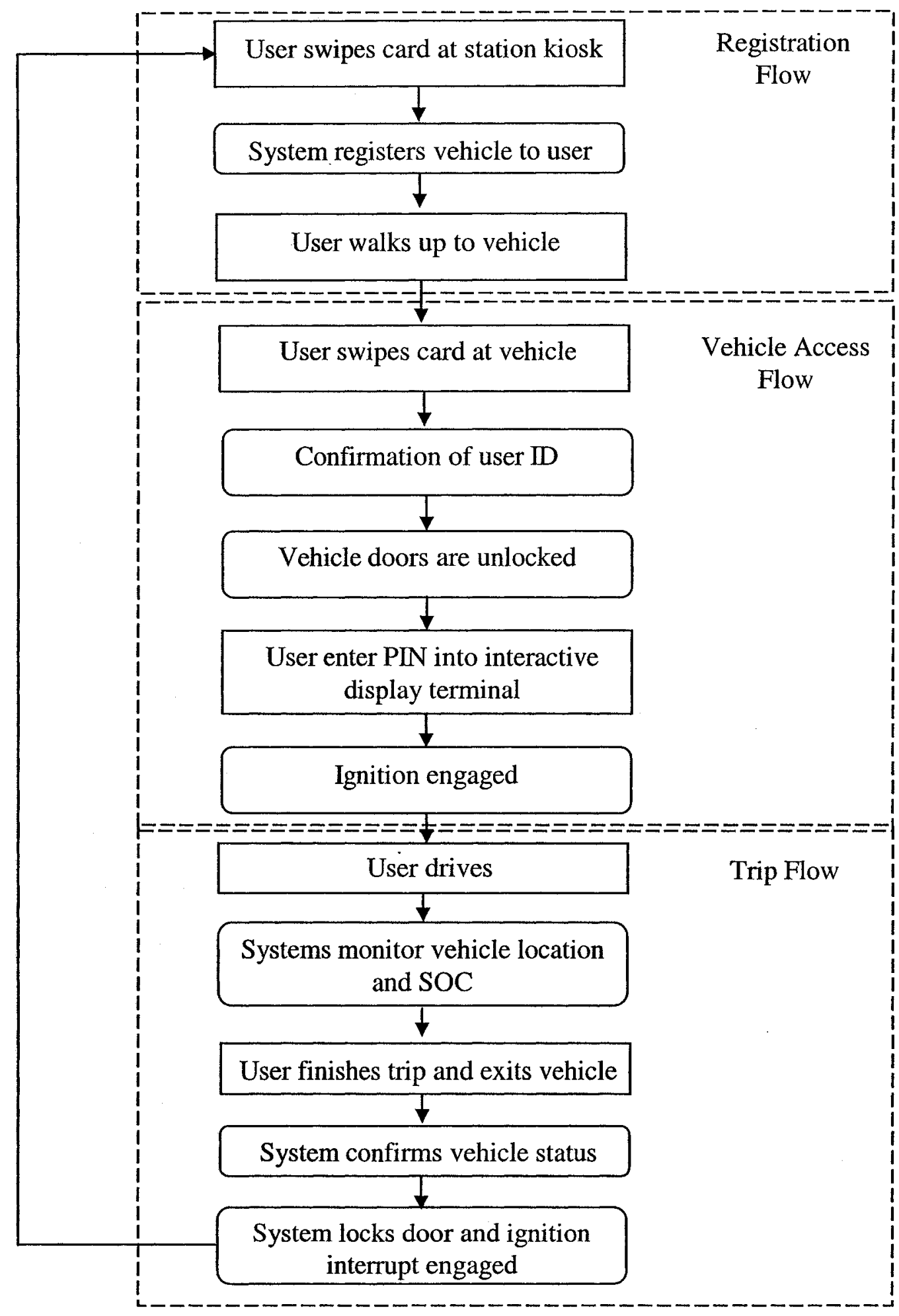

Figure 1.4 Multiple station shared vehicle system operation and user interaction flowchart (adapted from Barth and Todd, 2000) 


\subsection{Shared Vehicle Systems: Design and Operational Problems}

The two concepts, carsharing and the station cars, though developed simultaneously and independently over the last several decades, have many similar features. Carsharing, developed in Europe, is becoming a significant form of mobility system there, where as in North America implementation has just begun within the last half dozen of years (late 1990s). The concept of station car originated in United States and a number of programs have been implemented in Europe.

The station car concept is being developed through a series of field tests sponsored by mobility providers, governmental organizations, and corporations in the United States. On the other hand, carsharing starts at the grassroots level with fewer vehicles, usually one or two, and develops locally as a neighborhood car co-op type shared vehicle system. Both concepts are based on the principle/theory that individuals or households do not need to own cars to fulfill their mobility/travel needs. The underlying major objectives for both the carsharing and station car systems are to design and operate the system efficiently to provide the mobility with fewer hassles while improving urban livability. Objectives also include reduction in automobile ownership and use, reduction in parking requirement, partial alleviation of urban traffic congestion, increase in public transit share and/or change in travel behavior, environmental and economic benefits, and energy savings. This new and innovative form of urban mobility system is contemplated to provide the ultimate flexibility in selection of the most appropriate vehicle and/or transportation mode to best suit the requirement of the trip maker's particular travel demand. 
To date, a number of carsharing and station car systems have been implemented and evaluated. In cases where such systems were not successful, their design and operations were not well thought out. For example, in the case of San Francisco's STAR, due to a series of operational and management problems, most notably vehicle reliability and financial performance, the project was terminated prematurely (Walb and London, 1986).

The Institute of Transportation Studies, University of California at Davis, completed an evaluation of the major demonstration project of smart carsharing (CarLink I) in the United States in 2000. The evaluation findings include effect of carsharing on trip making, mode choice and commuting behavior, impact on public transit (BART) share, and user perspective about the service. Their findings suggest the need to enhance the design and operational issues of such systems. None of the available studies, experimental and modelling type, examined in detail the supply-demand interaction, and critical operational issues considering a complete set of decision variables. Methods and models also need to quantify benefits including energy, and economic factors. Hence, there is a need for further research to develop design and operations methods and models for demand-supply interaction and better system design and efficient operations. Therefore, the motivation of this research is to develop an improved modelling framework and simulation model for analyzing design and operational issues of SVS systems. 


\subsection{Research Objectives and Scope}

The purpose of this research is to develop an improved shared vehicle system simulation model and methodology in order to gain insight into the system's demandsupply interaction and critical operational issues. The underlying motivation is to improve the design and operations of shared vehicle systems. Improvements are required in the vehicle availability and system balance, vehicle distribution considering a set of measure of performance indicators namely vehicle relocation need, average user wait time, vehicle-to-user or vehicle-to-trip ratio etc. A complete set of decision variables has been considered for model development with focus on station car and multiple station shared vehicle systems. The model results would be used for better design, implementation, and operations of shared vehicle systems for a particular market setting, in North America and/or in other parts of the world, and to quantify potential benefits including energy, and

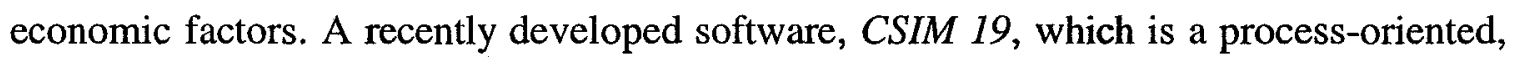
general-purpose simulation toolkit written with $\mathrm{C}$ and $\mathrm{C}++$ language functions from Mesquite Software, Inc., has been employed to develop the shared vehicle system simulation model in Microsoft Visual C++ environment.

The major objectives of this thesis research are summarized as follows:

1. Develop an improved shared vehicle system simulation model, considering a complete set of decision variables with focus on station car and multiple station shared vehicle systems (MSSVS) using CSIM 19,

2. Develop demand profile, simulate the system's demand-supply interaction in simulation environment, and determine efficient fleet size with vehicle mix against 
selected critical system performance indicators, such as number of vehicle relocations, average user wait time, vehicle-to-trip ratio, for both types of shared vehicle systems, and

3. Estimate potential benefits, including energy and economic factors of shared vehicle systems.

\subsection{Research Methodology}

A systematic research framework was developed and followed in this thesis research (Figure 1.5). At the outset, shared vehicle (also called carsharing) systems were studied and characterized. A closer look was taken at the issues formed the basis of problem definition, and definition of goals and objectives.

A very detailed review of literature was carried out and lessons were learned from experiments on carsharing systems as well as from recent modelling efforts and approaches.

A framework was defined for modelling shared vehicle systems, followed by the development of an improved simulation model based on discrete-event simulation technique. By using an available database, the simulation model was implemented, validated, and appropriate tests were carried out.

The focus of this research is on methodology development for the design, analysis, and evaluation of multiple station shared vehicle systems (MSSVS). For the illustration of methodology, an existing database on travel factors is adapted and used. However, knowledge is contributed on how to generate such data for application of the methodology at other sites. 


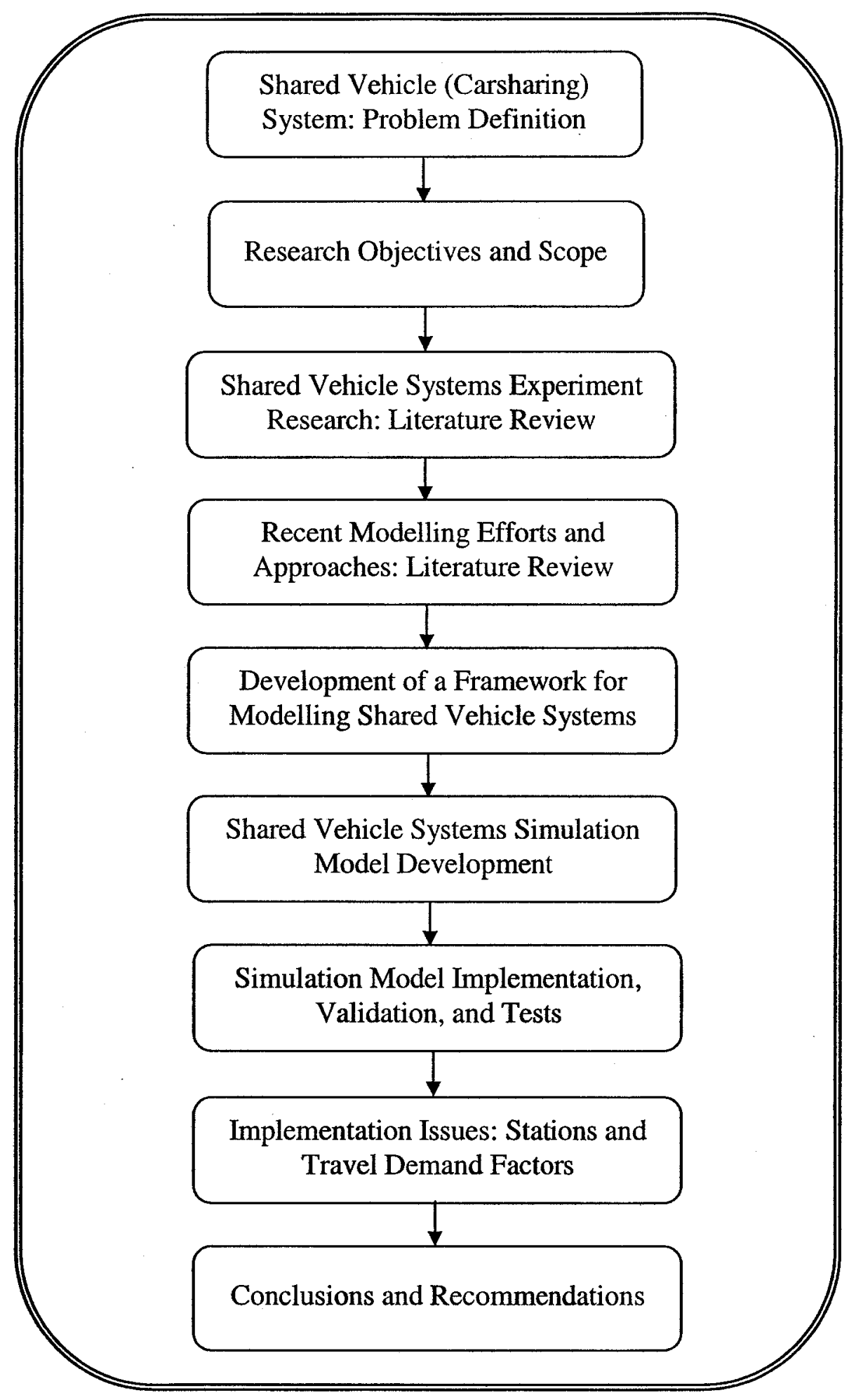

Figure 1.5 Research Framework 
In order to implement the simulation model for another system design (in Ottawa or any other City), data on stations and travel demand factors were required. Therefore, the next step in this research was to advance ideas on how to obtain such data, based on stated preference (SP) survey methodology. Since one application of the developed simulation model was regarded to be sufficient for this thesis research, no new data were generated as a part of this research.

Finally, on the basis of findings of all parts of this research, conclusions were made and recommendations were advanced.

\subsection{Thesis Organization}

This thesis is organized in the following format. The general background and design and operational issues of shared vehicle systems together with research objectives and research framework are presented in Chapter I.

A review on the history of shared vehicle systems (SVS) around the world and experimental programs in North America as well as the effects of SVS on user travel behaviour are described in Chapter II. Literatures on recent modelling efforts and approaches are summarized in Chapter III.

Model development methodology is explained in Chapter IV. It includes the modelling framework and the shared vehicle systems simulation model development 
strategy. The methodologies for benefit factors including energy and economy are also described in this chapter.

Chapter $\mathrm{V}$ explains in detail the discrete-event system simulation technique. A complete algorithm for the shared vehicle system simulation model is developed and described. Additionally, the Use Case Modelling technique and architecture of SVS simulation model using Use Case Modelling are illustrated in this chapter.

In Chapter VI, test database development, model implementation, validation, and test results for the case study system are explained. The analyses of the simulation model results under different case scenarios and decision on efficient system design configuration are presented. The model results are discussed in full length and inferences are made on system design and operation issues. The SVS response for different design variables are explored and presented.

Finally, Chapter VII includes the conclusions drawn from this thesis research. Additionally, recommendations are advanced for further research. 


\section{CHAPTER II \\ SHARED VEHICLE SYSTEMS EXPERIMENTAL RESEARCH: LITERATURE REVIEW}

\subsection{History of Carsharing or Shared Vehicle Systems}

Carsharing efforts mostly emerged from individuals who sought the benefits of cars but were ideologically opposed to widespread car use. Many carsharing organizations (CSOs) were initiated in the 1980 s, and a few even earlier, mostly in Europe, supported initially by government grants. Most found it difficult to make the transition from grassroots, neighborhood programs into viable business ventures. These earlier efforts probably miscalculated the number of vehicles needed, failed to manage the vehicle fleet, placed too much emphasis on advanced technology, and/or were ineffective in their marketing (Shaheen, 1999). Many failed organizations merged or were acquired by larger organizations. Those that grew and flourished were more business like and used intelligent transportation system (ITS) technologies.

\subsubsection{Carsharing in Europe}

Most carsharing efforts remained small scale and concentrated in Europe. Until the late 1990 s, virtually all CSO start-ups were subsidized with public funding and a few by corporate subsidies. Most car sharing trips are roundtrips from a neighborhood lot, with reservations made over the phone. One of the earliest European experiences with carsharing can be traced to a cooperative, known as "Sefage," which originated in Zurich, Switzerland in 1948 (Shaheen, 1999). Membership in "Sefage" was primarily motivated 
by economics. It attracted individuals who could not afford to purchase a car but who found sharing one to be appealing. Elsewhere, a series of "public-car" experiments were attempted, but failed, including a carsharing initiative known as "Procotip," begun in Montpellier, France in 1971, and another called "Witkar," deployed in Amsterdam in 1973 (Shaheen, 1999).

Shaheen (1999) mentioned that more successful experiences with carsharing began in Europe in the late 1980s. The two largest carsharing organizations are Mobility Car Sharing Switzerland, with 1,400 cars, and Drive Stadtauto (formerly StattAuto Berlin) with about 300 cars. The Swiss program, begun in 1987, operated in late 1990s in 700 locations in over 300 communities, with over 30,000 members. Drive Stadtauto, begun in 1988, operated in 110 locations and had approximately 7,500 members in late 1990s (Shaheen, 1999 and Stadtauto website). In 1999, approximately 200 CSOs were active in 450 cities throughout Switzerland, Germany, Austria, the Netherlands, Denmark, Sweden, Norway, United Kingdom, France, and Italy, collectively claimed over 130,000 members (Shaheen, 1999).

Both Drive Stadttauto and Mobility are entering a modernization phase, moving from manual "key box" operations to a system of smartcard technologies for making automatic and advanced reservations, accessing vehicle keys, securing vehicles from theft, and facilitating billing (Shaheen, 1999). The shift to smart cards simplifies vehicle access for customers and eases the administration and management of large systems. However, the 
large investment required for the new communication and reservation technologies puts pressure on these organizations to continue expanding to generate revenue to pay off these investments.

Lufthansa Airlines and Swiss Air offered an alternative model. Lufthansa instituted an automatic rental system at the Munich and Frankfurt airports in 1993, in which a computer releases a key and starts the billing. By the end of 1994, 12,000 employees at the two German airports had access to this "carpool" system. Lufthansa reportedly saved over $\$ 20$ million in avoided parking infrastructure costs (Fastlane, 1997). These cost savings have been used as a justification for corporate subsidies of the program. The system is being technologically enhanced with smart cards and coordinated with local transit operators. Swissair's program, called "CarShare," was introduced in 1993 at the Zurich airport for flight attendants. It was technologically simpler and works in collaboration with Hertz Rent-a-Car. In both cases, these companies sought to enhance employee access and reduce costs (Fastlane, 1997, mentioned in Shaheen, 1999). Volkswagen launched a broader smart carsharing program in Germany in 1997 and later on operated two carsharing projects. The first is operated in an apartment complex with several shared vehicles located outside the building, and the second in a business that shares a range of vehicles types. Volkswagen has indicated that it believes the carsharing market will grow at a rate of 50 percent per year into a potential market of 2.45 million shared-use vehicles in Europe by 2007 (Fastlane, 1997). 
From the early 1990s Daimler Chrysler (DC) devoted much efforts on the development of sustainable mobility systems and investigated concepts of alternative car utilization (Shaheen, 1999). Shaheen (1999) also mentioned that recently DC implemented an in-house carsharing fleet in order to provide mobility services for the employees traveling between the numerous plants in the agglomeration of Stuttgart University, Germany. Access and performance were simplified through the application of chip card technologies (called smartcard) and the introduction of an automated reservation process. The system was very much appreciated by the employees and grew in importance in recent years. As a manufacturer of premium mobility products, DC drives several research projects on transportation and telematic services in Europe and California, USA, partnering with vehicle fleet operators, public transportation companies, as well as IT and telematic service providers (Schmeck, 1999).

\subsubsection{Carsharing in North America}

At present, 26 carsharing organizations in North America and another four are expected to be launched in 2006 (Shaheen, Cohen, and Roberts, 2005). All of them follow the operational model of most European CSOs and some are multiple station in nature. Intelligent transportation system (ITS) technologies are deployed to enhance system operational issues.

Eleven of the twenty-six North American CSOs are located in Canada (Shaheen et al, 2005). By 2001, the U.S. claimed 14 carsharing organizations and more than 5000 
members and Canada claimed ten carsharing programs and nearly 3800 members. In Canada, most recent CSOs are located in Victoria (British Columbia), Toronto, Ottawa, and Waterloo (Ontario) and all of these are non-profit organization. Shaheen et al (2005) concluded that the carsharing industry is continued to expand.

Strong interest in car sharing is emerging in a number of US cities. Portland, Oregon, is the pioneer; starting carsharing early 1998 and showing constant growth based on the for-profit company 'Car Sharing Portland' (Shaheen, 2000). In Seattle, the city and surrounding King County offered funding (about $\$ 600,000$ for three years) to launch a for-profit private venture marketed as 'Flexcar' run by Mobility Inc. starting Jan. $7^{\text {th }}$, 2000. Flexcar had 170 users within the first three weeks of operation. In the San Francisco area Hertz in collaboration with BART (Bay Area Rapid Transit) began a limited program at a rail station in Fremont with $20-40$ vehicles in early 2000 . Other car sharing operations that started in year 2000 are at the Presidio National Park in San Francisco (Ford TH!NK), in Washington DC (DC Car Share), and in Boston (ZipCar) (Shaheen, 2000).

Two "smart" carsharing research demonstrations launched in 1999 in California provide more evidence of emerging interests and plans in the U.S. The CarLink project in northern California was initiated with 12-compressed natural gas Honda Civics and a variety of state-of-the-art advanced communication and reservation technologies, under the direction of the University of California, Davis. IntelliShare in southern California 
incorporates 15 Honda EV Plus electric vehicles, smart cards, and on-board computer technologies, under the direction of researchers at University of California at Riverside (UCR). The former one is used by residents near a rail transit station and employees of Lawrence Livermore National Lab, and the latter is used by the faculty, staff, and students at the University of California, Riverside. The later one is a prototype multiple station shared vehicle system (MSSVS) designed to fulfill travel need of potential faculty, staff, and students among stations within UCR campus and both one-way and the round trips are served.

\subsubsection{Carsharing in Asia}

Car sharing activities in Asia are more limited. Most prominent is the Car Co-op, launched in Singapore in 1997. It uses an electronic key box and on-board computers. Residents of two neighbouring condominiums automatically become members and have access to a fleet of shared vehicles, including a Mercedes-Benz limousine and several multi-purpose vehicles (MPV). As it expands, the objective is to provide one car for every 40 residents with an car:user ratio of 1:40. The developers of the two condominiums are each paid approximately $\$ 100,000$ towards this operation during the first three years of the program. Members did not pay membership fees during the first years, but pay for usage. Carsharing lots are also being located near public transit stations, so users can rent vehicles at the end of a transit trip (Shaheen, 2000 and www. carcoop.com.sg). 
Honda and Toyota in Japan have created two experimental programs. In October 1997, Honda unveiled its Intelligent Community Vehicle System (ICVS) in a remote site north of Tokyo. It comprises multiple lots/stations from which four different types of electric-powered vehicles (EV) can be selected for use, from an electric bicycle to a smart-sized electric car. The system includes smart cards to unlock and start a vehicle, combined with advanced information technologies for reservations and billing. Advanced vehicle monitoring and controls technologies are deployed to park and recharge the EV vehicles (Nakayama et al, 2001).

In May 1999, three hundred Toyota employees began a one-year experiment of a smart carsharing system called "Crayon". This system employed a bundle of advanced electronics technology, including smart card, a reservation kiosk, recharging management system, automatic vehicle location (AVL), and a vehicle information and communications system. A fleet of 35 small electric vehicles, E-com cars, is used in the system (Yamaguchi, 2000).

\subsubsection{Carsharing in Latin America}

A recent preliminary analysis of the possibilities for carsharing system/service in Latin America revealed promising potentials. Not only a number of different trip types and users were identified as feasible carsharing customers, but an analysis conducted based on current average auto ownership and usage costs in Santiago de Chile suggests the financial competitiveness of carsharing (Zegras and Gakenheimer, 1999). The 
analysis showed that carsharing would be a financially attractive alternative for car users who use their own vehicle less than $10,000 \mathrm{~km}$ per year. In the end, the study concluded that the real possibilities for and benefits of a carsharing system in Latin America could be known through more detailed market research, demand surveys, and series of pilot projects (Zegras and Gakenheimer, 1999).

\subsection{Effects of Carsharing on Travel Behavior}

Several experimental efforts, demonstration projects and field tests, on shared vehicle systems have been completed in North America, Europe, and around the World. Although, many of these experimental efforts did not become successful, they are well analyzed and documented. Results and lessons learned from these demonstration projects or field tests have been summarized in proper technical reports or papers. This information is important and critical for further investigation of this new innovative transportation paradigm.

Several European studies reported substantial amount of reduction in vehicle ownership and vehicle use in terms of vehicle kilometers travel (VKT) for the members of the carsharing organizations (CSO) (Euronet and ICLEI, 1996). The studies also indicated that there is significant amount of shift in mode choice for the carsharing members. Most of the studies in Netherlands, Switzerland, and Germany concluded that members of carsharing organizations use 'green transportation', for example transit bus, light rail, subway, bicycle, and walking, more than they did before they became members 
(European Car Sharing (ECS), www.carsharing.org). Similar effects on travel behavior are reported from the North American efforts. The total effects of carsharing on users' travel behavior could be categorized as follows:

1. Effects on vehicle ownership and mode choice, and

2. Mobility effect

\subsubsection{Effects on Vehicle Ownership and Mode Choice}

In a review of four commercial carsharing projects in the Netherlands, Lightfoot (1997) reported a $44 \%$ decrease in the number of car owners among the 847 participants of those programs. These four projects collectively claim a total of 972 members. Munheim (1998) reported that among the members of the Mobility Car Sharing Switzerland, $60 \%$ of the former car owners no longer have their own car after a few years. The field test results of carsharing projects in North America are consistent with those in Europe in terms of vehicle ownership reduction. In the final evaluation report of the Short Term Auto Rental (STAR) program by Walb and London of Cambridge Systematics, Inc., which was operated in San Francisco, CA, USA for a sixteen-month period from December 1983 to March 1985, the overall level of vehicle ownership among STAR users/members declined by $15.4 \%$ during the first year of project operation (Walb and London, 1986). Among them, $8.2 \%$ of the household reporting a shift from two to one vehicle and $9 \%$ shift from one to no vehicle. Furthermore, a sizeable number of households, about $43.1 \%$, reported that they delayed or cancelled a planned vehicle purchase as a result of the availability of those in the STAR fleet. 
In the first year evaluation report of "Carsharing Portland (CSP)", now renamed as Flexcar, Richard Katzev (1999) reported that $26 \%$ of members were able to sell their cars and 53\% were able to avoid purchasing one. This finding was attributed to the distance to the nearest station, an important carsharing design variable, and the car ownership. Richard Katzev (1999) explained that the membership duration in time and distance to station on CSP depend on whether a member owns a private vehicle. They concluded that the reduction in vehicle ownership and increased use of shared vehicle might be gained with shorter walking distance to the station and better car availability. This type of shared vehicle system may easily be achieved in dense and mixed land use communities or urban areas.

It is widely reported in Europe that members of carsharing organizations (CSO) make greater use of public transit and alternative modes of transport than they did before they join the organization. Lightfoot (1997) reported that in the Netherlands train ridership increased 7\%, bicycle use 5\%, and bus use $18 \%$. Similarly, Munheim (1998) reported that after becoming members of Mobility Car Sharing Switzerland, there was a "reduction of no less than 72\%" in the use of personal automobile for CSO members. Instead, public transportation was used for over $50 \%$ of all mileage traveled, with the remaining distance travelled by means of bicycle, motor scooter, and walking.

In the first year evaluation report of Carsharing Portland (CSP), Richard Katzev reported that the magnitude of effect in transit share increase is considerably less in 
United States carsharing efforts than in European, but somewhat similar effects were found among the members of CSP. While a sizeable increase was not observed for any travel mode, a large number of respondents in the year-end survey reported that they used alternative modes including transit, walking, and bicycle more often for commuting, shopping, and personal errands. Walb and London (1986) in their final evaluation report of STAR program, mentioned that some households experienced an increase in transit and ridesharing modes; although a somewhat larger number reported a decrease. Most households, however, reported no change, which suggested that STAR was not a significant competitor for transit or ridesharing. Rather, STAR primarily attracted trips that would otherwise be made by the private automobiles, or taxis. STAR did seem to compete most effectively with transit for short-term trips in the evening hours when individuals are more likely to be concerned about transit availability (due to larger headway) and their personal safety while using transit.

\subsubsection{Mobility Effect}

Most of the European carsharing or shared vehicle systems evaluation studies showed that there is significant change in the mobility pattern before and after use of carsharing vehicle. A survey conducted by the Federal Swiss Agency for Energy Economy shows that a typical license bearer mainly uses car for mobility where no carsharing organization exists (ECS, www.carsharing.org). The public transit is more or less a stopgap or temporary solution, when car use becomes a problem - for example when congestion is expected, parking facilities are rare or expensive. But once carsharing is introduced, the 
study observed significant change in mobility pattern (Euronet and ICLEI, 1996). The mileage of car becomes halved and the use of transit increases (European Car Sharing (ECS), www.carsharing.org). Similar result was observed in other European countries i.e., Germany, the Netherlands. The North American experience, such as Carsharing Portland, is somewhat different than European experience in this context. In the first year evaluation report, Richard Katzev (1999), mentioned that while the members of CSP did not drive fewer kms after they joined the organization, they did exhibit a number of notable changes in their mobility behavior. Some of them sold their vehicles, many avoided buying a new one, used transit and other modes more often than before. The study developed an important insight into the relationship between the usage of the carsharing vehicle, access to the nearest station, and the trip length. The report showed that a better accessibility to the station has significantly positive impact on the mobility pattern of the members. Similar results were also revealed from STAR evaluation report. In STAR evaluation report Walb and London (1986) explained that the total VKT (Vehicle Kilometers Traveled) increased for the STAR members. But they pointed out that this is due to the increase in car use for those members who did not have a car before. The analysis showed that the VKT clearly decreased for members who drove their own vehicles before. All of these results were derived from cooperative type neighborhood carsharing where all trips are round-trip type.

\subsection{Role of ITS Technologies in Shared Vehicle Systems Operations}

Intelligent transportation systems (ITS) technologies are proving to be powerful tools in transportation systems operations, control, and management. Also these technologies 
enhance capacity, mobility, and productivity (Barth and Todd, 1999). Critical to any new and innovative transportation system technology is how the user responds to the new technology and/or system (Shaheen, 1999). So the likelihood of success of any new transportation system technology would be enhanced when users adjust their behavior and embrace the system. However, user behavior is often difficult to predict and is often overlooked as a critical component when introducing new transportation system, service or technology. The shared vehicle system, which is thought as new and innovative solution to the sustainable urban transportation development, is similarly likely to suffer from this issue. Most of the carsharing scheme evaluations in North America showed that the usage of the carsharing vehicles is dependent on how the members accept the system. The system attributes (i.e., accessibility, vehicle availability, user-friendliness, car ownership, information system, marketing policy etc.) are major determinants for the viability of any new system.

Barth and Todd, in their paper 'User Behavior Evaluation of an Intelligent Shared Electric Vehicle System', showed that an appropriate bundle of intelligent transportation system (ITS) technology could help to enhance the likelihood of viability of a shared vehicle system (Batrh and Todd, 2001). They analyzed the University of California at Riverside (UCR) IntelliShare, an intelligent, smart, multiple station prototype electric shared vehicle system, which has been developed and implemented at the UCR. The ITS bundle includes smartcard, touch-screen registration kiosk, vehicle monitoring/tracking hardware, and sophisticated management software. The study develops important insight 
about the potentials of ITS technology to better manage the system and enhance user satisfaction and systems viability.

\subsection{Shared Vehicle System Demonstration Projects}

In the United States, two early formal shared vehicle system demonstration projects were conducted in the 1980 s. The first was Mobility Enterprise System, operated as a Purdue University research program from 1983 to 1986 in West Lafayette, Indiana (Liu, Sinha, and Fricker, 1983). Under this project, each household leased a very small car, (i.e., mini car), for short local trips and was given access to a shared fleet of special purpose vehicles (SPV) i.e., large sedans, trucks, and recreational vehicles.

In this field test, the mini cars leased to participants accounted for 75 percent of the household's vehicle miles of travel (VMT), which were available $100 \%$ of the time. In contrast, the shared fleet was made available only for 35 percent of the time, about $0.35 * 24 \approx 8$ (eight) hours per day, to households throughout the experiment. The amount of total VMT that was generated by the shared use fleet is attributed to the remaining 25 percent of household's travel demand or VMT.

The second major United States shared vehicle system demonstration project was the Short Term Auto Rental (STAR) project in San Francisco, CA. The STAR Company operated as a private enterprise from December 1983 to March 1985, providing service to individuals in an apartment complex. The vehicles were used on a short-term basis (i.e., 
from a few minutes to several days) (Walb and London, 1986). The members or users shared a fleet of 51 vehicles (i.e., 44 cars, 5 wagons, and 2 light duty trucks) with ten additional vehicles made available as backups during the period of peak demand. Membership peaked at approximately 350 users.

A more recent smart shared vehicle research project in the United States involved a two-year (1996-1998) study of station car rentals at Bay Area Rapid Transit (BART) District stations (Bernard, and Collins, 1998). Nearly 50 electric vehicles were used, including 40 PIVCO City BEES from Norway, 2 Toyota RAV-4s, and 5 Kewets from Denmark (Shaheen et al, 2002). In addition, several station car programs were launched in the mid-1990s by transit operators seeking to relieve parking shortages at transit stations and desiring to avoid the high cost of building more infrastructures. The operators also included Electric Utility companies, who are interested in a potential initial market for battery-powered electric vehicles and air quality regulators seeking to reduce vehicle usage and pollution (Bernard and Collins, 2001).

\subsection{State-of-the-Art of Shared Vehicle Systems Programs in North America}

Literature review revealed that, as of 2002 , in the United States there are ten co-op type carsharing programs (Table 2.1), five station car programs (Table 2.2), three shared vehicle research pilot projects (i.e., Carlink, Intellishare, and ZEVNet), and nine shared vehicle systems programs are in planning stage (Shaheen et al, 2002). In the ten cooperative type carsharing projects, the trips are round-trip type. On the other hand, 
three shared vehicle system pilot projects are multiple station type carsharing systems and both one-way and round trips are permitted. A brief description of these programs is given in Table 2.1 and Table 2.2.

Table 2.1 U.S. Co-operative type shared vehicle system programs

\begin{tabular}{|c|c|c|c|c|}
\hline $\begin{array}{c}\text { Program Name } \\
\text { \& Location } \\
\end{array}$ & $\begin{array}{c}\text { Launch } \\
\text { Date }\end{array}$ & $\begin{array}{c}\text { Business } \\
\text { Model }\end{array}$ & $\begin{array}{c}\text { Program } \\
\text { Size } \\
\end{array}$ & Other Details \\
\hline $\begin{array}{r}\text { Dancing Rabbit } \\
\text { Vehicle Coop } \\
\text { Rutledge, MO } \\
\end{array}$ & 1998 & Not-for-Profit & $\begin{array}{l}15 \text { users } \\
3 \text { vehicles }\end{array}$ & $\begin{array}{l}\text { Operating in Dancing } \\
\text { Rabbit Ecovillage Co- } \\
\text { operative }\end{array}$ \\
\hline $\begin{array}{r}\text { Flexcar } \\
\text { Seattle, WA }\end{array}$ & 1999 & Commercial & $\begin{array}{l}560 \text { users } \\
29 \text { vehicles }\end{array}$ & $\begin{array}{l}\text { Flexcar acquired Car } \\
\text { Sharing Portland in } 2001\end{array}$ \\
\hline Flexcar, D.C. & 1998 & Commercial & $\begin{array}{l}2017 \text { users } \\
64 \text { vehicles }\end{array}$ & $\begin{array}{l}\text { Flexcar launched operation } \\
\text { in Washington D.C. in } \\
\text { November } 2001 .\end{array}$ \\
\hline $\begin{array}{r}\text { Carsharing } \\
\text { Traverse } \\
\text { Traverse, MI } \\
\end{array}$ & 2000 & Commercial & $\begin{array}{l}28 \text { users } \\
3 \text { vehicles } \\
\end{array}$ & $\begin{array}{l}\text { Located in a small } \\
\text { community of } 15,000 \\
\text { residents. }\end{array}$ \\
\hline ZipCar, Boston & 2000 & Commercial & $\begin{array}{l}1400 \text { Users } \\
65 \text { Vehicles }\end{array}$ & Open in Boston in 2000 \\
\hline $\begin{array}{r}\text { ZipCar, } \\
\text { D.C. Metro Area }\end{array}$ & 2001 & Commercial & $\begin{array}{l}70 \text { users } \\
17 \text { vehicles }\end{array}$ & $\begin{array}{l}\text { Expanded to Washington } \\
\text { D.C. area in } 2001\end{array}$ \\
\hline
\end{tabular}


Table 2.1 U.S. Co-operative type shared vehicle system programs (continued)

\begin{tabular}{|c|c|c|c|c|}
\hline $\begin{array}{c}\text { Program Name } \\
\text { \& Location }\end{array}$ & $\begin{array}{c}\text { Launch } \\
\text { Date }\end{array}$ & $\begin{array}{c}\text { Business } \\
\text { Model }\end{array}$ & $\begin{array}{c}\text { Program } \\
\text { Size }\end{array}$ & Other Details \\
\hline $\begin{array}{r}\text { Anaheim EV } \\
\text { Program, } \\
\text { Anaheim, CA } \\
\end{array}$ & 2001 & Not-for-profit & $\begin{array}{l}28 \text { users } \\
8 \text { vehicles }\end{array}$ & $\begin{array}{l}\text { Residents of } 3 \text {-moderate } \\
\text { income groups use service for } \\
2 \text { hours with no charge }\end{array}$ \\
\hline $\begin{array}{r}\text { Boulder } \\
\text { CarShare Coop, } \\
\text { Boulder, CO }\end{array}$ & 2001 & Not-for-Profit & $\begin{array}{l}12 \text { users } \\
3 \text { vehicles }\end{array}$ & $\begin{array}{l}\text { Ultimate goal is to have a car } \\
\text { in every neighborhood in } \\
\text { Boulder }\end{array}$ \\
\hline $\begin{array}{r}\text { City CarShare, } \\
\text { San Francisco \& } \\
\text { Oakland, CA } \\
\end{array}$ & 2001 & Not-for-Profit & $\begin{array}{l}750 \text { Users } \\
29 \text { Vehicles }\end{array}$ & $\begin{array}{l}\text { Began intercity expansion with } \\
2 \text { vehicles in Oakland with } \\
\text { future expansion in plan. }\end{array}$ \\
\hline $\begin{array}{r}\text { Roaring Fork } \\
\text { Valley Vehicle, } \\
\text { Aspen, CO } \\
\end{array}$ & 2001 & Commercial & $\begin{array}{l}15 \text { users } \\
2 \text { vehicles }\end{array}$ & $\begin{array}{l}\text { Established as a } 24-36 \text { month } \\
\text { pilot project. }\end{array}$ \\
\hline $\begin{array}{r}\text { GoCar } \\
\text { Denver, CO } \\
\end{array}$ & 2001 & Commercial & $\begin{array}{l}5 \text { users } \\
1 \text { vehicle }\end{array}$ & $\begin{array}{l}\text { Housing development with } \\
\text { plan for } 3 \text { vehicles }\end{array}$ \\
\hline $\begin{array}{l}\text { Gaia Building } \\
\text { Berkeley, CA }\end{array}$ & 2001 & Commercial & $\begin{array}{l}250 \text { users } \\
3 \text { vehicles }\end{array}$ & $\begin{array}{l}\text { Housing development with all } \\
\text { tenants as users. Plans to } \\
\text { partner with City CarShare. }\end{array}$ \\
\hline
\end{tabular}

Source: Shaheen et al, 2002 
Table 2.2 U.S. Station car type shared vehicle system programs

\begin{tabular}{|c|c|c|c|c|}
\hline $\begin{array}{l}\text { Program Name \& } \\
\quad \text { Location }\end{array}$ & $\begin{array}{l}\text { Open } \\
\text { Date }\end{array}$ & $\begin{array}{c}\text { Business } \\
\text { Model }\end{array}$ & $\begin{array}{c}\text { Program } \\
\text { Size }\end{array}$ & Other Details \\
\hline $\begin{array}{r}\text { Clean Commute } \\
\text { Program, } \\
\text { New York, NY }\end{array}$ & 1995 & Not-for-Profit & $\begin{array}{l}7 \text { Users } \\
5 \text { Vehicles }\end{array}$ & $\begin{array}{l}\text { Began in } 1995 \text { with } 6 \\
\text { vehicles, driven from the train } \\
\text { station to an IBM facility. } \\
\text { Plans to expand with } 100 \\
\text { vehicles. }\end{array}$ \\
\hline $\begin{array}{l}\text { PowerCommute } \\
\text { Morristown, NJ }\end{array}$ & 1997 & Not-for-Profit & $\begin{array}{l}20 \text { Users } \\
10 \\
\text { Vehicles } \\
\end{array}$ & $\begin{array}{l}\text { Electric vehicles are used to } \\
\text { drive between train stations }\end{array}$ \\
\hline $\begin{array}{r}\text { Transport } \\
\text { Network Program, } \\
\text { Anaheim, CA } \\
\end{array}$ & 2000 & Not-for-Profit & $\begin{array}{l}28 \text { Users } \\
8 \text { Vehicles }\end{array}$ & $\begin{array}{l}\text { Worker carpool in electric } \\
\text { vehicles from two Metrolink } \\
\text { stations to their worksites. }\end{array}$ \\
\hline $\begin{array}{r}\text { Hertz-BART } \\
\text { Program, } \\
\text { Fremont, CA }\end{array}$ & 2000 & Commercial & $\begin{array}{l}112 \text { Users } \\
21 \\
\text { Vehicles ( } 7 \\
\text { are EV) } \\
\end{array}$ & $\begin{array}{l}\text { Hertz runs program based out } \\
\text { of BART station. Vehicles are } \\
\text { also used as traditional rental } \\
\text { vehicles. }\end{array}$ \\
\hline $\begin{array}{r}\text { Emory University } \\
\text { Station Car } \\
\text { Project } \\
\end{array}$ & 2001 & Pilot Program & $\begin{array}{l}100 \text { Users } \\
9 \text { Vehicles }\end{array}$ & $\begin{array}{l}\text { Used by university faculty and } \\
\text { staff. }\end{array}$ \\
\hline
\end{tabular}

Source: Shaheen et al, 2002

Some of the programs, including all three multiple station shared vehicle system pilot programs, deployed the intelligent transportation system (ITS) technologies for improved system operation and management. These United States shared vehicle systems programs collectively claimed 5,000 members and operated 280 vehicles (Shaheen et al, 2002). 
Canadian experience with shared vehicle systems is similar to that of the United States (see Table 2.3). According to the year 2002 statistics, a total of nine shared vehicle systems were in operation. They include both not-for-profit and the commercial enterprise. Canada's shared vehicle systems collectively claimed 3,774 users and operated 226 vehicles (Shaheen et al, 2002). More recent, year 2005, information suggests that a total of eleven carsharing organizations were in existence in Canada (Shaheen, et al, 2005).

Table 2.3 Canadian shared vehicle system programs

\begin{tabular}{|c|c|c|c|c|}
\hline $\begin{array}{c}\text { Program Name \& } \\
\text { Location }\end{array}$ & $\begin{array}{l}\text { Open } \\
\text { Date }\end{array}$ & $\begin{array}{c}\text { Business } \\
\text { Model }\end{array}$ & $\begin{array}{c}\text { Program } \\
\text { Size }\end{array}$ & Other Details \\
\hline $\begin{array}{r}\text { CommunAuto } \\
\text { Quebec City and } \\
\text { Montreal, QC }\end{array}$ & $\begin{array}{l}1994 \\
\text { and } \\
1995 \\
\end{array}$ & Commercial & $\begin{array}{l}2277 \text { Users } \\
128 \text { Vehicles }\end{array}$ & $\begin{array}{l}\text { Auto-Com and } \\
\text { CommunAuto merged in } \\
\text { 1997. They currently } \\
\text { manage reservations for } \\
\text { VrtCar }\end{array}$ \\
\hline $\begin{array}{r}\text { Victoria Car Coop, } \\
\text { Victoria, BC }\end{array}$ & 1996 & Not-for-Profit & $\begin{array}{l}50 \text { Users } \\
3 \text { Vehicles }\end{array}$ & $\begin{array}{l}\text { Vehicles include one car, } \\
\text { one truck, one minivan }\end{array}$ \\
\hline $\begin{array}{r}\text { Cooperative Auto } \\
\text { Network (CAN), } \\
\text { Vancouver, BC }\end{array}$ & 1997 & Not-for-Profit & $\begin{array}{l}800 \text { Users } \\
49 \text { Vehicles }\end{array}$ & $\begin{array}{l}\text { In April 2001, CAN repaid } \\
\text { its loans and became self- } \\
\text { sustaining. }\end{array}$ \\
\hline $\begin{array}{r}\text { AutoShare, } \\
\text { Toronto, ON }\end{array}$ & 1998 & Commercial & $\begin{array}{l}520 \text { Users } \\
33 \text { Vehicles } \\
\end{array}$ & $\begin{array}{l}\text { User fees currently cover } \\
\text { costs; would like to expand } \\
\text { to attain economy of scale }\end{array}$ \\
\hline
\end{tabular}


Table 2.3 Canadian shared vehicle system programs (continued)

\begin{tabular}{|c|c|c|c|c|}
\hline $\begin{array}{l}\text { Program Name \& } \\
\text { Location }\end{array}$ & $\begin{array}{l}\text { Open } \\
\text { Date }\end{array}$ & $\begin{array}{c}\text { Business } \\
\text { Model }\end{array}$ & $\begin{array}{c}\text { Program } \\
\text { Size }\end{array}$ & Other Details \\
\hline $\begin{array}{r}\text { People's Car } \\
\text { Cooperative, } \\
\text { Kitchener, ON }\end{array}$ & 1998 & Not-for-Profit & $\begin{array}{l}45 \text { Users } \\
4 \text { Vehicles } \\
\end{array}$ & $\begin{array}{l}\text { Plans to expand to } 200 \\
\text { members and } 18 \text { vehicles by } \\
2005\end{array}$ \\
\hline $\begin{array}{r}\text { Calgary } \\
\text { Alternative } \\
\text { Transportation } \\
\text { Cooperative, } \mathrm{AB} \\
\end{array}$ & 2000 & Not-for-Profit & $\begin{array}{l}9 \text { Users } \\
2 \text { Vehicles }\end{array}$ & $\begin{array}{l}\text { Plans to add a couple of } \\
\text { vehicles each year }\end{array}$ \\
\hline $\begin{array}{r}\text { Carsharing } \\
\text { Cooperative of } \\
\text { Edmonton, } \mathrm{AB} \\
\end{array}$ & 2000 & Not-for-Profit & $\begin{array}{l}9 \text { Users } \\
1 \text { Vehicle }\end{array}$ & Goal of three vehicles \\
\hline $\begin{array}{r}\text { VrtCar, } \\
\text { Ottawa, ON } \\
\end{array}$ & 2000 & Commercial & $\begin{array}{l}54 \text { Users } \\
4 \text { Vehicles }\end{array}$ & $\begin{array}{l}\text { Plans to enter adjacent areas, } \\
\text { working with CommunAuto }\end{array}$ \\
\hline $\begin{array}{r}\text { Commonwealth } \\
\text { Carshare Ltd., } \\
\text { Halifax, NS } \\
\end{array}$ & 2001 & Commercial & $\begin{array}{l}10 \text { Users } \\
2 \text { Vehicles }\end{array}$ & $\begin{array}{l}\text { Plans spread across city, as } \\
\text { appropriate }\end{array}$ \\
\hline
\end{tabular}

Source: Shaheen et al, 2002

\subsection{Lessons Learned}

From the foregoing literature review it is found that the early North American efforts on shared vehicle systems were not successful for a variety of reasons. A new era began in the late 1980s in Europe and also in North America. A number of shared vehicle systems are now well established and on steep growth trajectories. These organizations appear to provide tangible transportation and social benefits. Private automobile ownership and use reduced greatly when individuals gain access to shared vehicle 
system/services. This effect is could be greater than with virtually any other known demand management strategy (Shaheen et al., 2002). Particularly appealing is the idea that shared vehicles represent an enhancement in mobility and accessibility for many people in different travel market segment. Based on this literature review, it could be concluded that shared vehicle systems are more likely to be economically successful when they provide a dense network and a variety of services i.e., serve a diverse mix of users (residential, business, recreational). It is also obvious that research is necessary to study various aspects of this relatively new innovative transportation system, especially for the multiple station type shared vehicle systems, for better design, implementation, operation, and sustainable development. 


\section{CHAPTER III}

\section{RECENT MODELLING EFFORTS AND APPROACHES: LITERATURE REVIEW}

\subsection{Introduction}

Recent modelling efforts on shared vehicle system design and operation are scarce. Notable examples are Intelligent Community Vehicle system of College of Engineering, Center for Environmental Research and Technology, University of California at Riverside, CA, USA, "Praxitele Project" in Saint-Quentin, France, and the "Kyoto Public-Car System" in Kyoto, Japan (Barth and Todd, 1999; Arnaldi et al, 1998; Nakayama et al, 2001). Liu, Sinha, and Fricker undertook an earlier effort in 1983 at Purdue University, Indiana, USA. Models developed at the University of California at Riverside, CA, USA, and Saint-Quentin, France were applied to hypothetical resort communities whereas the model developed in Kyoto, Japan was applied in a central urban area (Nakayama et al, 2001). Arnaldi et al (1998) modelled the operations of small electric public car system in a virtual urban environment and studied the performance of vehicle control algorithm at "Praxitele Trial Project" in Saint-Quentin, France.

Barth and Todd (1999) at University of California at Riverside developed a processoriented, discrete-event simulation model with an application of queuing theory to network. Liu et al (1983) also developed simulation model at Purdue University using discrete-event simulation technique and applied it to a hypothetical mobility enterprise at Lafayette, Indiana, with a population of 65,000 people. John P. Miller (1982) developed a 
self-drive vehicle system, similar to the shared vehicle system concept, model at Carleton University, Ottawa, Canada. This model enabled the determination of the fleet size and cost analysis of the self-drive vehicle system. Cost of this system was compared with the cost of existing taxi system for the travel need of duty personnel at Canadian Forces Base (CFB) Ottawa. Brief synopses of each of these modelling efforts are given in the subsequent sections.

\subsection{Barth and Todd's Multiple Station Shared Vehicle System Simulation Model}

The multiple station shared vehicle system (SVS) simulation model developed by Barth and Todd at the University of California at Riverside (UCR) was applied to a hypothetical community, Coachella Valley, CA, USA. The studied SVS system consisted of six stations, selected through comprehensive travel demand survey and analysis. The model was a discrete-event simulation model and based on application of queuing theory to networks. Based on the SVS and its operational characteristics, Barth and Todd (1999) assumed and showed that shared vehicle systems can be modelled as discrete systems. The simulation model consists of three major components: (1) the stochastic trip generator, (2) the traffic simulator, and (3) evaluation of the results. The model block diagram is shown in Figure 3.1.

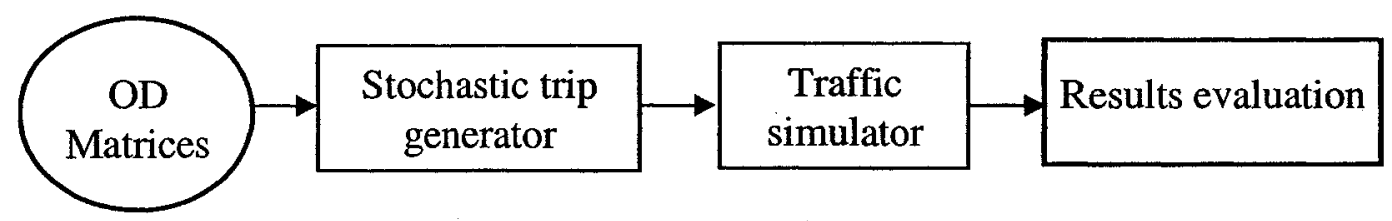

Figure 3.1 Model block diagram (Bath and Todd, 1999) 
The origin-destination (OD) matrices are the hourly travel demand between stations. The travel demand profile was developed considering the seasonal and weekday variations. A year is divided into three seasons i.e., peak, mid-peak, and off-peak and a week was divided into two periods i.e., weekdays (Monday-Thursday) and weekend (Friday-Sunday). From the available technical paper (Barth and Todd, 1999), it can be observed that six sets of hourly trip matrices, with OD information, for six peak-day periods were used as input to the stochastic trip generator model.

Among the three principal components of the simulation model, stochastic trip generator and the traffic simulator are the main components. The main function of the stochastic trip generator model was to randomly generate trip interarrival times. The analytical model employed in generating trip interarrival times in stochastic trip generator is as follows:

$$
T_{\text {next }}=-1.0349 \times \frac{\log (u) \times m t b g}{V_{\text {master }} \times V_{\text {hour }}}
$$

where $T_{\text {next }}$ is the randomly generated trip interarrival time, $\mathrm{u}$ is the uniformly distributed (UD) random number between 0 and $1, \mathrm{mtbg}$ is the mean time between arrival of trips for a given hourly demand. The mtbg was calculated in minutes and given by:

$$
m t b g(\text { in } \min )=\frac{60}{\text { hourly_demand }}
$$


$V_{\text {master }}$ and $V_{\text {hour }}$ are described as input control parameters to the trip generation model. Clear definitions of these two input control parameters are not provided in the report. But it has been found that the above stochastic model, generating interarrival times, is a modified form of the analytical model of statistical distribution to generate exponentially distributed random variate $(\mathrm{T})$ with mean arrival rate or demand $\lambda$, when the arrival process follows Markov process, the Markovian arrival process, as given below.

$$
T=-\frac{1}{\lambda} \log (u)
$$

where $\lambda$ is the mean rate of arrival and is hourly travel demand of shared vehicle system in this case, $u$ is the uniformly distributed random number which can take any value between 0 and 1.0, and $\mathrm{T}$ is the generated trip interarrival times and an exponentially distributed random variate that can take any value between 0 and $\infty$.

The authors developed a modified or shifted vector of the generated trip interarrival times excluding any generation(s) that are five standard deviations above the mean time between generations (mtbg) for a given hour and defined the interarrival time generation process as a modified Markov process. By doing so, they put an upper limit to the infinite support of the exponential distribution, a property of normal Markov process, of $\left(\frac{1}{\lambda}+5 \sigma\right)$. The report did not explain the effect of with and without this shifting and/or modification in interarrival times on system performance. 
The traffic simulator model used the output of the stochastic trip generator model and simulated each vehicle trip on the given network for a specific period of time. With the execution of the traffic simulator, a number of critical system performance indicators including customer average waiting time, average queue length, and number of vehicle relocations were recorded and evaluated using a set of analysis tools. Three different mechanisms for addressing the critical issue of vehicle relocation (if needed) are mentioned by Barth and Todd i.e., static relocation, historical predictive relocation, and exact predictive relocation. The variability of some other system variables (i.e., customer registration time, vehicle check-in and checkout times) was considered by assuming that they support Gaussian distribution. A very brief result of the simulation model is given in Table 3.1.

Table 3.1 Vehicle-to-trip ratios for wait time inflection point, and maximum and minimum number of vehicle relocations for different peak travel demand

\begin{tabular}{|c|c|c|c|c|c|}
\hline & $\begin{array}{c}\text { Peak } \\
\text { (Jan-May) }\end{array}$ & $\begin{array}{c}\text { Mid-Peak } \\
\text { (Nov-Dec) }\end{array}$ & $\begin{array}{c}\text { Off-peak } \\
\text { (Jun-Oct.) }\end{array}$ & $\begin{array}{c}\text { Min. } \\
\text { Value }\end{array}$ & $\begin{array}{c}\text { Max. } \\
\text { Value }\end{array}$ \\
\hline $\begin{array}{r}\text { Wait Time Inflection Point } \\
\text { Weekend (Fri-Sun) }\end{array}$ & 0.030 & 0.031 & 0.042 & & \\
Weekday (Mon-Thurs) & 0.032 & 0.037 & 0.058 & 0.030 & 0.058 \\
\hline Max. Number of & & & & & \\
Relocation & & & & & \\
Weekend (Fri-Sun) & 0.030 & 0.032 & 0.041 & & \\
Weekday (Mon-Thurs) & 0.031 & 0.037 & 0.059 & 0.030 & 0.059 \\
\hline Min. Number of Relocation & & & & & \\
Weekend (Fri-Sun) & 0.18 & 0.20 & 0.22 & & \\
Weekday (Mon-Thurs) & 0.18 & 0.20 & 0.24 & 0.18 & 0.24 \\
\hline Vehicle-to-trip ratio range & $0.030-0.18$ & $0.031-0.20$ & $0.041-0.24$ & - & - \\
\hline
\end{tabular}


From the above results it is obvious that vehicle-to-trip ratio is high at lower level-ofdemand and low at higher level-of-demand in all operating conditions such as whether to minimize average waiting time or to minimize number of vehicle relocations or both. The study results showed that 3-6 vehicles are required to meet a demand of 100 trips in 24hour period to satisfy customer average waiting time of 10 minutes for daily travel demand of 666 to 2261 trips for a 24-hour operation period. This includes the total range of peak and off-peak levels of demand and can be determined as $0.03 \times 100=3$ and $0.058 \times 100 \approx 6$ using results in columns 4 and 5 under row tilted "wait time inflection point'. From results shown in the Table 3.1, it is also obvious that 18 to 24 vehicles are required to meet a demand of 100 trips for 24-hour period in satisfying both customer average waiting time (same as above for different level of travel demand) and number of relocations and can be computed as $0.18 \times 100=18$ and $0.24 \times 100=24$ using the information in columns 4 and 5 along row title 'minimum number of relocation'. The above conclusions are assumed to be valid for 100 trips for a period of 24 -hour period for a six-station system. The study did not explain the effect of increase in number of stations on vehicle-to-trip ratio to satisfy desired level of service. The authors concluded that the shared vehicle system is most sensitive to the vehicle-to-trip ratio, the relocation criteria used, and the charging scheme employed when electric vehicles are deployed in the system.

Regarding the travel demand, the study estimated and used the daily travel demand of the hypothetical site based on the surveys done by some local agents and mentioned that 
more refined travel demand data is necessary. The distribution of the group or party size is shown in the travel demand data (Barth et al, 1997). It is found that $26 \%$ of the trips are with party size of $1,52 \%$ of size $2,11 \%$ of size $3,7 \%$ of size 4 , and $4 \%$ of size 5 . This whole range of party sizes could be aggregated in two groups as: $(26+52) \%=78 \%$ of the trip with party sizes $1-2$, and the rest $22 \%$ are of size $>2$ and $\leq 5$. In the developed model, the authors (Barth and Todd) did not mention the party size as a variable. It is assumed that the modelling effort did not consider party size as a variable in each arrival. This assumption appears to be true, because the model vehicle they used in simulation was a 2-seater electric vehicle (Barth et al, 1998).

Average travel times and speed are critical factors for any kind of transportation system design and operation. In shared vehicle system operations the factor travel time for a particular trip has gained an increased and significant importance. The sustainability of shared vehicle system depends on how quickly a user can get the appropriate size of vehicle that could best meet his/her travel need. This service attribute of shared vehicle system depends on how accurately we could estimate the trip travel time and the arrival of the vehicle to its destination station. In their model, Barth and Todd (1999) calculated the total trip time using the following equation.

Total Trip Time $(T T)=$ Boarding Time + Actual Travel Time $(A T T)$

$$
\text { + Alighting Time }
$$


And the actual travel time (ATT) is calculated using the following equation;

$$
\text { Actual Trip Time }=\frac{\text { Distance }}{\text { Max Cruise Speed Friction Factor }(f f)}
$$

where the friction factor (ff) is a quantitative measure of the impedance for a desired route between two SVS stations, and takes values in the range of 0 to $1.0(0 \leq f f \leq 1.0)$.

A friction factor of 0.75 indicates that the maximum cruise speed $\left(u_{\max }\right)$ will be reduced by $25 \%$, and the total trip time will be increased by $33.3 \%$. The friction factors are determined based on the prevalent peak traffic and geometric characteristics of a particular route and were used as constant parameters throughout the operation period. A detailed description of this friction factor and its calculation could be found elsewhere (Barth, Todd, Anderson, and Li, 1997). But, in reality the travel time is a variable quantity and is a function of the real time traffic condition along a particular route, weather, and other factors. Therefore, there is need to consider the real time traffic condition, and other factors in the estimation of the total trip time for a particular trip at a given time of the operation along a specific route so as to get more realistic results.

\subsection{The Kyoto Public-Car System's Simulation Model}

Nakayama et al (2001) developed their simulation model for multi-station 'Kyoto Public-Car System' using genetic technique (GT) algorithm to configure the operation of the system and search for optimal management configuration in Kyoto, Japan. The system 
had been in operation on an experimental basis. According to the operating policy, any user could try the system. Vehicle relocation was not accepted and assumed that the system is operating without vehicle relocation to avoid additional personnel cost.

The motivation behind the "Kyoto Public-Car" system was to search for a new system in order to use EVs for daily travel demand in the City Center of Kyoto. Owing to increased concern for Global Warming caused by greenhouse gases such as the 'tailpipe' $\mathrm{CO}_{2}$ gas emission, and the characteristics of the trips, the concept of shared vehicle system based on EVs appeared logical. Research by Barth and Todd and the French "Praxitele Trial" project were investigating the design and operations of shared vehicle systems. However, Nakayama et al found that both of these efforts are applicable in suburban regions. These two efforts also did not consider parking supply at a station as a design variable. It was assumed that considering these variables may need more effort and the system may be more complicated to model according to the Barth and Todd and the French trial project. Therefore, Nakayama et al adopted Genetic Technique algorithm, which facilitated the search with less computational and computer programming efforts. The objective was to search optimum system design and operations configuration for a multiple station shared vehicle system when vehicle relocation is not permitted.

\section{The Kyoto Public-Car System}

The Kyoto Public-Car system is a multiple station, EV car sharing demonstration project sponsored by New Energy and Industrial Technology Development Organization (NEDO) of Japan, which commenced it operation in Kyoto in December 2000. The 
system includes stations near Mass Transit stations and also in major activity locations. The users/members of the system are expected to reserve vehicles through Internet, cell phone, or using the touch-screen registration kiosk at the stations.

The system consists of five stations and a fleet of $35 \mathrm{EVs}$. All vehicles are 2-seater type, which implies that each trip is composed of $\leq 2$ passenger(s). The land use in Kyoto is dense and mixed, streets are narrow and auto occupancy rarely exceeds two. Therefore, it is implied that 2 -seater vehicles are suitable for all trips. The vehicle fleet is composed of 20 Toyota e-coms and 15 Nissan Hyperminis. The ranges per recharge of the e-com and Hypermini were 100 and $115 \mathrm{kms}$, respectively, and the top speed was $100 \mathrm{kph}$ for both. The Kyoto Public-Car System features are summarized as follows:

1. Ultra-compact 2-seater EVs equipped with GPS and in-vehicle information system

2. Advanced fleet management by two manufacturers

3. Unmanned checkout and return (check-in) using ITS technologies

4. Both one way and round trips are allowed

\section{Formulation of the Simulation Model}

Nakayama et al (2001) mentioned that shared vehicle system is premature in Japan. It is desired that as many people as possible should use the system. In the light of this point, checkout rate of EVs was set as the objective function. Due to its experimental in nature and philosophy, a $70 \%$ rejection rate was observed. 
Demand among stations was not even and necessity of relocation of vehicle during operation was apparent. A concept of not accepting trips that could potentially lead to uneven or skewed distribution of vehicles among stations was considered. It is also mentioned that the system allowed uneven distribution of vehicles during afternoon peak. To maintain an even vehicle distribution among stations, a minimum number of EV (numerical value not given) at each station and available empty parking slots per station were kept constant. The decision variables incorporated in the model include:

1. Total number of vehicles in operation, the fleet size $\leq 35$

2. Whether to permit uneven distribution

3. Number of users/members

4. Composition of members based on socio-economic characteristics

It was assumed that number of stations and parking lots is known.

\section{The Simulation Model}

A periodic scan approach was implemented in simulation, which simulated the states of the EVs at every scanning period. The states of the EVs are defined in terms of two variables: 1) the locations of EVs, and 2) battery state-of-charge (SOC). Genetic technique algorithm was used to implement the model. The model flowchart is shown in Figure 3.2. 


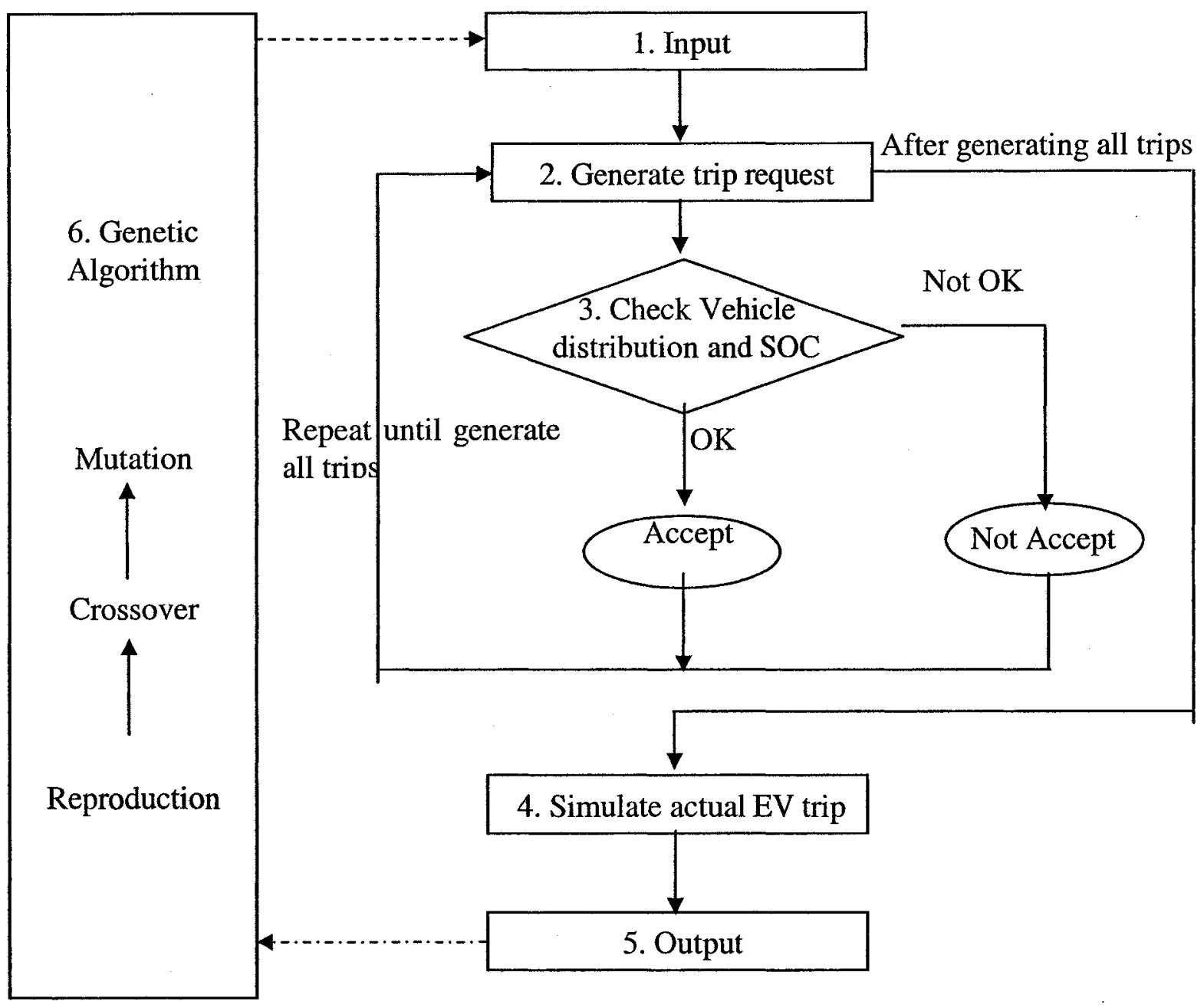

Figure 3.2 Model Flowchart, Kyoto Public-Car system

\section{Travel Demand Data}

The travel demand database that was used to develop the simulation model was derived from the reservation or trip request observed over a period of 12 days just after the Kyoto Public-Car system commenced its operation. The number of stations, their locations, and the number of parking slots at each station are kept fixed in each case. 
Nothing is mentioned about the trip travel time, its estimation method, and party size of individual trips.

\section{Model Results}

The study found that the optimal number of electric vehicles (EVs), the optimum fleet size, is about the half of the parking capacity. This means that for optimum operation of shared vehicle system the total number of parking supply should be twice the fleet size. But the authors mentioned that they were not able to include parking as a decision variable and kept it constant in each scenario or case. Although initially they decided to consider parking as a decision variable in order to check how it could affect the system efficiency. They mentioned that additional parking slots needed further negotiation with the parking provider and it was time consuming. A vehicle-to-member (user) ratio, on the average, of 1:23 was found from this research study. Since this result is different in unit from that in UCR model (vehicle-to-trip ratio) a direct comparison of two system models is not possible. The study concluded that the efficiency of the system does not necessarily improve as the number of vehicles is increased when the number of parking slots is kept constant. The analysis also showed that the system operation efficiency does not improve with the increase in the number of stations but did not provide any information on whether demand and number of vehicles were increased in same proportion.

During the experimental period, the system operation identified a surprising amount of reservation rejection of about $70 \%$, which is extremely high and could produce any kind of error in the estimation of decision variables values. The authors mentioned that, 
in general, genetic algorithms are not always able to locate the optimal solution (Nakayama et al, 2001). The Kyoto study also concluded that suitable setting of genetic algorithm is difficult and error prone.

\subsection{Simulation Models For French Praxitele Trial Project}

Arnaldi et al (1998) developed simulation models for French Praxitele Trial project in Saint-Quentin, France. The Praxitele project was charged with designing a new kind of transportation system in a suburban environment, which consisted of a fleet of electric public cars $(\mathrm{EV})$. These public cars or shared electric vehicles (EVs) are capable of autonomous motion (self-drive) of certain degree displacement between stations and the underlying concept was cooperative type car sharing.

The project recognized that the realization of such a system requires experimentation regarding the behavior of autonomous vehicles, platooning with a lead driver-control vehicle, in the urban environment. Because of the danger associated with these kinds of experiments at a real site, it was necessary to design a virtual environment in which simulation could be done. To perform an authentic simulation of a real environment composed of a large set vehicles (some of which are autonomous and others are controlled by drivers/users) different models were developed. These models include:

(1) geometric model of the environment, (2) mechanical simulation, (3) motion control model, (4) drivers model, (5) sensor model, and (6) visualization model. 
To implement the above set of models into a unique system, a simulation platform was designed. The main task devoted in this effort was to develop a virtual urban environment with selected transportation network in simulation and study the operations of Praxitele vehicles (electric public cars) and their motion control algorithm with information from virtual sensor.

\section{Project Motivation}

It has been realized that public transportation systems, i.e., trams, buses, subways, are usually designed for mass transportation. These kinds of passenger transportation in cities are efficient and economical. They also strongly support the region's sustainable urban transportation development. However, they lack many of the convenience of private automobile in terms of comfort and privacy, but most of all lack flexibility and availability. On the other hand, the success of the private automobile leads to failure: because it is not able to meet all transportation needs in a city. An efficient alternative to owning and using private automobiles in terms of resource sharing, to the taxi in terms of availability and cost, and to a carpool in terms of flexibility is the concept of carsharing that underlie Praxitele electric public car system. In this concept, a single car is used several times in a day by different users for various transportation needs.

\section{The System}

The public car system consists of a fleet of electric vehicles, a central management system, and an information and fare collection system. The vehicles are small and 2- 
seater with good performance characteristics. Concept and technologies, used by other shared vehicle systems, were used in trip reservation, vehicle allocation, and vehicle access control. Although the underlying concept was cooperative driving, it was assumed that the management center will monitor and manage vehicle distribution and relocation among different depots or parking locations that may realize from skewed demand.

\section{Model Development and Application}

The group of models described earlier were developed and implemented in a unique simulator. The case was designed for a small city, Saint-Quentin, with population of 140,00 people and 66,000 workers. The objectives include:

1. performance of on-board electronics and the management center

2. study the user behavior

3. configure the system for without vehicle relocation

Methodological details of model development and the technique used are not provided in the report. Also, the report is lacking information on travel demand, travel time, and how these variables were modelled. A brief description on how the EVs are traveling within urban environment, and how they could form platoon is given in the report. The performance of the individual model in simulating vehicle movement/trip is given. Nothing was mentioned on system design and operations. These deficiencies may be attributed to the stage of the model development. This effort was mainly devoted to the development of the total set of models and to test them in terms of simulating the operation of a public car system, platooning of the small public cars in urban environment, and to study the motion control algorithm. 


\subsection{A Model of Car Availability in Car Sharing Scheme of Different Sizes}

With the same view in mind that a car can be used more efficiently and could improve its productivity, Associate Professor H.S. Cousins developed a model based on the theory of binomial probability at the International Ecotechnology Research Centre at Cranfield University, Cranfield, Bedfordshire, UK (Cousins, 1998). In his model, the effect of different car sharing scheme/system sizes and failure rate (number of times a vehicle will not be available when needed) against fleet size for a given travel demand was formulated. The system size is defined as the number of users and/or stations in the car sharing system. The underlying concept was a cooperative type shared vehicle system in which all the trips were round trip type.

Based on the basic concept of binomial probability, a well-known discrete probability distribution, the total members were divided in to two distinct groups or classes. The class-I who ( $\mathrm{r}$ members) wanted to use a car at particular time of the day, say the peak hour and class-II, those who \{(n-r) members $\}$ do not. The probability of "success", wish to use a car, $\mathrm{p}$ and "failure", not wish to use a car, q were calculated from the ratio of the two distinct classes.

He assumed that there are $m$ cars supplied in the system. Under these given conditions, Prof. Cousins formulated an analytical model of "booking failure", the probability that a user will not get a car when he/she wants to use one. The developed analytical model is as follows: 


$$
b(m, n, p)=\frac{1}{p} \sum_{r=m+1}^{n} \frac{r-m}{n}\left(\frac{n !}{r !(n-r) !}\right) p^{r} q^{n-r}
$$

The parameters are defined as follows:

$\mathrm{b}=$ probability that any one member/user will not get a car when wants one

$\mathrm{r}=$ number of users who want to use a car in a given session

$\mathrm{n}=$ total number of users or members in the system

$\mathrm{p}=$ portion of the members who want to use a car in the given session

$\mathrm{q}=$ portion of the members who do not want to use a car in the given session

$\mathrm{m}=$ number of available cars in the system or the fleet size

The author defined this model as a 'scale efficiency' model, which is similar to system performance model. He implemented the model in MathCAD environment and developed insights on different system performance indicators and their relationships. These include: (1) relation between system size (user pool) and the vehicle fleet size, (2) booking failure rate and the fleet size, (3) system size and the gain in scale efficiency.

The model was capable to develop information on the number of cars needed to meet a given demand at different level of booking failure or level-of-service (LOS) ranging from 5 to 20 percent. The analysis led to conclusion that the vehicle-to-user ratio is less in larger systems than smaller one. This implies that the scale efficiency is higher at larger systems than that in the smaller. The study did not mention any systematic pattern of the demand and its variations. A one-hour peak period, the $18: 00 \mathrm{~h}$ of the day, was used in the 
analysis. None of the major system variables including the vehicle sizes and mix, trip distance, trip duration or travel time, party size of each trip are clarified properly. So, we may conclude that the results are very crude but are good to get information on fundamental relationships among different important system variables and measure of performance (MOP) indicators.

The model was applied to evaluate the performance of two stations of Dortmund car sharing system at Cranfield, U.K. From the perceived peak-hour demand for a period of 14 days, the value of $\mathrm{p}$ was determined. Using this value of $\mathrm{p}$, probability that a member wants to use a car, the required fleet sizes were determined, for different 'booking failure' b values, using the model. These fleet sizes were then compared with vehicle fleet of Dortmund car sharing system at two stations. For the selected two stations, he found that excessive number of cars is supplied in the system.

\subsection{Simulation Analysis of A Mobility Enterprise System's Operation - Purdue University, Indiana, USA}

Liu, Sinha, and Fricker (1983) developed a simulation model for a hypothetical "mobility enterprise" with their earliest effort in 1983 at Purdue University, Indiana, USA. They found that approximately $80 \%$ of the urban trips are short trips with one or two passengers. Most of these trips can be accommodated by vehicles smaller than subcompact cars. Therefore much of the capacities of household cars are wasted. Vehicle ownership pattern is thus not contingent upon the basis of "average use". They thought, 
if it is possible for a household to own a vehicle best suited to its member's most frequent travel needs and to have easy access to special purpose vehicles (SPV) from a cooperatively held pool of vehicles, much of this waste could be eliminated. At the same time, a greater level of service can be experienced by the households. These needs underlie the fundamental concept of "Mobility Enterprise" - providing an enterprise member with a small leased vehicle and sharing among the enterprise members special purpose vehicles in order to relax the multi-purpose requirements of the family car(s). The trips that were intended to be served by the shared use fleet were round trip in nature.

\section{The Mobility Enterprise Design Concept}

Liu et al thought that the automobile productivity improvement that can be achieved by a mobility enterprise, same as shared vehicle system, comes from better matching one's trip requirements to the vehicle characteristics. The basic theory or principle under the mobility enterprise is to ensure access of each member to a Minimum Attribute Vehicle (MAV) for mostly work trips as well as access to a wide range of Special Purpose Vehicles (SPV). The MAV is defined as the vehicle that would meet the highest percentage of the transportation requirements of a traveler. In most situations, this vehicle is in the category of so-called "mini-micro" with an engine size of less than one liter.

The first fleet, the leased fleet, consists of the MAV that was leased to the members for their own use. It provided each member the most economic means of accommodating his/her most frequent trips. When a member's minimum attribute vehicle (MAV) is inappropriate for a desired trip or additional vehicle(s) are needed, he/she may turn to the 
second fleet, the shared fleet of the enterprise or system for appropriate vehicle. Depending on the procedure of the enterprise, this involved some advanced planning, paper work, and out-of-pocket cost for a member. It was mentioned that the enterprise was not needed to be confined to the compulsory leasing of MAV's. It was expected that some members might join the enterprise solely for the purpose of having access to the shared fleet.

The operation of the mobility enterprise involved management as well as maintenance personnel. It is mentioned that a manager, receptionists, bookkeepers, and the like are needed to process reservations, dispatch vehicles, and maintain up-to-date membership account and vehicle inventory. Mechanics, on the other hand, were responsible for the maintenance of vehicles of both fleets. Members were totally relieved from responsibility of maintaining vehicles and thought to be performed better by the enterprise due to economy of scale.

\section{The Mobility Enterprise System Simulation Model}

The underlying objective was to simulate the operations of the mobility enterprise in cooperative driving concept and to carry out experiments in laboratory. The model was a discrete-event simulation model, which was developed employing a proven simulation language known as SLAM. It was a set of FORTRAN-based subroutines, like routines in $\mathrm{C} / \mathrm{C}++$, which provide necessary facilities and functions for simulation - generation of random numbers from a variety of probability distributions, dynamic storage of variable, execute control, gathering of statistics, and generation of reports. 
A total of thirteen events, as shown in the model flow chart, were included in the simulation model. These events were capable to define the potential changes in the state of a mobility enterprise that could occur at any event time. The mathematical-logical relationships prescribing the changes were implemented using the SLAM subroutines. An overall flow diagram, as found in Liu et al (1983), of the model is shown in Figure 3.3.

According to Liu et al (1983), there are four utility or facility subprograms including USERF, CHARGE, NDURTN, and BOOK. Among these four subprograms, BOOK was responsible to handle time advanced reservation functions of the shared fleet. Among the thirteen event subprograms, MINI and ENDREP dealt strictly with the leased fleet of the enterprise, while most of the rest are for shared fleet operations. 


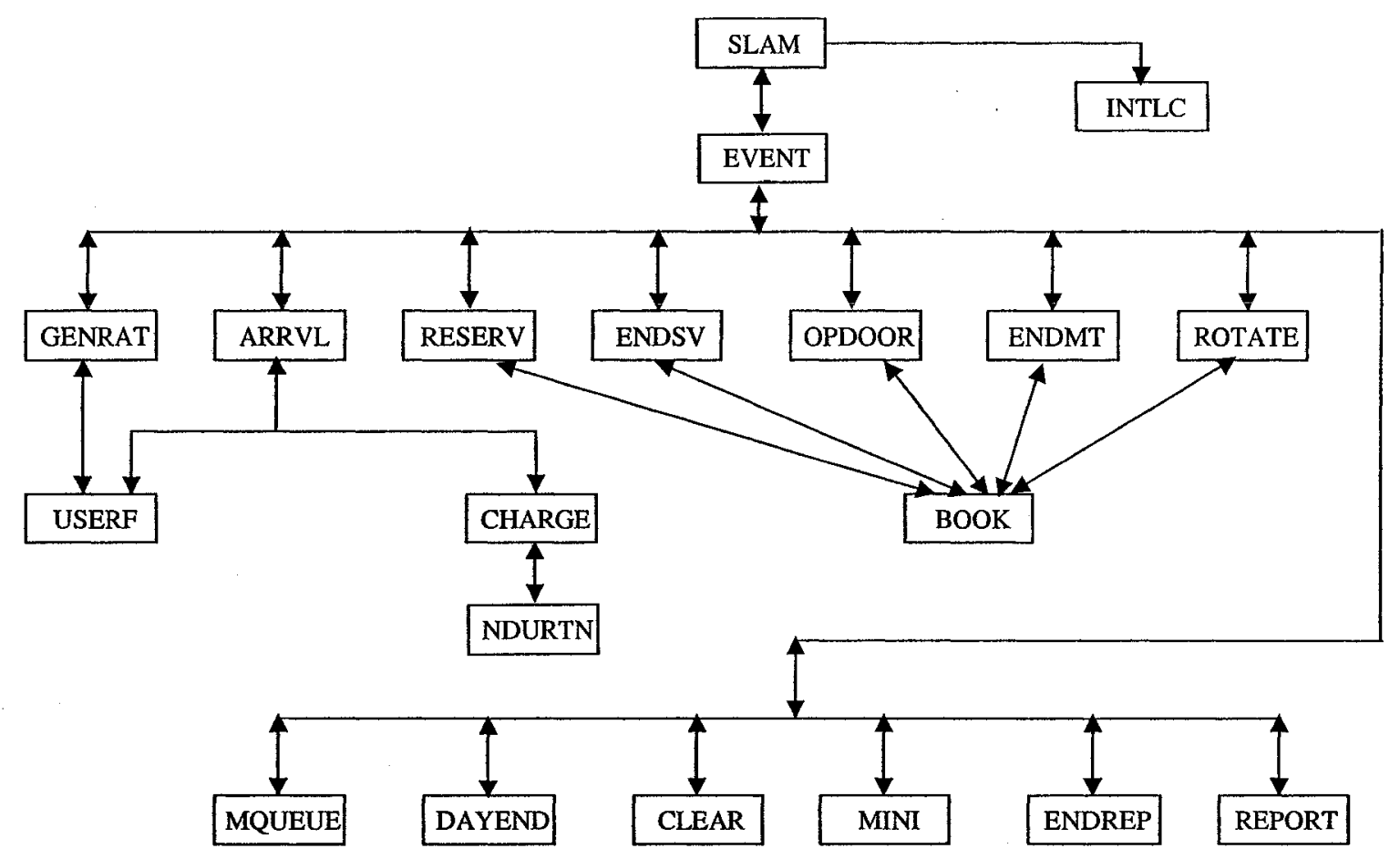

Figure 3.3 Simulation Model Flowchart, Liu et al (1983)

The entire operation of the mobility enterprise, including the leased and shared fleet, was included in the model. Various system decision/design variables such as fleet size and mix (composed of three different categories of vehicles), pricing and reservation schemes, maintenance, and organization structures were addressed by the model. The model was capable to produce a wide range of outputs including statistics ranging from an enterprise's financial (operating cost, revenue) and operating status (vehicle utilization, mechanics utilization) to each individual member's travel behavior belonging to such organization. 
In order to delineate a desirable system design, Liu et al (1983) implemented an optimization module in the model. A pattern search technique, known as Hooke-Jeeves pattern search, was used for the optimization of the system configuration. The module was capable to provide an automated optimization for a set of user defined decision/design variables.

\section{Model Application}

In order to demonstrate how the simulation model is practically useful for the evaluation of mobility enterprise system performance, Liu et al (1983) applied their model to a hypothetical mobility enterprise at Lafayette, Indiana, USA, with a population of 65,000 people. Three different types of vehicles were assumed to be made available in the shared fleet including subcompact, midsize, and large. The leased fleet was composed of subcompact type of vehicles. The characteristics of the vehicles are given in Table 3.2.

Table 3.2 Vehicle characteristics of mobility enterprise's fleet

\begin{tabular}{|l|c|c|c|}
\hline \multirow{2}{*}{ Characteristics } & \multicolumn{3}{|c|}{ Vehicle Types } \\
\cline { 2 - 4 } & Subcompact & Midsize & Large \\
\hline Fuel Economy (mpg) & $45(19 \mathrm{~km} / \mathrm{liter})$ & $25(10.6 \mathrm{~km} / \mathrm{liter})$ & $20(8.5 \mathrm{~km} / \mathrm{liter})$ \\
\hline Monthly Insurance (USD) & 20 & 30 & 40 \\
\hline Purchase Price (USD) & 4,000 & 8,000 & 10,000 \\
\hline
\end{tabular}

Note: the US dollars are in 1983 level 
The enterprise was assumed to be open for eight hours a day and access to the shared fleet was guaranteed. Two types of vehicle maintenance were performed in the garage: minor maintenance, basically oil, at every $6000 \mathrm{kms}$ and major maintenance, tune-up, at $32,000 \mathrm{kms}$.

Seven different trip purposes were considered in the example. Detail differentiation was thought to be necessary to capture distinct extent-of-usage associated with each purpose. The travel demand of the mobility enterprise with trip purpose breakdown is given in Table 3.3.

Table 3.3 Travel Demand of the Mobility Enterprise by trip purposes

\begin{tabular}{|l|c|c|c|}
\hline \multirow{2}{*}{$\begin{array}{l}\text { Trip Purpose } \\
\text { Laily trips (per member }\end{array}$} & $\begin{array}{c}\text { Weekday } \\
\text { (Off-peak) }\end{array}$ & $\begin{array}{c}\text { Weekend } \\
\text { (Peak) }\end{array}$ \\
\cline { 3 - 4 } & & 0.74 & 1.08 \\
\hline household) & 3.92 & $2 \%$ & $0 \%$ \\
\hline Work & $36 \%$ & $30 \%$ & $35 \%$ \\
\hline Shopping & $19 \%$ & $25 \%$ & $8 \%$ \\
\hline Personal Business & $20 \%$ & $30 \%$ & $40 \%$ \\
\hline Civic, educational, and religious & $18 \%$ & $7 \%$ & $9 \%$ \\
\hline Vacation & $4 \%$ & $1 \%$ & $3 \%$ \\
\hline Other & $0 \%$ & $5 \%$ & $5 \%$ \\
\hline Total & $3 \%$ & $100 \%$ & $100 \%$ \\
\hline
\end{tabular}


Source: Liu, Sinha, and Fricker, 1983

Various probability distributions (i.e., lognormal, shifted lognormal, and exponential) were used to simulate the trip length (in mile), and trip duration (in hours) in the model. Trip duration was defined as follows:

trip_duration $=$ vehicle in $_{-}$moving time + vehicle in $_{-}$idle time

The model also considered a probability of 0.3 that a member will reserve a shared vehicle in advance. That means $30 \%$ of the time or $30 \%$ of the members will book or reserve the vehicle in advance. The model found the optimum system configuration for the studied hypothetical site, as shown in Table 3.4 .

\section{Model Results}

The simulation model was used to determine the optimal system configuration for six different sizes of mobility enterprise ranging from 20 to 200 member households. The size of the shared fleet and its vehicle mix were considered as important design variables for optimum system configuration. The optimization was configured based on weekly operating cost minimization. The resulting optimum system configurations are shown in Table 3.4. 
Table 3.4 Optimum system configurations for six systems

\begin{tabular}{|c|c|c|c|c|c|}
\hline \multirow{2}{*}{$\begin{array}{c}\text { System size } \\
\text { (no. of members) }\end{array}$} & \multicolumn{3}{|c|}{ Shared fleet mix } & \multirow{2}{*}{$\begin{array}{c}\text { Shared } \\
\text { fleet size }\end{array}$} & \multirow{2}{*}{$\begin{array}{l}\text { Vehicle-to- } \\
\text { member ratio }\end{array}$} \\
\hline & Subcompact & Midsize & Large & & \\
\hline 20 & 4 & 4 & 1 & 9 & 0.45 \\
\hline 50 & 9 & 6 & 2 & 17 & 0.34 \\
\hline 80 & 13 & 8 & 3 & 24 & 0.30 \\
\hline 100 & 15 & 9 & 4 & 28 & 0.28 \\
\hline 150 & 20 & 17 & 7 & 44 & 0.29 \\
\hline 200 & 24 & 19 & 8 & 51 & 0.25 \\
\hline
\end{tabular}

Source: Liu, Sinha, and Fricker, 1983

From the above simulation model results it is obvious that a certain level of demand could be matched with lower vehicle-to-member ratio in a larger system than a smaller one. That means, in a larger system the average demand of the user pool could be matched more efficiently and economically than in a smaller system. A similar result was found by Prof. Cousins (1983) at Cranfield University, Cranfield, U.K.

\subsection{The Use of Electric Vehicles (EVs) in CFB Ottawa's Base Taxi Fleet-A Comparative Cost Study}

John P. Miller carried out this research as an M. Eng. thesis at Carleton University, Ottawa, Canada, in 1982 under supervision of Prof. Ata M. Khan. This study examined a self-drive taxi system as an alternative to the base taxi system that was in operation at Canadian Forces Base (CFB) Ottawa, in support of duty personnel of the Department of National Defense (DND). The duty personnel had to travel between 46 locations in 
Greater Ottawa. The effort developed a cost model for the self-drive taxi service as a part of economic analysis. Two different scenarios of self-drive taxi system, namely with electric vehicle (EV) and conventional gasoline powered vehicle, were studied and their costs were compared with the existing base taxi system.

With the rapid change in the price and availability of gasoline, the researchers were motivated to study this alternative mode of transport, self-drive taxi system that is similar in concept to shared vehicle systems. As noted above, Miller assumed fleet alternatives based on electric and conventional gasoline powered vehicles to meet the travel demand of the duty personnel and analyze its economic feasibility. The travel demand for October 1979 was used for modelling and analysis purposes. Computer models were developed and coded in FORTRAN to compute the number of vehicles needed to satisfy the travel demand for 19 eligible locations (station/depot in shared vehicle systems) out of the total 46 locations, without considering any measure of performance. The study assumed that the self-drive system must meet $100 \%$ of the travel demand in order to be an alternative to the base taxi system. The modelling methodology for the system is not described in detail in the thesis but the findings of the model, such as the required fleet size to meet the total travel demand of the duty personnel, relocation need etc, are included. The study found that the distribution of vehicles at the end of any operation day was not the same as required for the following day's travel demand and hence vehicle relocation was necessary. Using Miller's results, an analysis is performed here and plotted in Figure 3.4. 


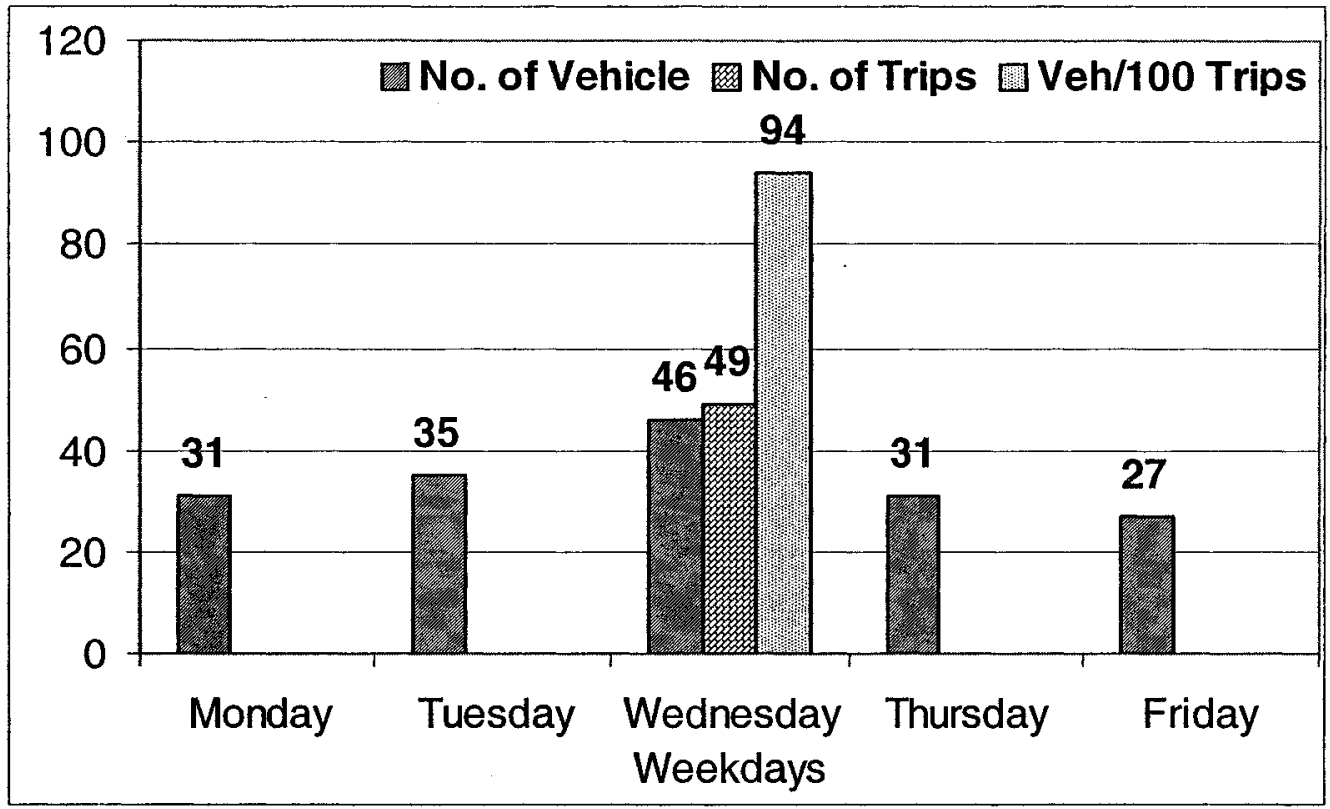

Figure 3.4 Number of vehicles needed to serve 100 trips in self-drive taxi system, CFB, Ottawa (based on Wednesday demand)

From the above figure it is obvious that a total of 94 vehicles are needed to serve 100 trips for a 9-hour period (8:00am to $5 \mathrm{pm})$ among 19 stations. Therefore the vehicle-to-trip ratio is 94 percent. This result is significantly different from Barth and Todd findings. Barth and Todd (1999) found a vehicle-to-trip ratio of 3-6\% to satisfy the user average wait time and $18-24 \%$ to satisfy both user average wait time and number of vehicle relocations for a 24 -hour operation period.

Since the major objective of this study was cost comparison of the alternative selfdrive system, it only determined the fleet size and used it for cost estimation. The model vehicle was a two-seater EV powered by eight 6-volt batteries. This effort could be considered as an initial modelling effort for multiple stations shared vehicle system in Canada and deserves further research. 


\subsection{Lessons Learned}

From the foregoing literature it is obvious that the models developed at Purdue University and University of California at Riverside (UCR) are similar in modelling concept and used discrete-event simulation technique. They differ in system concept that they simulated. Models developed at Purdue University did not provide details about the customer arrival pattern, party size, vehicle availability and/or distribution, relocation need, and dealt with cooperative type shared vehicle system. It also lacks in detail about the method of trip generation. The models developed at UCR by Barth and Todd assumed that the system followed modified Markov process, in which the trip interarrival time or inter-trip generation time is exponentially distributed with an upper limit of $\frac{1}{\lambda}+5 \sigma$, where $\frac{1}{\lambda}$ is the mean interarrival time and $\sigma$ is the standard deviation given by $\left(\frac{1}{\lambda^{2}}\right)$. The underlying system is a multiple stations shared vehicle system and both one-way and round trips are possible. In their methodology, Barth and Todd used a deterministic model to calculate the total travel or trip time. Vehicle imbalances are allowed and are treated using 'historical predictive relocation' method. Some degree of randomness in customer registration, vehicles checkout, vehicle check-in is considered through implementation of analytical probabilistic model (Gaussian model) of random phenomena. The concept of the self-drive taxi system for CFB Ottawa was similar to a multiple stations shared vehicle system but the model lacked in detail and produced significantly different results from that of Barth and Todd model. Other two modeling efforts, Kyoto Public-Car system model and Prof. Cousins's car availability model, are different either in system 
concept or modeling concept or both. The Praxitele Trial project simulation model developed by Arnaldi et al is different by modelling context.

Based on this literature review, it could be concluded that scope exists to develop improved and more realistic simulation model of the shared vehicle systems by considering additional variables. A complete set of variables, including party size, travel time, vehicle mix, vehicle-to-parking ratio would lead to more realistic design and operation model. An improved model could help in gaining insights that are not yet explored and enhance the design and operations of shared vehicle systems. It also could enhance the likelihood of sustainable development of this new innovative and potential transportation system and the urban transportation for $21^{\text {st }}$ century in North America, Europe, and other parts of the world. 


\section{CHAPTER IV \\ A FRAMEWORK FOR \\ MODELLING SHARED VEHICLE SYSTEMS}

\subsection{Introduction}

The main purpose of this chapter is to outline the general approach and methodology that has been employed in this research study. It begins with a comprehensive description of the development of the methodological framework to develop an improved shared vehicle system simulation model. The model development strategy is then followed. The developed model is then used to simulate and analyze the shared vehicle system design and operations. A detailed description of discrete system simulation and comprehensive algorithm to implement the model is given in Chapter V.

The operations spectrum of shared vehicle systems is divided into a reasonable number of scenarios to capture the influences of all possible input or control variables and to determine the best values of design variables for the purpose of getting more insights for better design, efficient operation, and improved management of the shared vehicle systems in the real world case. These are also the key elements to make the system economically viable and to extract all possible advantages in terms of sustainable urban transportation. Methodologies for the estimation of petroleum energy savings and economic analysis are then followed. Possible data sources are identified, adjusted, and used for the development of the simulation model and to test the model performance. 
The complete methodological framework is guided by the following eight tasks:

1. Shared vehicle systems definitions, their potentials, and identification of design and operational problems

2. Lessons learned from the review of the recent experimental and modelling efforts

3. Structuring the new modelling approach

4. Study site identification and development of input database

5. The discrete-event simulation technique and development of the simulation model

6. Model application, performance evaluation, and sensitivity analysis

7. Estimation of petroleum energy savings, and economic analysis

8. Conclusions and recommendations.

A brief overview of the classification of the shared vehicle systems is provided in Chapter I. The definitions of different forms of shared vehicle systems are gathered from the available literature and presented in detailed form in Chapter I. The potentials of shared vehicle system and its design and operational problems are also identified and mentioned in Chapter I. A historical overview of the evolution of shared vehicle systems is given in Chapter II. The literatures on recent demonstration projects, modelling efforts, and their findings are summarized in Chapters II and III, respectively. As previously noted, the notable recent modelling efforts include the following:

1. Intelligent Community Vehicle System (ICVS)) simulation model by Barth and Todd at the University of California at Riverside (UCR), California, USA, 
2. Genetic Technique (GT) algorithm based "Kyoto Public-Car System" computer simulation model by Nakayama et al, Kyoto, Japan,

3. Simulation model for Praxitele Trial Project by Arnaldi et al. in Saint-Quentin, France, and

4. Simulation Analysis of Mobility Enterprise System Operations by Liu, Sinha, and Fricker at Purdue University, Indiana, U.S.A.

The remaining tasks of the modelling framework of this research effort are described in the following sections.

\subsection{Structuring the New Modelling Framework}

The available literature on shared vehicle systems modelling is extremely insufficient in North America as well as elsewhere in the world. Among the literature, notable efforts are identified and explained in the previous Chapters. Barth and Todd (1999) used discrete-event simulation technique to develop simulation model for their shared vehicle systems named "Intelligent Community Vehicle System (ICVS)" and UCR IntelliShare. On the other hand, Nakayama et al used genetic technique (GT) algorithm with periodic scan approach (interval oriented, fixed increment in time advance) to model shared vehicle system operations for Kyoto Public-Car System in Kyoto, Japan. 
In their models, Barth and Todd used hourly OD matrices for six peak days from peak, mid-peak, and off-peak seasons weekdays and weekends to optimize the vehicle-totrip ratio in satisfying the user average waiting time or number of relocation or both. The total daily demand was not considered. The model was applied to a hypothetical resort community, Palm Springs, Coachella Valley, CA, USA. Although a complete distribution of the party sizes for a given 24-hour demand for a particular season is illustrated in the report, the party size of the arrival at each time was not taken into consideration in the modelling effort. Consideration of party size is an important factor to represent the real world demand more realistically and need to match it with the available size of vehicle in the supply fleet and enhance the total automobile productivity (higher occupancy etc). Moreover, they calculated the travel time using deterministic model (please see equations 3.2 and 3.4).

Nakayama et al optimized checkout rate per vehicle and determined optimal vehicleto-user ratio for "Kyoto Public-Car System". Nakayama et al also found a relation between number of required parking slots and number of vehicles in operation for optimum system operation without vehicle relocation for given travel demand. But in their report they mentioned that parking was not considered as a design variable and kept constant due to some constraints in arranging additional parking slots. The study report also mentioned that genetic algorithm is not usually capable to produce optimum solution and it is error prone. In addition, the model did not take into account some important 
system variables such as travel times and method of estimation, pattern of customer arrival, party size in each arrival and parking-to-vehicle ratio. Hence sufficient opportunities still exist to use findings from these recent modelling efforts in selecting system variables, measures of performance indicators and integrate them to develop improved and more refined shared vehicle system design and operations model.

This refined model could provide further insight into optimum values of decision variables and system performance indicators, and help to extract all possible benefits. This is the main objective of this effort. This thesis research is an extension of the most recent modelling efforts in dimensions including: (1) capturing real-time supply-demand interaction of shared vehicle systems (SVS) operations for a suitable operation period (i.e., a day) considering a complete set of design variables (see section 4.2.1.1) including trip travel time, party size, vehicle-to-parking ratio, and vehicle mix, (2) introduction of the Bayesian statistical model to better estimate the trip travel times for various trips, and (3) development of an application of the CSIM19, a recent powerful process-oriented, discrete-event based general purpose system simulation toolkit developed by Mesquite Software, Inc. to model shared vehicle system design and operations using discrete-event simulation technique. The conceptual flowchart of the new modelling framework is shown in Figure 4.1. Detailed coverage of the various components is presented in the following sections. 


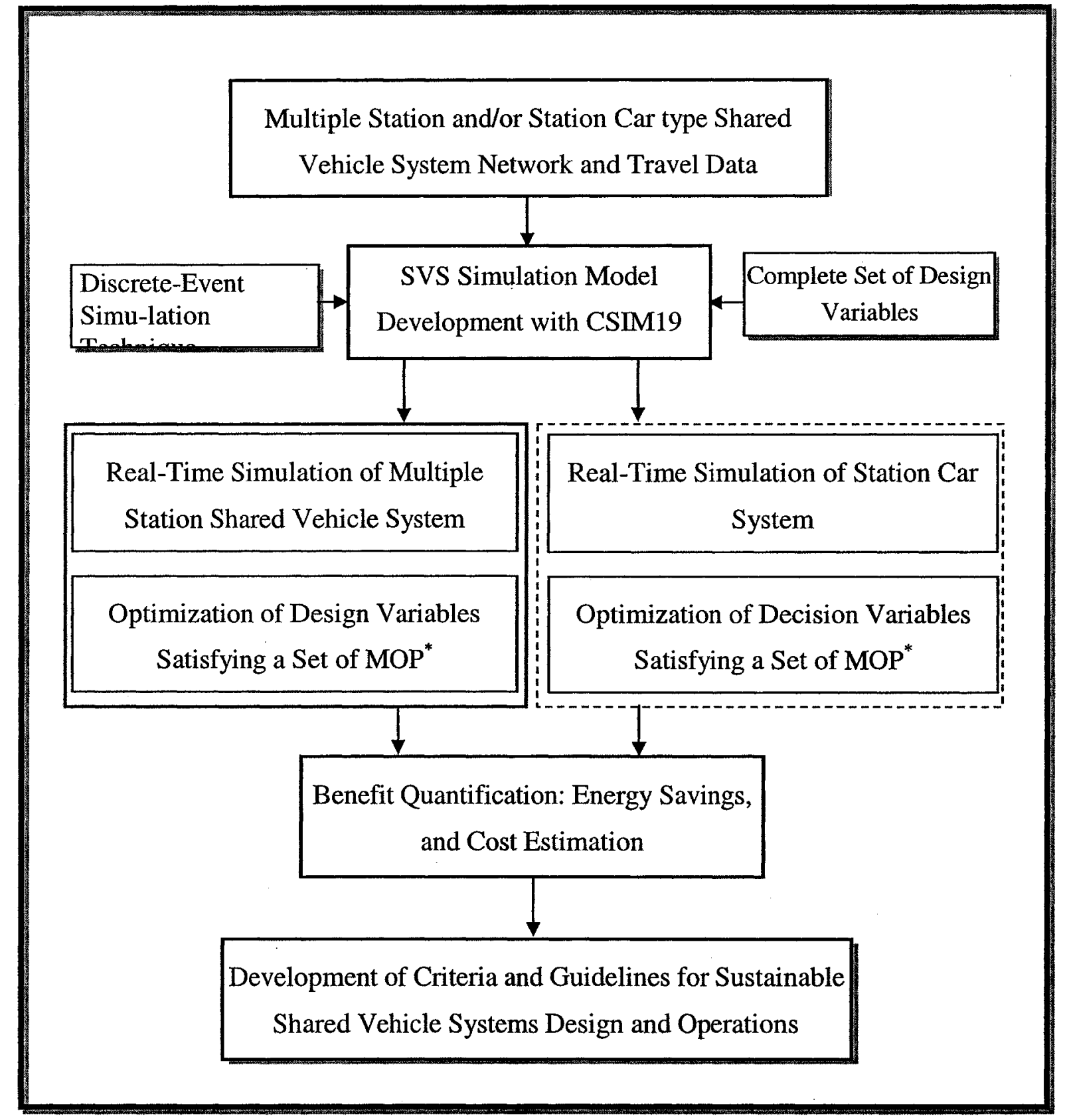

Figure 4.1 Conceptual Framework for Modeling Shared Vehicle Systems

Notes: ${ }^{*} \mathrm{MOP}-$ Measure of Performance 


\subsubsection{Demand-Supply Interaction in Shared Vehicle Systems Operations}

The efficient operation of shared vehicle systems is dependent on the availability of vehicles when a user wants to use one. In conventional carsharing, neighborhood car coop type carsharing system, the trips are assumed to be round trip and the vehicles are assumed to return to the checkout station. So the vehicle availability, characterized by user wait time, will not be affected by the variation in demand between two different carsharing stations or depots. In this case, vehicles are usually placed in one convenient location to serve a particular target group within a geographic boundary (neighborhood, community). In the case of multiple station shared vehicle systems, the vehicle availability is critically dependent on the travel demand among stations over time and is a major critical factor in efficient operations of shared vehicle systems (Barth and Todd, 1999). The reason is that the multiple station shared vehicle systems are designed to serve both one-way and round trip travel demand among a number of pre-selected stations. Vehicles can be picked up from any station and dropped to the same or any other destination station. The asymmetric demand among stations with respect to time has tremendous potential to produce imbalance in vehicle availability at any given station. This means that a station may accumulate an excessive number of vehicles. On the other hand, another station may be deficient in vehicle supply. Hence there may be a mismatch between the vehicle distribution and the travel demand. To bring the system back to balance, a special mechanism called "vehicle relocation" may be used (Barth and Todd, 1999). Another important factor is to match the size of the party or group in each arrival 
with available vehicle size. The combined management of the vehicle availability and party size of each arrival/trip with the available vehicle fleet could significantly improve the shared vehicle system operation efficiency and productivity (utilization of vehicle's passenger carrying capacity) of the vehicles (automobiles).

The steps that have been followed in modelling demand-supply interaction in shared vehicle systems, focused on multiple station and station car type shared vehicle systems, operations are summarized as follows:

1. Identification of design variables and measures of performance (MOP) indicators

2. Formulation of dynamic database system and travel demand profile

3. Selection of a complete set of design variables and development of a possible set of case scenarios

4. Considering system efficiency (how efficiently the system is operating) as the objective function under each scenario for both multiple station and station car type shared vehicle systems, model and optimize the system design and operations and capture the optimum values of design variables considering a set of measures of performance (MOP) indicators. 
The demand-supply interaction of a multiple station or station car type shared vehicle system could be illustrated as in Figure 4.2.

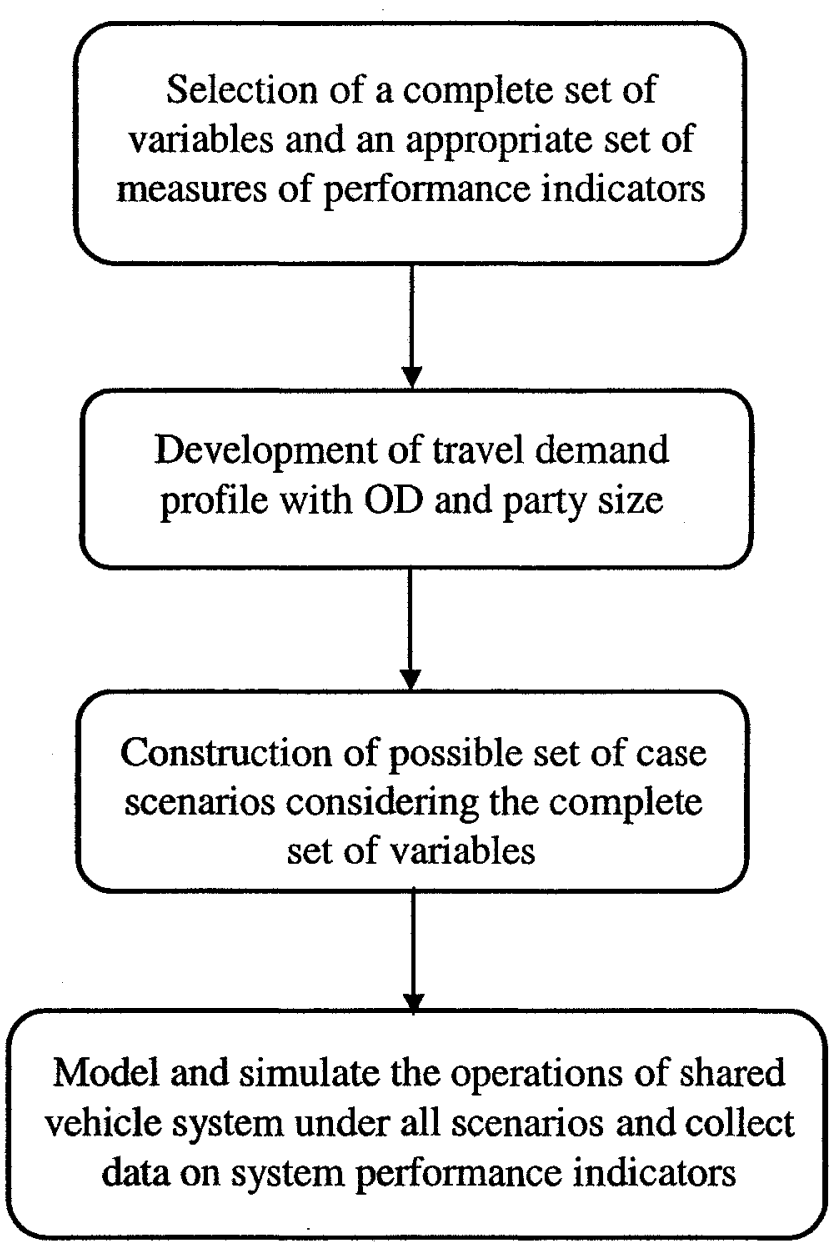

Figure 4.2 Steps in demand-supply interaction modelling process 


\subsubsection{Methodology for Design Variables Selection}

\section{Shared Vehicle Systems}

As an alternative transportation paradigm, shared vehicle systems have become increasingly popular in recent years (Barth and Todd, 1999). From the technical literature reviewed in Chapter I (section 1.2) it is revealed that the shared vehicle systems could be divided into the following two major categories/classes depending on the attributes of the travel demand and trip types they are designed to serve.

1. Round Trip Shared Vehicle Systems (RTSVS), which include car co-op type carsharing or shared vehicle systems

2. Multiple Station Shared Vehicle Systems (MSSVS), which include station car and multiple station type shared vehicle systems

Detailed definitions of these two major categories of shared vehicle systems are provided in Chapter I under section 1.2. Shared vehicle systems under subgroup 2 are considered in this thesis research.

\section{Methodology for Variables Selection}

From the available literature it is observed that the operation of the shared vehicle system is highly sensitive to the system attributes that include: accessibility, vehicle availability, characterized by user or customer wait time, and vehicle distribution, characterized by number of vehicle relocations. These attributes are direct functions of 
system variables including user pool or number of users, travel demand, diurnal demand pattern/variation, party size, vehicle fleet size and mix, vehicle-to-trip ratio, number of available parking slots or vehicle-to-parking ratio, network traffic conditions, user acceptable maximum wait time, and others when the system is of multiple station type for a given number of stations within the system. In the case of round trip type system, the system efficiency depends on variables including system size in terms of number of members, demand pattern, vehicle-to-user ratio, acceptable failure rate and/or maximum acceptable wait time, and accessibility. These system variables constitute a complete set of common decision variables. This means that these variables are common for any kind of urban and/or land use development.

Outside of this common set of decision variables, we may need to consider variables related to urban form and the density, other transportation services and their availability, and level of integration with other transportation services. If we consider the development or urban form in an area or zone where the carsharing system is in operation, we may be able to identify some decision variables that are critical for that given urban development. For example, in central area of any city, acquiring land is very costly and parking facility is expensive and in some cases difficult or impossible to acquire. On the other hand, in a suburban area, parking is cheap and not difficult to obtain, although creating a parking lot at any given location costs money especially when it needs to be equipped with charging and other servicing facilities. On the demand side, which is the key requirement to be 
met, the composition of the user's socioeconomic status could be an important factor. Hence the variables and factors that should be considered in the design and operations of any multiple station shared vehicle system(s) could be identified as follows:

1. Number of stations

2. Travel demand and its distribution among stations with respect to time of the day

3. Number of parking slots at each station (parking-to-vehicle ratio)

4. Party or group size in each arrival or trip

5. Vehicle fleet size (in terms of vehicle-to-trip ratio) and its composition (mix)

6. The road network and its traffic condition with respect to congestion as trip travel times in the area/community where the car sharing system is in operation

7. Distribution of vehicles at each station beginning of each day operation

8. Average acceptable waiting time and queue length

9. Vehicle relocation needs and criteria

10. Composition of the users' socioeconomic condition

11. Urban form and densities

12. Other transportation services, availability, and integration with carsharing

The above whole set of variables and factors may be aggregated into the following two subsets/groups:

1. Variables/factors that have a direct influence on shared vehicle systems design and operations in any market segment, include variables 1 to 9 , and 
2. Variables/factors that have site or market specific influence on shared vehicle system design and operations include variables 10 to 12 in the list above

Considering the available resources and scope of this study, variables under subset 1 have been considered in this thesis to model the shared vehicle system design and operations analysis.

\subsubsection{Formulation of Dynamic Database and Travel Demand Profile}

The demand estimation, in terms of origins and destinations (OD) and time variation, is the most resource consuming but fundamental task in transportation systems study, analysis, design, evaluation, and strategic planning. The viability of any transportation system and/or service is inherently dependent on the demand-supply balance. In the case of shared vehicle systems, demand is random and varies widely among stations and with respect to time. It is a dynamic attribute of the system with respect to time and space (stations), and produces enormous task to meet this demand by a given number of vehicles supplied at various stations. So we need to consider all possible factors in estimating demand at various stations of a multiple station shared vehicle system, and all of its attributes to model it in an efficient way. The traditional aggregate and disaggregate models for demand estimation and forecasting, used in conventional four-step urban transportation planning process, will no longer be applicable for specialized travel demand among stations in the transportation network as in the case of multiple station or 
station car type shared vehicle systems (Barth and Todd, 1999). Hence a special effort is needed to develop appropriate travel demand profile for a shared vehicle system, which includes the variations in demand among stations with respect to time and party sizes. Most established methods found in literature are to log the demand in an experimental shared vehicle system for a reasonable period of time (say a week) or to perform a detailed travel demand survey. This travel demand data in association with the network traffic condition in terms of trip travel times and distance between stations became the key elements in developing shared vehicle systems design and operations model.

In two most recent modelling efforts, such as the UCR Intelligent Community Vehicle Systems (ICVS) and "Kyoto Public-Car Systems" models, this demand profile was developed from pre-operation survey and during operation records respectively. In both studies separate peak daily demand was used for system design and operations modelling. None of these two modeling efforts consider demand with the party sizes in their models. To be realistic and capable to estimate appropriate values of the design variables, the travel demand should be estimated with maximum accuracy and be consistent with the reality. In the design of any system if the estimated demand or loading pattern and its nature (say variation and/or distribution) are not realistic the total system design definitely will produce false results. In the design of shared vehicle system we should follow the same philosophy to determine travel demand with its variations and party size distribution in time and space as realistically as possible. 
In its simplest form and to be a true representative of larger systems we may consider a multiple station shared vehicle system consisting of three stations as shown in Figure 4.3 .

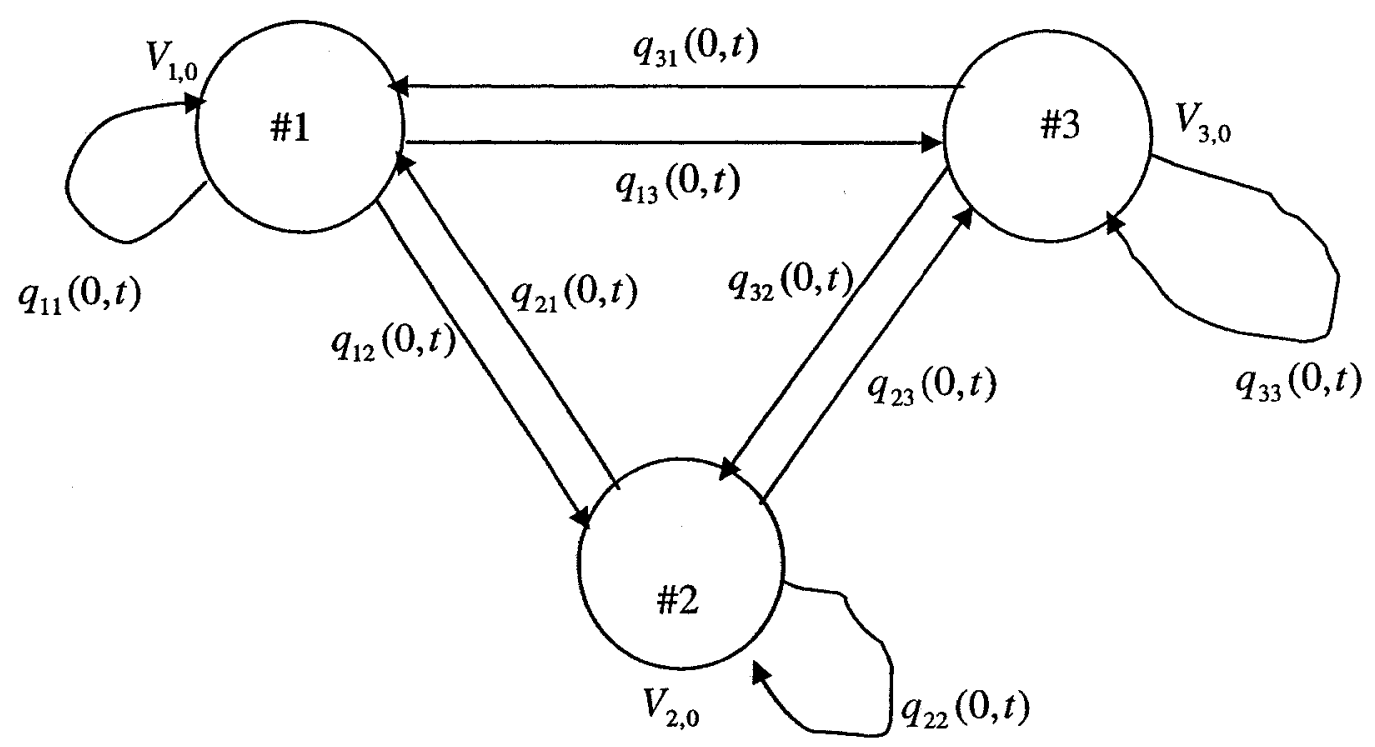

Figure 4.3 Real-Time travel demand and vehicle distribution at stations

The variables are defined below:

$V_{i, 0} \quad=$ number of vehicles at the beginning of operation of any day at station $\mathrm{i} ;$ for $i=1,2,3$

$q_{i, j}(0, t)=$ number of trips generated or realized from station $\mathrm{i}$ to station $\mathrm{j}$ during time 0 to t; for $i=1,2,3$ and $j=1,2,3$. 
The total number of trips generated at station \#1 during time interval 0 to $t$ (unit of the time could be minute or hour) could be calculated as follows:

$$
\begin{aligned}
& T_{1}(0, t)=q_{11}(0, t)+q_{12}(0, t)+q_{13}(0, t), \\
& \text { or } \quad T_{1}(0, t)=\sum_{1}^{3} q_{1 j}(0, t)
\end{aligned}
$$

where $T_{1}(0, t)$-is the total number of trips generated at station 1 and destined to stations $\mathrm{j}$ $(j=1,2,3)$ during the period 0 to $t$.

If the system consists of $\mathrm{n}$ number of stations or depots then the above expression could easily be generalized as follows;

$$
T_{i}(0, t)=\sum_{j=1}^{m} q_{i j}(0, t), \text { for } \mathrm{i}=1,2,3, \ldots . \mathrm{n}
$$

where $T_{i}(0, t)$ is the total number of trips generated at station $\mathrm{i}$ and destined to stations $\mathrm{j}(\mathrm{j}$ $=1,2,3 \ldots \mathrm{m}$ ) during the period 0 to $\mathrm{t}$. In the case of multiple station shared vehicle system $\mathrm{m}=\mathrm{n}$.

Knowing the number of trips realized and arrived at station $i$ from other stations within the time interval 0 to $t$, we can use the above models/logics to dynamically update the vehicle database and distribution to make decisions for vehicle relocation need. 
The most common time interval used in transportation studies and system analysis and design to capture variation in travel demand is an hour. To be consistent with the literature and normal practice a time interval of 'an hour' has been used in this research study to model demand and its variation among stations with time.

Shared vehicle systems are designed to meet specified travel needs. Demonstration project findings (Walb and London, 1986) and modelling research findings of Barth and Todd (1999) showed that shared vehicle systems could be an excellent complement to public transit, taxis, and individually owned private automobiles. This means that shared vehicle system is intended to satisfy those travel needs, which are not economical to serve by private automobile use, where public transit service is not available or inconvenient, and taxi is highly expensive. This system complements the public transit where it is insufficient or unavailable. On the other hand, the assumption is that social, business, and midday errand trips could be made more economically using shared vehicle systems. It is not implied here that the shared vehicle systems could handle the whole travel demand of a metropolitan community/region. Therefore the appropriate segment of the travel market that the shared vehicle systems are assumed to meet should be identified carefully.

In this thesis research, a 9-hour period of any day, week or weekend, is divided into hours and the travel demand matrix with origin and destinations (ODs) has been developed. Now we also need to assume an appropriate operation period for any given 
day. We must have the period of operation and outside this period we assumed that the demand is zero at all stations and the systems will be completely idle. To be realistic and consistent with the activities of metropolitan areas in North America and around the World, we assumed that the operation will be started at 8:00 am in the morning and end at 5:00 pm in afternoon, which constitutes a total operation period of 9 hours per day. A shared vehicle system with ' $n$ ' stations will then have 9xn hourly travel demand matrices with ODs. A typical real-time travel demand matrix for a time period $t_{k}\left(\mathrm{k}^{\text {th }}\right.$ hour of the operation day) within the operation period that includes trips among all stations within the system is shown in Table 4.1 .

Table 4.1: Typical travel demand matrix with ODs of $k^{\text {th }}$ operation hour that includes trips between all stations

\begin{tabular}{|c|c|c|c|c|c|c|c|c|}
\hline TripFrom $i / j$ & 1 & 2 & 3 & $\cdot$ & $\cdot$ & $\cdot$ & $\mathrm{n}-1$ & $\mathrm{n}$ \\
\hline 1 & $q_{1,1}$ & $q_{1,2}$ & $q_{1,3}$ & & & & $q_{1, n-1}$ & $q_{1, n}$ \\
\hline 2 & $q_{2,1}$ & $q_{2,2}$ & $q_{2,3}$ & & & & $q_{2, n-1}$ & $q_{2, n}$ \\
\hline 3 & $q_{3,1}$ & $q_{3,2}$ & $q_{3,3}$ & & & & $q_{3, n-1}$ & $q_{3, n}$ \\
\hline$\ldots$ & $\ldots .$. & $\ldots$ & $\ldots .$. & $\ldots$ & & & & \\
\hline $\mathrm{n}-1$ & $q_{n-1,1}$ & $q_{n-1,2}$ & $q_{n-1,3}$ & & & & $q_{n-1, n-1}$ & $q_{n-1, n}$ \\
\hline $\mathrm{n}$ & $q_{n, 1}$ & $q_{n, 2}$ & $q_{n, 3}$ & & & & $q_{n, n-1}$ & $q_{n, n}$ \\
\hline
\end{tabular}

Note: $\mathrm{i}$ and $\mathrm{j}$ indicate the origin and destination station for a particular trip 
In this way, the total numbers of OD matrices have been reduced to the number of operation hours per day and 9 in this case. These OD matrices together with party size, the network traffic conditions (measured in terms of trip travel time) with respect to congestion, and distance among stations have been used to model the shared vehicle systems design and operations.

\subsubsection{Selection of Complete Set of Design Variables and Development of Case}

\section{Scenarios}

From the users point of view, the success of a shared vehicle system is dependent on getting a vehicle easily when they want to use one (Cousins, 1998). From operators or service providers' viewpoint, they wish to meet the users need from a minimum number of vehicle inventories. These aspects come together in the form of car:user ratio. The actual ratio is dependent on many factors - most importantly, the level of local services within the walking distance, public transportation quality, walking and bicycling facility, type of urban form, user demographics, trip purposes etc. However, the ratio is highly dependent on the size of the system, the user pool or demand itself (Cousins, 1998). As the systems become larger, the percentage variation in demand is reduced, and the supply of vehicles could be matched more closely to the average demand of the user pool. Under these circumstances far fewer vehicles are idle and maximum number of users can be served with a vehicle when required (Cousins, 1998). Cousins (1998) defined this shared vehicle system performance indicator as the scale efficiency. Nakayama et al (2001) 
identified this performance indicator as "checkout rate" and is defined as the total number of checkouts per vehicle per unit time (i.e., day). Barth and Todd (1999) defined as vehicle-to-trip ratio in percent or number of vehicles needed to serve 100 trips for a given operation period. All these literatures have been reviewed and illustrated in the previous chapters.

In the case of multiple station shared vehicle system where one-way trips are allowed and are the major demand to serve, the system is highly sensitive to be imbalanced due to the uneven travel demand among different stations at different time periods (Barth and Todd, 1999). The dominant operational issue centers on vehicle availability (characterized by user wait time) at any station at a given time period. If a user has to wait a longer period to pick up and use a shared vehicle, it is likely that he/she will not use the system and the system will fail. On the other hand, an excess of vehicles is economically detrimental for the shared vehicle system owners/operators. Therefore, a demand-supply balance of the system must be achieved in order to have just enough vehicles operating within the system to achieve higher system efficiency and to make the system viable for future development.

Another key issue centers on the distribution of the vehicles (characterized by number of vehicle relocations). As previously mentioned, if demand for vehicles among stations is asymmetrical with time-of-day, some stations will tend to accumulate vehicles, while 
others will end up short of supply. In order to avoid this situation a special arrangement, relocation of vehicle, must exist to rearrange the vehicles according to the immediate future demand. It is envisioned that such a relocation mechanism can be implemented using a car-carrying truck or platooning (towing) a set vehicles from one station to another (Barth and Todd, 1999). If the shared vehicles are electric, as assumed in this study, close monitoring of the battery state-of-charge (SOC) is also critical (Barth and Todd, 1999). The knowledge and insights into these design, operational, and system performance issues are important and critical for better design and efficient operations of a viable shared vehicle system.

According to the discussion above, it is obvious that the scale efficiency or the checkout rate or vehicle-to-trip ratio, user average wait time, relocation need are the most critical performance indicators for any shared vehicle system evaluation, and are functions of many variables. Some variables may be relatively easy to tune up in system modelling and other may be not and are resource consuming. Therefore, it is not realistic that all the decision variables can be optimized together (Nakayama et al, 2001). For this particular study, the resources are limited and need to develop an evaluation framework to help organize the decision variables of shared vehicle systems in a meaningful way. Such decision variables include various input variables i.e., number of stations, fleet size, number of parking slots at each station or depot, travel demand and its variations with time and space, and party size in each arrival. 
Suitable data may be collected and various performance indicators can be computed for assessment against some desired objectives. However, without having insight into the characteristics of the decision variables and the degree of complexity to model them for a set of desired objectives, there may be an enormous need of resources and the effort becomes ineffective. For example, a higher value of checkout rate or the scale efficiency is not necessarily an indicator of higher quality of service and/or a viable system. It could happen due to higher demand for service with higher rate of booking failure or rejection. Similarly a higher waiting time does not imply that we need to increase the vehicle fleet size. It could happen due to asymmetric vehicle distribution and/or unavailability of vehicle on real time basis, poor vehicle management, combination of users, poorly designed station or depot, and many other reasons. The size of the party in each arrival also has influences on wait time and system's operation when we need to serve them with appropriate vehicles. A method is, therefore, required to reveal the interrelationships of the system variables and the system performance measures to develop meaningful scenarios including a complete set of decision variables. Therefore, variables and MOP selection information depicted in Table 4.2 and Figure 4.4 are used in this study. 
Table 4.2 Variables and measures of performance (MOP) indicators selection

\begin{tabular}{|c|c|c|c|}
\hline $\begin{array}{c}\text { Recent Studied } \\
\text { Models }\end{array}$ & $\begin{array}{l}\text { Variable Considered } \\
\text { in the Models }\end{array}$ & $\begin{array}{l}\text { Selected } \\
\text { Variables }\end{array}$ & $\begin{array}{c}\text { Measures of } \\
\text { performance (MOP) }\end{array}$ \\
\hline $\begin{array}{l}\text { UCR ICVS } \\
\text { Model by Barth } \\
\text { and Todd }\end{array}$ & $\begin{array}{l}>\text { Number of stations } \\
>\text { Travel demand in } \\
\text { trips, } \\
>\text { Fleet size }\end{array}$ & $\begin{array}{ll}\checkmark & \text { No. of stations } \\
\checkmark & \text { Travel demand } \\
& \text { in trips } \\
\checkmark & \text { Fleet size }\end{array}$ & $\begin{array}{ll}> & \text { Vehicle-to-trip ratio } \\
> & \text { User wait time } \\
> & \text { Number of relocations }\end{array}$ \\
\hline $\begin{array}{l}\text { Kyoto Public } \\
\text { car model by } \\
\text { Nakayama et al }\end{array}$ & 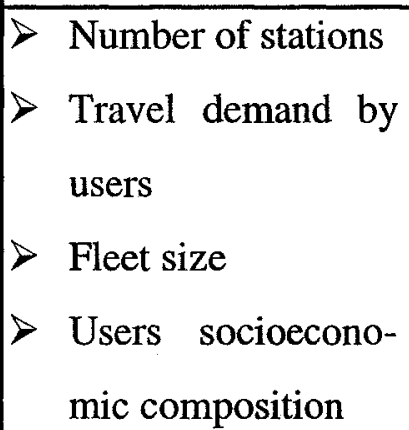 & $\begin{array}{ll}\checkmark & \text { Number of } \\
& \text { stations } \\
\checkmark & \text { Fleet size }\end{array}$ & $\begin{array}{l}>\text { Vehicle-to-user ratio } \\
>\text { User wait time }\end{array}$ \\
\hline $\begin{array}{l}\text { Variables and } \\
\text { MOP carried } \\
\text { over for this } \\
\text { thesis research } \\
\text { study }\end{array}$ & & $\begin{array}{ll}\checkmark & \text { Number of } \\
\text { stations } \\
\checkmark & \text { Travel demand } \\
\text { in trips } \\
\checkmark \quad \text { Vehicle-to-trip } \\
\text { ratio (Fleet) }\end{array}$ & $\begin{array}{ll}\checkmark & \text { Vehicle-to-trip ratio } \\
\checkmark & \text { User wait time } \\
\checkmark & \text { Number of relocations }\end{array}$ \\
\hline
\end{tabular}

Note: $\checkmark$ - Considered in this thesis research, $>-$ Considered in previous studies 
A complete set of variables that has been used in this effort was determined using the following variable selection logic.

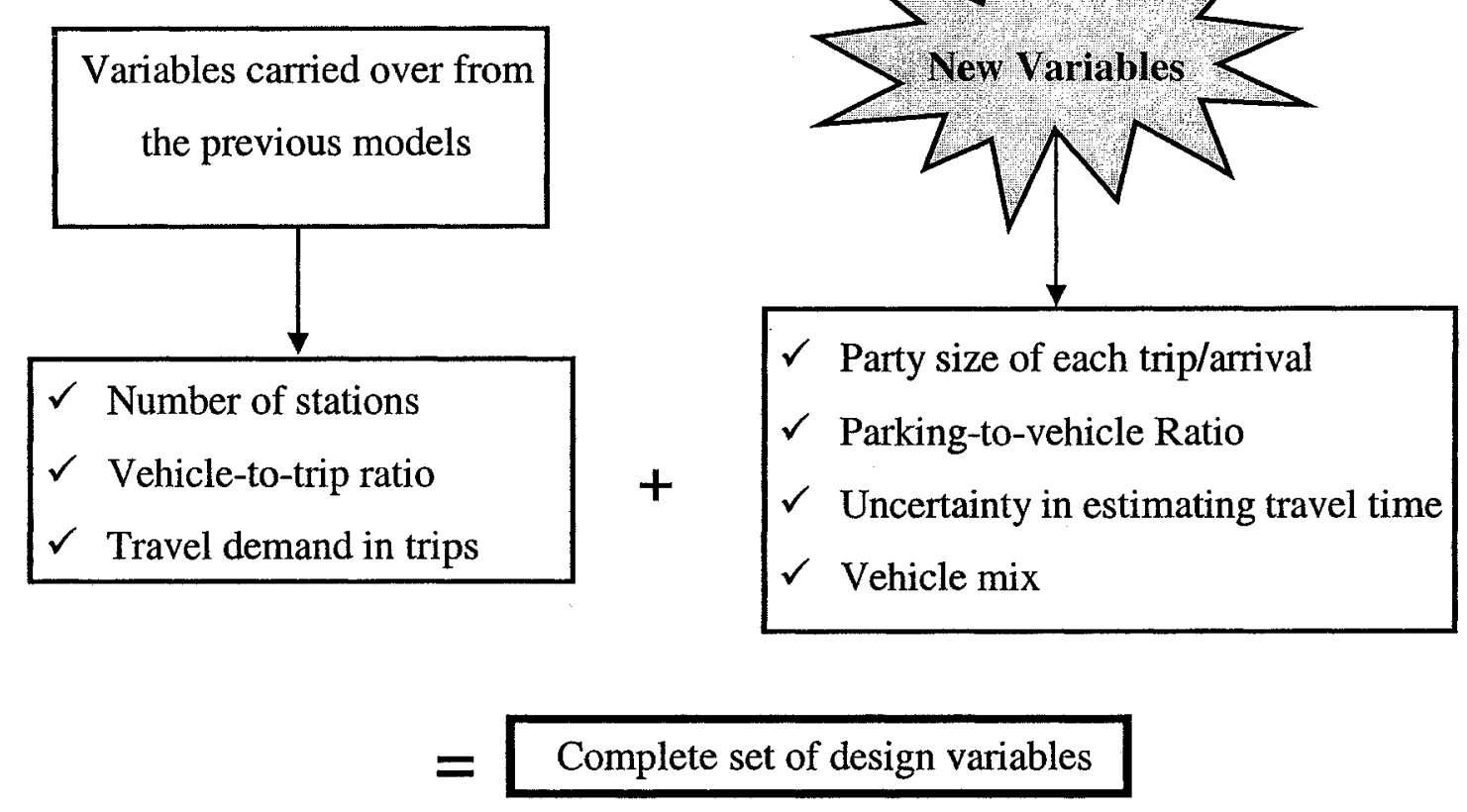

Figure 4.4 Complete set of variables

Based on this complete set of variables and identified critical system performance indicators, the following case scenarios were considered to model and study the shared vehicle systems design and operations and to capture the best design values of the decision variables under each scenario.

Scenario-1: Under this scenario the shared vehicle system has been modelled using the complete set of variables except the travel time between stations, which is 
considered as predetermined parameter. The system is assumed to follow modified Markov process (Barth and Todd, 1999) with limits in interarrival time as $0 \leq t \leq\left(\frac{1}{\lambda}+3 \sigma\right)$

Scenario-2: All the variables and conditions considered in scenario-1 have been used in this scenario. Additionally the system is assumed to follow normal Markov process. This implies that the interarrival times of the consecutive trips or customers is an exponentially distributed variate with an infinite support $(0 \leq t \leq \infty)$, where it can take any value between 0 and $\propto$.

Scenario-3: Under this scenario, the shared vehicle system has been modelled using the complete set of variables. Additionally, travel times are considered as variable or random parameter. Distributions for average trip travel times of different trips were considered to be found from previously known or collected data on travel times, called a priori distribution. Then real-time traffic information or advisory, from City Traffic Control Center, is combined to update this prior distribution using Bayesian technique to develop the posterior distribution of travel time. The later has then been used to estimate the best-expected travel times on a real time basis. It is assumed that the system follows a modified Markov process and includes all decision variables as of scenario-1. 


\subsection{Shared Vehicle Systems Simulation Model Development}

\subsubsection{System Description}

A multiple station shared vehicle or matured station car system consists of several components (Barth and Todd, 1999). These components include vehicles, stations, and operation control center (OCC). It is assumed that an appropriate bundle of intelligent transportation system (TTS) technologies are deployed for the improved management of the operational issues of these components and to make the system user-friendly. A detailed description on the appropriate ITS architecture for a shared vehicle system could be found elsewhere "Intelligent Transportation System Architecture for a Multi-Station Shared Vehicle System," 2000 IEEE Intelligent Transportation Systems Conference Proceedings, Barth and Todd (2000). A Schematic illustration (Figure 4.5) with possible interfaces among components and a brief description of each component is given below.

\section{Vehicle}

In recent years, much development has occurred in electric vehicles (Barth and Todd, 1999). There are currently three types of electric vehicles: battery electric, hybrid electric, and fuel cell electric. Literature review showed that such vehicles are suitable to use in a shared vehicle system. Therefore, it is assumed that the vehicle fleet is comprised of electric vehicles (EV). These are low polluting, also known as zero polluting, and offer 


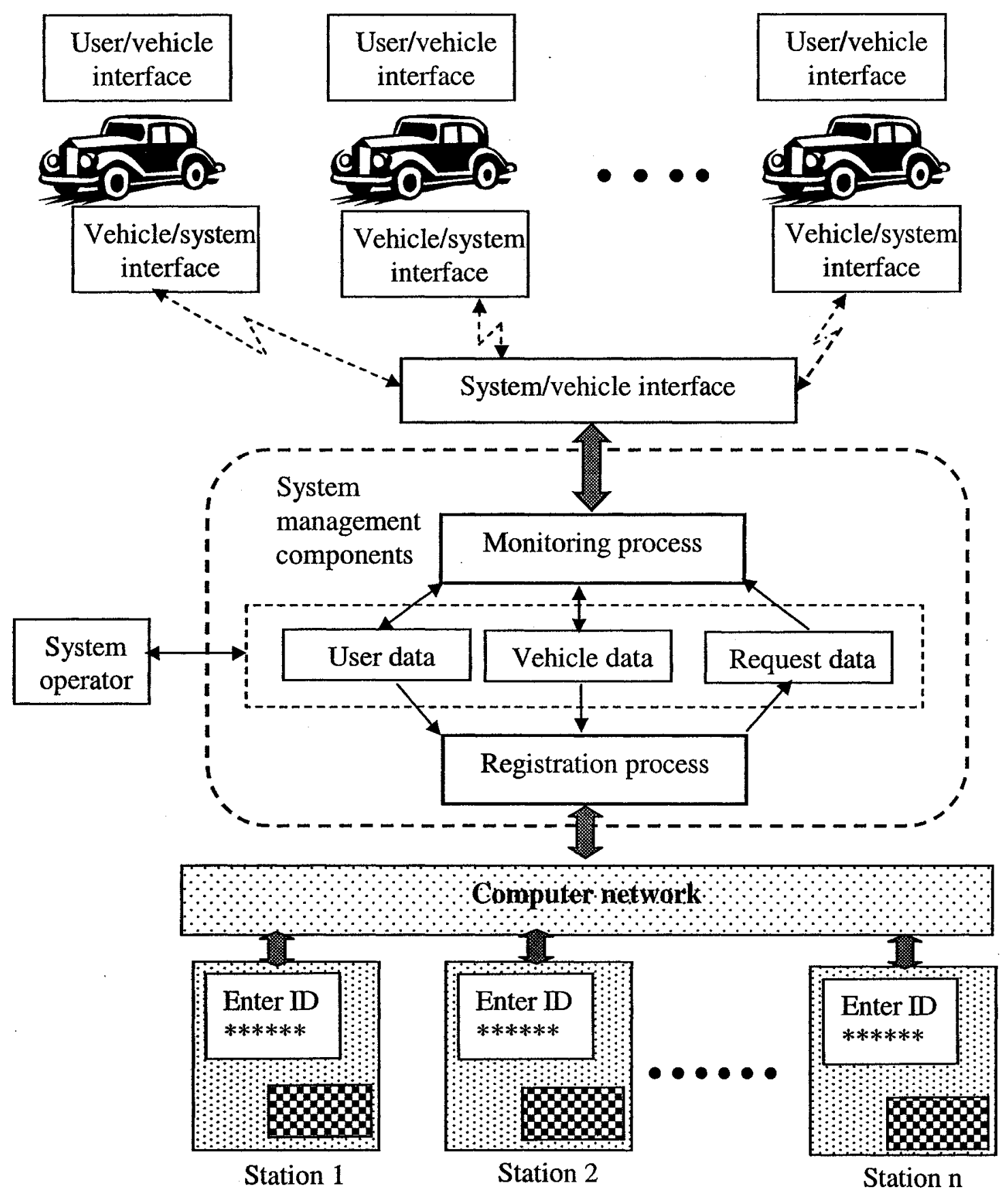

Figure 4.5 Multiple station shared vehicle system architecture (adapted from Barth and Todd, 2000) 
the advantage of charging opportunity at the holding stations (Barth and Todd, 1999). The model vehicles are comprised of two categories. Category one is an ultra compact small electric car and can carry two passengers and the category two is a compact size electric car and can carry five passengers with ample room for luggage. Smart card technology is employed for access (to the vehicle) control. Other information services are made available for onboard route guidance and planning.

Another key aspect of electric vehicles is that they are much easier to control and automate than conventional, internal-combustion-engine (ICE) vehicles. Shared vehicle systems lend themselves well to automation, particularly when relocations are necessary (Barth and Todd, 1999). An illustration of model vehicles is shown in Figure 4.6.

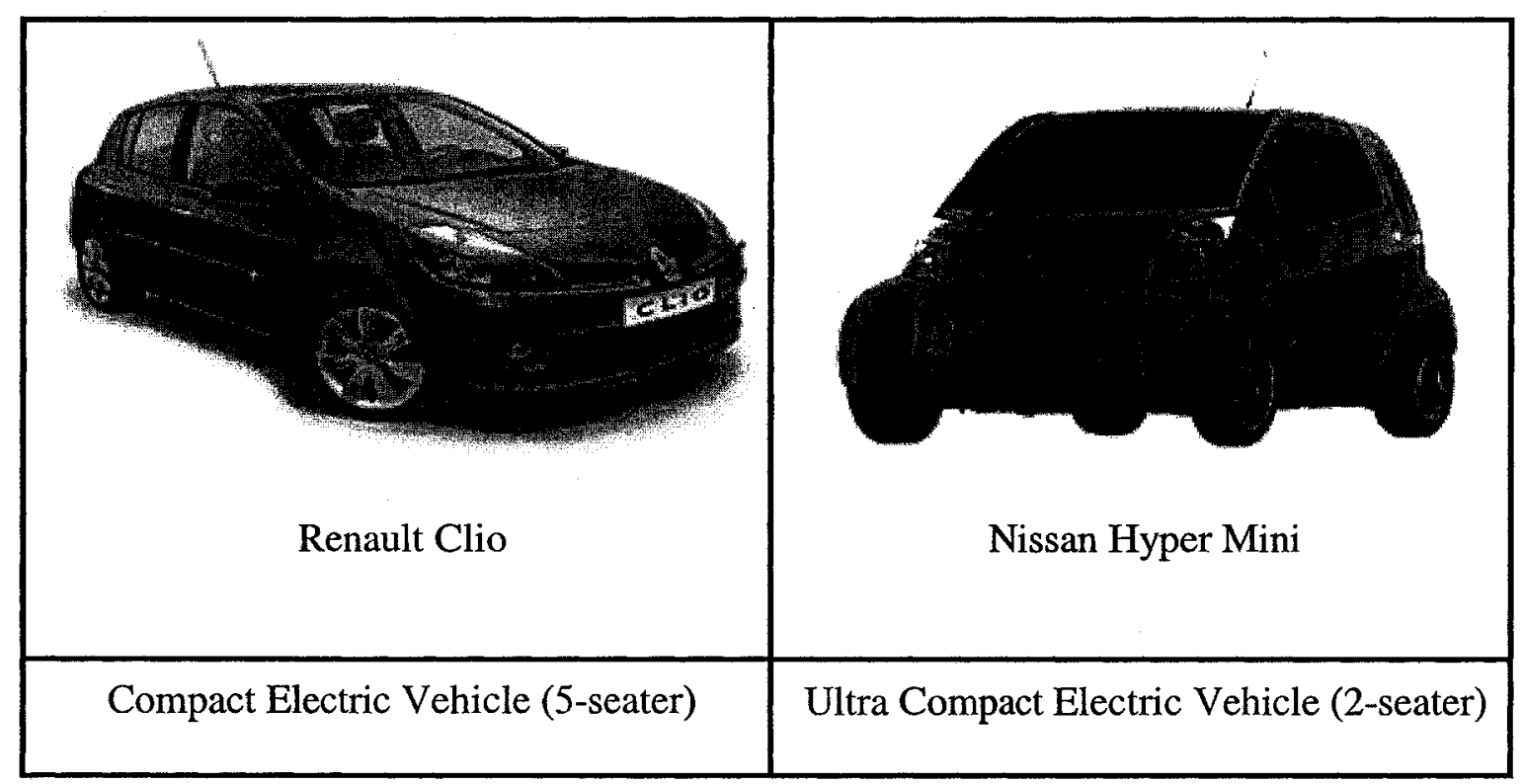

Figure 4.6 Model Electric Vehicles 


\section{Stations/Depots}

Stations or depots (Figure 4.7) are the high activity locations within the urban community where the vehicles are made available for use. For station car type shared vehicle system, stations include the transit stations of major corridors and the major activity centers near transit stations. Stations are equipped with EV vehicle recharging facility and the vehicles are able to recharge when they are idle at the stations. Stations are also equipped with registration kiosks that allow the system users to interface with the system, primarily to request the use of a vehicle. Access, to the database through registration kiosk, control is done through a smart-card system with an appropriate personal identification number (PIN).

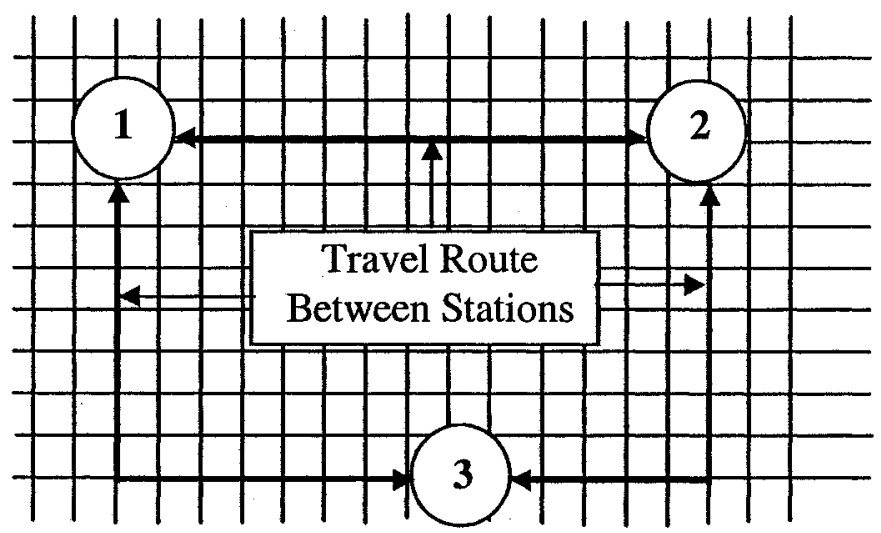

Figure 4.7 Shared vehicle system stations with hypothetical travel route 


\section{System Operation Control Center (OCC)}

Monitoring of vehicles and battery state-of-charge (SOC) are critical issues for efficient operations of shared vehicle systems. These are done at shared vehicle system's operation control center (OCC). An OCC may consists of 1) a station manager for vehicle checkout, 2) a station manager for vehicle check-in, and 3) vehicle relocation manager or controller (Barth and Todd, 1999) (Figure 4.8). The station managers handle the allocation of the vehicles to the users and update the station inventory on a real-time basis. By monitoring the location of each vehicle through vehicle relocation manager or controller, the system operation control center can run appropriate algorithms to efficiently determine the redistribution or relocation needs of available vehicles among stations on a real-time basis (Barth and Todd, 1999). For a real world case it is assumed that two managers (personnel) together with ITS technology could do all jobs at OCC.

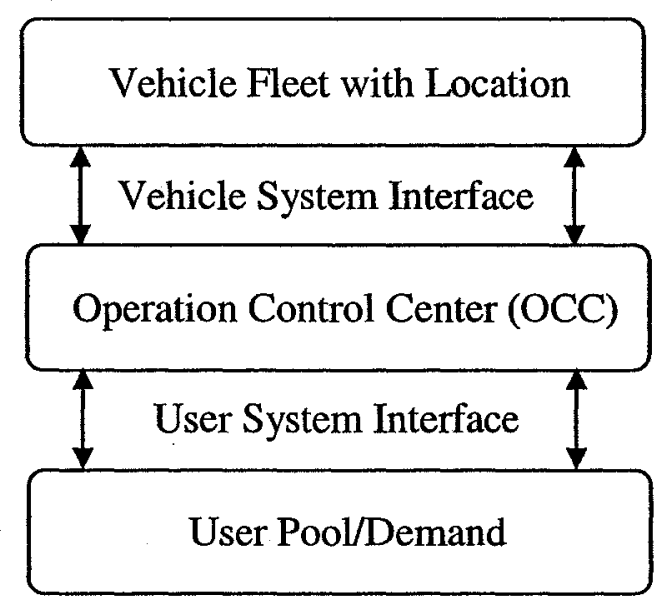

Figure 4.8 OCC with possible interfaces with vehicle fleet and users 


\subsubsection{Data Requirement}

The conventional microscopic transportation system models will not be appropriate for modelling the shared vehicle system operations within a shared vehicle system network (Barth and Todd, 1999). Based on the literature, shared vehicle systems are best characterized as event driven systems and hence event-based simulation model is need to be developed. For the development of an appropriate simulation model of shared vehicle system design and operations; selection of study site, number of stations, the potential travel demand among stations, distances and/or routes among stations, and the trip travel time data have been identified as most essential.

\section{System Network and Travel Time Data}

The first step in creating a computer simulation model of shared vehicle systems is to establish the system network for the area of interest. This consists of identifying the critical locations of stations that correspond to high level of activity, routes between them, and the real-time traffic condition, in terms of trip travel times, on the possible routes. The appropriate locations for stations can be found through proper survey and area study (Barth and Todd, 1999). The system network, travel time between stations, average vehicle speed, level of congestion or friction factor can be defined using a combination of Geographic Information System (GIS) software and an instrumented vehicle equipped with Global Positioning System (GPS) technology (Barth and Todd, 1999). Available 
historical data set could also be used in this aspect. These data will then directly be used to select stations and estimate travel time for a particular trip between stations.

In this thesis research, there was a need to define and model a shared vehicle multiple station network. Since such a system does not exist in Ottawa or even in Canada, two options were considered. One option was a hypothetical network located in a Canadian City, say Ottawa. The other option was to use the historical CFB (Canadian Force Base) Ottawa case for which the real data were available. It should be noted that the reason that the CFB Ottawa duty personnel travel activity network ceased to exist related to downsizing of the Department of National Defence (DND). Given the availability of data, this option had a higher scientific merit vis-à-vis a hypothetical network.

For the above noted reason Canadian Force Base (CFB) Ottawa's duty personnel travel activity network was selected and used as the case study area for this research study. According to the Miller (1982) study, the locations of activity for the duty personnel are previously fixed. But the high activity locations or station were not established in Miller's study. Here, the potential stations were identified through proper analysis of historical daily travel demand data among locations of duty personnel. A preliminary analysis was done, in this effort, with the projected data of Miller study. The candidate station locations are shown in Chapter VI and in appendix B. All the candidate 
stations satisfy the minimum travel demand warrant specified by Barth and Todd (Barth and Todd, 1997), for an operation period of 9 hours (8:00 am to 5:00 pm).

\section{Travel Demand Data}

One of the most important tasks in developing the shared vehicle systems model is estimating the most realistic travel demand between the stations. As mentioned in section 4.2.1.2, the travel demand is organized as trip OD matrices that are indexed by time of day. An OD matrix simply contains the number of trips that are taken from an origin station to all destination stations in a specified period of time of the operation day. All combinations of stations can be presented in a single OD matrix, and one matrix corresponds to a single time period.

Travel demand data of the CFB Ottawa's duty personnel was sourced from Miller's (1982) thesis. According to Miller, the CFB Ottawa kept a record of their personnel daily travel with origins and destinations. A sample data table logged by CFB Ottawa in October 1979 with origin-destination (OD) is shown in Table B.1 in Appendix B (source Miller, 1982). A projection of these data was carried out using compound growth rate model. The results for candidate stations are shown in Table B.2 in Appendix B and in Chapter VI. Any information related to the duty personnel travel (i.e., travel demand by time, travel time, party size) that is not available from Miller's study was outsourced or 
generated from Barth and Todd's study for model development, application, and testing purposes.

\subsubsection{Simulation Model Development Strategy General Description}

In order to simulate the operations of the real world shared vehicle systems in a computer (virtual) environment; a process-oriented, discrete-event simulation model type was chosen. An overall block diagram of the simulation model is presented in Figure 4.9. There are four principal processing stages, these are: (1) stochastically generating the vehicle trips with destination and party size, (2) simulating the trip or traffic in the network, (3) collecting the model output/results, and (4) evaluating the results with analysis tools including Microsoft Excel.

The main function of stochastic trip generator is to generate the trips. This trip generator used the hourly travel demand OD matrices and distribution of party size as primary input data. It then generated the trips on a real time basis. The output of this trip generator is a time-sequenced list of trips with party size and destination and is used as input to the next processing component, the traffic simulator. The main task of the traffic simulator is to simulate the traffic on the network depending on the need of vehicle type on the basis of the party size and availability of the respective vehicle at a given station at a given time of the operation. As the traffic simulator executes on a real time basis, a 
number of critical measures of performance (MOP) of the system operation are recorded for various scenarios and are evaluated using a set of analysis tools mentioned earlier.

Travel Variations

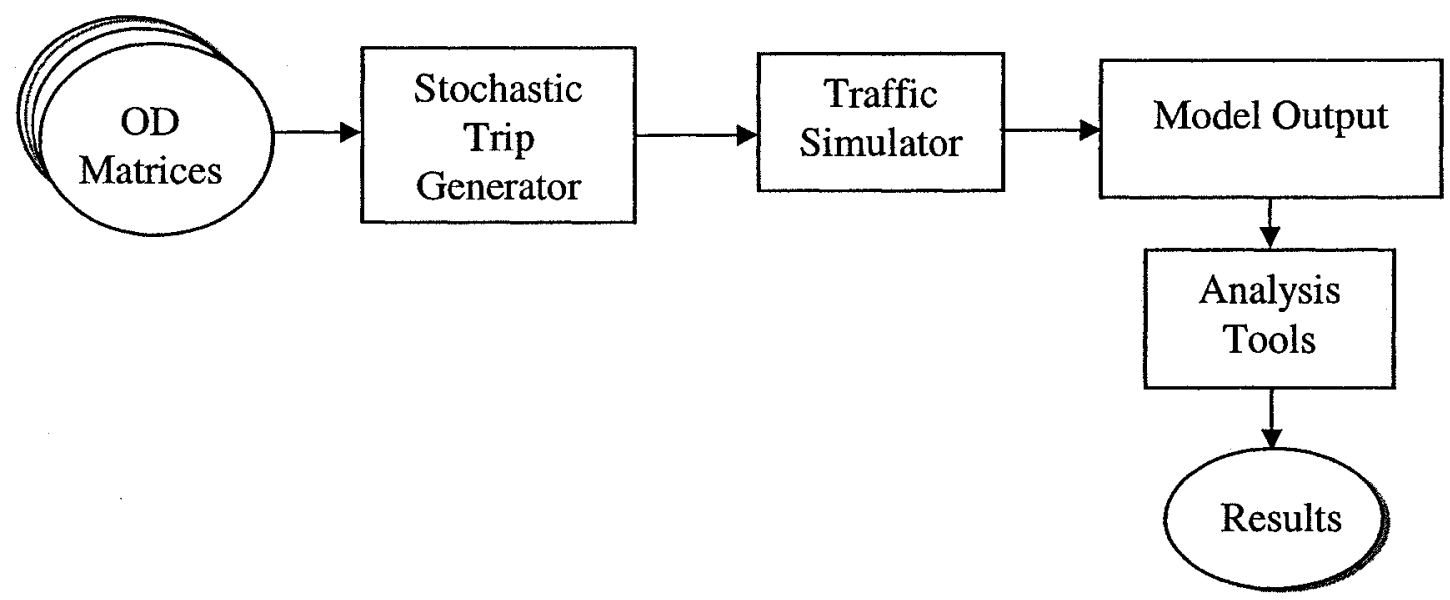

Figure 4.9 Overall Model Block Diagram, adapted from Barth and Todd (1999)

\subsubsection{Stochastic Trip Generator}

Hourly origin-destination (OD) matrices with party size distribution are used as input in the stochastic trip generating process. The OD matrices specify the number of trips made among stations on an hourly basis. Since the entire process of customer arrivals at any station in the shared vehicle systems is random or stochastic process, we assumed that it would follow Markov process. In a normal Markov process, times between arrivals 
have an exponential distribution with infinite support $(0 \leq t \leq \infty)$. This means that the interarrival times could take any value between 0 to $\infty$ as shown in the Figure 4.10.

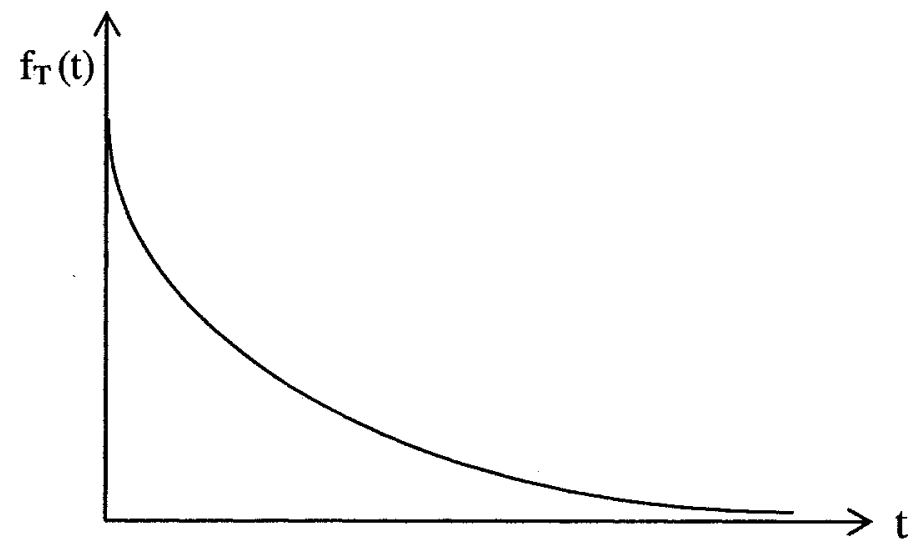

Figure 4.10 Exponential Probability Distribution Function (Qualitative)

The generated interarrival time is expressed as;

$T=-\frac{1}{\lambda} \ln \left(R_{n}\right)$

where

$R_{n}$ is uniform random number between 0 and 1.0 and can be generated by computer software, and

$\lambda$ is hourly travel demand in this study. 
The trip interarrival times in each scenario, developed in section 4.2.1.3, are generated. Using these generated inter-arrival times data, vehicles are then spawned in the network as real trips. Both types of trips, one-way and round trips, are made possible in the simulation model. The destination and party size of particular arrival are modelled completely on a random basis, based on the information on input travel demand OD matrices and the distribution of party size. This method is explained in detail in the following sections.

None of the previous modelling efforts took consideration of party size in each arrival and also the technique to model destination of each arrival is not clearly noted in the literature. Therefore, past experience cannot be used as a guide on how to model these attributes. On the other hand, transportation engineering literature review revealed that by using simple numerical technique based on random numbers in association with relative cumulative probability of party size distribution in the total system, the party size of each arrival and destination could be modelled efficiently (Banks, 2002). Therefore, this technique is used to model party size and destination for a particular arrival. An illustration is presented next.

As explained in section 4.2.1.2, in its simplest form a shared vehicle system may consist of three stations. From the available data it is established that for a particular 
hourly demand, station \#1 (as shown Figure 4.1) experienced the destination pattern shown next (Table 4.3).

Table 4.3 Sample OD pattern of Station \#1

\begin{tabular}{|c|c|c|c|}
\hline Origin & Destination & Relative Proportion & Relative Cumulative Proportion \\
\hline Station \#1 & Station \#1 & 0.15 & 0.15 \\
\hline Station \#1 & Station \#2 & 0.25 & 0.40 \\
\hline Station \#1 & Station \#3 & 0.60 & 1.00 \\
\hline
\end{tabular}

We assume that three consecutive interarrival times generated from the stochastic trip generator under a particular scenario are 6.00, 6.50, and 5.75 minutes (for demand of 10 trips $/ \mathrm{hr}$ ) and the respective generated uniformly distributed random numbers are 0.6954 , 0.3501 , and 0.1405 (Table 4.4). Next we can use the following simple numerical technique to determine the destination of the above three generated trips.

Table 4.4 Determination of trip destination in stochastic trip generation process

\begin{tabular}{|c|c|c|c|c|}
\hline $\begin{array}{c}\text { Generated } \\
\text { Trip Number }\end{array}$ & $\begin{array}{c}\text { Generated Inter- } \\
\text { arrival Time (min) }\end{array}$ & $\begin{array}{c}\text { Random } \\
\text { Number, } \mathrm{R}_{\mathrm{n}}\end{array}$ & $\begin{array}{c}\text { Identified Trip } \\
\text { Destination }\end{array}$ & Comments \\
\hline 1 & 6.00 & 0.6954 & Station \#3 & $0.40<0.6954<1.00$ \\
\hline 2 & 6.50 & 0.3501 & Station \#2 & $0.15<0.3501<0.40$ \\
\hline 3 & 5.75 & 0.1405 & Station \#1 & $0<0.1405<0.15$ \\
\hline
\end{tabular}


From the above analysis we found that the three consecutive trips produced two oneway trips with destination stations 2 and 3, and one round trip with destination same as the origin, station 1 .

Similarly, let us assume that the collected data on party size of the trips during any operational day was observed as follows (Table 4.5).

Table 4.5 Party size distribution observed in collected data set

\begin{tabular}{|c|c|c|}
\hline Party Size $(\mathrm{p})$ & Relative Proportion & $\begin{array}{c}\text { Relative Cumulative } \\
\text { Proportion }\end{array}$ \\
\hline$P \leq 2$ & 0.600 & 0.600 \\
\hline $2<\mathrm{P} \leq 5$ & 0.400 & 1.000 \\
\hline
\end{tabular}

We have two different types of vehicles to serve the demand and we have divided the party sizes into two groups. Now using the same simple numerical technique the party size of the above three consecutive arrivals or trips could be determined. Using the information from Table 4.5 and the previously generated random numbers we can find out the party size of each arrival (Table 4.6). 
Table 4.6 Sample party size modelling in stochastic trip generation process

\begin{tabular}{|c|c|c|c|c|}
\hline Trip number & $\begin{array}{c}\text { Interarrival } \\
\text { Time }(\mathrm{min})\end{array}$ & $\begin{array}{c}\text { Random } \\
\text { Number, } \mathrm{R}_{\mathrm{n}}\end{array}$ & $\begin{array}{c}\text { Party Size } \\
(\mathrm{P})\end{array}$ & Comments \\
\hline 1 & 6.00 & 0.6954 & $2<\mathrm{P} \leq 5$ & $0.60<0.6954<1.00$ \\
\hline 2 & 6.50 & 0.3501 & $P \leq 2$ & $0<0.3501<0.60$ \\
\hline 3 & 5.75 & 0.1405 & $P \leq 2$ & $0<0.1405<0.60$ \\
\hline
\end{tabular}

Therefore, among the three arrivals we found 2 arrivals with party size $\leq 2$ and one of party size $>2$ but $\leq 5$. Once the destination and party size is determined, the checkout station manager can use this information to allocate available appropriate vehicle to the party or trip and inform the traffic simulator to assign the trip in the network. A complete flowchart of the stochastic trip generation process that produces a time sequenced list of trips with party size and destination is illustrated in Figure 4.11. 


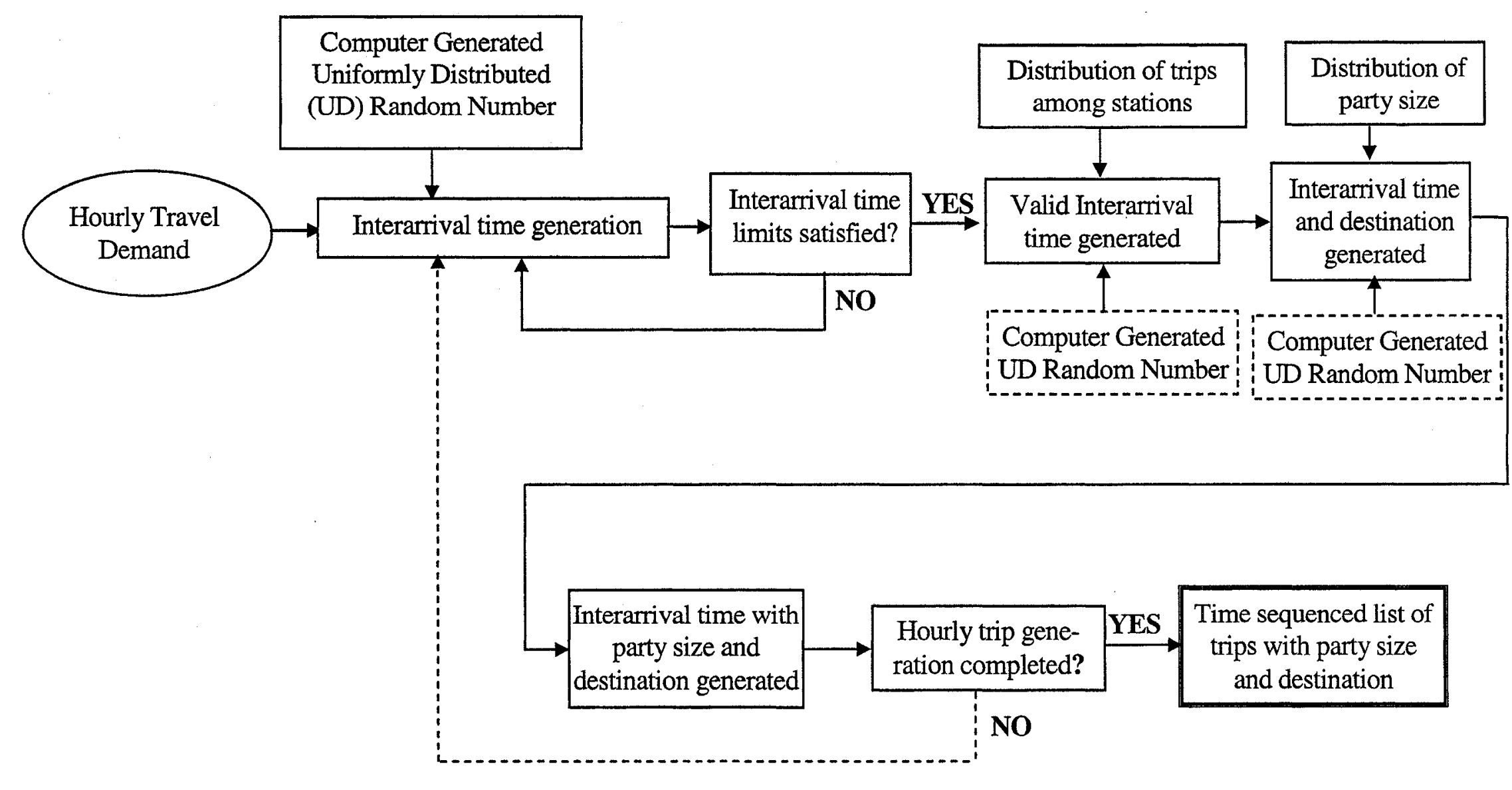

Figure 4.11 Flowchart for stochastic trip generator process 


\subsubsection{Traffic Simulator}

Traffic simulator is the heart of the simulation model. The trip information produced in the stochastic trip generation model, described in the previous section, was used as input into the traffic simulator. In turn, it simulated each trip as vehicle in the given network for the design period of daily operation of the shared vehicle systems. The traffic simulator is a hybrid discrete-event and time-stepped simulation model (Barth and Todd, 1999). It is based on the application of queuing theory to network and features single vehicle level-of-detail. Figure 4.12 illustrates the flowchart of the traffic simulator.

The traffic simulator models the operations of shared vehicle system as a collection of independent processes, facilities, and coordinating and communication structures. Functional components of the shared vehicle system, such as customers, station managers, and relocation controller were simulated as individual processes. Shared resources, such as vehicles, registration kiosks, and parking slots were modelled as facilities within the simulation environment. Major events that have significant effects on the overall system state and behavior were simulated in the model. Some examples of important events include customer arrival at a station, vehicle departure from a station, vehicle arrival at a station, relocation start, and relocation end. 


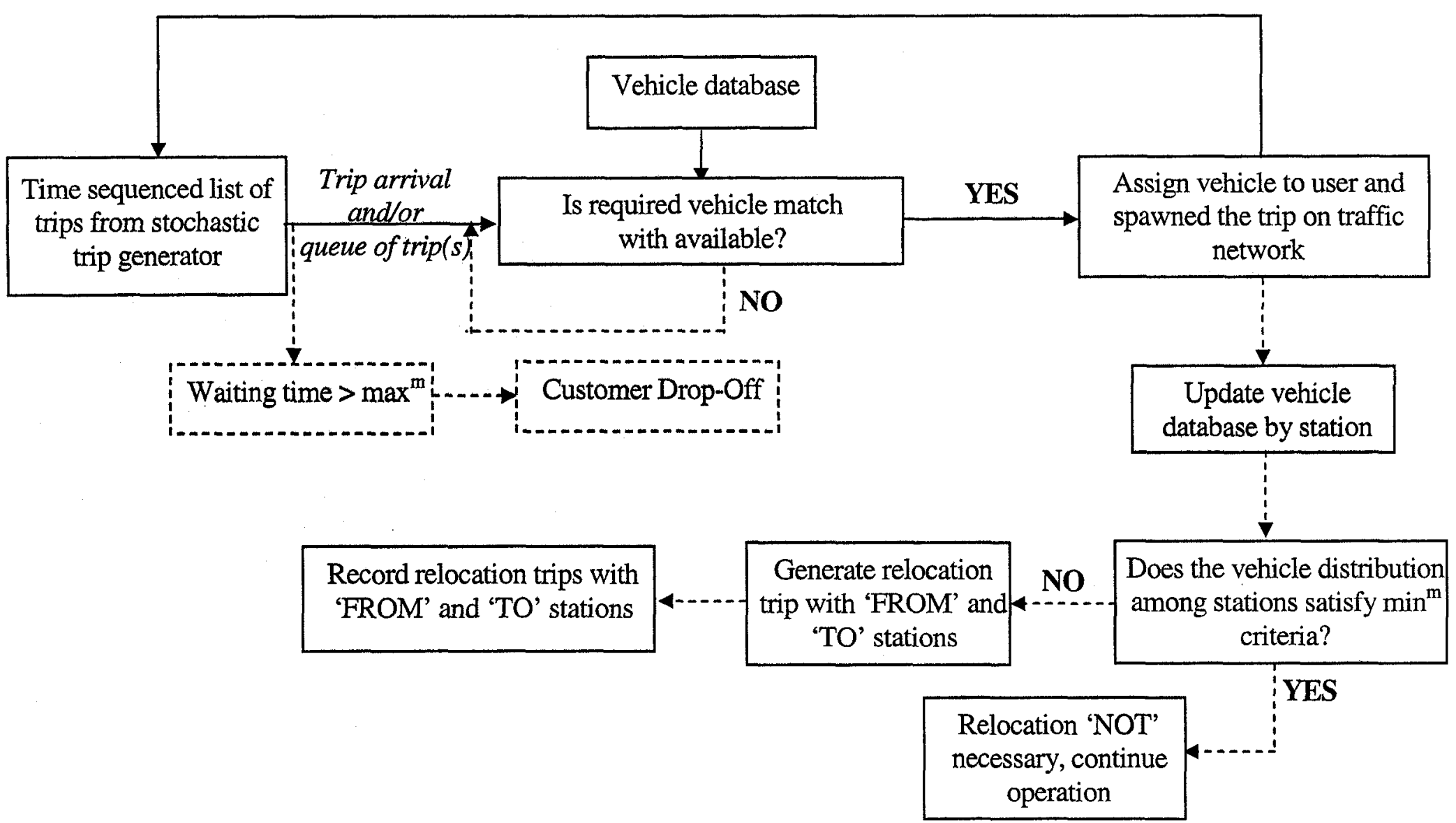

Figure 4.12 Flowchart for traffic simulator process 
The inter-station related parameters that have a significant effect on the system operation and efficiency are determined. The important parameters include, (1) distance between stations, and (2) travel time for a particular pair of stations. Since the distance is a constant factor for a particular pair of stations at any time during the operation along a given corridor, it is considered as a constant parameter. The second parameter, travel time is assumed to have a significant effect on the system performance. In reality, this travel time is a function of inter-station distance and real-time traffic condition of the site, and a random quantity. This randomness is considered in scenario-3 to simulate shared vehicle systems design and operations and the procedure is discussed in the following section.

A probability distribution of the travel time was developed from the available data on traffic condition and distance for each station pairs. This was used as a priori as described in section 6.3.2. A likelihood or conditional probability chart or table is then developed from the historical data on observing a given operation state/traffic condition at a particular time point. It is assumed that the shared vehicle systems have direct access to the city traffic control center (TCC) or transportation management center (TMC) on a real time basis. The Bayesian technique (Press, 1989), a well known statistical technique for combining subjective and real world data, was employed to update the prior information on travel times for different trips on a real time basis to develop a posterior distribution combining real time traffic information from the TMC. This posterior 
information was used to obtain better estimate of the expected travel time for a given trip on a real time basis. The basic Bayesian model is as follows:

$$
P^{\prime \prime}\left(\theta_{i} / y\right)=\frac{P\left(y / \theta_{i}\right) P^{\prime}\left(\theta_{i}\right)}{\sum_{i=1}^{n} P\left(y / \theta_{i}\right) P^{\prime}\left(\theta_{i}\right)}
$$

where

$$
\begin{gathered}
P^{\prime}\left(\theta_{i}\right)=\text { prior probability of observing travel time } \theta_{i} \text { (inferred from historical } \\
\text { frequency distribution or assumed) for a given trip }
\end{gathered}
$$

$P\left(y / \theta_{i}\right)=$ likelihood/probability of observing traffic condition or advisory $y$ for a given travel time $\theta_{i}$.

$P^{\prime \prime}\left(\theta_{i} / y\right)=$ posterior probability of travel time $\theta_{i}$ with observed traffic condition or advisory $y$.

$\mathrm{i}=1$ to $\mathrm{n}$; the discrete value of travel time $\theta_{i}$

Literature review suggested that three discrete levels of Advisory are sufficient (Riley, 2002). Let us assume the levels are R1, R2, and R3. Also assume that the three states of travel time $\left(\theta_{i}\right)$ are $\mathrm{T} 1, \mathrm{~T} 2$, and $\mathrm{T} 3$ indicating reduced, normal and delayed travel time. 
Having advisory information $\mathrm{R} 1$ from $\mathrm{TCC}$ or $\mathrm{TMC}$, the posterior probability of a certain trip travel time can be calculated as follows;

$$
\begin{aligned}
& P^{\prime \prime}(T 1 / R 1)=\frac{P(R 1 / T 1) P(T 1)}{P(R 1 / T 1) P(T 1)+P(R 1 / T 2) P(T 2)+P(R 1 / T 3) P(T 3)} \\
& P^{\prime \prime}(T 2 / R 1)=\frac{P(R 1 / T 2) P(T 2)}{P(R 1 / T 1) P(T 1)+P(R 1 / T 2) P(T 2)+P(R 1 / T 3) P(T 3)} \\
& P^{\prime \prime}(T 3 / R 1)=\frac{P(R 1 / T 3) P(T 3)}{P(R 1 / T 1) P(T 1)+P(R 1 / T 2) P(T 2)+P(R 1 / T 3) P(T 3)}
\end{aligned}
$$

A similar approach is applicable in the case of advisory R2, and R3. Knowing these posterior probabilities, the better expected travel times were estimated using the following models.

\section{For $\mathbf{R} 1$ case:}

The expected travel time $=P^{\prime \prime}(T 1 / R 1) * T 1+P^{\prime \prime}(T 2 / R 1) * T 2+P^{\prime}(T 3 / R 1) * T 3$

\section{For R2 case:}

The expected travel time $=P^{\prime \prime}(T 1 / R 2) * T 1+P^{\prime \prime}(T 2 / R 2) * T 2+P^{\prime}(T 3 / R 2) * T 3$..(4.9)

\section{For $\mathbf{R 3}$ case:}

The expected travel time $=P^{\prime \prime}(T 1 / R 3) * T 1+P^{\prime \prime}(T 2 / R 3) * T 2+P^{\prime}(T 3 / R 3) * T 3 \ldots(4.10)$ 
This technique is implemented to calculate trip travel times in scenario-3 on a trip-bytrip basis and the traffic information from CTCC was kept constant within particular operating hour.

\subsubsection{Modeling Shared Vehicle System's Other Dynamic Characteristics}

To reflect a higher degree of realism in simulation, probabilistic models were employed for various random phenomenon of the shared vehicle system. For example, the amount of time required by different users to register for vehicle was assumed as a random quantity and modelled using the normal or Gaussian probability model. Similarly, vehicle check-in times at destination station was modelled using normal probability model. A detail description and values of the model parameters (mean, standard deviation) are given in Chapter $\mathbf{V}$ in the model algorithm section.

\subsection{Modelling Tool}

The CSIM 19 is a recent revolutionary programming and application development environment for virtually limitless systems from Mesquite Software, Inc. TX, USA. It is a process-oriented, event based, general-purpose simulation toolkit written with $\mathrm{C}$ and $\mathrm{C}++$ language functions. It allows programmers to create and implement process-oriented, discrete-event simulation models, which can simulate complex systems and offer insight into the system's dynamic behavior. Because of its flexible nature, CSIM 19 has already been used successfully in corporations to analyze a variety of systems including: 
Intelligent transportation systems (ITS)

Air traffic control systems

Communications systems

Computer systems and network of computer systems

Based on CSIM19's successful and proven history and flexibility, it was selected and used in this research to develop simulation model for the design and operations of shared vehicle systems in Microsoft Visual C++ environment.

\subsection{Evaluation of the Simulation Model Results}

To generate information on the efficient design values of decision variables and develop relationships with selected system performance indicators, a rigorous analysis was carried out on model outputs/results. A set of tools was used to analyze the simulation model results. This tool set includes SPSS and Microsoft Excel Spread sheet. Main objectives include development of correlations among various decision variables and the critical system performance measures of the shared vehicle systems, multiple stations and station car type shared vehicle systems, operations and estimates of the optimal values of the decision variables. Items included in the previous modelling efforts, especially those included in Barth and Todd's ICVS in UCR, USA and Kyoto, Japan efforts, were exclusively included in the evaluation. Additional variables (shown in Table 4.2), included in this effort, and their relationships with MOPs are included in the analysis and model performance evaluation. 
Using the developed simulation model it was possible to track the trip-by-trip activity of the shared vehicle system. The model output, under different scenarios, are collected and analyzed in detail to determine the overall system performance. Iterative approach in simulation was used to determine the best values of the system design variables including vehicle-to-trip ratio, vehicle-to-parking ratio, and vehicle mix in satisfying the critical system performance indicators including user average wait time, average number of relocations, and percent of trips served. Two- and three-dimensional graphical plots are developed to show the relationships of design variables and the system performance indicators, including customer average wait time, number of vehicle relocations, percent of trips served, and average queue lengths and their nature of change. These are called the system design variable and performance indicator characteristics plots.

\subsection{Simulation Model Sensitivity Analysis}

Major design variables were varied and the operations of shared vehicle system (SVS) were simulated to check their effects on the overall system performance. This process is defined as SVS system sensitivity analysis. These major design variables include number of stations in the system, travel time between stations, and total daily travel demand. In each variable case, the parking-to-vehicle ratio was kept constant to $2: 1$ but the vehicleto-trip ratio was varied gradually. The system operation was then simulated at each point of vehicle-to-trip ratio. 
For example, to check the effect of travel time between stations on SVS system performance, travel time sensitivity, other variables such as number of stations in the system and total daily travel demand were kept constant. The primary independent variable vehicle-to-trip ratio was then varied gradually and the SVS system operations were simulated at each point of vehicle-to trip ratio. For individual simulation, data were collected on SVS system MOP indicators including user average waiting time, number of vehicle relocations, percent of trips served, and queue length. The collected data were grouped, analyzed, and plotted using Microsoft Excel and SPSS to determine/infer the overall effect of travel times on system performance.

The same approach and methodology is used to evaluate the effect of other major design variables, number of stations in the system and total daily travel demand, on the system performance. These results of analyses could be useful for improving the design and operations of shared vehicle systems in real world case.

\subsection{Energy Savings Estimation and Cost Analysis of Shared Vehicle Systems}

Beyond the evaluation of the specific critical system performance indicators such as the user average wait time, fleet size and its composition, the number of relocations, it is obvious that energy savings and cost competitiveness are a key effectiveness and feasibility measures of viable shared vehicle systems. In the analysis of energy consumption, first the number of displaced trips for the case study area was calculated. 
Then established methodologies, noted below, were employed to estimate the energy savings. A cost analysis was then carried out to check the economic viability and competitiveness of shared vehicle systems with other modes of transportation.

\subsubsection{Methodology for Petroleum Energy Savings Estimation}

One objective of this research is to estimate the petroleum energy savings that may be gained from the real world implementation of shared vehicle systems (SVS). This attempt is assumed to be necessary to check the SVS as a sustainable urban public transportation system candidate from energy aspect of transportation systems.

In order to estimate energy benefits of shared vehicle systems (SVS), this research focused on current vehicle trips that are displaced by SVS in the case study area, CFB Ottawa. In this respect, it is possible to compare a "build" versus a "no-build" scenario by first estimating energy consumption associated with the "no-build" vehicle trips followed by an estimation of the energy consumption of SVS vehicle trips. The developed method is assumed to be applicable to estimate energy savings from SVS in other applications by knowing vehicle fleet size, and vehicle fuel efficiency/economy.

\subsubsection{Methodology for Economic Analysis}

The economic feasibility of shared vehicle systems revolves around many parameters. The most significant economic issues include the following: technology of electric 
vehicle and its costs, system infrastructure set-up/construction costs, personnel costs, costs of automation with ITS technologies, and acceptable customer usage rates. Therefore, the implementation and operation cost of shared vehicle system could be broken down into capital or fixed cost (i.e., system set-up, vehicle cost, personnel wages, ITS technology costs) and variable cost including the operation, and maintenance costs.

The possible number of scenarios could be determined or established based on the degree of deployment of ITS technologies for system operations and management. Available literature is insufficient in this area. Miller (1982) in his master thesis did a comparative cost study for self-drive vehicle system with the existing CFB Ottawa taxi system. But the underlying assumption about the system and its operation configuration is not clarified. Also today's electric vehicles are much developed in energy efficiency and driving range. Hence consistent models are required for appropriate cost estimation under possible scenarios. The potential system configuration could be the following:

Configuration-1: Personnel intensive, where majority of the work is performed manually.

Configuration-2: Addition of some degree of automation, say 50-75 percent, such as registration kiosk, smart card access, and automatic vehicle location (AVL) and mobile communication technology.

Configuration-3: Automation as much as possible with ITS technologies. 
Among the above three system configurations with respect to the application of ITS technology, configuration-2 was considered for SVS economic feasibility analysis in this research. This configuration was assumed to be a balanced one based on available literature (Barth and Todd, 1999). Three scenarios based on analysis periods 3 years, 5 years, and 10 years were considered for cost analysis of SVS for system configuration-2. The average cost per $\mathrm{km}$ and trip were estimated under these different analysis periods or scenarios. Finally a comparison was made among costs of these three different scenarios. The cost per $\mathrm{km}$ or trip was used to check the shared vehicle system's competitiveness with other modes of transportation e.g., taxis and private automobiles, and its economic viability. 


\section{CHAPTER V \\ DISCRETE EVENT SIMULATION TECHNIQUE}

\subsection{Introduction}

The concept of modelling, on which simulation is based, has been in use for many years (Pooch and Wall, 1993). Some examples of historical model are Newton's second law of motion, $F=\bar{m} a$, relating force exerted on a body to its acceleration; Kepler's model of the universe; and Einstein's theory of relativity. Question like "since the concept of simulation modelling is so old, what has happened to increased interest in this problem solving method in the recent years?" has risen (Pooch and Wall, 1993). The answer is that the electronic computer has been invented. With the advent of the computer, simulation has been applied to nearly every field of human endeavor (Pooch and Wall, 1993). Problems in the fields as diverse as engineering, natural science, business, politics, and law enforcement have been successfully solved with the use of simulation.

Simulation has been defined by Shannon (Shannon, 1975) as " the process of designing a computerized model of a system or process and conducting experiments with this model for the purpose either of understanding the behavior of the system or of evaluating various strategies for the design and operations of the system". Though the literature gives many definitions for simulation, this definition seems to encompass the more important aspects of this problem-solving technique (Pooch and Wall, 1993). From 
the above definition it is obvious to us that the underlying concept of using simulation in problem solving is the "system concept".

\subsection{System Concept}

Central to any simulation study is the idea of system concept (Pooch and Wall, 1993). To model a system, we must first understand what a system is. The term system is defined in Funk and Wagnall's Standard Dictionary as "an orderly collection of logically related principles, facts or objects". When used in the context of a simulation study, the term system generally refers to a collection of objects with a well-defined set of interactions among them (Pooch and Wall, 1993). An example is a generic queuing system. The users, queue, and server form the collection of objects or elements of the system. This definition of a system is found general enough, by many researchers, to allow its application in many problems.

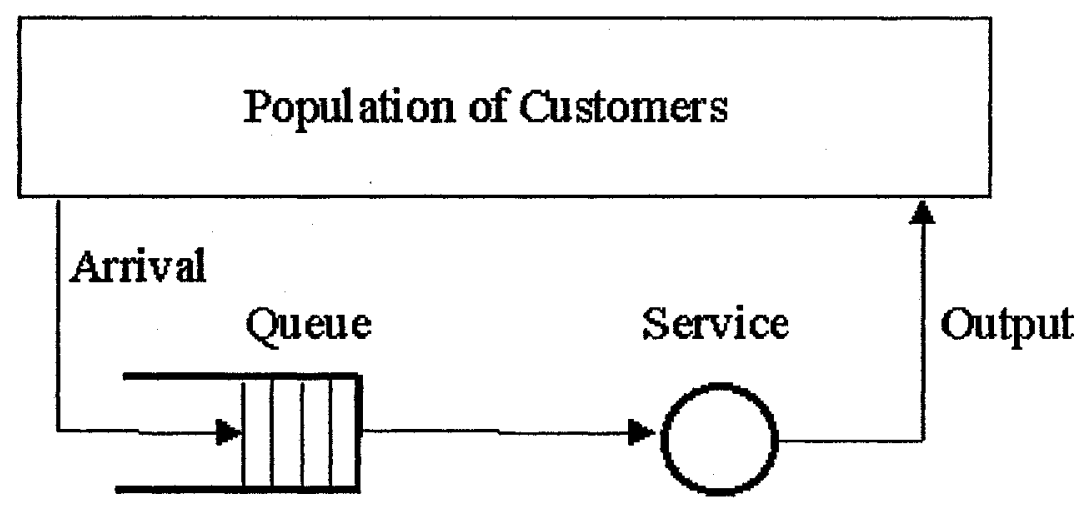

Figure 5.1 A generic queuing system 
There are a number of ways of classifying systems. An obvious classification, given by Pooch and Wall (1993), distinguishes between systems that are natural and those that are man-made. A solar system is a natural, while the queuing system is a man-made system. Therefore, the shared vehicle systems are man made. Other classification that has been suggested by Pooch and Wall (1993) as follows:

1. Continuous versus discrete systems

2. Stochastic versus deterministic systems

3. Open versus closed systems

The objective of this study is to simulate the design and operations of shared vehicle systems.

\subsection{Discrete Systems}

The terms discrete and continuous applied to a system refer to the nature or behavior of changes in the system states with respect to time. Systems that changes in states occur in finite quanta or jump in time are discrete systems, e.g., all simple queues, shared vehicle systems. Systems that changes in states occur continuously over time are continuous systems. There are systems in which some of the system variables change continuously and other change discretely over time and defined as hybrid systems.

\subsubsection{Discrete Systems Terminology}

Discrete systems simulation implies that the dependent variables, the state indicators, change discretely at points in time referred to as events. Since the new and innovative shared vehicle systems behavior strongly support discrete system characteristics, the next 
sections concentrate only on the description of discrete system simulation technique and its terminology. For these models, it should be remembered that the state-of-the-system changes only when an event occurs, and simulated time advances in occurrence with those events.

An object is called an entity. The characteristics of an entity are referred to as attributes. The collection of entities or objects and attributes for a given system is referred to as the system state, and it is generally expressed in a time frame of reference.

Any process that changes the system state is referred to as an activity. The occurrence of such a change in the system state at a point in time is referred to as an event. An event may be a change in the value of some attributes, the creation or deletion of an entity (customer), or the initiation or termination of an activity. A process is the time ordered collection of events that may include several activities. The key concept in discrete system simulation is that of scheduling of events and the changes for events i.e., additions, deletions, modifications etc. (Pooch and Wall, 1993). Events have to be synchronized with one or more of the following approaches:

1. Event Orientation,

2. Activity Scanning, and

3. Process Coordination

\subsubsection{Event-Oriented Discrete System Simulation}

For this research study, event orientation approach is used for event synchronization. Event-orientation describes the scheduling of events that may occur in proper time order 
based on generation time and the changes in system states that may occur at each event based on attribute(s) of entity (customer or trip). In this orientation, the user must identify the events that may occur. The simulationist must also describe the activities associated with each event, and how the system state(s) may be altered by the events, whether conditioned on the current system states or not (Pooch and Wall, 1993). Therefore, the results of events are very much conditioned on prior events and system states.

\subsubsection{Simulation Time}

The state of a system is usually expressed as a function of time. Two time references are involved in the simulation of a system:

1. Simulation time, and

2. Run time

The term simulation time is used to refer to the period of time simulated by the model, say 30 minutes, 1 day, 5 years etc, whatever the interval the researcher is interested in. The run time is simply the time taken by computer to simulate the period of interest. The run time is influenced by factors such as the complexity of the simulation model, the number of events to be simulated, and the duration of the simulation time. Run time, although crucial from an economic standpoint, is generally not as easily controlled as simulation time and is not the subject of this research. A brief description of simulation time management methods/techniques is given in the section below. 


\subsubsection{Time Management Techniques in Discrete System Simulation}

Simulation models have been used to model both the static (time-independent) and dynamic (time-dependent) system. A static model shows the relationships between entities and attributes when the system is in a state of equilibrium (Pooch and Wall, 1993). In this case, when the value of an attribute is changed to allow observation of its effect on the rest of the system, new attribute values can be derived for the rest of the system. No information, however, can be obtained on the manner in which the change occurs. The dynamic model allows the changes in attribute values to be derived as a function of time. The manner in which a change occurs can then be studied.

Most simulation models are dynamic or time dependent by nature. For that reason a simulator must generally include a means for depicting a time change in the system (Pooch and Wall, 1993). This has resulted in the use of the phrase "time management". There are a number of different ways of managing time in a simulator. Two of the more common ways are periodic scan and event scan approaches.

\section{Periodic Scan Technique}

The periodic scan or interval-oriented or fixed-time increment technique adjusts the simulation clock by one predetermined uniform unit and then examines the system to determine whether any event occurred during that interval. If any occurred, event or events are simulated; otherwise no action is taken, the simulation clock advances to the next unit and the process is repeated. In the periodic scan method, the unit interval must be smaller than the smallest inter-event interval, or else the method becomes very inefficient. 


\section{Event Scan Technique}

In the event scan or event-oriented time management technique, the clock is advanced by the amount of time necessary to trigger the occurrence of the next most imminent event, and not by some fixed, predetermined, interval. Thus the time advance intervals are of variable lengths. This approach requires some scheme for determining when events are to occur. When the events are discovered or generated, they are generally stacked in a list in time order. The length of the required time advance interval can then be determined simply by scanning the event list to determine the next earliest event. The simulation clock is then advanced to that time, and occurrence of the event is simulated.

From the above discussion it appears that the time increment used in the periodic scan approach should be as small as possible to minimize the possibility of lost information. The smaller the time unit, the larger the number of calculations is necessary to complete the simulation. Thus the actual run time and the cost of the simulation are increased.

Even if the time advance unit is small enough that the likelihood of multiple event occurrences in a single interval is small, the precise point at which an event occurs within that interval is still uncertain. Model like shared vehicle systems design and operations requires a great deal of precision about the time of exact occurrence of the event. There seems to be no solution to this problem, short of making the time advance interval even smaller and thus increasing the cost of computer simulation. 
In the case of transportation demand, there are peaks i.e., AM and PM peaks. This demand variation creates some periods of high activity and other of low activity. The periodic scan approach is not well suited to this type of system behavior because it is designed to give equal attention to each interval when more emphasis should be given to the periods of high activity. This fact along with the problem of determining the time advance interval length suggests that the event-scan or event-oriented discrete system simulation technique known as 'discrete-event simulation' is suitable to model shared vehicle systems design and operations and is used in this thesis research. An illustration of both of these time management techniques is shown in Figure 5.2.

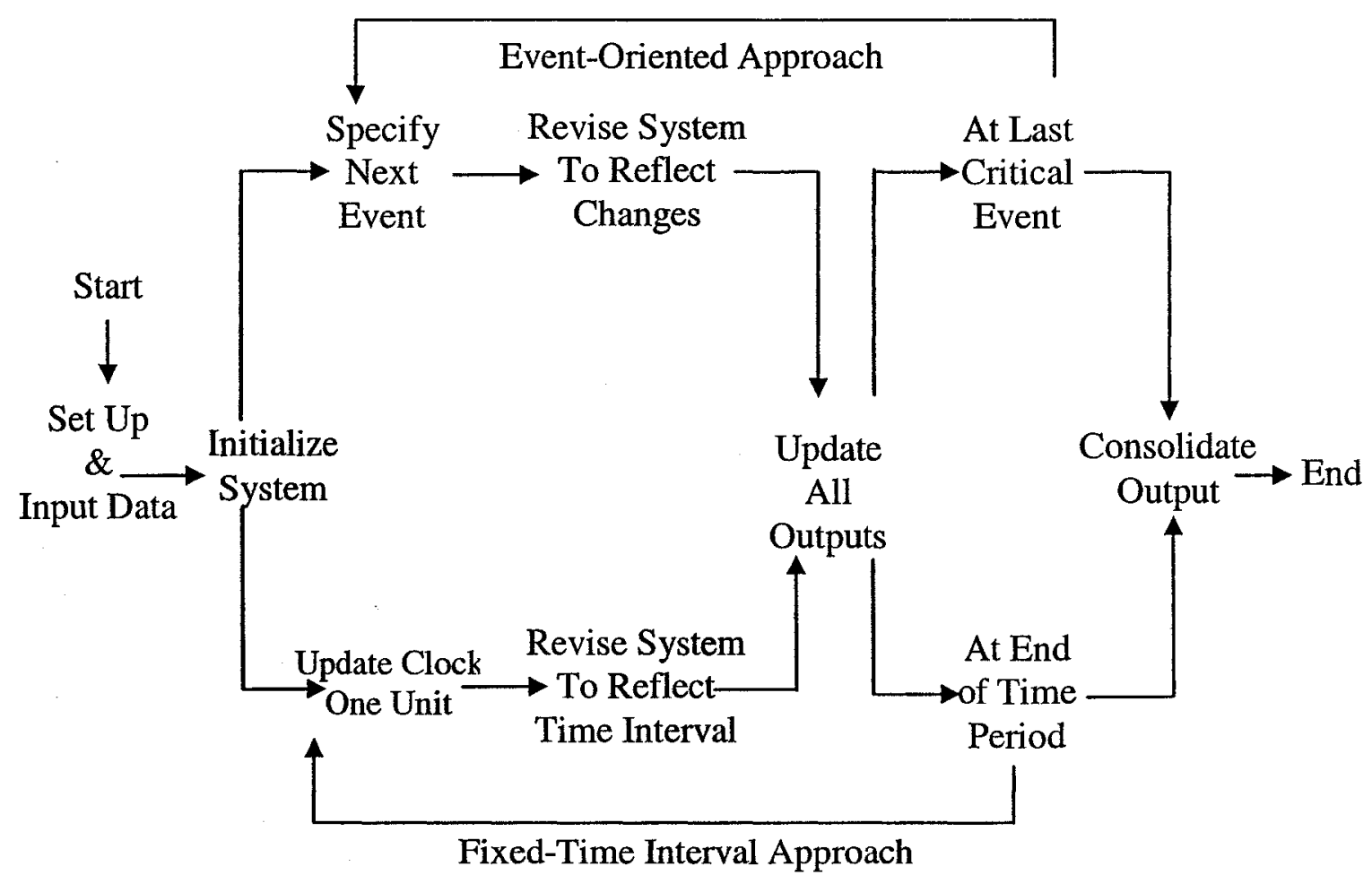

Figure 5.2 Time management techniques in discrete simulation (adapted from Pooch and Wall, 1993) 


\subsection{Use Case Modelling with UML}

\subsubsection{Introduction}

The Unified Modeling Language (UML) emerged from the unification that occurred in the 1990 s within the information systems and technology industry. The UML is an evolutionary general-purpose, broadly applicable, tool-supported, and industrystandardized modeling language for specifying, visualizing, constructing, and documenting the artifacts of a system-intensive process (Sinan Si Alhir, 2000). The language is broadly applicable to different types of systems (software and non-software), domains (business versus software), and methods and processes.

The UML enables and promotes, but does not require nor mandate, a use-case-driven, architecture-centric, iterative, and incremental process that is object oriented and component based. The UML enables the capturing, communicating, and leveraging of knowledge. Models capture knowledge (semantics), architectural views organize knowledge in accordance with guidelines expressing idioms of usage, and diagrams depict knowledge (syntax) for communication.

System development may be characterized as problem solving, including understanding or conceptualizing and representing a problem, solving the problem by manipulating the representation of the problem to derive a representation of the desired solution, and implementing or realizing and constructing the solution (Alhir, 2000). This process is very natural and often occurs subtly and unconsciously in problem solving. 
Models are used to capture knowledge (semantics) about problems and solutions (Alhir, 2000). Architectural views are abstractions of models. Diagrams are graphical projections of sets of model elements. Diagrams are used to illustrate knowledge or syntax about problems and solutions. Within the fundamental UML notation, concepts are depicted as symbols and relationships among concepts are depicted as paths (lines) connecting symbols (Alhir, 2000).

\subsubsection{Use Case Model Diagram}

Use Case Model diagrams are consisting of the following elements:

\section{Actors}

Actor classes are used to model and represent roles for "users" of a system, including human users and other systems. Actors are denoted as stick person icons. They have the following characteristics:

- Actors are external to a system.

- Actors interact with the system. Actors may use the functionality provided by the system. Actors may provide functionality to the system.

- Actors may receive information provided by the system. Actors may provide information to the system.

- Actor classes have actor's instances or objects that represent specific actors

\section{Use Cases}

Use case classes are used to model and represent units of functionality or services provided by a system (or parts of a system: subsystems or classes) to users. Use cases are 
denoted as ellipses or ovals. They may be enclosed by a system boundary or rectangle labeled with the name of the containing system. They have the following characteristics:

- Use cases are interactions or dialogs between a system and actors, including the messages exchanged and the actions performed by the system. Use cases may include variants of these sequences, including alternative and exception sequences.

- Use cases are initiated by actors and may involve the participation of numerous other actors. Use cases should provide value to at least one of the participating actors.

- Use cases may have extension points that define specific points within an interaction at which other use cases may be inserted.

- Use case classes have use case instances or objects called scenarios that represent specific interactions. Scenarios represent a single sequence of messages and actions.

Figure 5.2 shows a project management system with a project manager actor and a project database actor. The project manager is a user who uses the system to manage projects. The project database is a system that is responsible for housing project management data.

Project

Management System

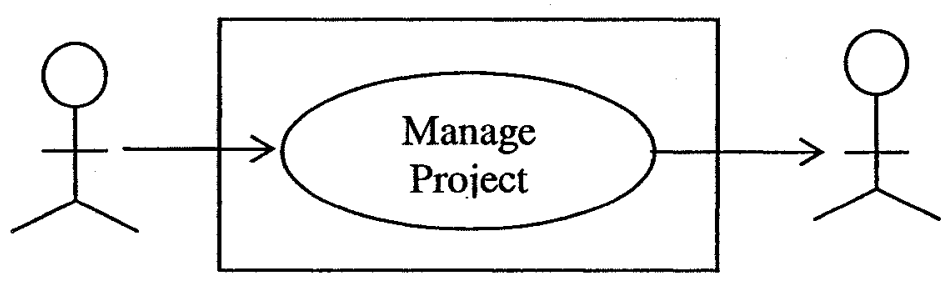

Figure 5.3 Use Case diagram: Project management system 


\subsection{SVS Simulation Model Development Algorithm}

\subsubsection{Introduction}

In order to simulate the operations of a shared vehicle system (SVS), the CSIM19, a process-oriented, discrete-event simulation platform was used in Microsoft Visual C++ environment using the methodology developed in the previous sections. The CSIM19 is a process-oriented, general-purpose simulation toolkit written with $\mathrm{C} / \mathrm{C}++$ language functions that enable a modeler to develop robust and realistic models of complex systems (CSIM19, 2002). Three major types of CSIM19 components were used to simulate the operations of SVS. The components are as follows:

1. Processes,

2. Facilities, and

3. Events.

Processes are active entities (objects) that carry out certain functions, require service at facilities, set events and wait for some other events.

Facilities are generally servers that provide certain services. A facility can be reserved (used) and released (freed) by processes. It also maintains a queue of processes waiting for its service while the facility is in use by other process.

Events are implemented as pointers to counters that record the status of the simulated events (i.e., occurred or not-occurred). They are typically set by processes when the event occurs, and cleared by other processes waiting (consumed) for the event. The events are used to synchronize the processed activities and control the operational flow of the simulation. 
In addition to the three major components, the event-based SVS simulation model consists of global data structure sets and is used to monitor the shared vehicle system's key global parameters. These global data structure sets form a dynamic database, which is updated with the occurrence of any event, and is used by the simulated processes (i.e., station managers and relocation controllers) to make control decisions.

\subsubsection{Global Data Sets}

For each station and vehicle in the SVS (shared vehicle system) simulation model, an instance of some predefined structure type variable (in $\mathbf{C +}$ language) is used to organize its characteristics parameters. This record structure is dynamically updated throughout the simulation to record the current status of stations and vehicles.

There are some other sets of global variables that are used as "mailboxes", which hold information that certain processes put forth for other processes to pick up. Table 5.1 lists the global data structures implemented within the SVS simulation model. The global data sets are described below.

Table 5.1 Global data sets and their respective data fields

\begin{tabular}{|l|l|}
\hline Data Structure & Fields \\
\hline veh_node & carid, mode, slot, socveh \\
\hline stn_status & PortNum, chargeStn, n_total, n_lowsoc, n_coming, n_queue, slots \\
\hline veh_dest & num_stn \\
\hline veh_coming & veh_id \\
\hline
\end{tabular}




\section{Vehicle Data}

An instance of the veh_node structure is created for each vehicle at the initialization stage of the simulation. An array, the size equal to the number of vehicles simulated, is used to keep the pointers to the respective vehicle records. The veh_node structure has the following fields. In other words, the veh_node structure consists of the following members.

\begin{tabular}{lr}
\hline Fields/ Members & Data Type \\
\hline carid & integer \\
mode & integer \\
slot & integer \\
socveh & float \\
&
\end{tabular}

The integer field/member 'carid' is a unique number that is assigned upon creation of a vehicle, and also corresponds to the array index (of the vehicle array) used for identifying vehicles. The carid for each vehicle never changes throughout the simulation.

The integer fields mode and slot are used to indicate the vehicle's current motion and/or location. While a vehicle is parked in a station, the station ID is kept as its mode (means the vehicle is in stop/parked condition) and parking slot ID is kept as its slot. This detail states that the vehicle is parked at a station and it is a certain parking slot. When the vehicle is traveling from station $\mathrm{m}$ to $\mathrm{n}$, mode is assigned a two digit number $m n$. The slot field is assigned to zero while vehicle is traveling between stations. 
The float/real field socveh keeps a record of the current state-of-charge (SOC) level of the vehicle. The value of SOC is decreased by the trip process based on the trip distance and/or travel time, as a function of travel distance or travel time, and increased by charging process as a function of time.

\section{Station Data}

For each station in the simulation, an instance of the structure stn_status is created and kept in an array called stn [numbr_of_station]. There are six integer fields and an array of integers field in this structure which keeps track of the vehicle parking lot, arriving vehicles, and the user/customer queuing status of the represented station. The fields or members of this data structure and their data types are as follows:

\begin{tabular}{|l|l|}
\hline Fields/Members & Data Type \\
\hline PortNum & integer \\
\hline n_total & integer \\
\hline n_lowsoc & integer \\
\hline n_coming & integer \\
\hline n_queue & integer \\
\hline slots & array of integers \\
\hline
\end{tabular}

where;

PortNum - maintain the station ID

n_total - maintains the total number of vehicles currently parked at the station 
$\mathrm{n} \_$lowsoc - keeps track of the number vehicles parked in the station whose battery stateof-charge lower than the minimum allowable level say $25 \%$ or 0.25

n_coming - this field records the number of vehicles traveling or coming toward a particular station

$\mathrm{n} \_$queue - records the number of users or customers waiting for vehicle at a given station slots - this is an array of integer field or member. An array slots [vehtotal] or slots [number_of_slots] describes the current status of the station's parking slots. If there is no vehicle parked in a slot of the slots[] array, the corresponding slots[] array element is assigned to zero. If a vehicle is parked in a slot and the vehicle state-of-charge is higher than the minimum allowable level or value, then the vehicle's ID is stored to the slots[] array element. When the state-of-charge is lower than allowable, $1000+($ vehicle ID) is assigned instead. The station data structure is used by station managers, and relocation controller to make operations control decisions.

\section{Communication Data}

Some global variables/data structures are used as virtual mailboxes to aid inter process communications. Processes write to some global variable a specific message they want to send to some other process, and the receiving process receives the message by reading that specific global variable. The writing and reading sequences are synchronized by events.

An integer array or array of integers veh_dest[num_stn] is used for communication between customer/user processes and station manager processes. A customer process tells its starting station's (say station $m$ ) check-out manager where it wants to go to, its destination station, by setting veh_dest[num_stn] to its destination station ID. Another 
integer array, veh_coming[carid], defined as global variables or data structure, is used for communication between trip processes and check-in station manager processes. A trip process tells the check-in station manager which vehicle needs to come in when it reaches the entrance of the destination station and requires the station manager's service.

\subsubsection{Processes}

In the SVS simulation, there are five main/persistent processes and three temporary processes that are carried out in parallel throughout the whole simulation. The general purpose of each process is listed in Table 5.2. A detailed description of each process is then provided.

Table 5.2 Persistent and Temporary processes and their corresponding purpose

\begin{tabular}{|l|l|}
\hline \multicolumn{1}{|c|}{ Process } & \multicolumn{1}{|c|}{ Purpose } \\
\hline Persistent Processes & $\begin{array}{l}\text { Handles customer details of customer arrive } \\
\text { events }\end{array}$ \\
\hline Generation of customers & $\begin{array}{l}\text { Handles station operations of customer arrive } \\
\text { events }\end{array}$ \\
\hline Station manager (check out) & $\begin{array}{l}\text { Handles station operation of vehicle arrive } \\
\text { events }\end{array}$ \\
\hline Station manager (check in) & Determines relocation needs \\
\hline Relocation controller & Updates SOC of charging vehicles \\
\hline Charging controller & \\
\hline Temporary Processes & Represents customer during registration \\
\hline Customer & $\begin{array}{l}\text { Represents customer and vehicle during the } \\
\text { trip }\end{array}$ \\
\hline Trip & \begin{tabular}{l} 
Execute relocation trips \\
\hline Relocation and charging relocation trip
\end{tabular} \\
\hline
\end{tabular}




\section{Persistent Processes}

\section{Generation of customers}

This process gets generated when the simulation initializes. The process waits for and handles customer_arrive events until the end of the simulation. An external simulation model called customer generator based on Markov/modified Markov process is used to generate a list of customer travel demand. The demand data specifies the customer arriving time, party size, starting station, and destination station. The customer generator reads the customer travel demand one line at a time, treats the demand as customer_arriving event, and handles each event by generating a customer process with proper starting station, party size, and destination station at the appropriate time. The process is idle between customer arrival events.

\section{Station manager (check out)}

This process handles the station operation when customers arrive. It initializes the station record and related vehicle records. It waits for customer_request_service events. When such an event occurs, it reads the customer's destination station from a particular global location, makes a decision on which vehicle to send on the trip using pre-defined rules, and generates a trip process with the proper vehicle $\mathrm{DD}$, start and destination stations. It then updates its record data and acknowledges the requesting customer process by setting a station_responded_to_the_customer_request event that is queued by the customer. The process is idle until the next customer_request_service event occurs. 


\section{Station Manager (check in)}

This process handles the station operation when vehicles arrive. It waits for a vehicle_arrive_at_station event. When an incoming trip process sets such an event, the station manager first gets the incoming vehicle ID by reading the proper global variable. It then finds an available parking slot in the station, updates the record, and then signals the requesting trip process by setting a station_responded_to_the_vehicle_request event. The process is then idle until the next vehicle_arrive_at_station event occurs.

\section{Relocation Controller}

This process does the following tasks periodically, say every 5 minutes:

1. Checks the status record of each station;

2. Determines when a relocation should be made;

3. Determines which station to relocate to; and

4. Determines where the relocation should come from.

The process uses the following parameters to make decisions on regular relocations:

1. The station's total number of vehicles;

2. The number of waiting customers;

3. The number of vehicles arriving; and

4. The travel demand.

The relocation controller process generates relocation trip process(es) with proper from-station and to-station IDs whenever relocation(s) should be and can be made. 


\section{Charging Controller}

This process simulates the charging process for the vehicles parked at a station. Every minute this process updates the state-of-charge (SOC) level of each vehicle parked at a particular station according to charging formula. The station's record of the number of qualified charged vehicles increases when a given vehicle SOC rises above a predetermined minimum threshold level.

\section{Temporary Process}

\section{Customers}

Each customer is treated as a separate process operating in the SVS. A customer is created by the customer generator process in response to the customer_arriving event. A customer process begins by queuing at its starting station's kiosk. The current customer using the kiosk is served by the station manager. The station destination ID is set, followed by the customer_request_service event, and then the customer waits for the station_responded_to_customet_request event. The process terminates when the station manager responds to customer_request_service event and the remaining operation is then handled by the trip process.

\section{Trip}

A trip process continues to model a customer's actions after the customer process is terminated, by concentrating on the vehicle the customer is riding in. The process is generated by the check out station manager as a response to a customer_request_service 
event. It updates the corresponding vehicle and station record, makes the trip, and then queues the vehicle at the destination station entrance at the end of the trip. The process that has the right-of-way to the destination station entrance communicates with check-in station manager, sets the vehicle_requres_service event, tells the station which vehicle is coming in, and then waits for the station_responded_to_vehicle_request event set by the check-in station manager. After receiving that event, the trip process terminates.

\section{Relocation Trip}

The relocation controller process generates this process when the relocation is needed and possible. A relocation trip process first picks up the proper vehicle(s) to be relocated from the from-station, updates station records and vehicle records to remove the vehicles from the station. After making the trip, the process finds open parking slot(s) in the tostation to park the relocated vehicle(s), and updates the vehicle record and to-station's record. Note that the relocation process makes vehicle transfers without notifying the check-out and check-in station managers.

\subsubsection{Facilities}

Facilities are designed to represent entities that can be used only one at a time. If a facility is currently occupied, any additional requests will be queued. This characteristic is ideal for various SVS components, as summarized in Table 5.3. A brief description of all SVS facilities is then provided. 
Table 5.3 Facilities and their functions

\begin{tabular}{|l|l|}
\hline Facility & Represented Use \\
\hline Registration Kiosk & Represents the electronic kiosk used for SVS vehicle acquisition \\
\hline Station Entrance & Represents the station driveway entrance \\
\hline Database Lock & Ensures proper sequencing of reading/writing to the database \\
\hline
\end{tabular}

\section{Registration Kiosk}

A registration kiosk for each station is simulated as a facility within the simulation. These facilities are required, queued, and used by customer processes to ensure sequential, First Come First Serve (FCFS) service from the station manager. The facility is reserved when a customer is generated and released after the customer receives a signal from the station manager indicating that the request is processed with station_responded_to_customer_request event. A give up time is implemented to allow a customer to cancel the trip after excessive waiting.

\section{Station Entrance}

For each station, its entrance is simulated as a facility. The trip processes require and use the station entrance facility before entering their destination stations. Theses facilities ensure sequential FCFS services from the station manager to arrange in-coming vehicle. The entrance facility is reserved when a trip reaches its destination station and released after the trip receives the signal from the station indicating the service is completed with station_responded_to_vehicle_request event. 


\section{Database Lock}

A facility is used to synchronize each process to access to the system's database, vehicle record, and station record. Reading and writing to the database are permitted only when the process holds the database lock facility.

\subsubsection{Events}

Some of the major events in the simulation are handled as generating processes, such as customer_arrive, vehicle_arrive, relocation_start, etc. Others are simulated using the CSIM19 event structure as discussed below. These events are used to control and coordinate the interacting operations of processes.

Table 5.4 Event structure and respective data fields

\begin{tabular}{|l|l|}
\hline Event Structure & Fields \\
\hline customer_request_service & $\begin{array}{l}\text { request service from station after being set by } \\
\text { kiosk }\end{array}$ \\
\hline station_responded_to_customer_request & $\begin{array}{l}\text { event to release kiosk and resume customer } \\
\text { process }\end{array}$ \\
\hline vehicle_arrives_at_station & $\begin{array}{l}\text { signals end of trip and resumes station's check- } \\
\text { in manager }\end{array}$ \\
\hline station_responded_to_vehicle_request & $\begin{array}{l}\text { signals that vehicle has been parked at the } \\
\text { station }\end{array}$ \\
\hline
\end{tabular}

\section{customer_request_service}

This event is set by customer holding a station's kiosk to signal that it needs service from the corresponding station. The station manager that is waiting for this event is then activated and starts its operation of assigning a vehicle to the customer. 


\section{station_responded_to_customer_request}

This event is set by a station manager after it processes the request from a customer. The requesting customer process resumes, and subsequently releases the kiosk and terminates.

\section{vehicle_arrives_at_station}

This event is set by a trip process after it completes the trip, indicated by the triggering of the destination station entrance facility. The corresponding station's checkin manager resumes and starts its operation to arrange vehicle parking at an open slot.

\section{station_responded_to_vehicle_request}

The check-in station manager sets this event after it finishes the operation of park an incoming vehicle in a free parking slot. The trip process that is waiting on the event resumes and continues to release the station's entrance and exit.

\subsubsection{Stochastic Distributions}

The SVS simulation model was developed with CSIM19 built-in stochastic distributions to provide a higher degree of realism to the simulation output. Customer generation, customer registration, and vehicle check-in actions were simulated with stochastic distributions. Table 5.5 shows the stochastic distributions with related characteristics that are used in SVS simulation. 
Table 5.5 Stochastic distributions used in SVS simulation

\begin{tabular}{|l|l|}
\hline Distribution & Characteristics \\
\hline Customer generation & Distribution based on modified and normal Markov process \\
\hline Customer registration & Normal distribution with mean $60 \mathrm{sec}$ and std. $8 \mathrm{sec}$. \\
\hline Vehicle check-in & Normal distribution with mean $60 \mathrm{sec}$. and std. $8 \mathrm{sec}$ \\
\hline
\end{tabular}


5.6 UML Architecture of Shared Vehicle Systems Model

5.6.1 Use Case Modelling

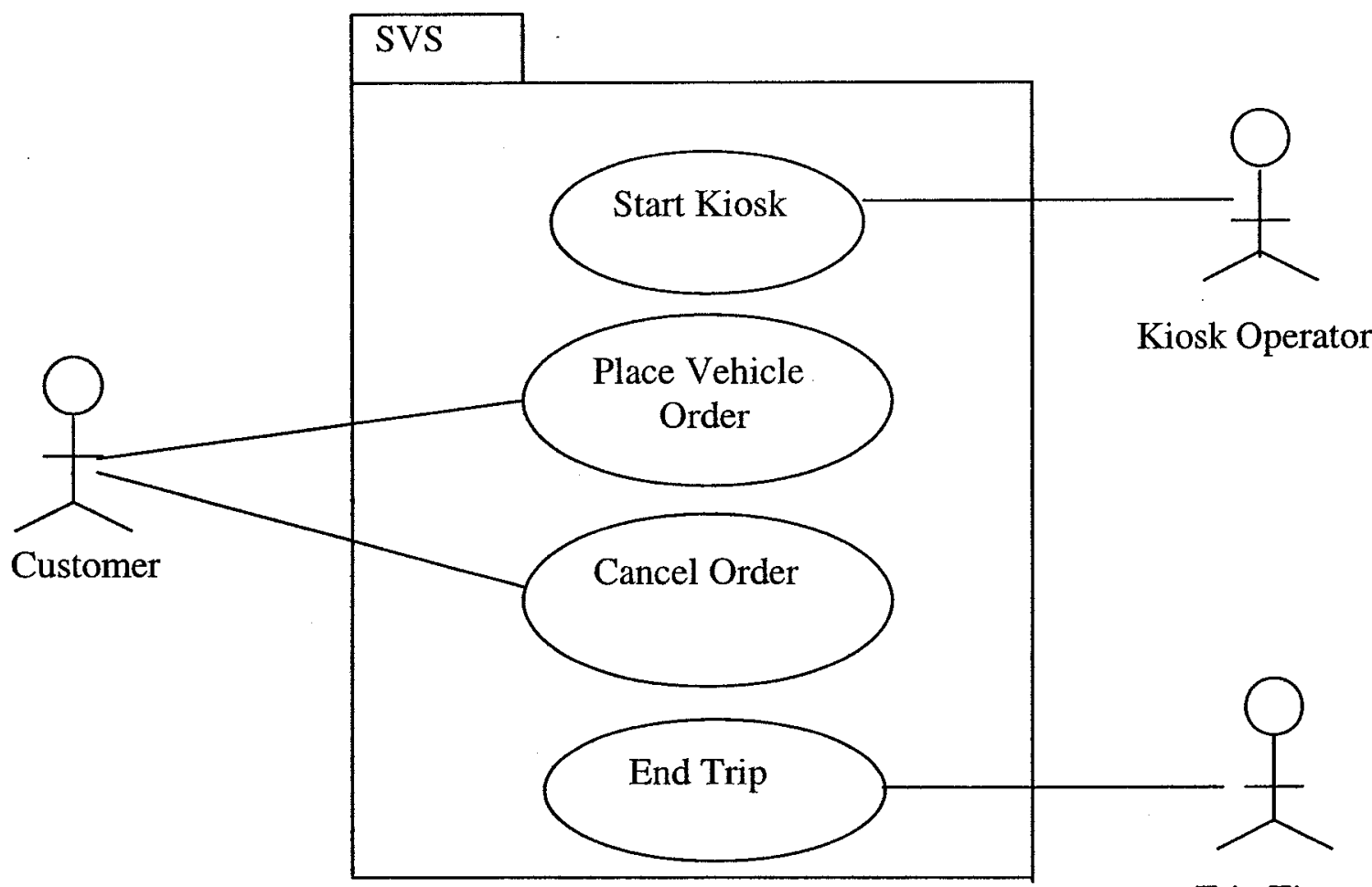

Figure 5.4 Use Case model diagram of shared vehicle system

Trip Timer

\subsubsection{Documenting Use Cases}

Start Kiosk Use Case

Actor: Kiosk Operator

Precondition: None

Description:

Operator starts the main kiosk application. It initializes some start-up parameters like station data, vehicle data, travel time data for stations etc.

Alternatives: None 
Postcondition: Kiosk is set to take order from customers.

\section{Place Vehicle Order Use Case}

Actor: Customer

Precondition: The kiosk is waiting for a new order.

Description:

Customer places his/her order by mentioning his/her destination station and party size.

- $\mathrm{He} /$ she waits for station manager's response.

- Station manager responds after allocating the required vehicle.

Alternatives: None

Postcondition: System (check out station manager) allocates a vehicle for the customer according to his/her order and releases the customer.

\section{Cancel Order Use Case}

Actor: Customer

Precondition: The customer has already placed his/her order and waiting for the response from the system's check-out manager.

Description:

- The customer waits a given time for the response from the system.

- If he/she does not get the system's response within that given time (time out), he/ she asks the station manager to cancel his order and release him/her (give-up).

- Check out station manager releases the customer.

Alternatives: None 
Postcondition: System (check out station manager) cancels the order, releases the customer.

\section{End Trip Use Case}

Actor: Vehicle (in simulation a trip timer) in which the customer is riding in.

Precondition: Station manager is waiting for an incoming vehicle.

Description:

- The trip timer (vehicle) sends a signal (i.e. sets an event) to the station manager after a given trip time (end of trip).

- It waits for response from the station manager.

- Station manager sends its response and releases the vehicle.

Alternatives: None

Postcondition: Trip ends. 


\subsubsection{Analysis Modelling}

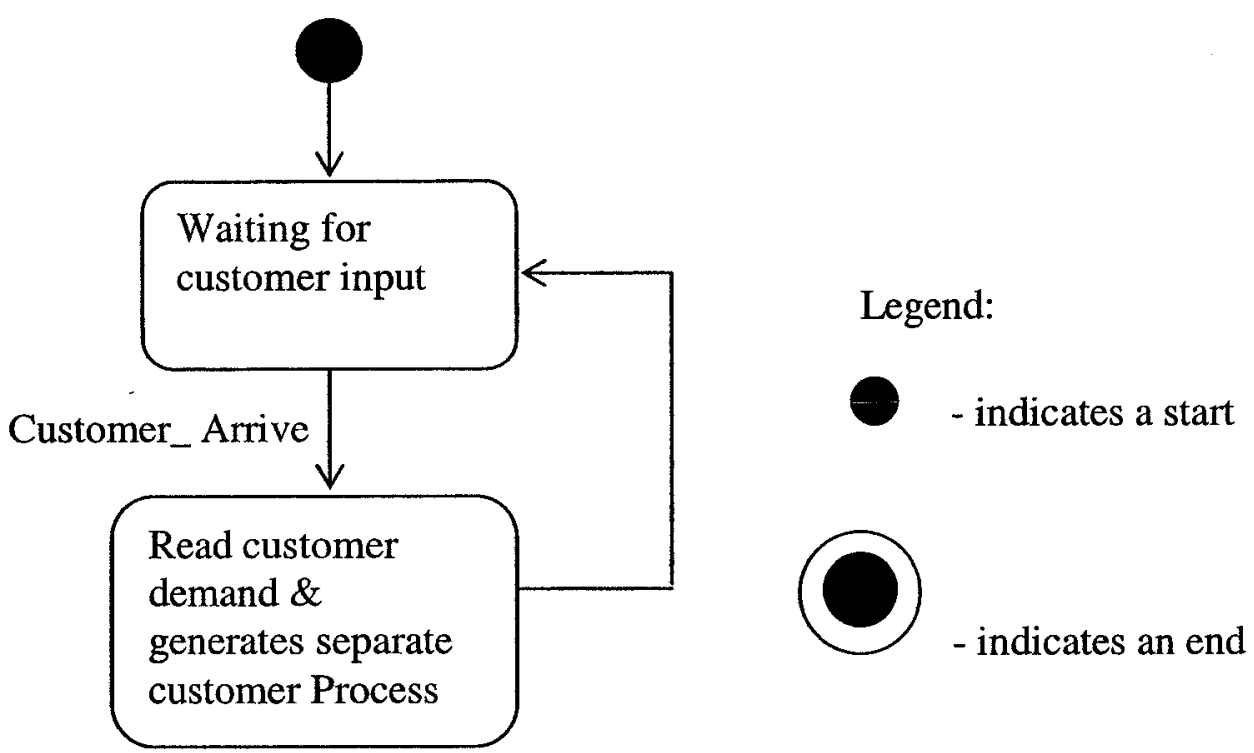

Figure 5.5 State machines of customer generation process

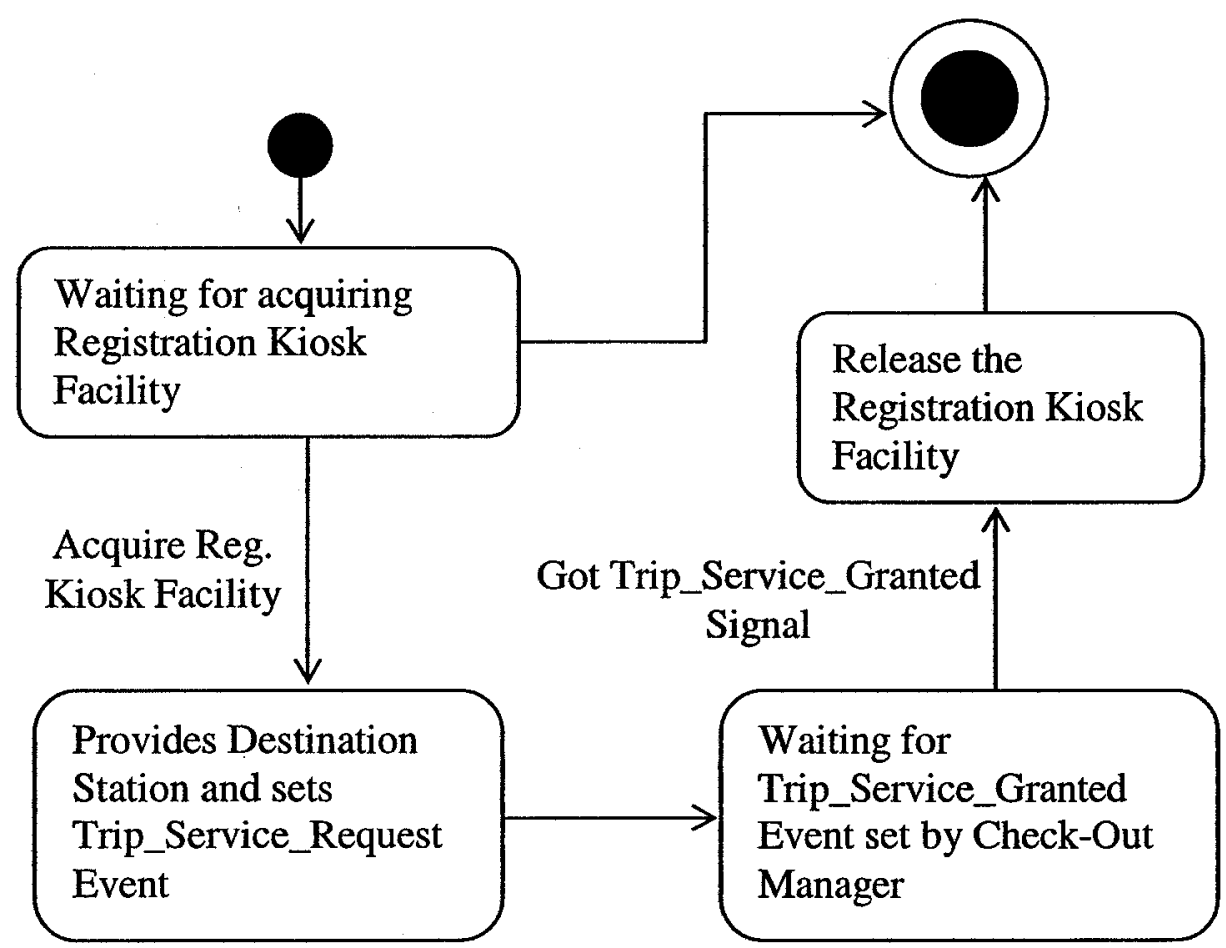

Figure 5.6 State machine of customer process 


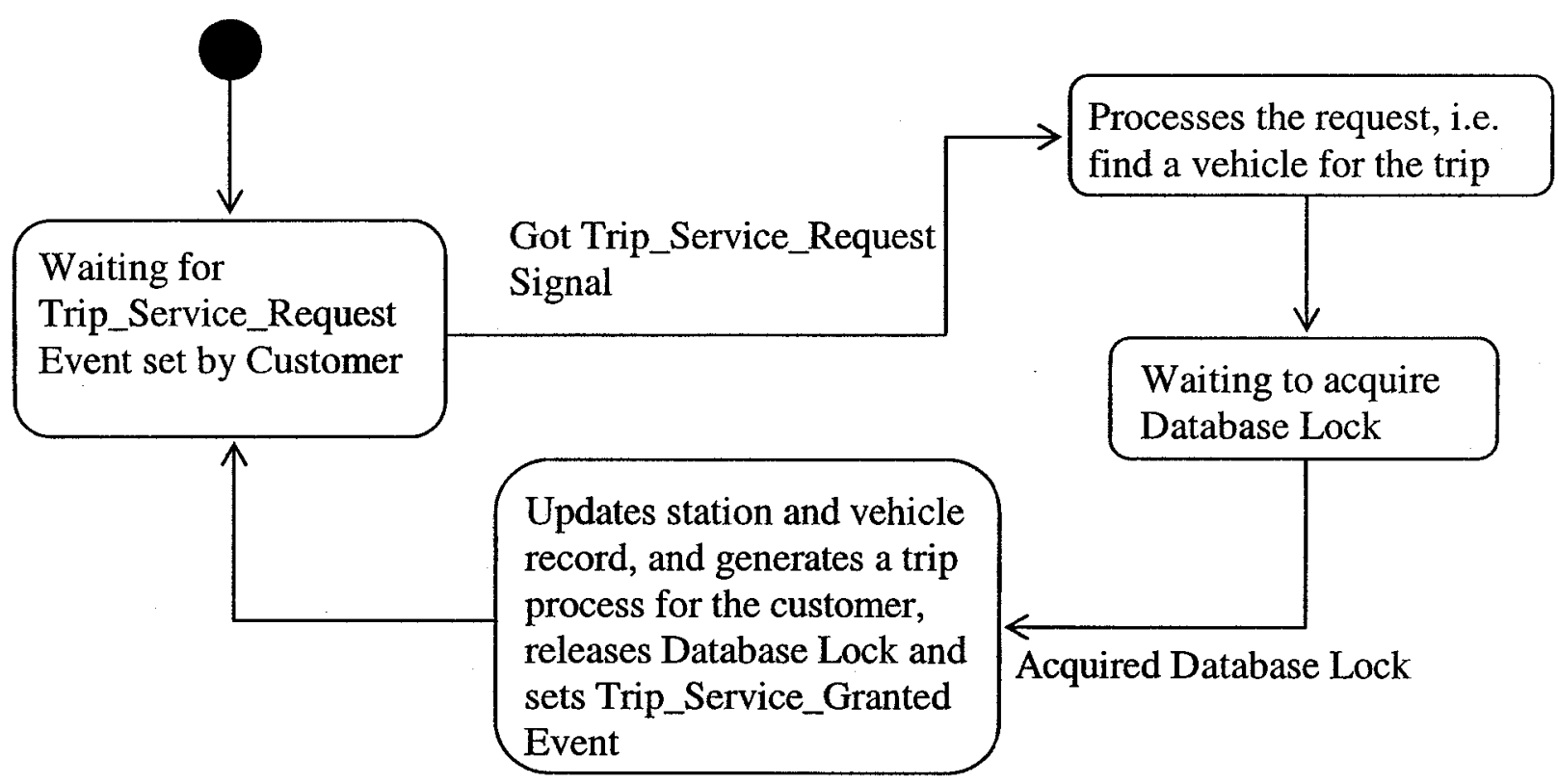

Figure 5.7 State machine of check-out manager process

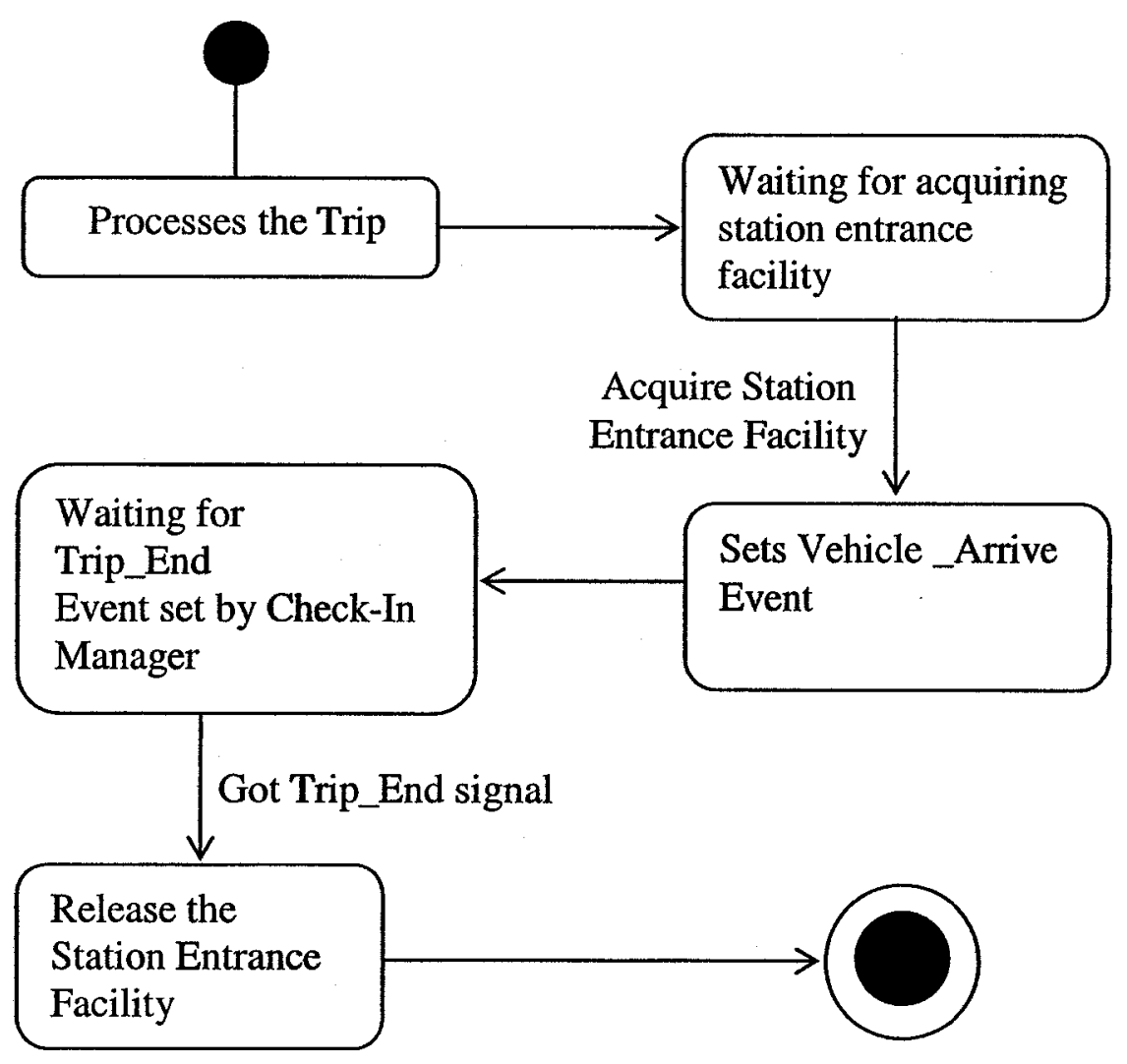

Figure 5.8 State machine of trip process 


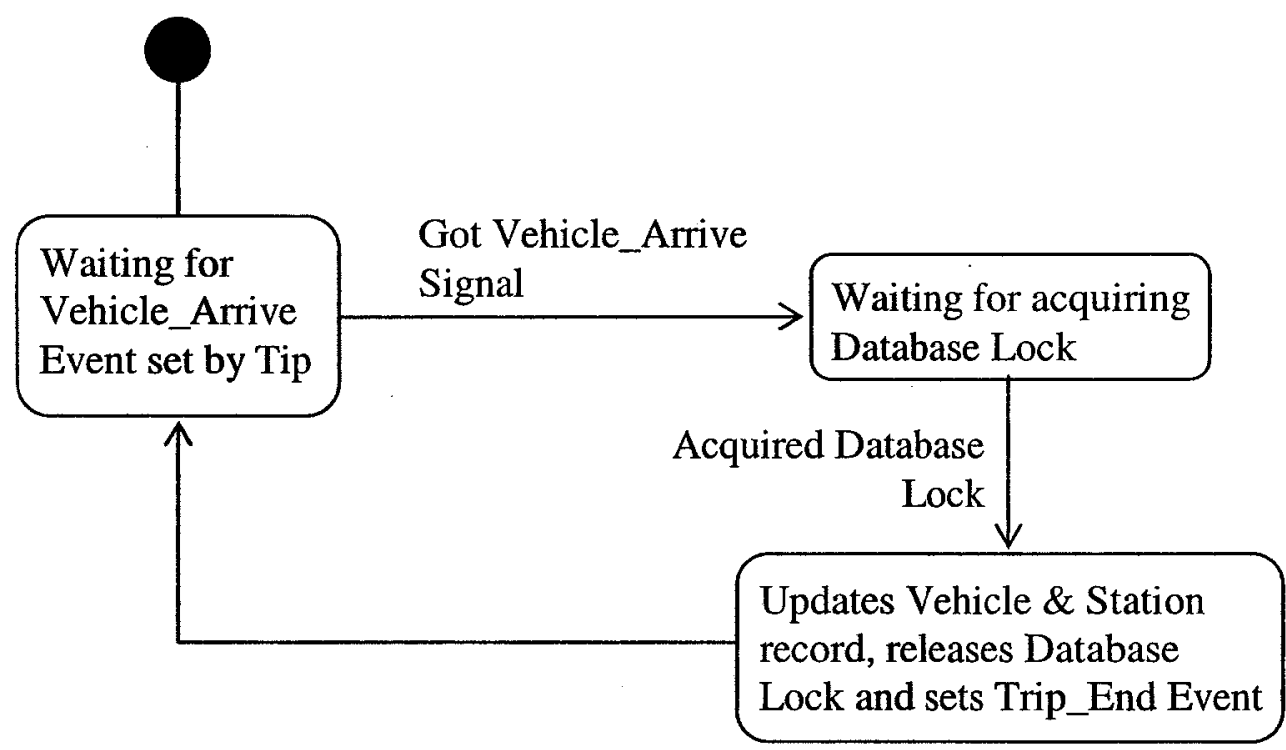

Figure 5.9 State machine of check-in manager process

Legend:

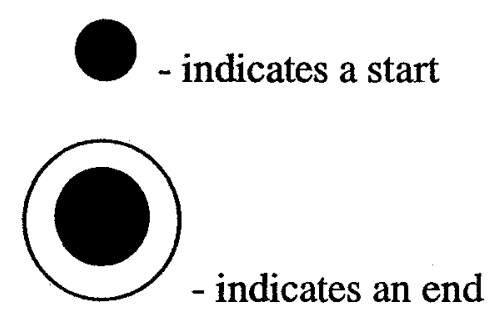

This Use Case Model and the algorithm is combined with methodology and implemented with CSIM19 in Microsoft Visual C++ environment to simulate shared vehicle system (SVS) design and operations. The application of the model together with the test results and its performance evaluation is illustrated in Chapter VI. 


\section{CHAPTER VI}

\section{MODEL IMPLEMENTATION, VALIDATION, TEST RESULTS}

\subsection{Introduction}

In order to simulate the operations of a multiple station shared vehicle system and to provide insight on critical operational and performance issues including vehicle availability, vehicle distribution, and vehicle state-of-charge (SOC), the model and algorithm described in Chapters IV and V, were implemented in CSIM19 within Microsoft Visual $\mathrm{C}++$ environment. The CSIM19 is a library of $\mathrm{C} / \mathrm{C}++$ routines/functions. Using these routines, the $\mathrm{C}++$ code was developed to implement the algorithm using unified modelling language (UML) based "Use Case" implementation technique.

\subsection{Model Implementation}

$\mathrm{C}++$ is a powerful object-oriented programming (OOP) language. The discrete-event simulation technique is unique to simulate complex systems whose changes in state occur in finite quanta, or jumps in time. The CSIM19 is a process-oriented, general-purpose simulation toolkit written with $\mathrm{C}$ and $\mathrm{C}++$ language functions/routines. It allows programmers to create and implement process-oriented, discrete-event simulation models, which can simulate complex systems and offer insight into the system's dynamic behaviour. According to Alhir (2000), Unified Modelling Language (UML) is an evolutionary general-purpose, broadly applicable, tool-supported, and industrystandardized modelling language for specifying, visualizing, constructing, and 
documenting the artifacts of a system-intensive process. Blending three tools, the Use Case Modeling technique using UML, Microsoft Visual C++, and the CSIM19, with queuing based discrete-event simulation technique the powerful multiple station shared vehicle system model was implemented in Microsoft Visual C++ environment. The complete computer code is given in appendix $\mathrm{C}$.

\subsection{Case Study Data Set}

As noted earlier, the data set used by Miller (1982) in his master's thesis study was used as case study "test data" to implement and experiment with the simulation model. The criteria set by Barth et al (1998) were used to check that the minimum demand warrant is met. Although a 3-station system is sufficient to implement, verify, and validate the model, a 5-station shared vehicle system was considered. First five high activity stations were selected from Miller's study area, the Canadian Forces Base (CFB) Ottawa, and are implemented. The selected stations are shown in Table 6.1.

Table 6.1 Selected candidate stations

\begin{tabular}{|c|l|c|}
\hline $\begin{array}{c}\text { Station No. in } \\
\text { Miller's Study }\end{array}$ & \multicolumn{1}{|c|}{ Description } & $\begin{array}{c}\text { Station Number } \\
\text { in this Research Study }\end{array}$ \\
\hline 3 & Berger Bldg - 100 Metcalfe & 1 \\
\hline 13 & Elggar Bldg - 200 Elgin & 2 \\
\hline 23 & L'Esplanade Laurier - 140 O'Connor & 3 \\
\hline 26 & National Defence HQ - 101 Col By & 4 \\
\hline 44 & CFB Ottawa - Rockcliffe Park & 5 \\
\hline
\end{tabular}

The CFB Ottawa's then office locations with the selected offices considered as case study in this research are shown in Figure 6.1. The selected office locations are shown by placing "star" symbol on them. A detailed orientation of the selected five stations and surrounding road network is shown in Figure 6.2. 


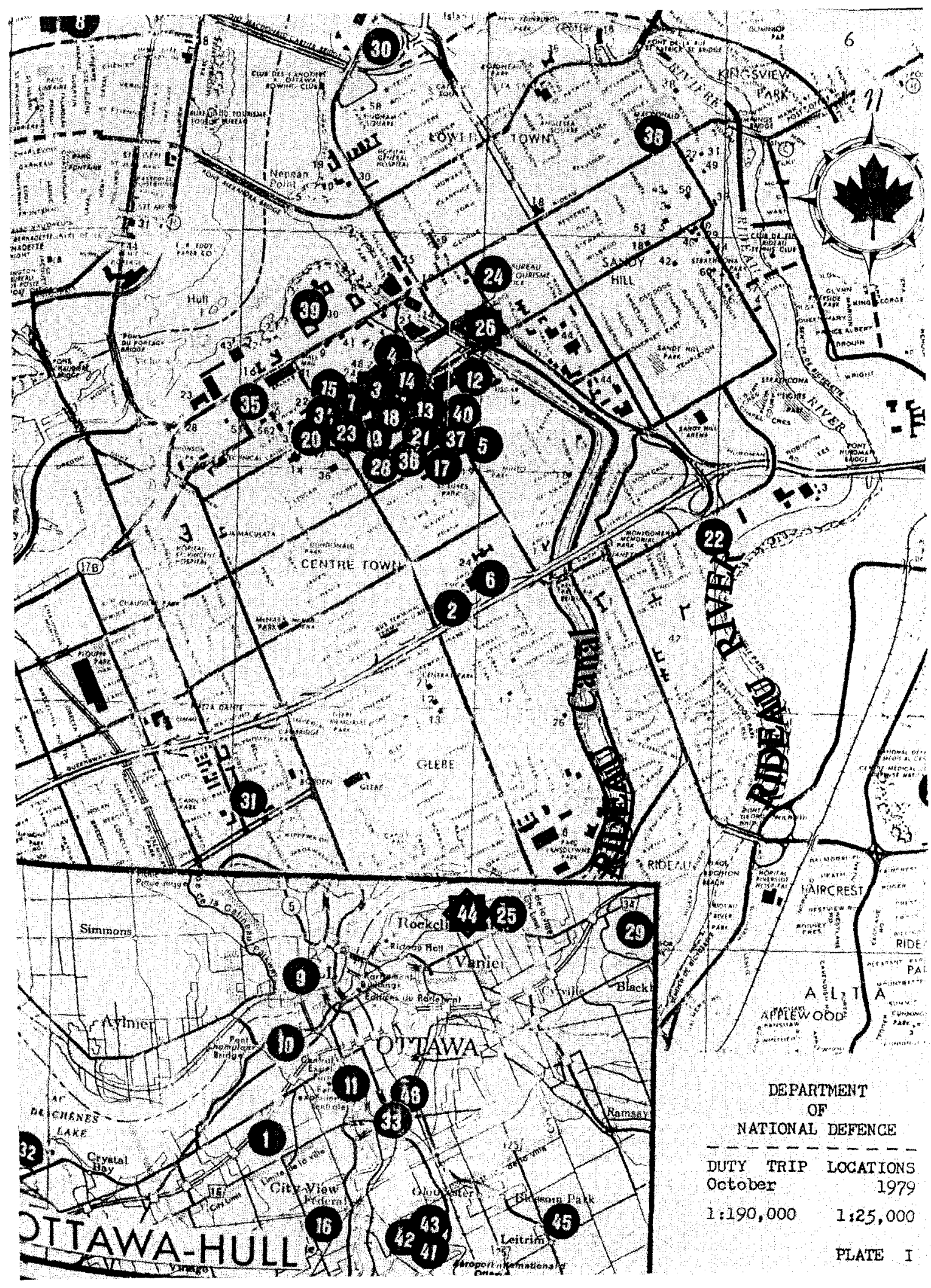

Figure 6.1 Case study area CFB Ottawa's departmental locations with selected stations (red star bordered). source: Miller (1982) 


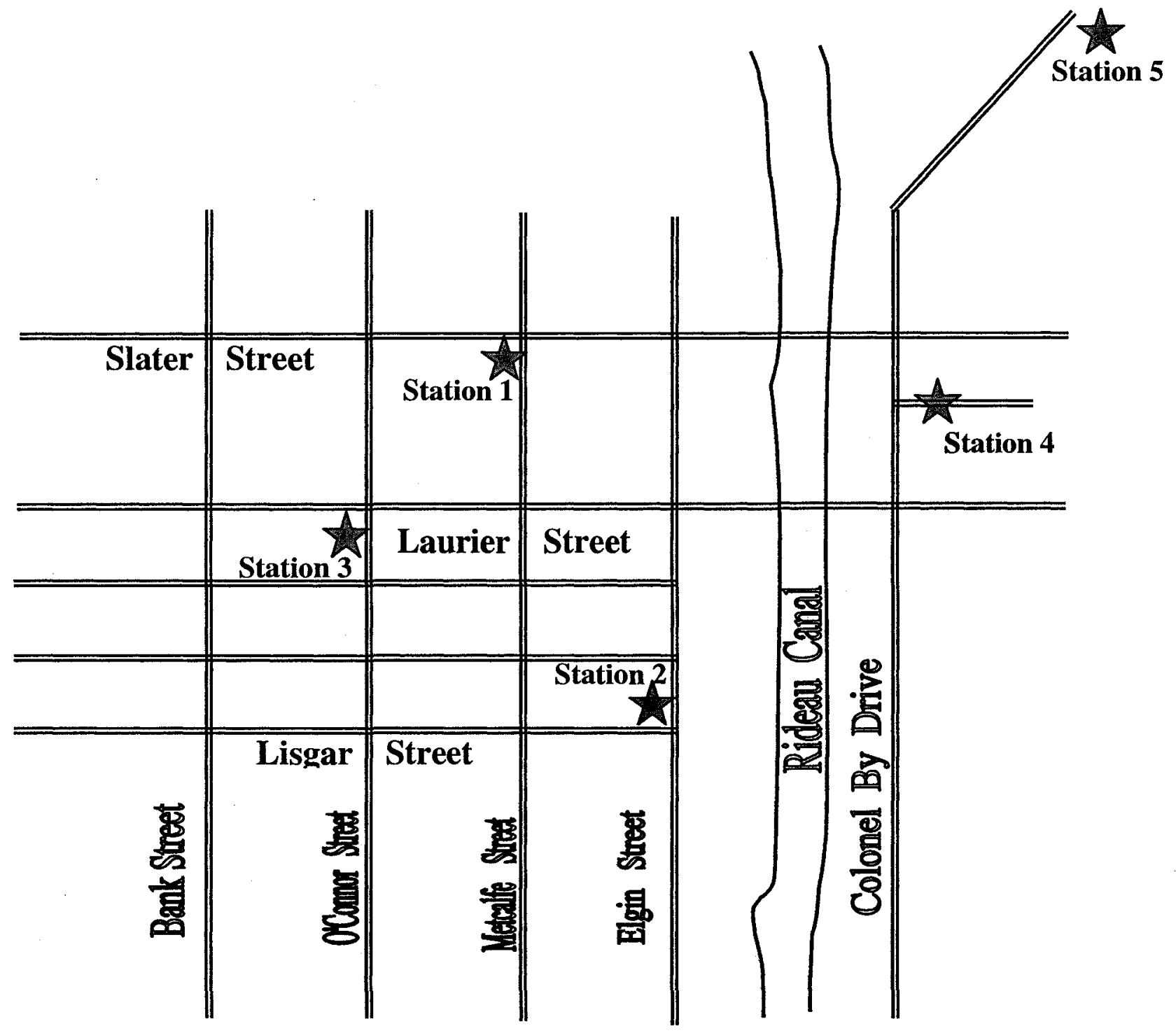

Figure 6.2 Detailed of selected five stations and surrounding road network 


\subsubsection{Travel Demand Data}

The daily travel demands among stations are extracted from Miller's study (Miller, 1982). A compound annual growth factor of $3 \%$ was used to project demand to the year 2005. Miller did not break down the demand on an hourly basis but presented in OD on a daily basis. To estimate the hourly demand considering the usual peaks in a typical weekday, a typical demand distribution pattern (i.e., based on the University of California Riverside experience, reported by Barth and Todd, 1999) was used. Then the travel demands among the selected five stations of CFB Ottawa were converted into hourly demand. Although this conversion may have inconsistency with the actual variation in demand of CFB Ottawa, it represents the typical diurnal variation of travel demand of typical market segments i.e., resort communities, business corporations in Central Business District (CBD). Figure 6.3 shows the estimated diurnal variation of travel demand of a typical weekday in selected five stations of CFB Ottawa and Table 6.2 represents the travel demand numerically.

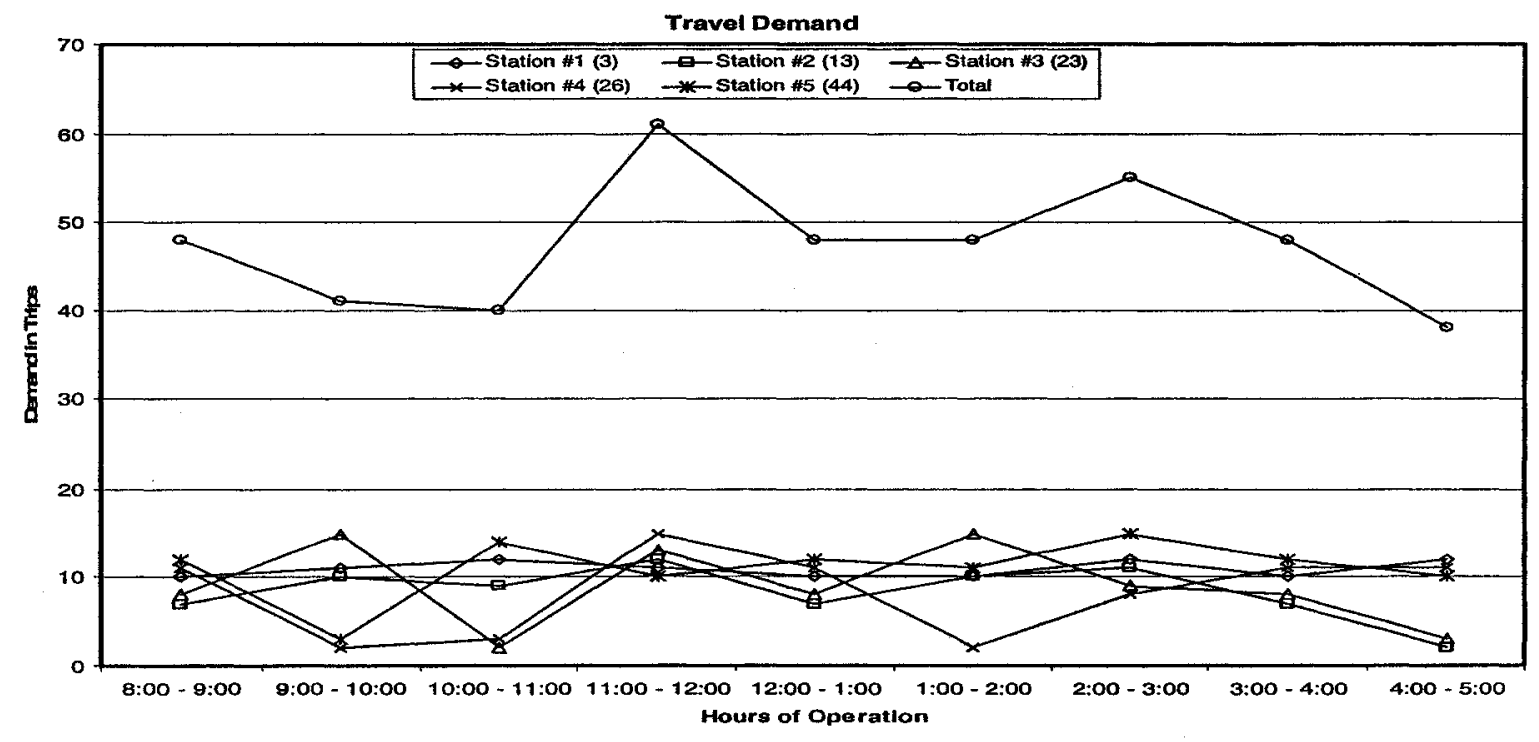

Figure 6.3 Diurnal variation of travel demand of selected stations 
Table 6.2 Travel demand for five stations case study system

\begin{tabular}{|l|c|c|c|c|c|c|c|c|c|}
\hline & \multicolumn{10}{|c|}{ Operation Hour } \\
\hline & $8: 00-9: 00$ & $9: 00-10: 00$ & $10: 00-11: 00$ & $11: 00-12: 00$ & $12: 00-1: 00$ & $1: 00-2: 00$ & $2: 00-3: 00$ & $3: 00-4: 00$ & $4: 00-5: 00$ \\
\hline Station \#1 & 10 & 11 & 12 & 11 & 10 & 10 & 12 & 10 & 12 \\
\hline Station \#2 & 7 & 10 & 9 & 12 & 7 & 10 & 11 & 7 & 2 \\
\hline Station \#3 & 8 & 15 & 2 & 13 & 8 & 15 & 9 & 8 & 3 \\
\hline Station \#4 & 11 & 2 & 3 & 15 & 11 & 2 & 8 & 11 & 11 \\
\hline Station \#5 & 12 & 3 & 14 & 10 & 12 & 11 & 15 & 12 & 10 \\
\hline
\end{tabular}

Miller's (1982) study conducted an interview with the responsible officer at CFB Ottawa to gather information on party size of the trips that were made during the month of October 1979. According to the available information in Miller's study, approximately $10 \%$ of the trips had party size of $>2$ and rest of the trips had party size of $\leq 2$. The Barth and Todd (1999) study found party size distribution of $20 \%$ greater than 2 and $80 \%$ less than or equal to 2 . In none of the cases, party size was found to be greater than 5 . In this thesis research, Barth and Todd's information was used to model party size in each arrival with an upper limit of 5 .

\subsubsection{Trip Travel Time Data}

The distances between stations and travel times are not reported clearly in Miller's study. He came up with an average trip length of $7.0 \mathrm{~km}$ and one-way travel time of 30 minutes. He also mentioned a round trip travel time of 90 minutes. In this regard, Barth and Todd's (1999) study was reviewed. Blending these information sources enabled the synthesis of a trip travel time data matrix, based on inter-station distance, for all possible one-way and round trips for the five station shared vehicle system. Table 6.3 shows the estimated trip travel times for all possible combinations of trips among five stations. 
Table 6.3 Estimated travel times in minutes of trips among five stations

\begin{tabular}{|c|c|c|c|c|c|c|}
\hline & & & & & & \\
\hline & & 1 & 2 & 3 & 4 & 5 \\
\hline & 1 & 15 & 10 & 10 & 15 & 20 \\
\hline & 2 & 10 & 15 & 14 & 12 & 20 \\
\hline $\begin{array}{c}\text { From } \\
\text { Station }\end{array}$ & 3 & 10 & 14 & 15 & 15 & 20 \\
\hline & 4 & 15 & 12 & 15 & 15 & 10 \\
\hline & 5 & 20 & 20 & 20 & 10 & 20 \\
\hline
\end{tabular}

For the implementation of scenario number 3 , described in the methodology section, a priori data set on travel time distribution is needed. None of the previous shared vehicle system modelling efforts used the Bayesian approach to estimate travel time between stations. Sarah Riley, a master student at Carleton University, in her M.A.Sc. thesis used Bayesian technique to improve estimates of transit bus travel times between $\mathrm{OC}$ Transpo's stations/stops in Ottawa (Riley, 2002). The priori information available on travel time in Riley's thesis was reviewed. A reasonable priori data set was then developed (see Table 6.4).

In this research, the stations are located in Ottawa and the travel time experience can be inferred from available data on travel times of road links with mixed traffic. Therefore, OC Transpo data used by Riley (2002) can serve the purpose of inferring probabilities for the Bayesian analysis part of this research methodology. For implementation of the 
shared vehicle system elsewhere, data can be acquired from the traffic control center (TCC) and analyzed so as to estimate the probabilities.

This approach treats origin-destination travel time as uncertain. To begin the analysis, three travel time estimates (i.e., states of nature) $\mathrm{T} 1, \mathrm{~T} 2$, and $\mathrm{T} 3$ are defined. These correspond to reduced, normal, and delayed travel time, respectively, for a particular trip. The definition of reduced and delayed travel time for a particular trip is according to the viewpoint of the researcher. In this research, travel time that is 3 minutes less than the normal travel time is defined as reduced (T1), and 3 minutes longer than the normal travel time is defined as delayed (T3). Therefore, the probabilities are based on these conditions.

Since the travel times are discretely defined, meaning that the travel times can either be one of three choices, the probabilities have been regarded as 'discrete'. The probabilities were estimated on the basis of frequency analysis of the travel time data (Riley, 2002). As noted above, the travel time states were defined as below:

T1: normal travel time -3 min or more

T2: normal travel time \pm 2 min

T3: normal travel time +3 min or more 
Table 6.4 Sample prior probabilities for station \#1

\begin{tabular}{|c|l|l|l|l|}
\hline Trip & $\mathrm{P}(\mathrm{T} 1)$ & $\mathrm{P}(\mathrm{T} 2)$ & $\mathrm{P}(\mathrm{T} 3)$ & Sum \\
\hline $1-1$ & 0.240 & 0.645 & 0.115 & 1.000 \\
\hline $1-2$ & 0.325 & 0.560 & 0.115 & 1.000 \\
\hline $1-3$ & 0.265 & 0.595 & 0.140 & 1.000 \\
\hline $1-4$ & 0.250 & 0.625 & 0.125 & 1.000 \\
\hline $1-5$ & 0.215 & 0.610 & 0.175 & 1.000 \\
\hline
\end{tabular}

The conditional probabilities are a mechanism to express the reliability of estimated travel times between stations to become true. From an analysis of recent historical data, these probabilities can be quantified. On the basis of OC Transpo data, Riley (2002) estimated conditional probabilities (Table 6.5). In this research, these estimates are used.

Table 6.5 Conditional probabilities estimated by Riley (2002)

\begin{tabular}{|c|c|c|c|c|}
\hline State & $P(R 1)$ & $P(R 2)$ & $P(R 3)$ & Sum \\
\hline T1 & 0.700 & 0.250 & 0.050 & 1.000 \\
\hline T2 & 0.150 & 0.700 & 0.150 & 1.000 \\
\hline T3 & 0.050 & 0.250 & 0.700 & 1.000 \\
\hline
\end{tabular}

From the above information it can be observed that under the state $\mathrm{T} 1$ the probabilities of receiving advisory $\mathbf{R} 1$ (reduced travel time), $\mathrm{R} 2$ (normal travel time), and R3 (delayed travel time) are $70 \%, 25 \%$, and $5 \%$, respectively. The prior probability and conditional probability estimates presented in Tables 6.4 and 6.5, respectively and others 
are used in the Bayesian methodology for the purpose of enhancing travel time estimates on a real time basis. Please see section 4.3.3.2 for the Bayesian methodology.

\subsection{Model Validation}

The validity of a simulation model depends on the accuracy of the model representing the real world system (Pooch and Wall, 1993). The simulationists face significant difficulties in validating their developed simulation models. Pooch et al (1993) mentioned that the truly satisfactory method of validating a simulation model is to judge its performance and comparison with real world system observed values, if available. He also mentioned that if the inferences drawn from the analysis of the output allow correct conclusions to be drawn about the system being modelled, then the simulation model can be assumed to be valid.

Martin (1988) suggested a set of methods to assess the validity of simulation model. These methods include the conceptual phase validation, and the implementation phase validation. The first method deals with checking the interrelationships among various subsystems of the system being simulated. The second method deals with checking the correctness of the computer code of the individual subsystems.

According to Pooch and Wall (1993), Emshoff and Sisson (1970) have suggested other validity tests including:

1. Internal Validity Test, and

2. Variable-Parameter Validity Test 
The internal validity test consists of performing several simulations using the same model and same input parameters and then comparing the output to detect variability. If the variability is low that may occur due to the dynamic nature of the model then we may assume that the model is valid. The variable-parameter validity test consists of varying parameters and variables to determine their effects on the simulator and the subsequent output. If the impacts of the changed parameters comply with the expected values, the validity of the model is assumed. In this research study, the conceptual, the implementation, internal validity, and variable-parameter tests were used to check the validity of the model. The values of the performance indicators obtained from several model runs using the same parameter value were grouped, plotted, and shown in Figure

\section{4.}

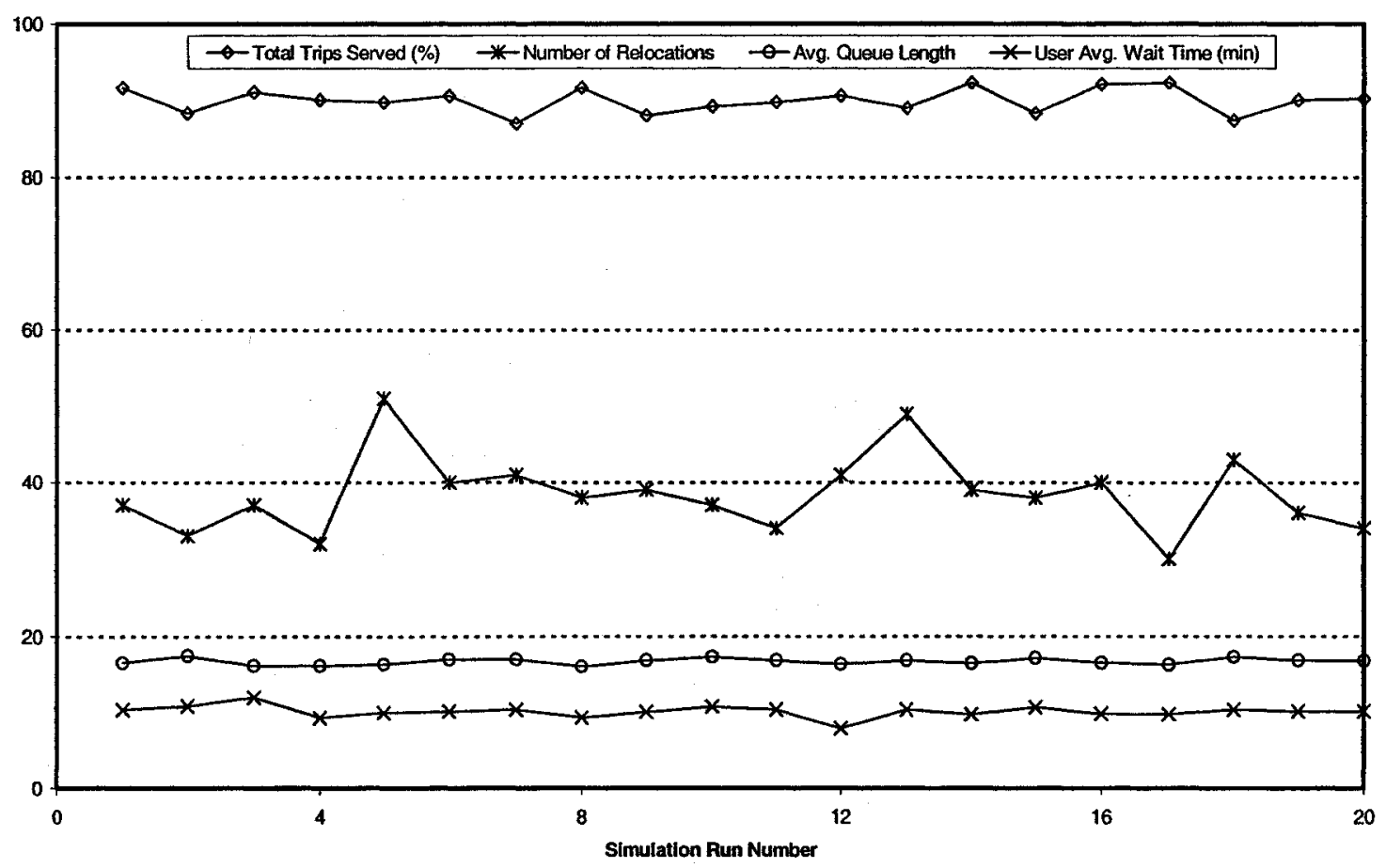

Figure 6.4 Performance indicators variability level during model validation 
From figure 6.4 it is obvious that the values of different performance indicators from 20 simulation runs, while keeping all control variables constant, are very consistent. The model output analysis results were compared with Barth and Todd (1999) results. The calculated values of the performance indicators obtained from several model runs are given in Table 6.6.

Table 6.6 MOP indicators values in model validation

\begin{tabular}{|c|c|c|c|c|}
\hline $\begin{array}{c}\text { Simulation } \\
\text { Run \# }\end{array}$ & $\begin{array}{l}\text { Total Trips } \\
\text { Served (\%) }\end{array}$ & $\begin{array}{l}\text { Number of } \\
\text { Relocations }\end{array}$ & $\begin{array}{c}\text { Avg. Queue } \\
\text { Length (Trips) }\end{array}$ & $\begin{array}{c}\text { User Avg. } \\
\text { Wait Time (min) }\end{array}$ \\
\hline 1 & 91.6 & 37.0 & 16.6 & 10.5 \\
\hline 2 & 88.3 & 33.0 & 17.5 & 11.0 \\
\hline 3 & 91.1 & 37.0 & 16.2 & 12.1 \\
\hline 4 & 90.0 & 32.0 & 16.2 & 9.5 \\
\hline 5 & 89.7 & 51.0 & 16.4 & 10.1 \\
\hline 6 & 90.6 & 40.0 & 17.0 & 10.3 \\
\hline 7 & 87.0 & 41.0 & 17.0 & 10.5 \\
\hline 8 & 91.6 & 38.0 & 16.1 & 9.5 \\
\hline 9 & 88.0 & 39.0 & 16.9 & 10.2 \\
\hline 10 & 89.2 & 37.0 & 17.3 & 10.9 \\
\hline 11 & 89.7 & 34.0 & 16.9 & 10.5 \\
\hline 12 & 90.6 & 41.0 & 16.4 & 8.1 \\
\hline 13 & 89.0 & 49.0 & 16.9 & 10.5 \\
\hline 14 & 92.3 & 39.0 & 16.5 & 9.9 \\
\hline 15 & 88.3 & 38.0 & 17.2 & 10.8 \\
\hline 16 & 92.1 & 40.0 & 16.6 & 10.0 \\
\hline 17 & 92.3 & 30.0 & 16.3 & 9.9 \\
\hline 18 & 87.4 & 43.0 & 17.3 & 10.5 \\
\hline 19 & 90.0 & 36.0 & 16.9 & 10.3 \\
\hline 20 & 90.2 & 34.0 & 16.8 & 10.3 \\
\hline
\end{tabular}


Table 6.7 Descriptive statistics of MOP indicators

\begin{tabular}{|l|c|l|c|l|l|l|l|}
\hline \multicolumn{2}{|l|}{ Trip Served, \% } & \multicolumn{2}{l|}{ Number of Relocation } & \multicolumn{2}{l|}{ Queue Length (Trips) } & \multicolumn{2}{l|}{ Wait Time (min) } \\
\hline Mean & 89.95 & Mean & 38.45 & Mean & 16.75 & Mean & 10.27 \\
\hline Mode & 91.6 & Mode & 37 & Mode & 16.9 & Mode & 10.5 \\
\hline $\begin{array}{l}\text { Standard } \\
\text { Deviation }\end{array}$ & 1.61 & $\begin{array}{l}\text { Standard } \\
\text { Deviation }\end{array}$ & 5.15 & $\begin{array}{l}\text { Standard } \\
\text { Deviation }\end{array}$ & 0.41 & $\begin{array}{l}\text { Standard } \\
\text { Deviation }\end{array}$ & 0.76 \\
\hline COV & 1.79 & COV & $\mathbf{1 3 . 3 9}$ & COV & $\mathbf{2 . 4 4}$ & COV & $\mathbf{7 . 4 0}$ \\
\hline Minimum & 87.0 & Minimum & 30 & Minimum & 16.1 & Minimum & 8.1 \\
\hline Maximum & 92.3 & Maximum & 51 & Maximum & 17.5 & Maximum & 12.1 \\
\hline 95\% C.I & \pm 0.75 & $95 \%$ C.I & \pm 2.41 & $95 \%$ C.I & \pm 0.19 & $95 \%$ C.I & \pm 0.36 \\
\hline
\end{tabular}

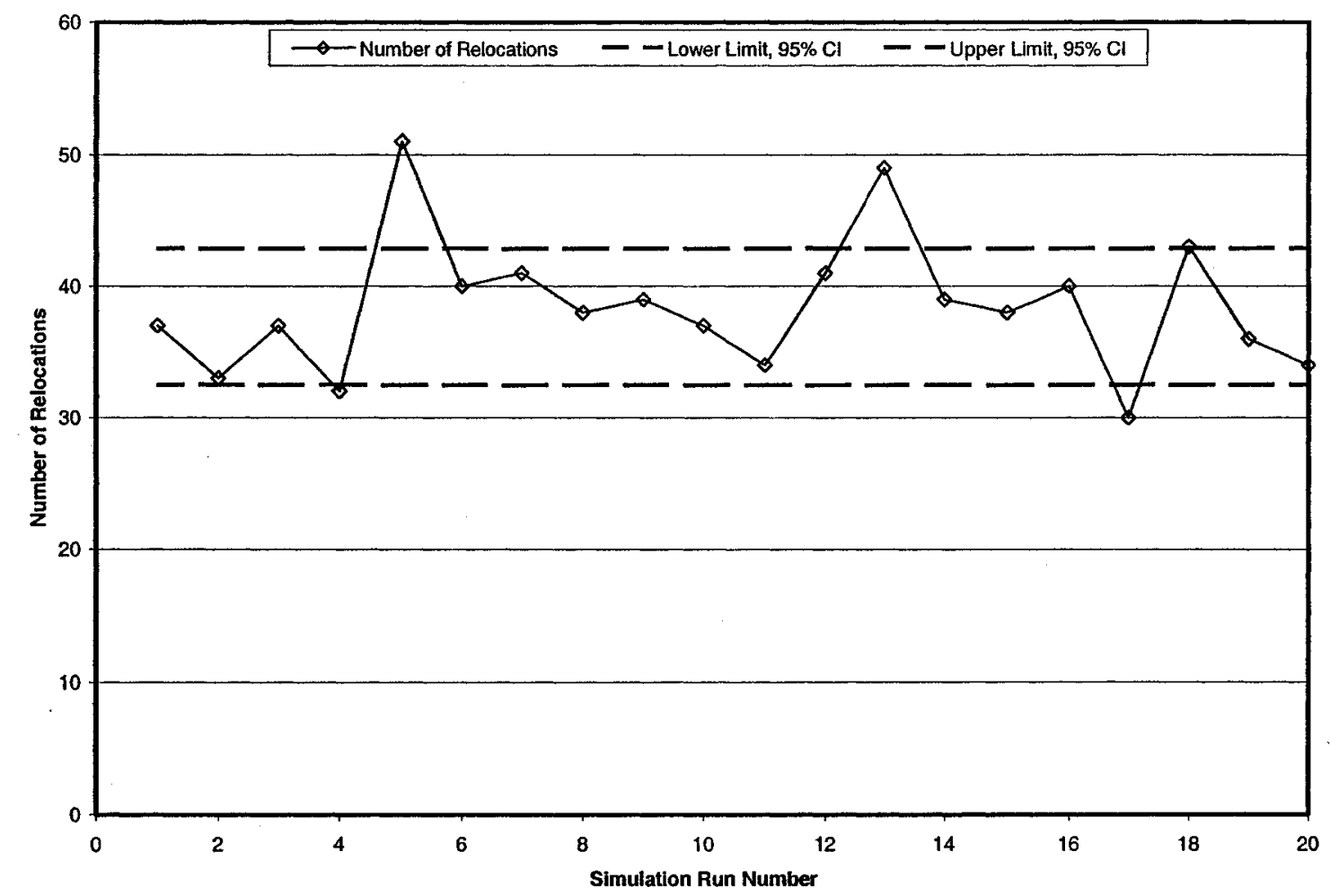

Figure 6.5 Number of relocations and its $95 \%$ confidence interval in 20 runs 
Table 6.7 summarizes the descriptive statistics of different SVS system performance indicators. The statistic COV indicates that the variation in sample data for a particular MOP is within the range of "very low" to "acceptable". Figure 6.5 shows the analysis of number of relocations and its $95 \%$ confidence interval (CI) for a total of 20 simulation runs. Similar results were observed in the case of user average wait time, trip served, and queue length (please be referred to Figures E.18 to E.21 in appendix E).

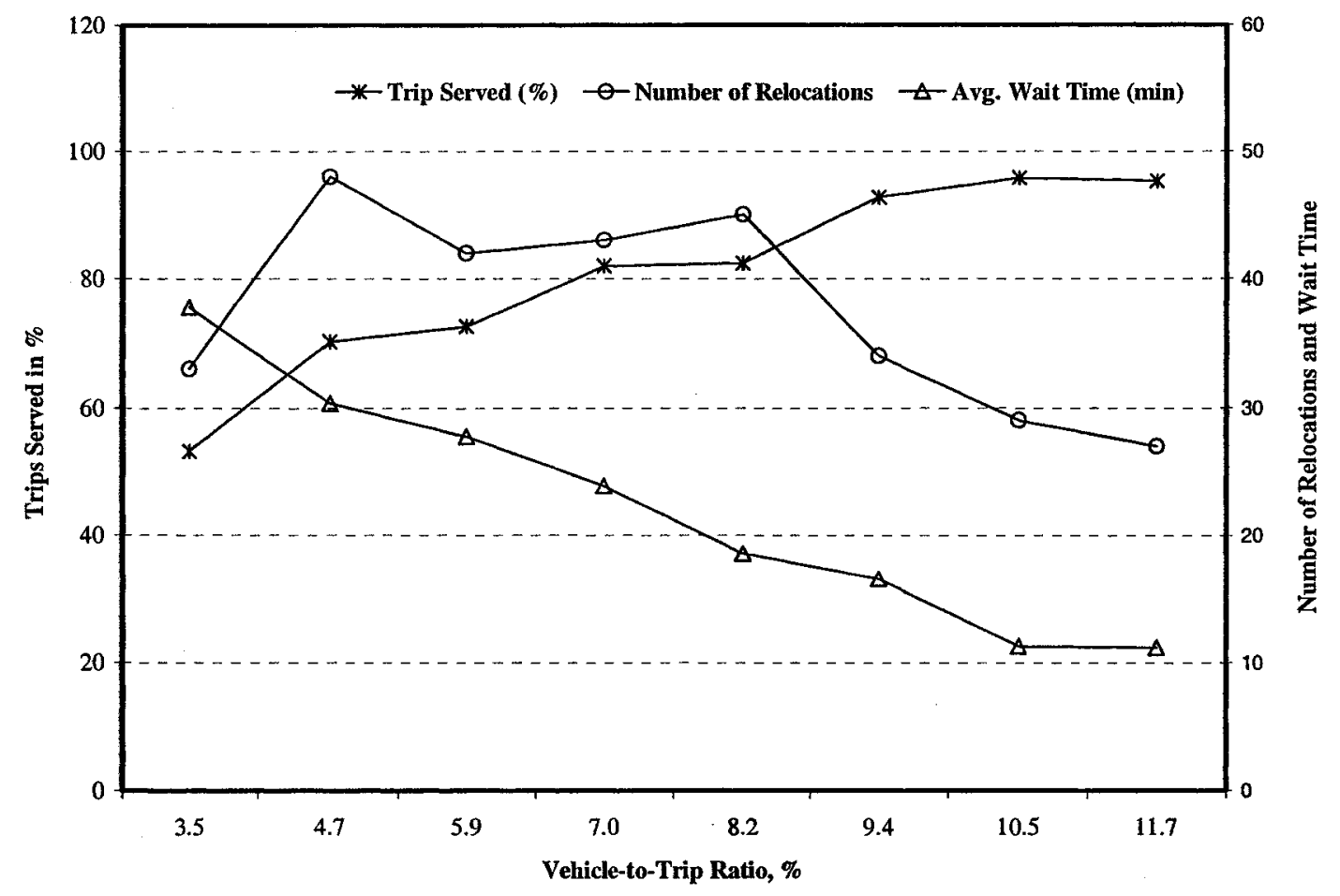

Figure 6.6 Variable-Parameter Test Results

Figure 6.6 illustrates the variable-parameter test results in model validation process. The primary independent variable vehicle-to-trip ratio was varied to observe its impact on the simulation output. It is obvious that the total system capacity in terms of number of 
trips served increases non-linearly with increased values of vehicle-to-trip ratio in percent. This result is consistent and intuitive with the real world expectation. User average waiting time decreases for an increase in vehicle-to-trip ratio. The number of required relocations generally increases against vehicle-to-trip ratio of around 8 percent, and decreases beyond that. These model outputs/results are also intuitive and consistent with the real world expectation. These analysis results prove that the developed model is valid in order to correctly simulate the shared vehicle systems and their operations.

\subsection{Case Study Results}

The primary objective of this research is to develop an improved simulation model for multiple station and/or station car type shared vehicle system design and operations. Literature review showed that all the developed shared vehicle system (SVS) simulation models lack many important variables. In this research, an attempt has been made to consider a complete set of variables and three scenarios defined in methodological framework and were implemented.

As mentioned in the previous sections, data collected by Miller (1982) was projected to 2005 and was used as case study to test the model. Test results show that the developed algorithm is correctly simulating the shared vehicle system operations, verify the accuracy of the computer code in C++ and CSIM19, and evaluate system critical issues. Trip-by-trip activities of each station were monitored during the execution of a single run. This monitoring process demonstrated the shared vehicle system operation with highest level of detail. The actual and simulated trips were checked, the party size distribution 
was verified, and travel time for a particular trip was crosschecked. Considering demand, the criterion that a minimum $95 \%$ of the total demand should be served was used and verified for the best values of measures of performance (MOP).

The input control parameters such as vehicle-to-trip ratio and parking-to-vehicle ratio were varied to determine the efficient system design configuration. This experimentation also helped to study the sensitivity of shared vehicle system performance with respect to design variables mentioned above. The model results were extracted, processed, and analyzed to determine the values of a set of system's MOP and relationships were developed among different input control parameters and system performance measures. Using these MOPs, the system can be iteratively designed and evaluated on the simulation results. This process leads to the determination of basis of resolution of critical operating issues. The major MOPs include the following:

1. Average waiting time

2. Total average waiting time

3. Average number of customers (trip) waiting or average queue length (trip)

4. Number of vehicle relocations

5. Average battery state-of-charge (SOC)

\section{Average Waiting Time}

This MOP corresponds to the average length of time customers have to wait for a vehicle when a vehicle is not immediately available. The underlying assumption is that users of the system will indeed wait a short time in order to obtain a vehicle (Barth and 
Todd, 1999). This MOP is computed by averaging the waiting times of all users that had to wait for a vehicle. Waiting time spent by give-up or dropout from the queue is also included.

\section{Total Average Waiting Time}

The total average waiting time is similar to average waiting time, but the average is calculated for all of the user trips regardless if the user had to wait for a vehicle or not. Again the waiting times spent by customers who give up and drop out of the queue are also included.

\section{Number of Trips Waiting or Queue Length (trip)}

The number of trips waiting in the system is important to evaluate in conjunction with the waiting times (Barth and Todd, 1999). This MOP represents the total number of user trips that had to wait for a vehicle prior to departing from a station.

\section{Number of Vehicle Relocations}

During the simulation of real world operation of multiple station SVS or station car system, vehicles are relocated from one station to another in order to bring back the balance in vehicle distribution among stations. This MOP corresponds to the number of vehicles that are relocated between stations throughout the operation period (i.e., day). Each vehicle that is relocated is counted as a single relocation although several vehicles may be relocated in a group. 


\section{Average Battery State-of-Charge (SOC)}

It is assumed that electric vehicles (EV) are deployed in the SVS systems. Electric vehicles have a limited range and hence energy management within the system is very important. It is monitored through each vehicle's SOC status. The average vehicle SOC and other statistics (i.e., minimum SOC, maximum SOC etc) of all vehicles are used to evaluate the system's overall energy management efficiency.

\subsubsection{Results based on Scenario-1}

The SVS methodology was implemented for the case study site and a large number of results were produced under different scenarios. Sample model output is shown in appendix C. A comprehensive analysis of the results obtained in scenario-1 is given below.

\subsubsection{User Waiting Time and Number of Relocations Analysis}

Literature review showed that the success of any shared vehicle system depends on the availability of a vehicle when a user wishes to use it (Barth and Todd, 1999). Two primary performance parameters, namely vehicle availability and vehicle distribution are critical in this aspect. These were considered when analyzing the system design and operations. These MOPs are defined as: vehicle availability; characterized by the average user waiting time and vehicle distribution; characterized by the number of vehicle relocations needed during shared vehicle system operations. For an ideal SVS system, both of these two parameters should be kept to a minimum (Barth and Todd, 1999). 
Both average user waiting time and number of relocations are primarily a function of vehicle-to-trip ratio and parking-to-vehicle ratio. If there are $X$ vehicles in the system, and $Y$ trips realized per operation period (i.e., day), then the vehicle-to-trip ratio is simply $\frac{X}{Y}$. The vehicle-to-trip ratio is one of the key independent variables and is expressed in percent. Using this vehicle-to-trip ratio one could easily determine the fleet size. On the other hand, if there are $\mathrm{N}$ parking slots/stalls in the system, then the parking-to-vehicle ratio is $\frac{N}{X}$.

According to scenario-1, this study assumed that the system follows modified Markov process and customer or trip interarrival time follows negative exponential distribution with a limit of $0 \leq t \leq \frac{1}{\lambda}+3 \sigma$, where $\lambda$ is the mean hourly travel demand, $\sigma$ is the standard deviation of trip interarrival time. We also assume that the travel time for a particular type of trip is constant all over the system operation period. Number of stations is constant for a particular SVS system. But the number of parking slots is not constant. To analyze the system under scenario-1, a parking-to-vehicle ratio of 2:1 was assumed. This assumption is generated from a preliminary experimentation with the model developed here and information from Miller (1982) and Nakayama et al's (2001) studies results. 


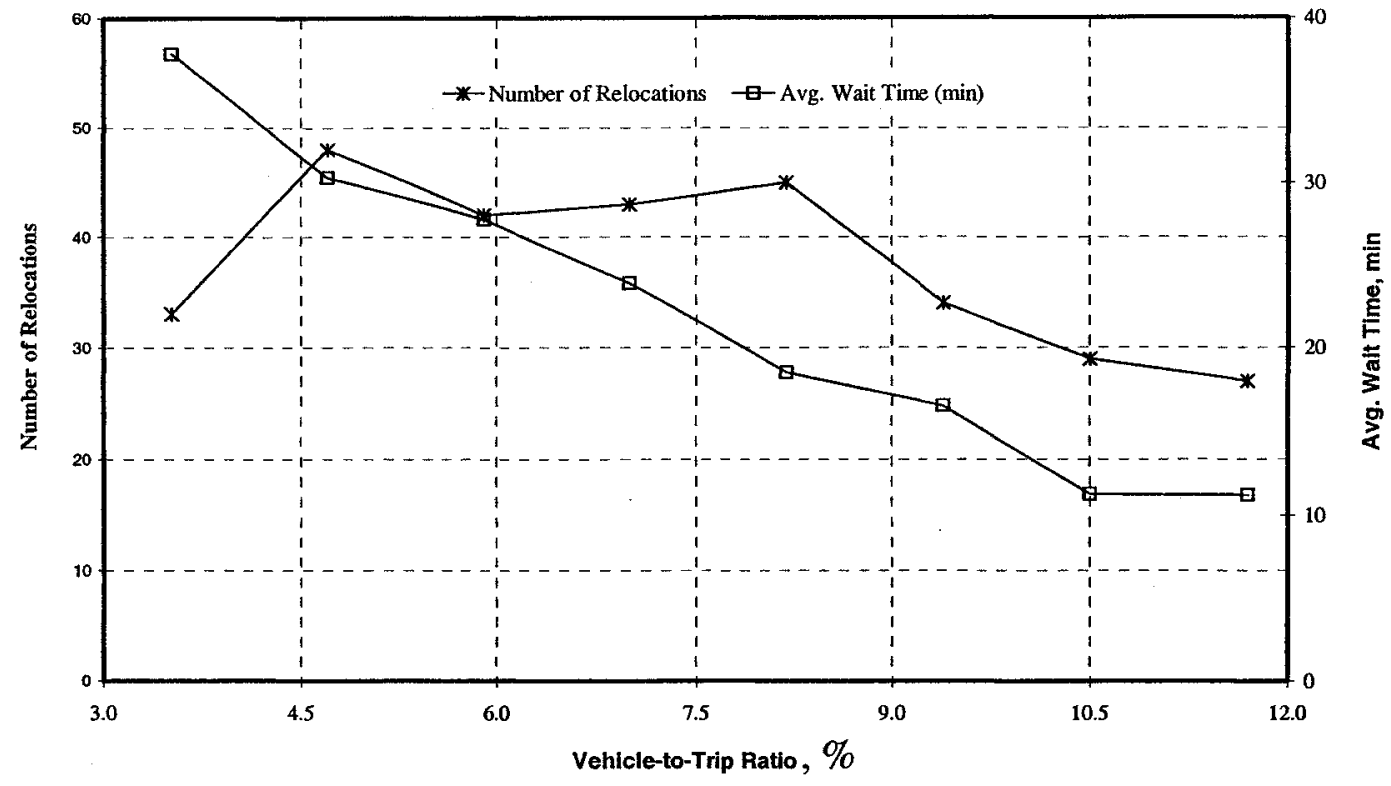

Figure 6.7 Average wait time and number of relocations as a function of vehicle-totrip ratio

Figure 6.7 shows user average waiting time and number of relocations as a function of vehicle-to-trip ratio. The values of each shared vehicle system performance indicators (i.e., average wait time and number of relocations) were computed from the mean value obtained from several simulation runs for a particular value of vehicle-to-trip ratio. It is obvious that the effect of vehicle-to-trip ratio on wait time and number of relocation is significant at lower values and diminishes at 10.5. Therefore for the demand considered in this study, the best/optimum design value of vehicle-to-trip ratio is 10.5 percent. This suggests that to keep the user wait time and number of relocations at a minimum, about 11 minutes and 30 relocations, respectively for this system, 10.5 vehicles are needed to serve 100 trips for a daily total demand of 427 trips with a parking-to-vehicle ratio of 2:1. 
In this case, the operation period was 9 hour. The numerical results of the analysis are shown in Table 6.8 below.

Table 6.8 Analysis of vehicle-to-trip ratio for a 5-station SVS system

\begin{tabular}{|c|c|c|c|c|c|c|c|c|}
\hline $\begin{array}{c}\text { Total } \\
\text { Demand }\end{array}$ & $\begin{array}{c}\text { Veh/Trip } \\
\text { Ratio } \\
(\%)\end{array}$ & $\begin{array}{c}\text { Sleet } \\
\text { Size }\end{array}$ & $\begin{array}{c}\text { Trips } \\
\text { Served } \\
\text { (Vehicle) }\end{array}$ & $\begin{array}{c}\text { Trip } \\
\text { Served } \\
\text { (Total) }\end{array}$ & $\begin{array}{c}\text { Avg. } \\
\text { Service } \\
\text { Time } \\
(\mathrm{min})\end{array}$ & $\begin{array}{c}\text { Avg. } \\
\text { Wait } \\
\text { Time } \\
(\mathrm{min})\end{array}$ & $\begin{array}{c}\text { Queue } \\
\text { Length } \\
\text { (trips) }\end{array}$ & Number of \\
\hline 427 & 3.5 & 15 & 227 & 53.2 & 14.0 & 37.8 & 27.1 & 33 \\
\hline 427 & 4.7 & 20 & 300 & 70.3 & 12.8 & 30.3 & 23.7 & 48 \\
\hline 427 & 5.9 & 25 & 310 & 72.6 & 12.3 & 27.7 & 22.0 & 42 \\
\hline 427 & 7.0 & 30 & 350 & 82.0 & 11.5 & 23.9 & 19.4 & 43 \\
\hline 427 & 8.2 & 35 & 352 & 82.4 & 11.5 & 18.5 & 18.9 & 45 \\
\hline 427 & 9.4 & 40 & 396 & 92.7 & 10.6 & 16.5 & 16.5 & 34 \\
\hline 427 & 10.5 & 45 & 409 & 95.8 & 10.4 & 11.3 & 15.9 & 29 \\
\hline 427 & 11.7 & 50 & 407 & 95.3 & 10.7 & 11.2 & 15.2 & 27 \\
\hline
\end{tabular}




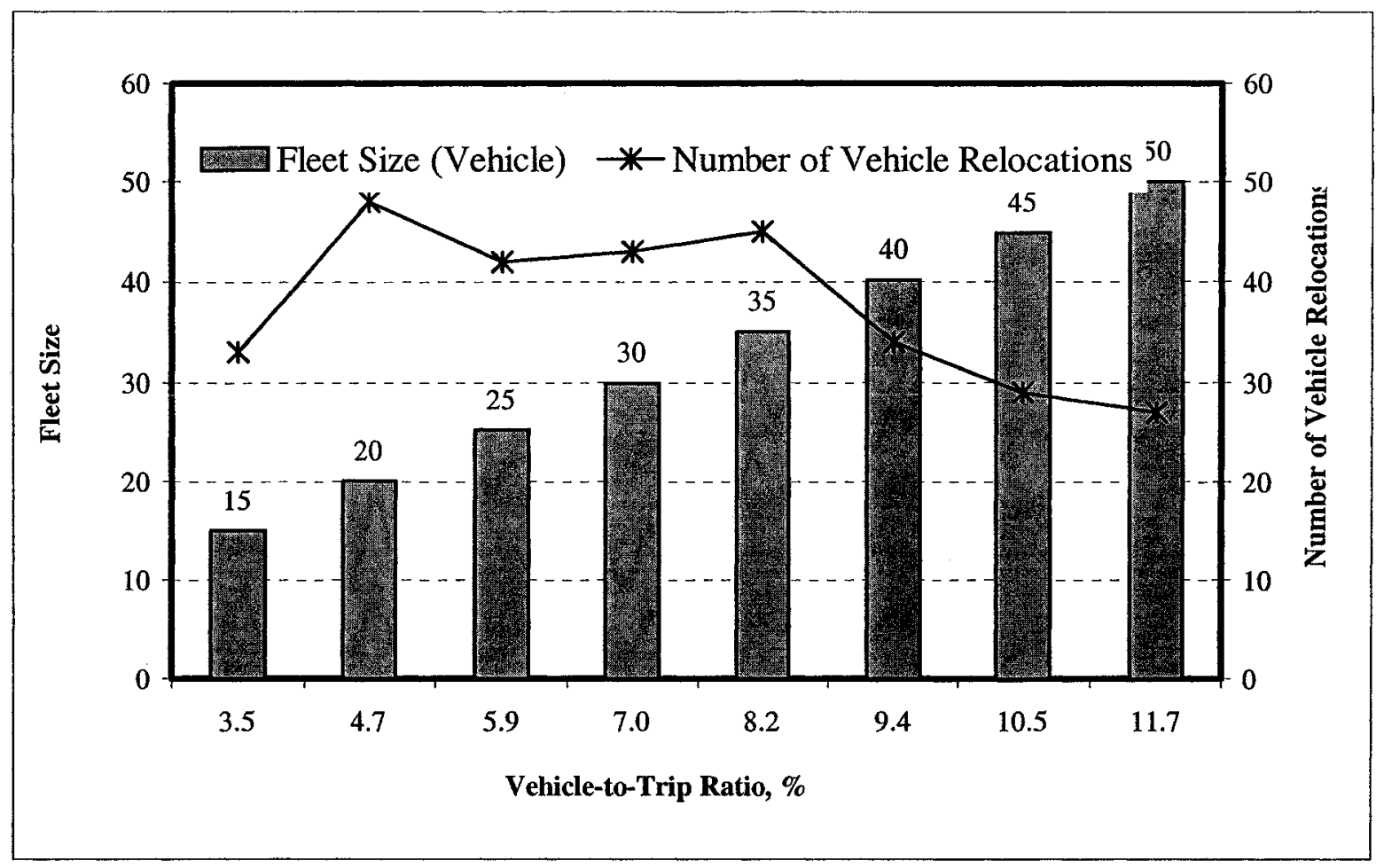

Figure 6.8 Vehicle fleet size and number of relocations as a function of vehicle-totrip ratio

Figure 6.8 illustrates the relationships of fleet size, and number of relocations as a function of vehicle-to-trip ratio. For vehicle-to-trip ratio of 3.5\%, the size of fleet is 15 . At this point, the observed number of relocations is 33 . With the increase of vehicle-tripratio, up to 8.2 percent, the number of relocations generally increases. This explains the attribute that at lower vehicle-to-trip ratio, fewer vehicles are available to relocate. At higher vehicle-trip ratio, above $8.2 \%$, more vehicles are available and hence the number of relocations increases. At values higher than 8.2 percent number of relocations decreases and reaches its best level/value at vehicle-to-trip ratio of 10.5 percent and is 
about 30 relocations. A typical simulation model output on vehicle relocations is given in

Table 6.9.

Table 6.9 Sample simulation model relocation activity output

\begin{tabular}{|c|c|c|c|}
\hline $\begin{array}{l}\text { Relocation } \\
\text { Number }\end{array}$ & $\begin{array}{l}\text { Source } \\
\text { Station }\end{array}$ & $\begin{array}{c}\text { Destination } \\
\text { Station }\end{array}$ & $\begin{array}{l}\text { Car } \\
\text { ID }\end{array}$ \\
\hline 1 & 5 & 3 & 31 \\
\hline 2 & 3 & 2 & 39 \\
\hline 3 & 2 & 3 & 38 \\
\hline 4 & 2 & 4 & 2 \\
\hline 5 & 1 & 5 & 29 \\
\hline 6 & 3 & 2 & 3 \\
\hline 7 & 2 & 3 & 29 \\
\hline 8 & 1 & 4 & 38 \\
\hline 9 & 2 & 5 & 31 \\
\hline 10 & 3 & 1 & 5 \\
\hline 11 & 5 & 2 & 9 \\
\hline 12 & 1 & 3 & 2 \\
\hline 13 & 3 & 1 & 7 \\
\hline 14 & 3 & 2 & 37 \\
\hline 15 & 2 & 3 & 4 \\
\hline 16 & 4 & 1 & 9 \\
\hline 17 & 2 & 5 & 22 \\
\hline 18 & 3 & 2 & 39 \\
\hline 19 & 2 & 1 & 44 \\
\hline 20 & 2 & 3 & 11 \\
\hline 21 & 2 & 5 & 26 \\
\hline 22 & 5 & 1 & 37 \\
\hline 23 & 3 & 1 & 42 \\
\hline 24 & 5 & 1 & 11 \\
\hline 25 & 4 & 1 & 21 \\
\hline 26 & 5 & 1 & 31 \\
\hline 27 & 5 & 3 & 17 \\
\hline 28 & 3 & 4 & 17 \\
\hline 29 & 4 & 1 & 26 \\
\hline 30 & 4 & 1 & 43 \\
\hline
\end{tabular}


In Table 6.9, the source station is the station from where the relocation is to be done and destination station is the station where the vehicle is to be relocated. Vehicle ID is a specific vehicle identification number in the simulation that is never changed in a particular simulation run.

\subsubsection{Analysis of Trips Served and Queue Length}

The SVS system capacity is a function of the total number of available vehicles or fleet size. The optimum fleet size is a function of vehicle-to-trip ratio, the customer tolerance for waiting or the maximum wait time, the acceptable policy on relocations per operation period. Studies by Barth and Todd (1999) and Cousins (1998) explained this behaviour. For economic viability of SVS, optimal fleet size is an important factor.

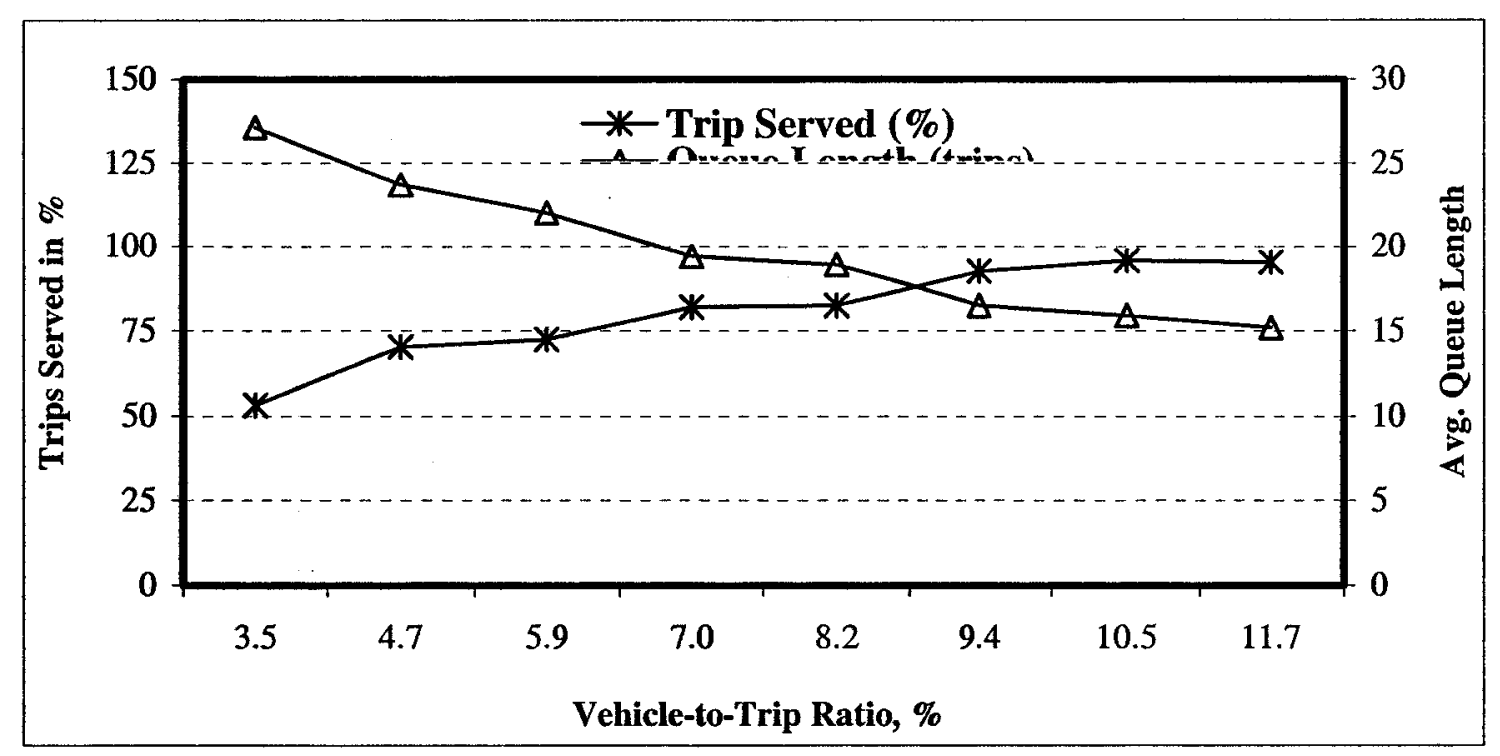

Figure 6.9 Trips served and queue length as a function of vehicle-to-trip ratio

Figure 6.9 illustrates the effect of vehicle-to-trip ratio on the capacity of SVS system to serve the demand and associated queue length. For the case study area, it is found that 
at vehicle-to-trip ratio of 10.5 percent, the system is capable to serve about $96 \%$ of the demand while keeping customer average wait time at around 11 minutes and average queue length for the 5-station system is 15.9 trips for a 9-hour operation period for a given day. From Figure 6.9 it is clear that the capacity of SVS system has a positive nonlinear relationship with vehicle-to-trip ratio. The system capacity rises with increasing value of vehicle-to-trip ratio. The rate of increase is higher at the lower value and diminishes at vehicle-to-trip ratio of 10.5 . The numerical analysis results are shown in Table 6.11.

The average queue length is an important measure of performance (MOP) for SVS since it directly affects the customers. For an efficient operation of a system, this MOP indicator should be kept low. From Figure 6.9 it is obvious that queue length is nonlinearly decreasing with increasing values of vehicle-to-trip ratio. Although much of the reduction in queue length is gained at vehicle-to-trip ratio of 10.5 , it is still reducing with the increasing value of vehicle-to-trip ratio but at a decreasing rate. The average queue length of 15.9 was found at vehicle-to-trip of 10.5 percent for the case study SVS system. Therefore, the vehicle-to-trip ratio of 10.5 is considered as the best design value for the case study system with respect to queue length.

\subsubsection{Analysis for Parking-to-Vehicle Ratio for a 5-Station SVS System}

It is believed that shared vehicle systems can reduce the total of number of vehicles needed to serve a travel demand market and hence the parking demand. In this research study, number of parking stall/slot was considered as a variable. Under scenario-1 while 
keeping all other variables constant, parking-to-vehicle ratio was varied and system operations were simulated. Various selected measures of performance indicator values were collected and analyzed. Analysis results are shown in Table 6.10 and Figure 6.10.

Table 6.10 Analysis of parking-to-vehicle ratio for a 5-station SVS

\begin{tabular}{|c|c|c|c|c|c|c|c|c|}
\hline $\begin{array}{c}\text { Total } \\
\text { Demand } \\
\text { (Trips) }\end{array}$ & $\begin{array}{c}\text { Parking- } \\
\text { to- } \\
\text { Vehicle } \\
\text { Ratio }\end{array}$ & $\begin{array}{c}\text { Parking } \\
\text { slots per }\end{array}$ & $\begin{array}{c}\text { Total } \\
\text { Trips } \\
\text { Served } \\
\text { (Trips) }\end{array}$ & $\begin{array}{c}\text { Trip } \\
\text { Served } \\
(\%)\end{array}$ & $\begin{array}{c}\text { Avg. } \\
\text { Service } \\
\text { Time } \\
\text { (min) }\end{array}$ & $\begin{array}{c}\text { Avg. } \\
\text { Wait } \\
\text { Time } \\
\text { (min) }\end{array}$ & $\begin{array}{c}\text { Queue } \\
\text { Length } \\
\text { (trips) }\end{array}$ & $\begin{array}{c}\text { Number of } \\
\text { Relocation } \\
\text { s }\end{array}$ \\
\hline 427 & 1.0 & 9 & 387 & 90.6 & 10.8 & 41.8 & 17.1 & 79 \\
\hline 427 & 1.2 & 11 & 385 & 90.2 & 10.7 & 32.3 & 16.7 & 55 \\
\hline 427 & 1.4 & 13 & 391 & 91.6 & 10.5 & 25.7 & 16.1 & 45 \\
\hline 427 & 1.8 & 16 & 392 & 91.8 & 10.4 & 17.9 & 16.6 & 31 \\
\hline 427 & 2.0 & 18 & 406 & 95.1 & 10.4 & 11.5 & 15.9 & 29 \\
\hline 427 & 2.2 & 20 & 390 & 91.3 & 10.7 & 11.4 & 17.1 & 37 \\
\hline
\end{tabular}

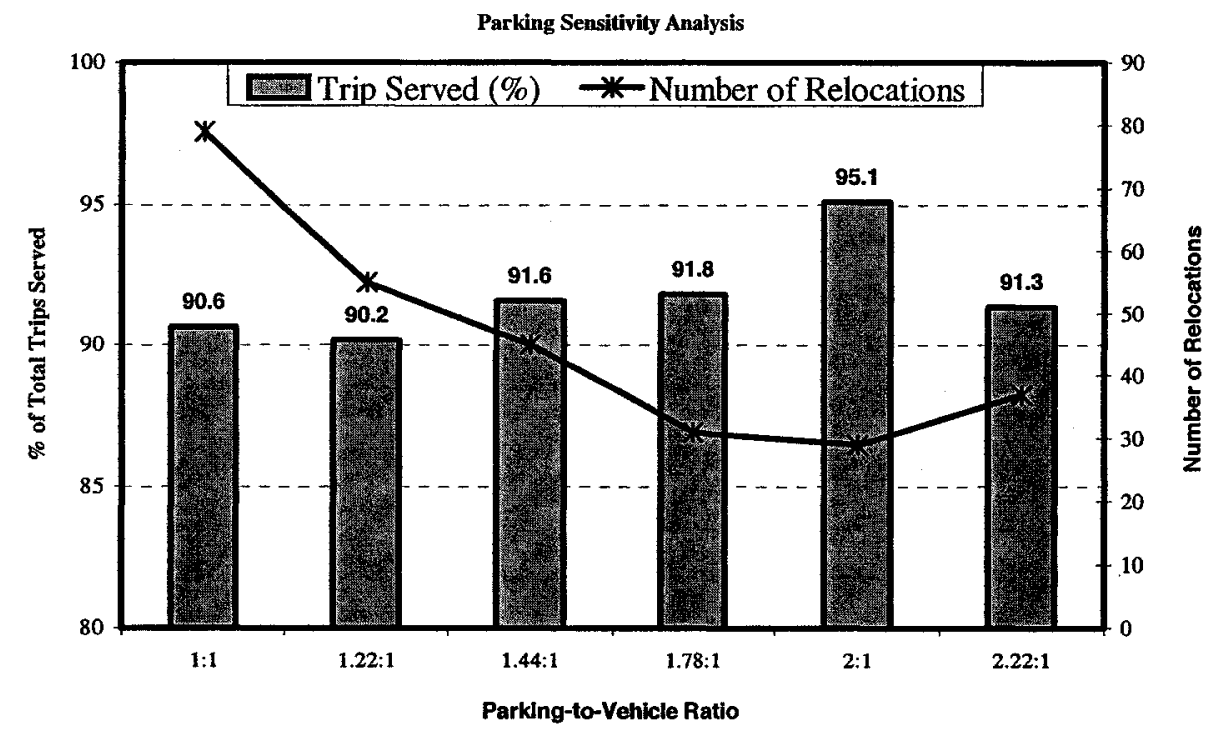

Figure 6.10 Number of relocations and trips served in percent as a function of Parking-to-Vehicle Ratio 
From Table 6.10 and Figure 6.10 it is obvious that shared vehicle system performance is highly sensitive to the availability of parking slots or parking supply. Major MOP indicators; average customer wait time, number of relocations, queue length, and system capacity (as \% of trip served), all are a direct function of parking-to-vehicle ratio. Figure 6.10 explains the fact that the SVS capacity to serve demand increases with the value of parking-to-vehicle ratio. Analysis results show that the system performance is optimized at parking-to-vehicle ratio of $2: 1$ or 2.0. It is also clear from Figure 6.10 that the number of relocations decreases with increase in parking-to-vehicle ratio and optimized at a ratio of $2: 1$.

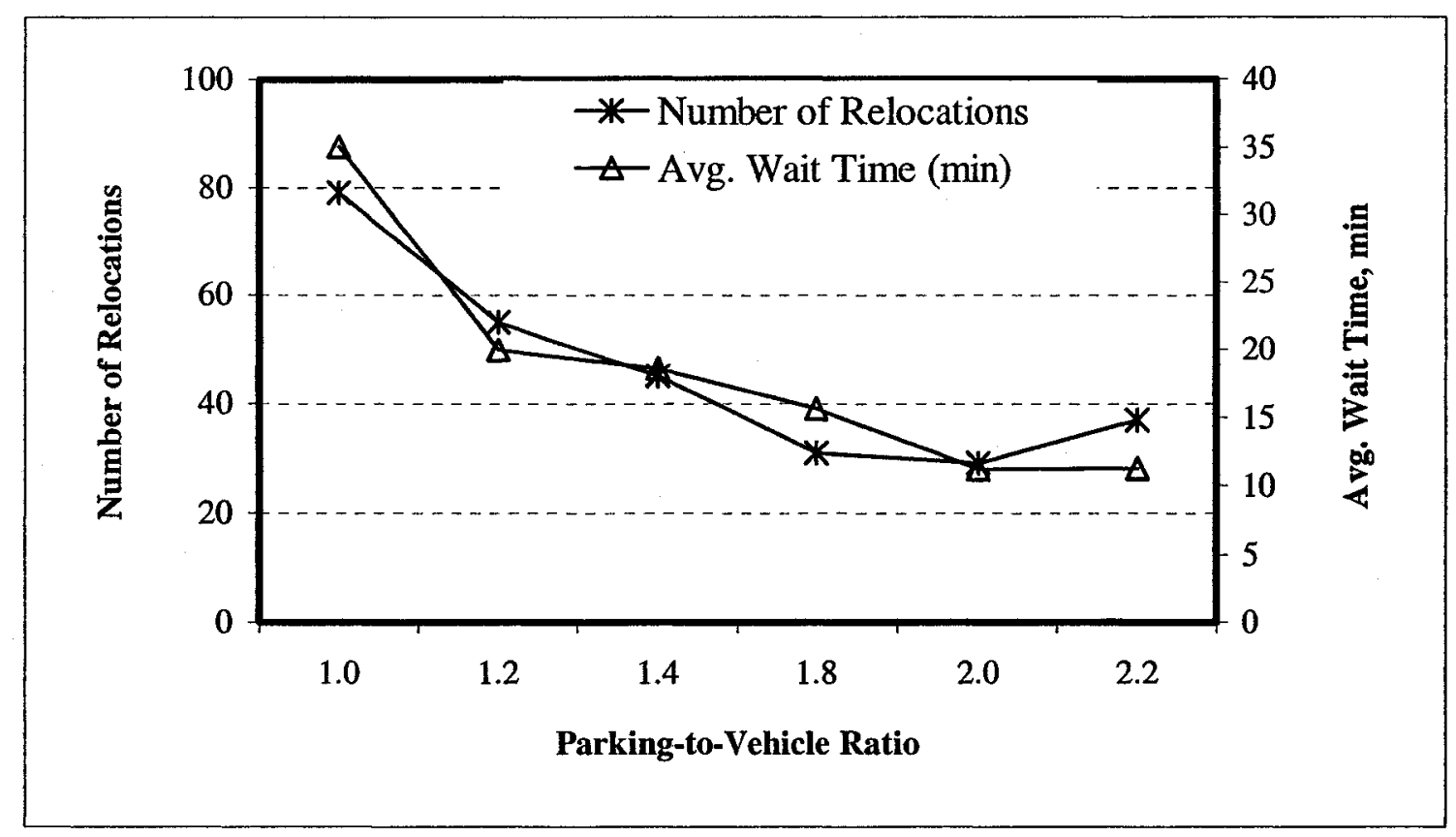

Figure 6.11 Number of relocations and user average waiting time as a function of parking-to-vehicle ratio 
Similar results are observed for the MOP customer average waiting time and shown in Table 6.10 and Figure 6.11. These results prove the fact that excessive parking supply does not increase the system capacity and improve performance. This finding could help to design parking supply optimally for a particular SVS system.

\subsubsection{SVS Capacity Sensitivity with Fleet Size}

The optimal fleet size is a function of design vehicle-to-trip ratio, the total demand to be served, the system operation criteria including maximum allowable user wait time, maximum number of relocations, and allowable average queue length. One of the major objectives in modelling SVS is to determine the optimum fleet size, with appropriate vehicle mix, to meet a given travel demand while keeping other system performance indicators within the acceptable limit. Fleet size, number of vehicles and mix, determines the system capacity in term of trips that could be served at acceptable level of service (LOS). 


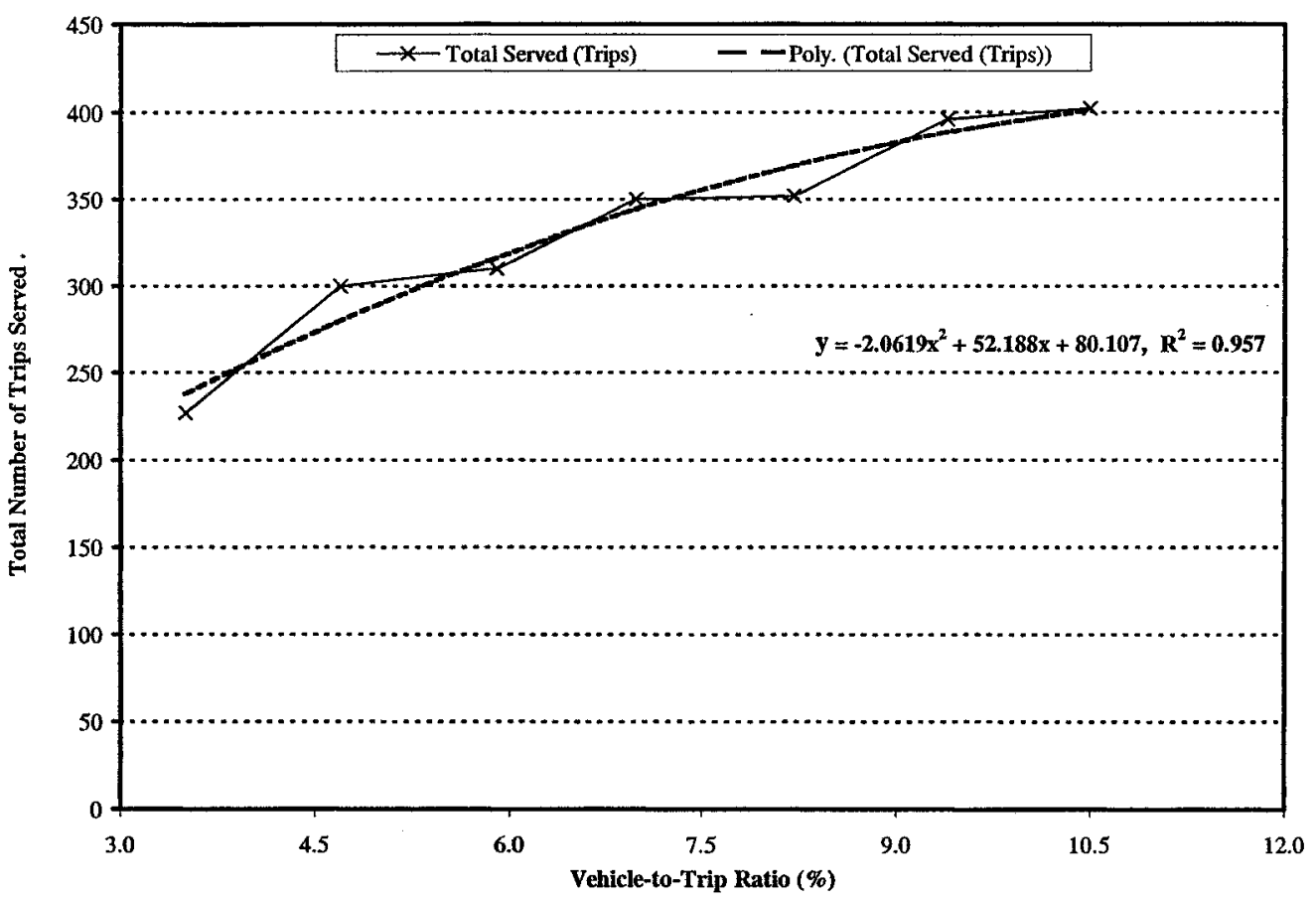

Figure 6.12 Relationship of total trips served and vehicle-to-trip ratio

Figure 6.12 illustrates the relationship between vehicle-to-trip ratio and the total number of trips served out of 427 , the travel demand of the case study area, CFB Ottawa. A nonlinear regression line is fitted to the plot of number of trips served versus vehicleto-trip ratio and shown as dotted line. The obtained nonlinear model is, $y=-2.062 x^{2}+$ $52.188 x+80.107$

where

$$
\begin{aligned}
& y=\text { estimated number of trips served, and } \\
& x=\text { vehicle-to-trip ratio in percent }
\end{aligned}
$$


The coefficient of determination $R^{2}$ value was 0.957 and shown on the graph. This statistic implies that the fitted line is 'good' to explain 95.7 percent of the variance in the independent variable data.

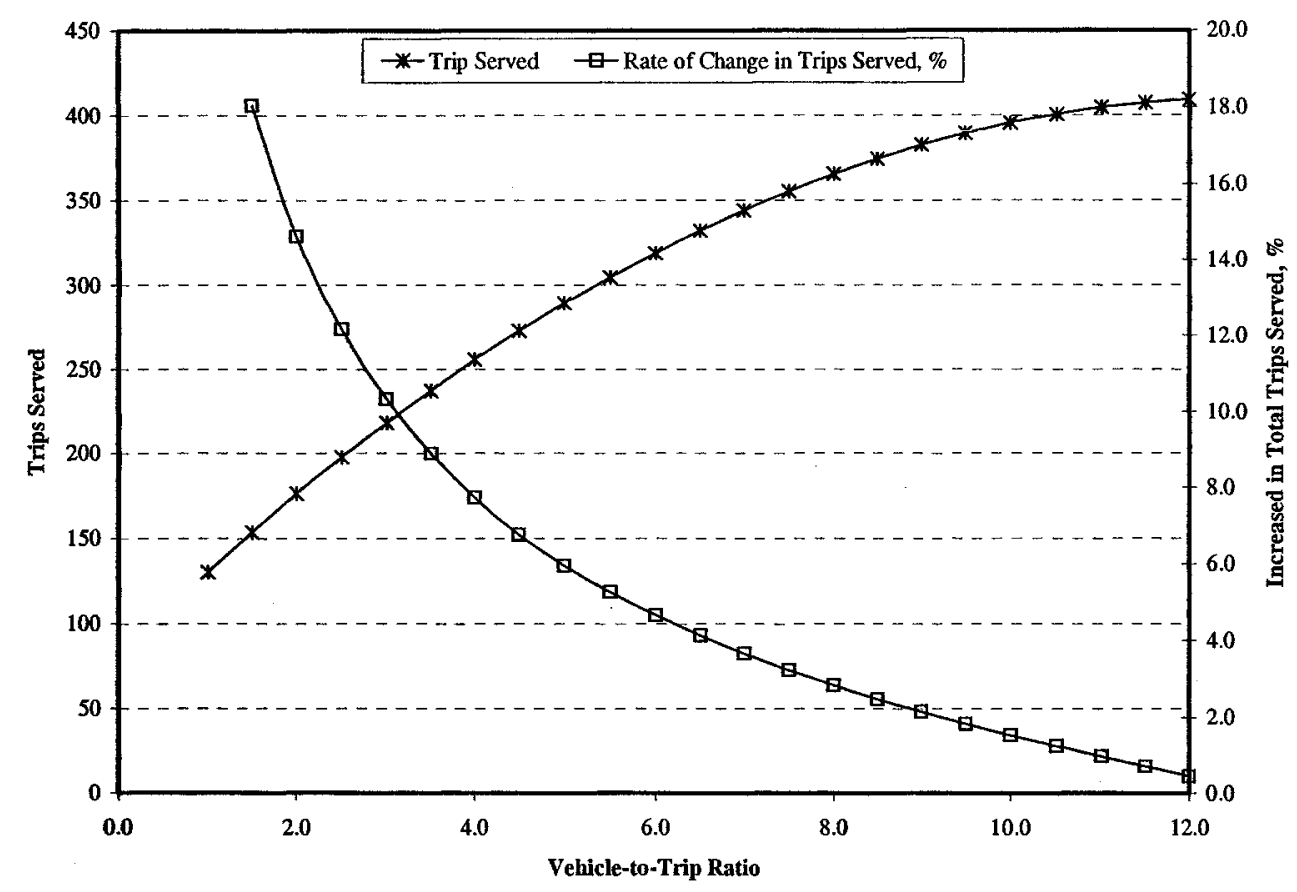

Figure 6.13 Effect of vehicle-to-trip ratio on system capacity

Using the fitted nonlinear model, developed in the previous section, an analysis was performed on the sensitivity of SVS system capacity to vehicle-to-trip ratio. The analysis result is plotted in Figure 6.13. This figure (Figure 6.13) illustrates both the estimated number of trips served at a particular value of vehicle-to-trip ratio and the capacity gain, in percent, with an increment in vehicle-to-trip ratio. It is clear that the capacity increases with rising vehicle-to-trip ratio and shows a diminishing trend. It is clear that the increase in capacity gain as a result of rising vehicle-to-trip ratio following a diminishing return phenomenon. The rate of capacity gain beyond vehicle-to-trip ratio of $10.5 \%$ becomes 
very low. The model calculated values of estimated trips served and capacity gains in percent for different vehicle-to-trip ratios are shown in Table 6.11.

Table 6.11 SVS capacity gains with respect to vehicle-to-trip ratio

\begin{tabular}{|c|c|c|}
\hline Vehicle/Trip Ratio, \% & $\begin{array}{c}\text { Estimated Number of Trips } \\
\text { Served } \\
\end{array}$ & \begin{tabular}{|c|} 
Capacity Gain w.r.t. Previous \\
vehicle-to-trip ratio, \% \\
\end{tabular} \\
\hline 1.0 & 130 & \\
\hline 1.5 & 154 & 18.1 \\
\hline 2.0 & 176 & 14.6 \\
\hline 2.5 & 198 & 12.2 \\
\hline 3.0 & 218 & 10.3 \\
\hline 3.5 & 238 & 8.9 \\
\hline 4.0 & 256 & 7.7 \\
\hline 4.5 & 273 & 6.8 \\
\hline 5.0 & 289 & 6.0 \\
\hline 5.5 & 305 & 5.3 \\
\hline 6.0 & 319 & 4.7 \\
\hline 6.5 & 332 & 4.1 \\
\hline 7.0 & 344 & 3.7 \\
\hline 7.5 & 356 & 3.2 \\
\hline 8.0 & 366 & 2.8 \\
\hline 8.5 & 375 & 2.5 \\
\hline 9.0 & 383 & 2.1 \\
\hline 9.5 & 390 & 1.8 \\
\hline 10.0 & 396 & 1.5 \\
\hline 10.5 & 401 & 1.3 \\
\hline 11.0 & 405 & 1.0 \\
\hline 11.5 & 408 & 0.7 \\
\hline 12.0 & 409 & 0.5 \\
\hline
\end{tabular}




\subsubsection{Response of the System to Miscellaneous Variables}

\subsection{Trip Travel Time}

Among previous modelling efforts, Barth and Todd (1999) at University of California, Riverside, analyzed the effect of distance between stations on SVS system's performance. Barth and Todd computed the travel time based on distance between stations and congestion related friction factor (ff). Urban transportation networks are subject to variable demand throughout the daily operation period. Hence, travel time is a function of distance between origins and destinations, real time level of traffic congestion, and other environmental factors. Therefore, it is logical to analyze the effect of variation in travel time on the system's performance indicators for a particular system setting. This thesis research effort modelled travel time with Bayesian probabilistic technique, under scenario-3, considering uncertainty resulting from traffic congestion, weather, and other factors.

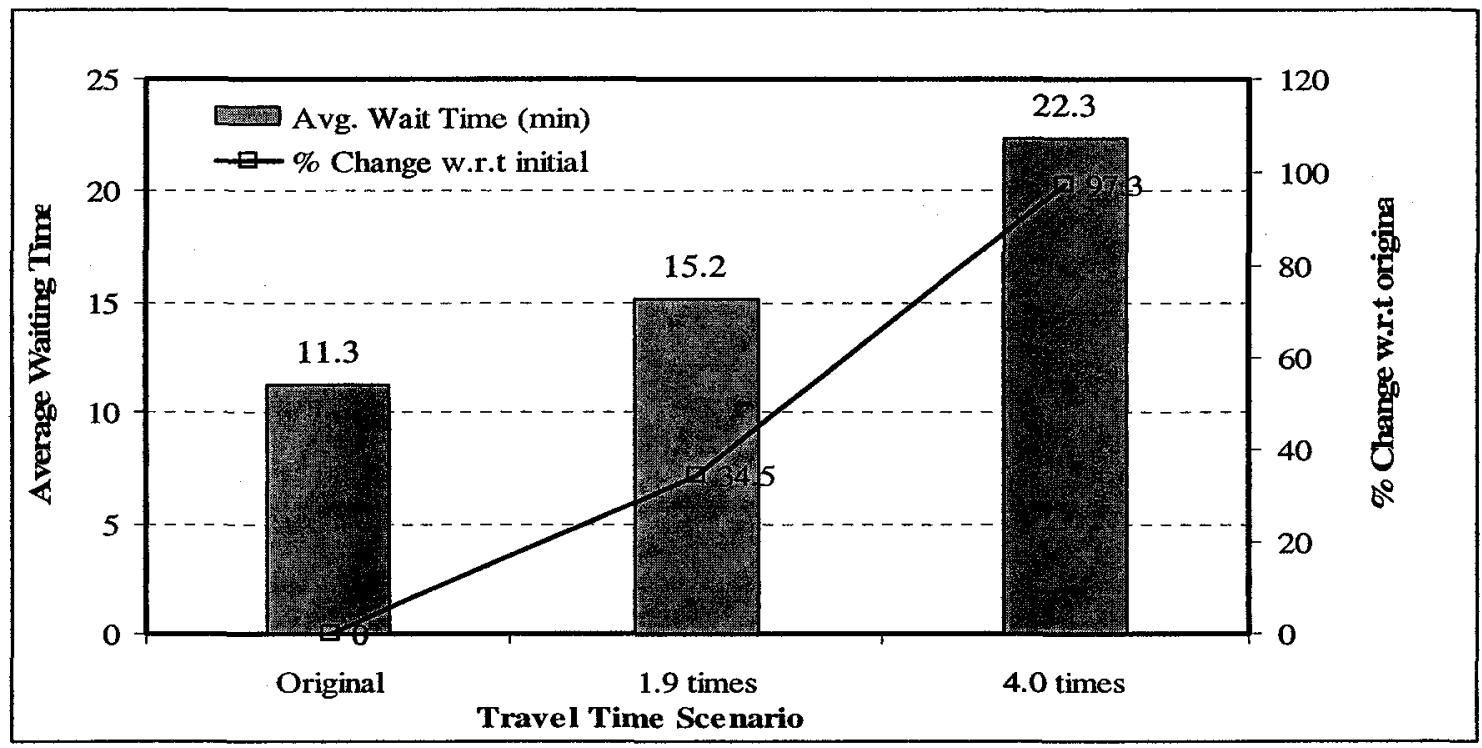

Figure 6.14 Effect of travel time on user wait time 
To quantify the effect of longer travel time, three scenarios were tested. These are original or base travel times, 1.9 times the base, and 4.0 times the base travel times. Figure 6.14 illustrates the effect of travel time on user average wait time. It is obvious that the user wait time is not affected significantly, at $10 \%$ level of significance, until the travel times become a factor 1.50 times than the base travel times of the modelled system.

Figure 6.15 shows the effect of travel time on the number of relocations needed to keep the wait time minimum in three different travel time scenarios. It is clear that the system is insensitive to travel time until the travel time is about 2 times the original value at 10 percent level of significance. The system performance, with respect to number of vehicle relocations, may be drastically affected when travel times would become 1.75 times the original modelled values. Figure 6.16 illustrates the effect of increased travel time on number of trips served. The SVS system performance with respect to trips served is not affected significantly, at 5 percent level of significance, until the travel times between stations becomes 2.0 times longer than the base travel time values. 


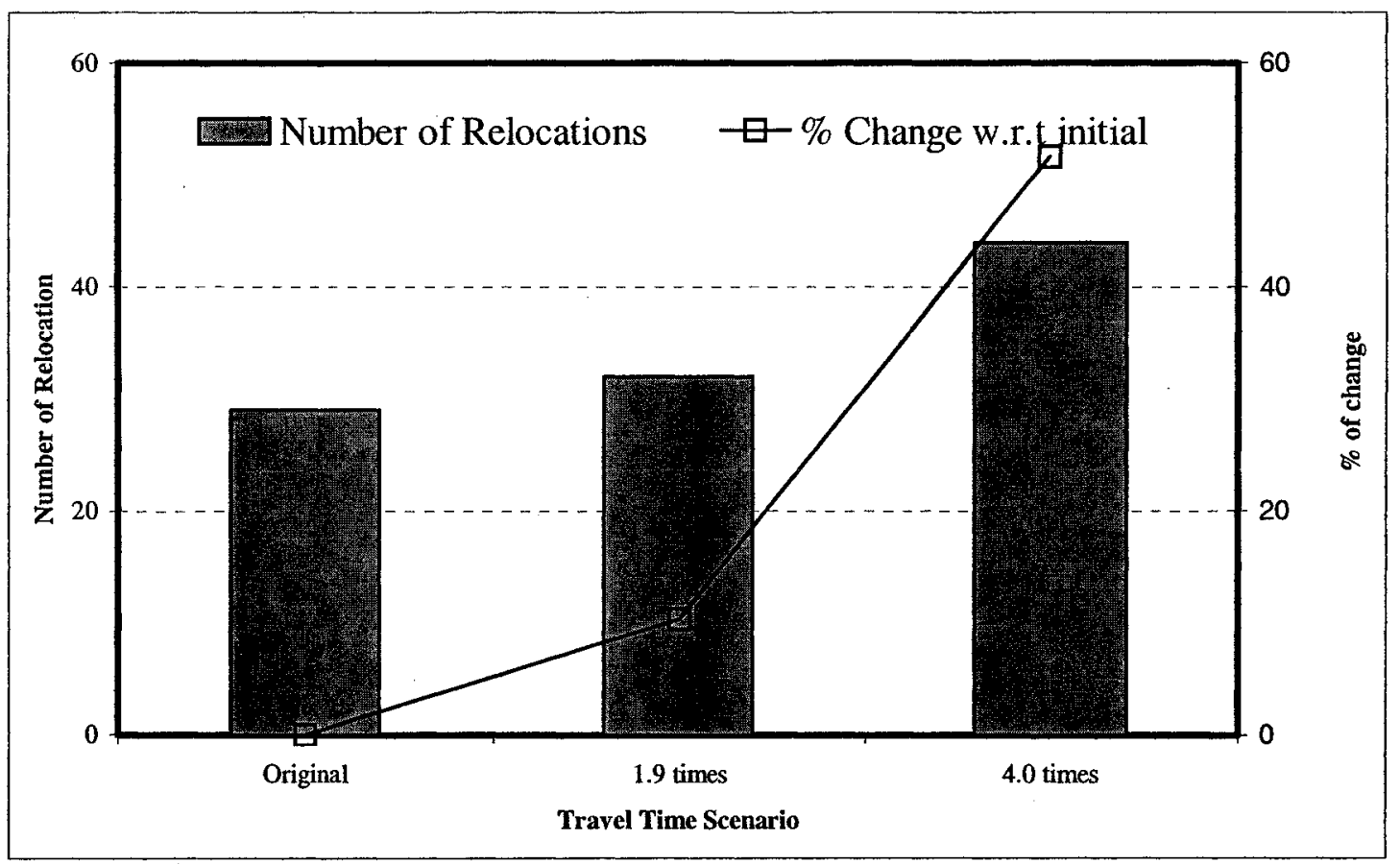

Figure 6.15 Effect of Travel Time on Number of Relocations

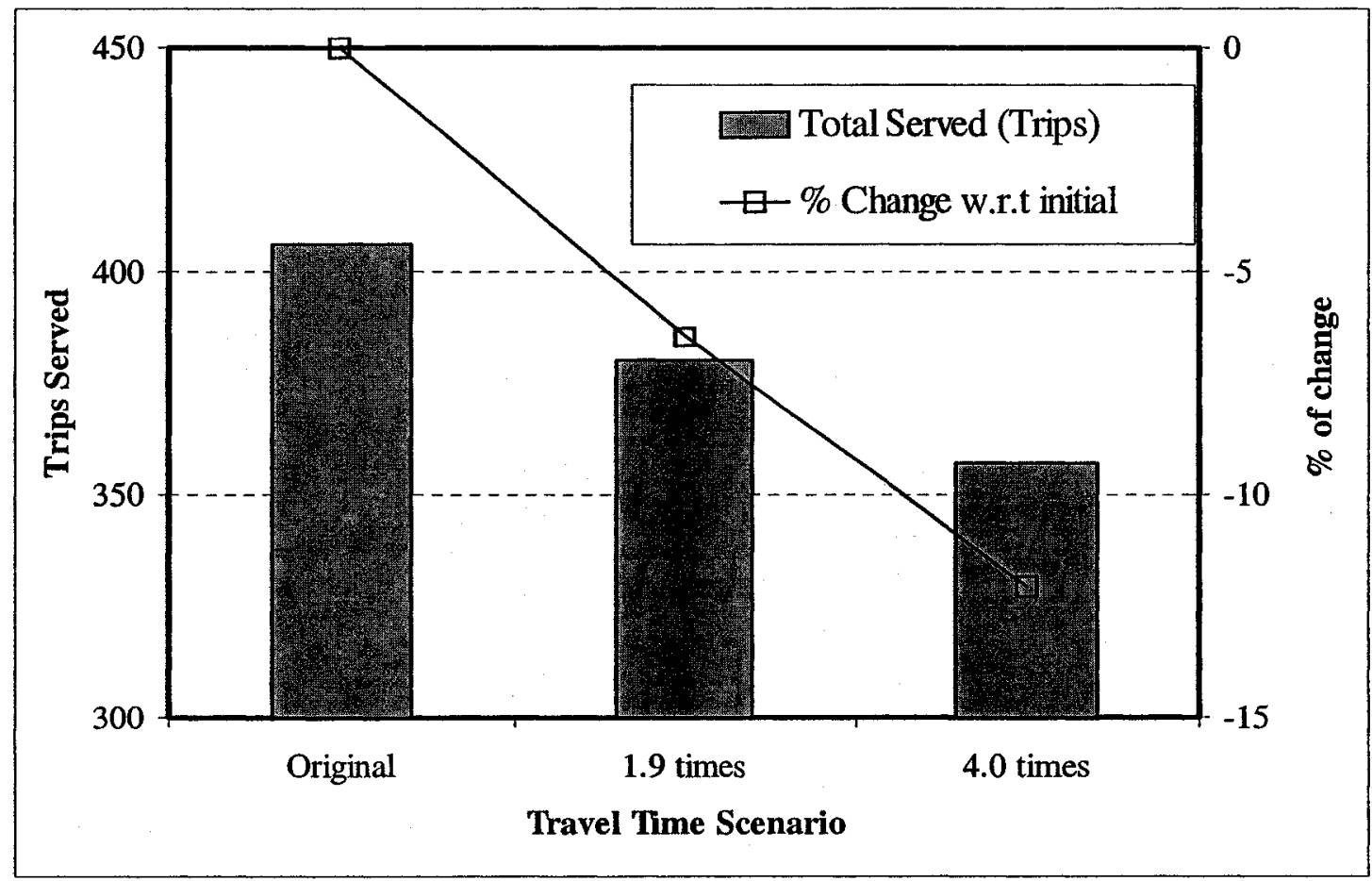

Figure 6.16 Effect of travel time on trips served 
From the above travel time sensitivity analysis it is obvious that SVS system operation is not affected significantly, at significance level of $5 \%$ or $10 \%$, until the travel become a factor of at least 1.5 times the original/base values. A combined plot of the major MOP for different travel time scenarios is shown in Figure 6.17.

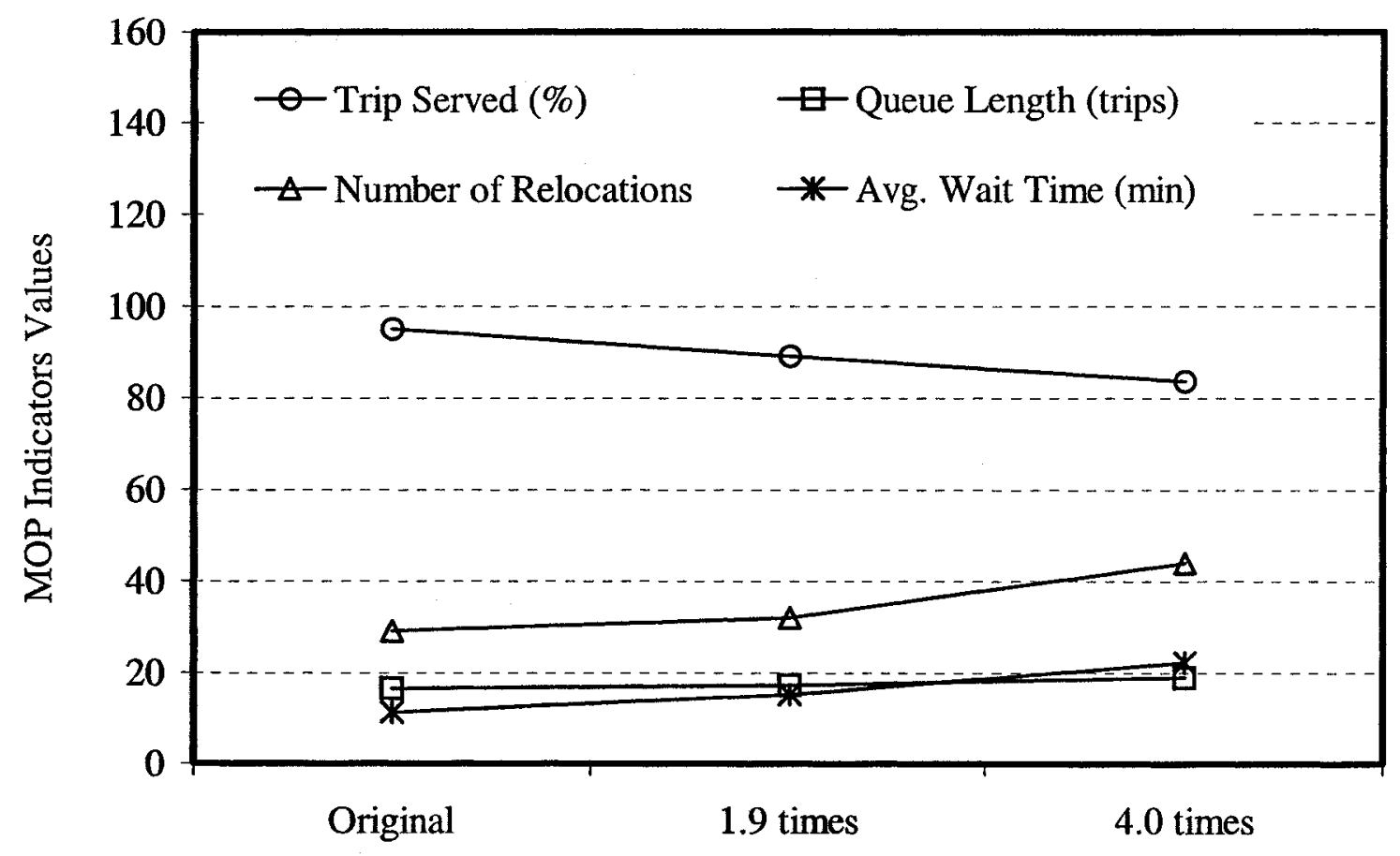

Travel Time Scenarios

Figure 6.17 Combined plot of trips served, queue length, number of relocations, and user average wait time for different travel time scenarios 


\subsection{Number of Stations}

In the case study, five stations were selected, based on the CFB Ottawa site travel demand reported by Miller (1982), but modified to some extent. The selected 5-station system was then modelled and analyzed. Additional simulation experiments were also carried out, with decreased (fewer) and increased (greater) number of stations to check SVS response. During modification, the system was scaled linearly with respect to number of stations and the travel demand. This means that the total travel demand was increased linearly (proportionately) with increase in number of stations. The vehicle-totrip and parking-to-vehicle ratios were kept constant. The analysis result is shown in Figure 6.18.

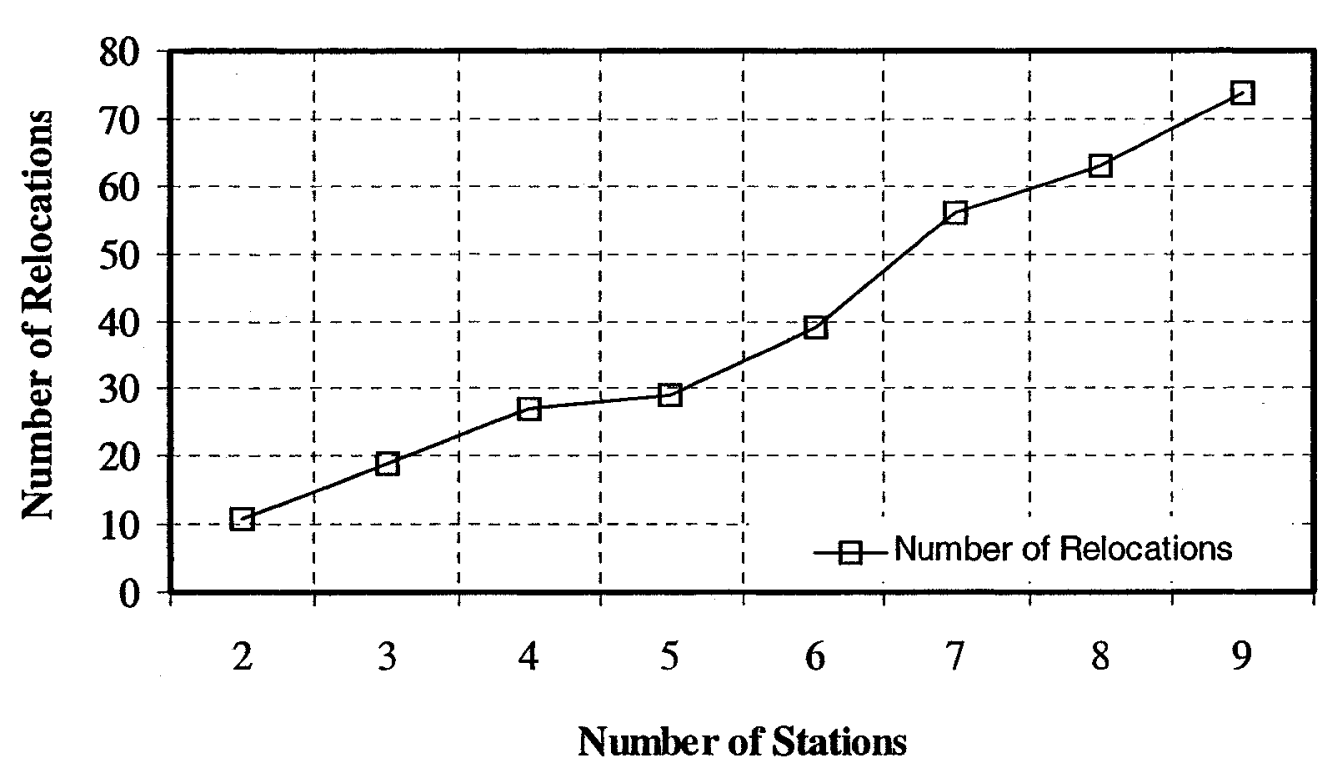

Figure 6.18 Effect of number of stations on number of relocations 
From Figure 6.18 it is evident that the number of relocations needed to keep the wait time minimum, at better/optimum vehicle-to-trip and parking-to-vehicle ratios, increases linearly with the number of stations in the SVS system. This result suggests that the design of SVS system should select optimum number of stations. This optimal number of station may vary from market to market or case to case (residential, commercial downtown, commuting, etc) and depends on the allowable maximum number of relocations and wait time. This thesis research found that SVS systems with maximum of 5 to 7 stations would be optimal system with respect to number of relocations (with range 40 to 60 relocations on average), while keeping customer average wait time within acceptable limit, in this case about 11 minutes.

\subsection{Higher Travel Demand}

The success of any shared vehicle system is dependent on the reliability to get a vehicle when a customer wants to use it. At higher travel demand level, the customer demand could be matched more efficiently with available fleet of vehicles having smaller vehicle-to-trip ratio (Cousins, 1998). This attribute is known as scale efficiency and is characterized by primary independent variable vehicle-to-trip ratio. To examine this characteristic of shared vehicle systems (SVS), simulation experiments were performed with higher daily travel demands, namely 1.5 and 2.0 times the original modelled demand. The effects of higher travel demand on the system performance indicators or MOPs were evaluated. These MOPs were then grouped and analyzed. Selected results are shown in Figures 6.19 to 6.21 . 


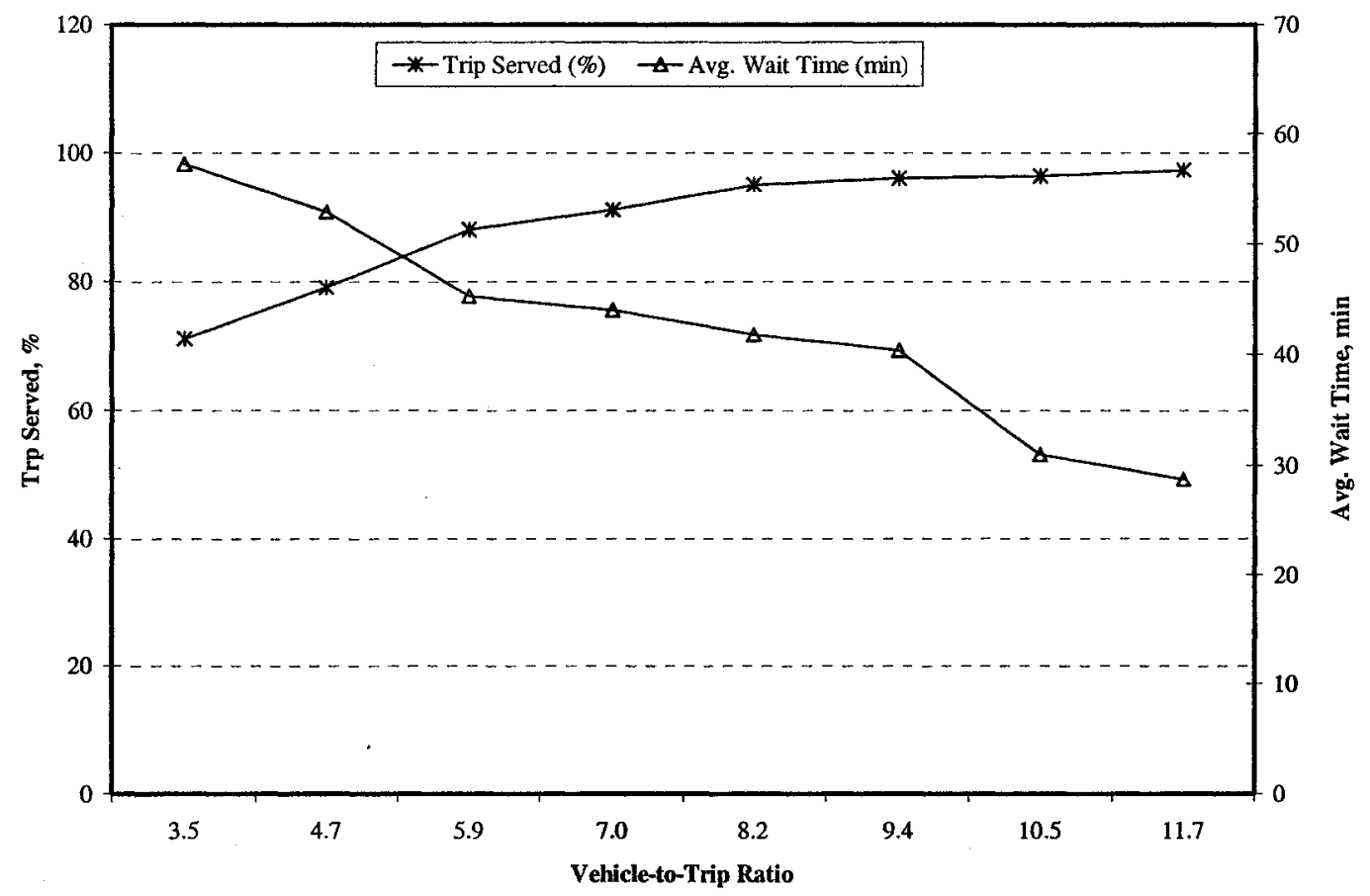

Figure 6.19 Trip served and customer average wait time as a function of vehicle-totrip ratio at 1.5 times of original modelled demand

From Figures 6.19 and 6.20 it is clear that the general shape of the number of trips served, user average wait time, and number of relocations curves as a function of vehicleto-trip ratio are similar to those for the original modelled demand. The analyses carried out on customer average wait time, number of relocations, and trips served against vehicle-to-trip ratio using higher travel demand shown in Table 6.12 prove the fact that the optimum vehicle-to-trip ratio is smaller at higher travel demand satisfying the same LOS. 


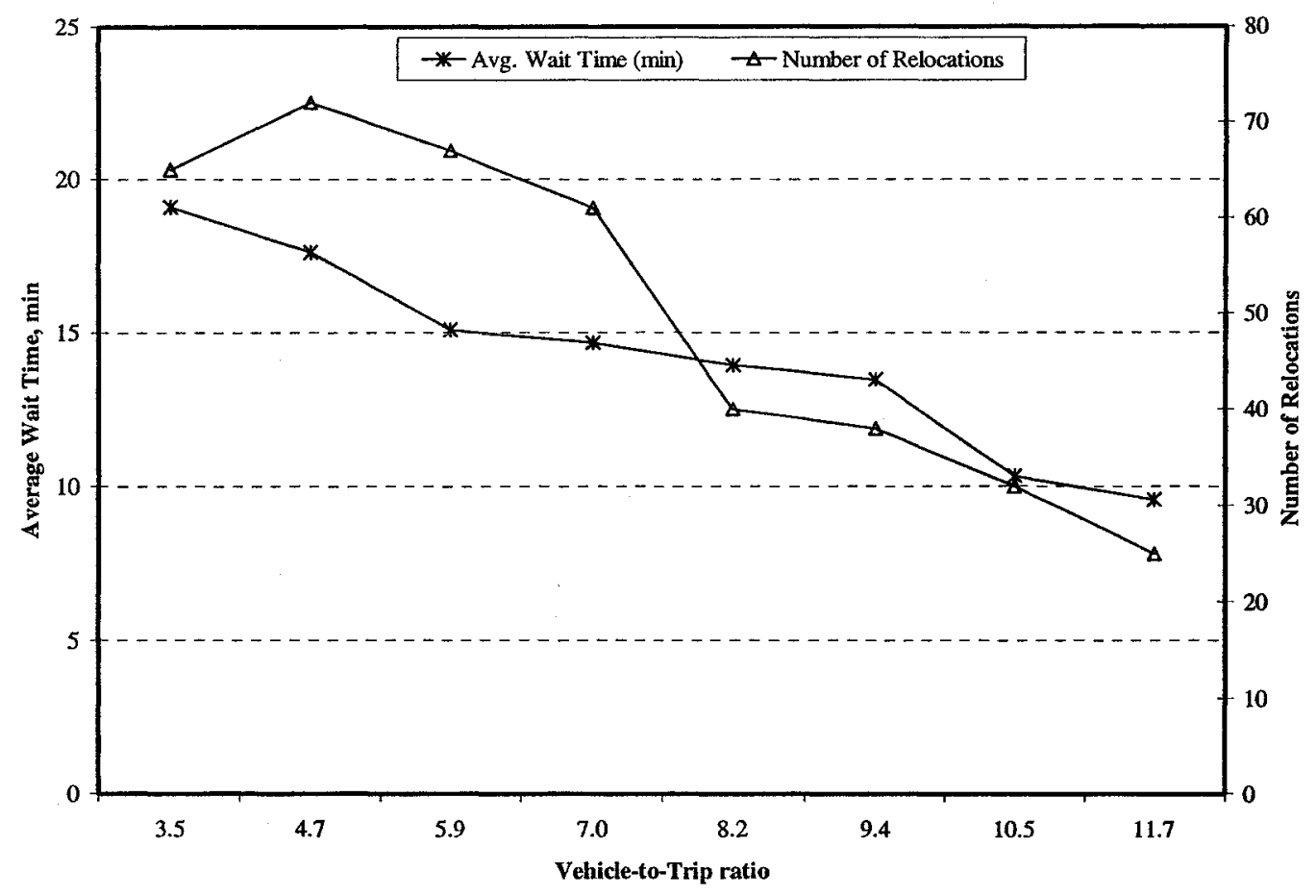

Figure 6.20 User wait time and number of relocations as a function of vehicle-to-trip ratio at demand 1.5 times of the original

Therefore, the total number of trips served is higher at higher travel demand for a certain value of vehicle-to-trip ratio and satisfying other MOPs. These findings confirm the results obtained by Barth and Todd (1999), and Cousins (1998). These results suggest that at vehicle-to-trip ratio $8.2 \%$, which is about 11 percent less than the value $(10.5 \%)$ obtained with original travel demand, same level of service (LOS) could be expected when the travel demand is 1.5 times the original demand in the case study. 
A 3-D (three dimensional) bar chart of these findings, at vehicle-to-trip ratio 10.5 percent and parking-to-vehicle ratio of 2:1, is shown in Figure 6.21.

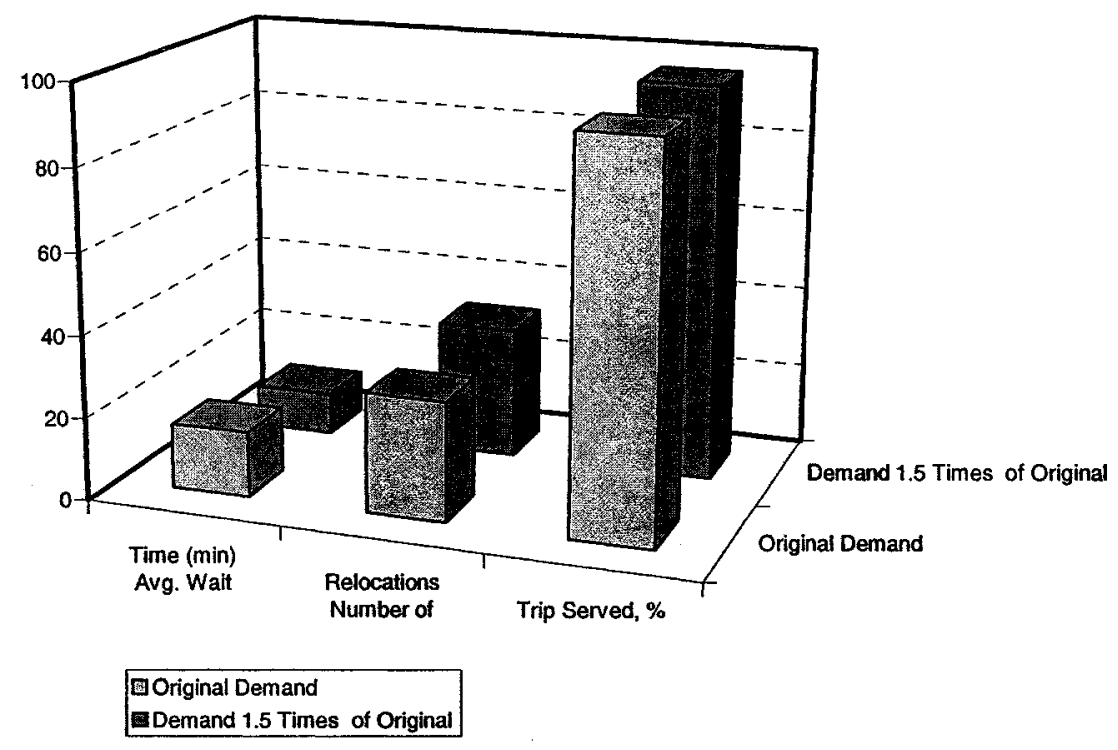

Figure 6.21 Comparison of trips served (\%), number of relocations, and user average wait time between original and 1.5 times the original travel demand

A comparison of the values of major MOPs at travel demand level of original, and 1.5 and 2.0 times of original demand is shown in Table 6.12. All of these analyses were based on scenario-1. The system was assumed to follow a modified Markov process and the customer interarrival times are exponentially distributed with a limit of $0 \leq t \leq \frac{1}{\lambda}+3 \sigma$. 
Table 6.12 Comparison of optimal values of user average waiting time, number of relocations, trip served (\%), and vehicle SOC for three demand scenarios

\begin{tabular}{|l|c|c|c|}
\hline \multicolumn{1}{|c|}{$\begin{array}{c}\text { Measure of } \\
\text { Performance }\end{array}$} & Original Demand & $\begin{array}{c}\text { Demand 1.5 Times } \\
\text { of Original }\end{array}$ & $\begin{array}{c}\text { Demand 2.0 Times } \\
\text { of Original }\end{array}$ \\
\hline $\begin{array}{l}\text { Optimum Vehicle-to- } \\
\text { trip ratio }\end{array}$ & 10.5 & 8.2 & 6.0 \\
\hline Avg. Wait Time, min & 11.3 & 13.9 & 17.2 \\
\hline $\begin{array}{l}\text { Number of Relocations } \\
\text { (trips) }\end{array}$ & 29.0 & 40.0 & 79.0 \\
\hline Trip Served in \% & 94.1 & 95.0 & 95.0 \\
\hline Avg. Vehicle SOC (\%) & 62.0 & 60.0 & 55.0 \\
\hline
\end{tabular}

Note: parking-to-vehicle ratio $=2: 1$

To examine the effect of higher travel demand on major shared vehicle system (SVS) performance indicators (i.e., user average wait time, number of relocations, total trips served), further analysis was performed. The values of the these performance indicators were collected for different values of the SVS system's primary independent variable vehicle-to-trip ratio at three level of travel demand. Each performance indicator's values at three demand levels for different values of vehicle-to-trip ratios were then analyzed. These results are shown in Tables 6.13 to 6.15 and Figures 6.22 to 6.24 . 
Table 6.13 Customer average wait time (min)

\begin{tabular}{|c|c|c|c|}
\hline $\begin{array}{c}\text { Vehicle-to-Trip } \\
\text { Ratio (\%) }\end{array}$ & $\begin{array}{c}\text { Avg. wait time (min) } \\
\text { at base demand }\end{array}$ & $\begin{array}{c}\text { Avg. wait time (min) } \\
\text { at 1.5 times base demand }\end{array}$ & $\begin{array}{c}\text { Avg. wait time (min) } \\
\text { 2.0 times base demand }\end{array}$ \\
\hline 3.5 & 37.81 & 28.7 & 25.0 \\
\hline 4.7 & 30.31 & 26.5 & 23.7 \\
\hline 5.9 & 27.74 & 22.7 & 17.2 \\
\hline 7.0 & 23.85 & 21.2 & 16.2 \\
\hline 8.2 & 18.54 & 16.6 & 14.5 \\
\hline 9.4 & 16.53 & 14.3 & 12.9 \\
\hline 10.5 & 11.29 & 12.4 & 12.8 \\
\hline 11.7 & 11.21 & 11.6 & 12.6 \\
\hline
\end{tabular}

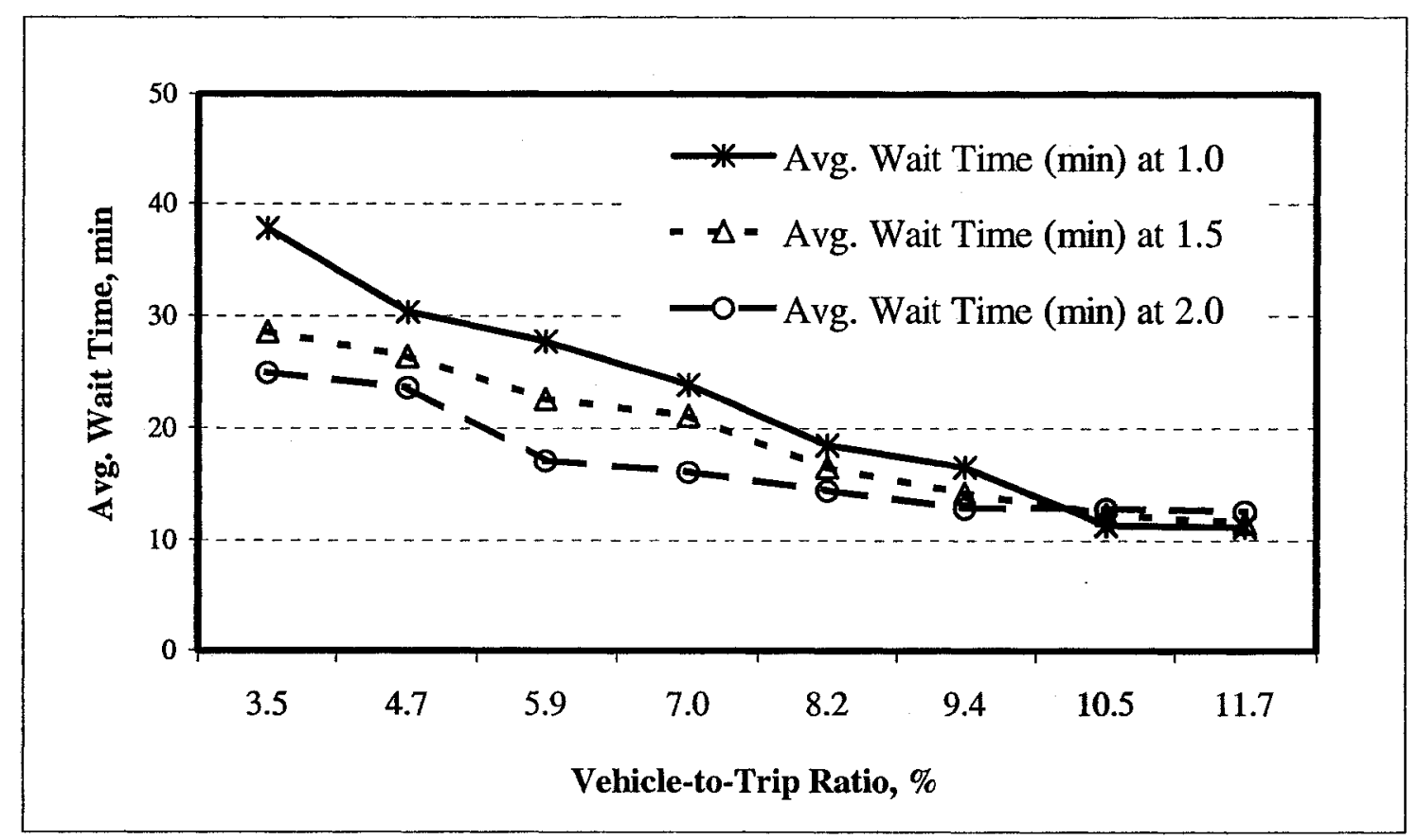

Figure 6.22 User average wait time (min) as a function of vehicle-to-trip ratio for base demand and 1.5 and 2.0 times of base demand 
Table 6.14 Number of relocations

\begin{tabular}{|c|c|c|c|}
\hline $\begin{array}{c}\text { Vehicle-to-Trip } \\
\text { Ratio (\%) }\end{array}$ & $\begin{array}{c}\text { Number of relocations } \\
\text { at base demand }\end{array}$ & $\begin{array}{c}\text { Number of relocations } \\
\text { at 1.5 times base demand }\end{array}$ & $\begin{array}{c}\text { Number of relocations } \\
\text { at } 2.0 \text { times base demand }\end{array}$ \\
\hline 3.5 & 33 & 65 & 97 \\
\hline 4.7 & 48 & 72 & 91 \\
\hline 5.9 & 42 & 67 & 79 \\
\hline 7.0 & 43 & 61 & 70 \\
\hline 8.2 & 45 & 40 & 61 \\
\hline 9.4 & 34 & 38 & 49 \\
\hline 10.5 & 29 & 32 & 31 \\
\hline 11.7 & 27 & 25 & 35 \\
\hline
\end{tabular}

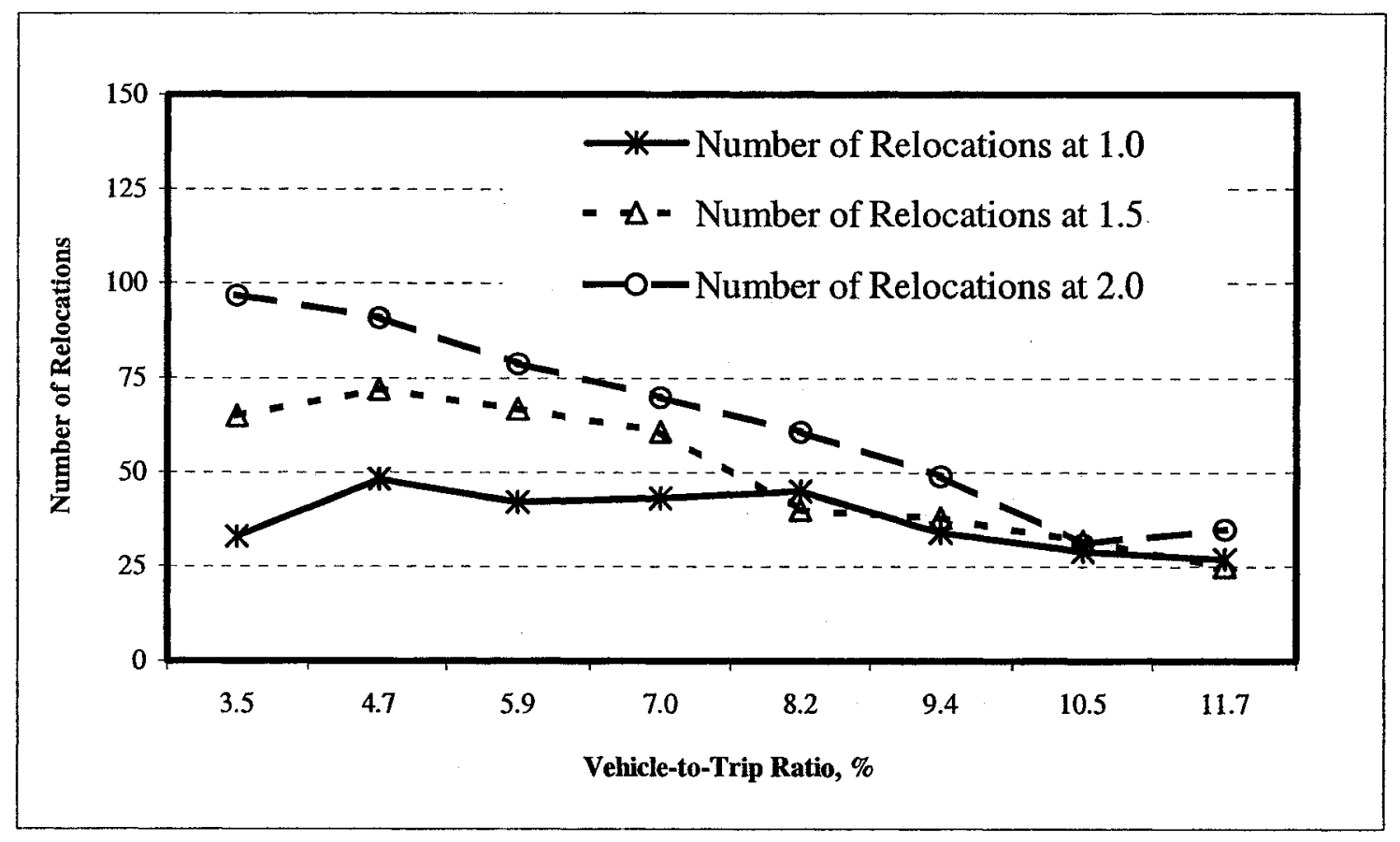

Figure 6.23 Number of relocations as a function of vehicle-to-trip ratio for base demand and 1.5 and 2.0 times of base demand 
Table 6.15 Percent of trips served

\begin{tabular}{|c|c|c|c|}
\hline $\begin{array}{c}\text { Vehicle-to-Trip } \\
\text { Ratio (\%) }\end{array}$ & $\begin{array}{c}\text { Trips served (\%) at } \\
\text { base demand }\end{array}$ & $\begin{array}{c}\text { Trips served (\%) at } \\
1.5 \text { times base demand }\end{array}$ & $\begin{array}{c}\text { Trips served (\%) at } \\
\text { 2.0 times base demand }\end{array}$ \\
\hline 3.5 & 53.2 & 71.0 & 79.3 \\
\hline 4.7 & 70.3 & 79.0 & 86.1 \\
\hline 5.9 & 72.6 & 88.0 & 91.3 \\
\hline 7.0 & 82.0 & 91.0 & 93.1 \\
\hline 8.2 & 82.4 & 95.0 & 93.4 \\
\hline 9.4 & 92.7 & 96.0 & 93.9 \\
\hline 10.5 & 95.8 & 96.3 & 96.3 \\
\hline 11.7 & 95.3 & 97.3 & 95.9 \\
\hline
\end{tabular}

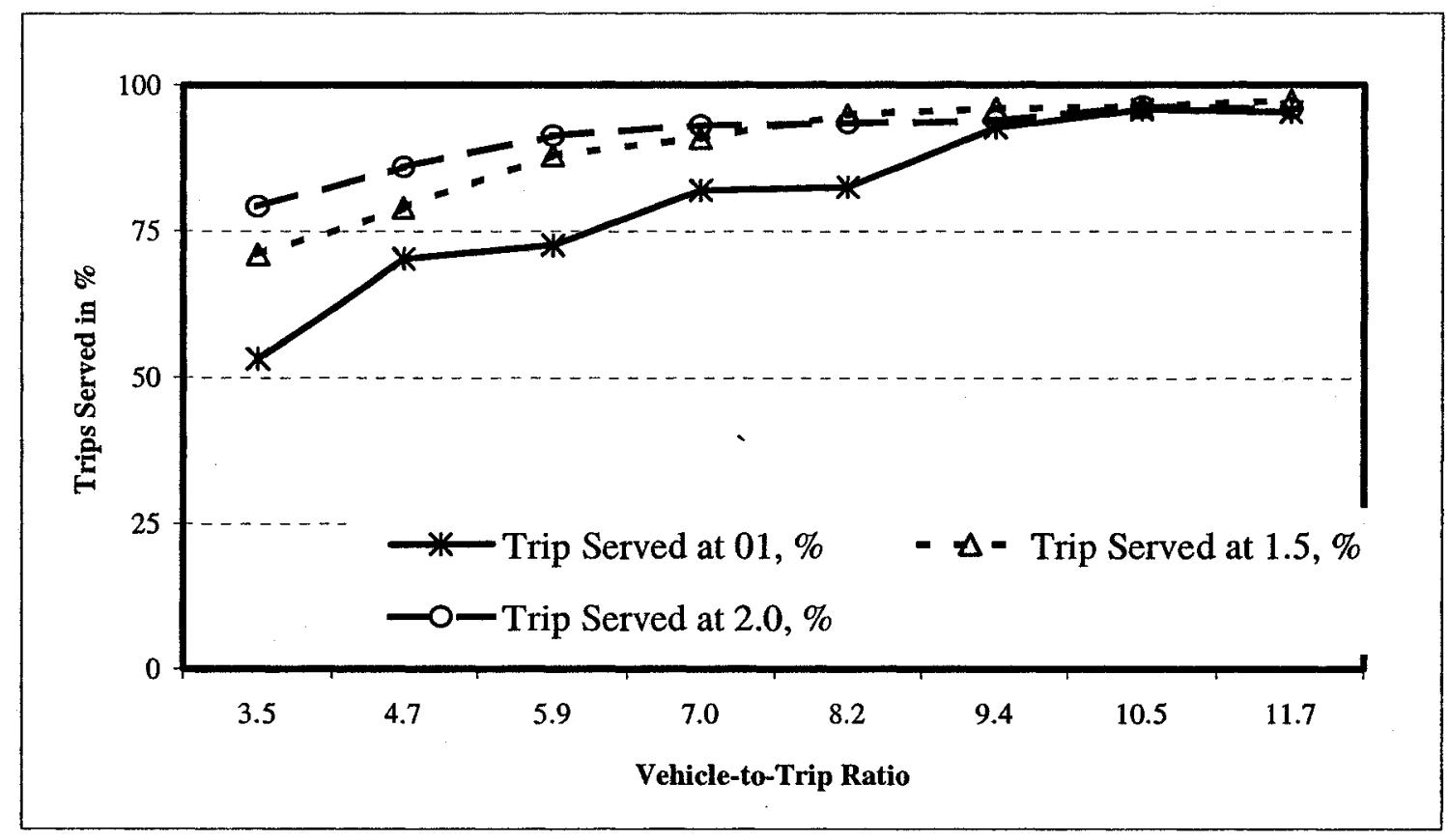

Figure 6.24 Percent of trips served as a function of vehicle-to-trip ratio for base demand and 1.5 and 2.0 times of base demand 
These results explain the SVS performance and its behaviour with increased travel demand. The two-dimensional plots in Figures 6.22-6.24 show how the three major MOP indicators respond to different demand levels for a range of values of vehicle to-trip ratio. This information is critical for shared vehicle system design and operations.

\subsection{Vehicle State-of-Charge (SOC)}

Electric vehicles (EVs) are well suited for shared vehicle systems (Barth and Todd, 1999). Electric vehicles produce zero emissions and are therefore environmentally beneficial, but they still suffer from limited battery range. This range limitation is not a problem in a shared vehicle system, where the trip distances or travel times are short and the vehicles can take advantage of the opportunity to recharge when they are idle at a station's parking lot (Barth and Todd, 1999). In this case study, close monitoring of vehicle SOC was performed in the simulation model through the implementation of "charging controller". Two different models, as a function of time and/or distance, are employed for charge depletion and recharge (adapted from Barth et al, 1997).

Recharge Model: $Y=0.35 X$

where

Y percent of charge gain, and

$\mathrm{X}$ time in minute and $\leq 4$ hours or 240 minutes

Depletion Model: $Y=1.66 X$

Y percent of charge used, and

$\mathrm{X}$ distance traveled in $\mathrm{km}$ 
Vehicle SOC information is collected on a real time basis. A statistical analysis was performed using the collected SOC data and the results are shown in Table 6.16.

Table 6.16 Descriptive statistics of vehicles SOC (\%)

\begin{tabular}{|l|l|}
\hline Descriptive Statistics & Observed Value \\
\hline Mean & 60.2 \\
\hline Median & 60.1 \\
\hline Mode & 71.3 \\
\hline Standard Deviation & 6.6 \\
\hline Coefficient of Variation (COV), \% & 10.9 \\
\hline Minimum & 42.0 \\
\hline Maximum & 79.6 \\
\hline Confidence interval (95\%) & $57.7-62.7$ \\
\hline
\end{tabular}

From Table 6.16 it is obvious that the mean vehicle state-of-charge is 60.2 percent with a standard deviation of 6.6 that constitutes a coefficient of variation (COV) 10.9 percent. The minimum and maximum SOC are 42.0 and 79.6 percent, respectively. A distribution, with cumulative curve, of the vehicle's real time state-of-charge (SOC) is shown in Figure 6.25. 


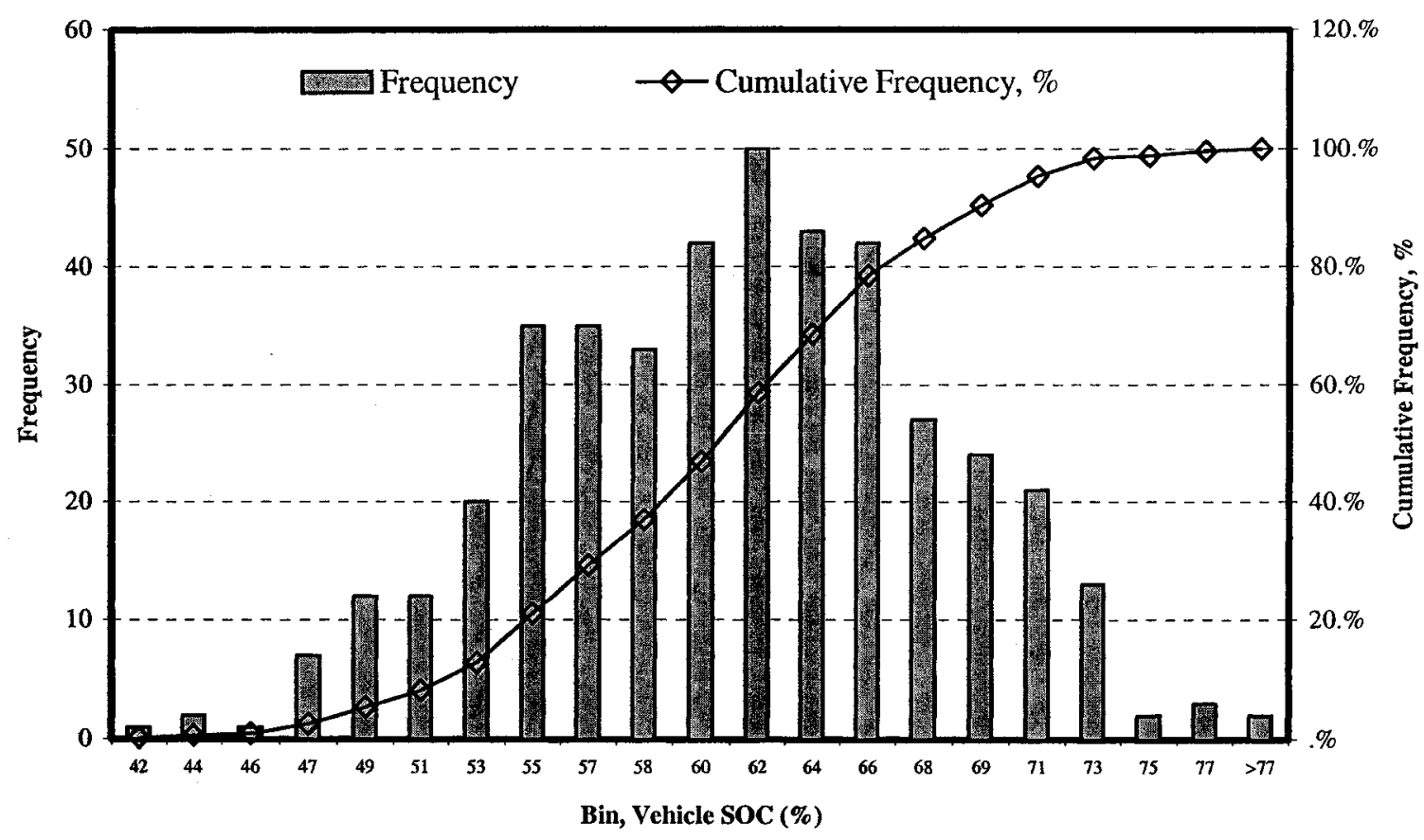

Figure 6.25 Distribution of the Vehicle's Battery State-of-Charge

This finding could be different if the trip travel times or distances were much higher. In this research effort, the system operations were studied with longer travel times. In the experiments, the travel times were increased and the system MOPs were evaluated. The results showed that the vehicle SOC was not drastically affected until the trip travel times were 1.75 times longer than the base travel times.

\subsubsection{Test Results Based on Scenario-2}

Literature review showed that Barth and Todd (1999) modelled the shared vehicle system operations based on modified Markov process. This attempt had put an upper limit of "mean +5 -standard deviation $\left(\frac{1}{\lambda}+5 \sigma\right)$ " to the generated interarrival times. One of the objectives of this thesis research is to check the effect of normal Markov process in 
modelling SVS system operations. Based on this objective, scenario-2 is developed. The main assumptions of scenario-2 include interarrival times followed normal Markov process with "infinite support", travel times between stations are constant, and consideration of the complete set of variables. Major shared vehicle system performance indicators including customer average waiting time, number of vehicle relocations, queue length, and trips served were considered to evaluate the effect(s). A constant parking-tovehicle ratio of 2:1 was used. A set of values of the major system independent variable, vehicle-to-trip ratio, was taken into consideration and the system operations were simulated. For the SVS system performance indicators, mentioned above, values were collected for all the vehicle-to-trip ratios. These collected data are then analyzed, and plotted with Microsoft Excel to gain insights. The results are described in the following sections (6.5.2.1 and 6.5.2.2).

\subsubsection{Wait Time and Relocation Analysis}

Based on the assumptions of scenario-2, the SVS operations were simulated. To evaluate the effect of the generation of customer interarrival time based on normal Markov process on customer wait time and number of vehicle relocations, respective data were collected from simulation output for all values of vehicle-to-trip ratio. This information was then grouped, analyzed, and plotted to make inference. 


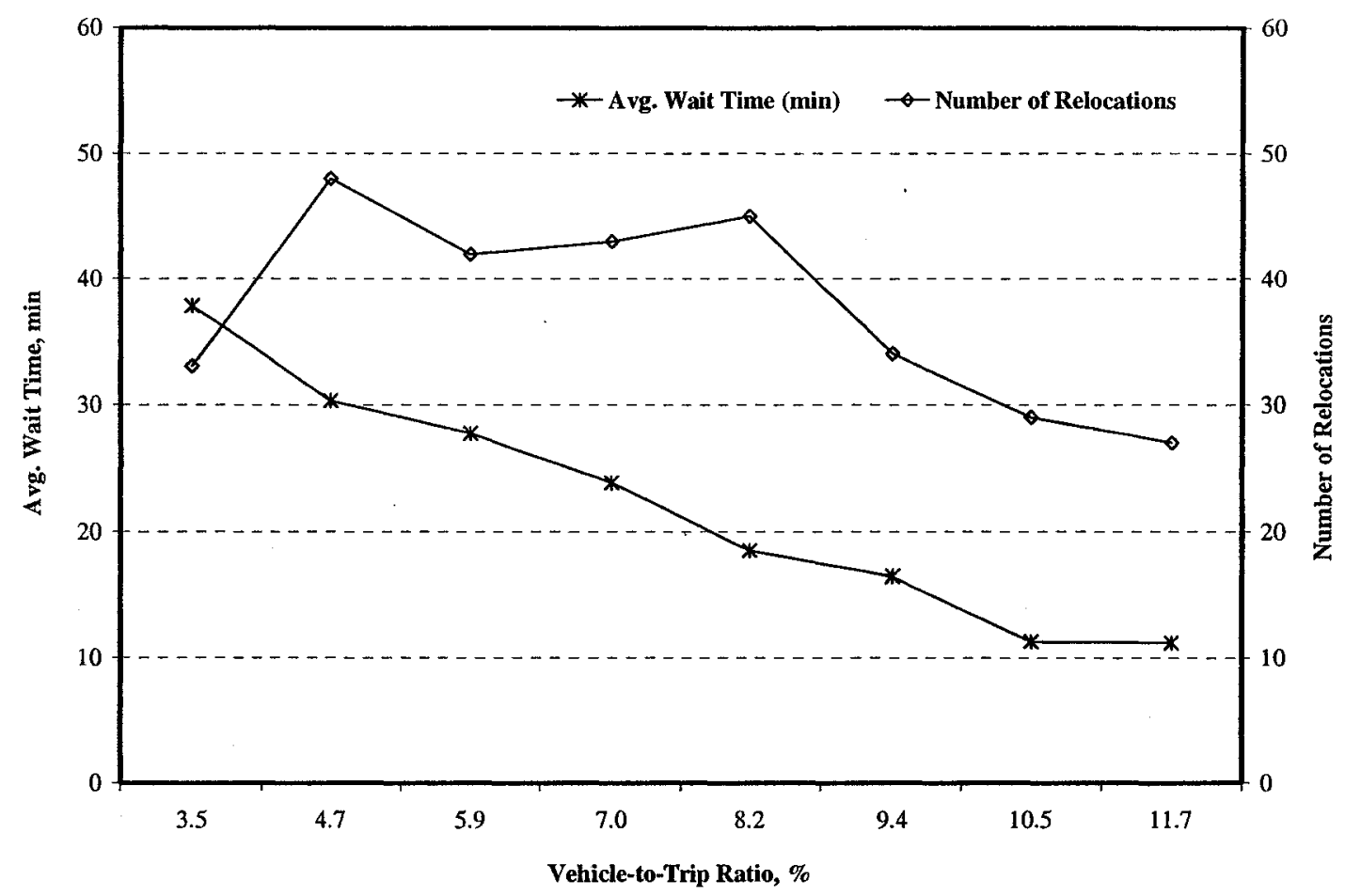

Figure 6.26 User average wait time, and number of relocations as a function of vehicle-to-trip ratio in scenario-2

Figure 6.26 illustrates the relationships of customer average wait time and number of vehicle relocations as a function of vehicle-to-trip ratio. It is obvious that the observed relationships are indistinguishable with scenario-1 (SC-1). It is apparent that the system is optimized (reached at best design point) at vehicle-to-trip ratio of 10.5 percent with respect to average customer wait time. The user average wait time at this vehicle-to-trip ratio is about 11 minutes as observed from Figure 6.26. The researcher would like to call this as the "best design vehicle-to-trip ratio" for the studied system. The corresponding average number of relocations is 32 relocations per day as shown in Figure 6.26. This relocation result differs by 2 relocations per day, on average, and is higher than that was obtained in scenario-1. These results illustrate the fact that the effect of normal Markov 
process with infinite support on user average wait time and number of relocations is not significant.

\subsubsection{Analysis of Trips Served and Queue Length}

As mentioned in the analysis of scenario-1 results, the capacity of SVS depends on many factors including user acceptable wait time, allowable maximum number of relocations, and vehicle-to-trip ratio or vehicle fleet size. It is realistic to assume that the longer user interarrival time, which may result from the normal Markov process with infinite support, could affect the system in terms of serving policy level demand within the operation period and hence may produce artificially lower system performance.

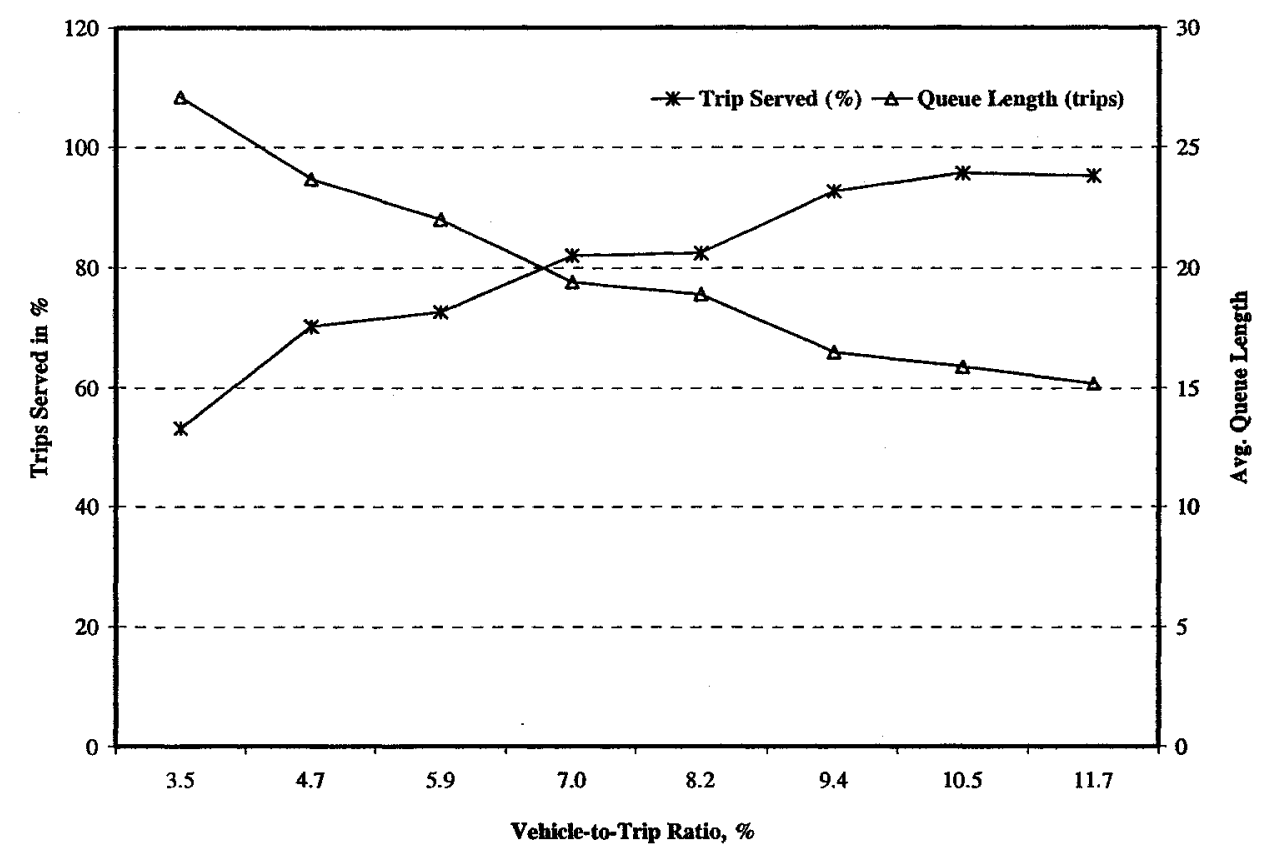

Figure 6.27 Total trips served and queue length as a function of vehicle-to-trip ratio in scenario-2 
Figure 6.27 demonstrates the relationships of total trips served (\%) and average queue length (trips) as a function of vehicle-to-trip ratio. In this case, results identical to scenario-1 were obtained for system capacity and queue length. The policy demand, 95 percent of total, was served at vehicle-to-trip ratio of 10.5 percent. The average queue length of 16 trips results from the analysis at the same vehicle-to-trip ratio (10.5\%).

From the above results, we may conclude that the effect of normal Markov process, in modelling user/customer interarrival times, on SVS performance is not significant. This may be due to the fact that only a few extremely large interarrival times are generated. Finally we may conclude that the modified Markov process is a realistic technique or method to model the customer "arrival process" for modelling shared vehicle system operations.

\subsubsection{Test Results Based on Scenario-3}

In scenario-3, the system is assumed to follow the modified Markov process and includes the complete set of variables defined in the methodology section. It is assumed that the customer interarrival times follow exponential distribution with an upper limit of "mean $+3 * s \tan$ dard deviation". Furthermore, the trip travel times between stations were considered as uncertain.

Under scenario-1, an attempt was made to check the travel time sensitivity of shared vehicle system (SVS) performance. The analysis showed that the SVS system 
performance indicators including customer average wait time, number of relocations, and trips served for given vehicle-to-trip and parking-to-vehicle ratios, do not vary significantly with travel time for a certain limit. It was found that the system performance was not affected significantly until the travel times would be a factor of 1.50 and 1.75 higher than the original modelled values for customer average wait time and number of relocations, respectively.

The Bayesian approach in modelling travel time found that improved expected travel times calculated using posterior probability were, on average, either about $25 \%$ lower or higher than the normal average travel times. A sample of estimated travel times using Bayesian technique and a comparison with average travel times are shown in Table 6.17.

Table 6.17 Comparison of normal average travel times with travel times estimated using Bayesian technique

\begin{tabular}{|c|c|c|c|c|c|}
\hline $\begin{array}{c}\text { Trip } \\
(\mathrm{OD})\end{array}$ & $\begin{array}{c}\text { Average TT } \\
(\mathrm{min})\end{array}$ & $\begin{array}{c}\text { TT with } \\
\text { Advisory R1 }\end{array}$ & $\begin{array}{c}\text { Relative to } \\
\text { Average TT }\end{array}$ & $\begin{array}{c}\text { TT with } \\
\text { Advisory R3 }\end{array}$ & $\begin{array}{c}\text { Relative to } \\
\text { Average TT }\end{array}$ \\
\hline $1-2$ & 9 & 6.85 & $23.8 \%$ lower & 11.2 & $24.4 \%$ higher \\
\hline $1-3$ & 12 & 10.2 & $15 \%$ lower & 15.7 & $23.6 \%$ higher \\
\hline
\end{tabular}

Experiments were performed to examine the effects of Bayesian technique for travel time estimation on shared vehicle system performance. The values of major performance indicators (i.e., user average wait time, number of relocations, queue length, and trips served) were collected, grouped and analyzed. These results are then plotted and shown in figures 6.28 and 6.29 . 


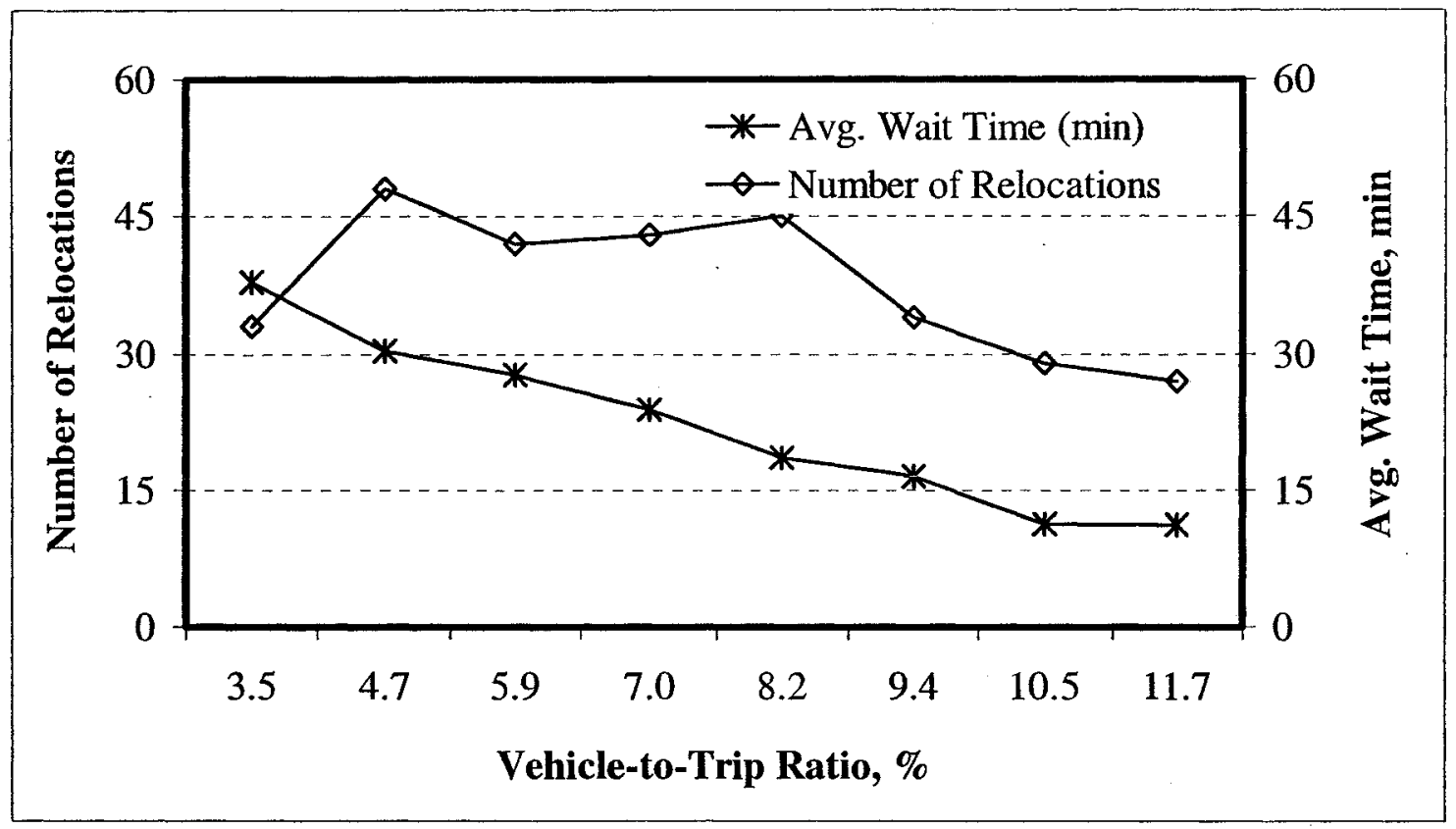

Figure 6.28 User average wait time, and number of relocations as a function of vehicle-to-trip ratio in scenario-3

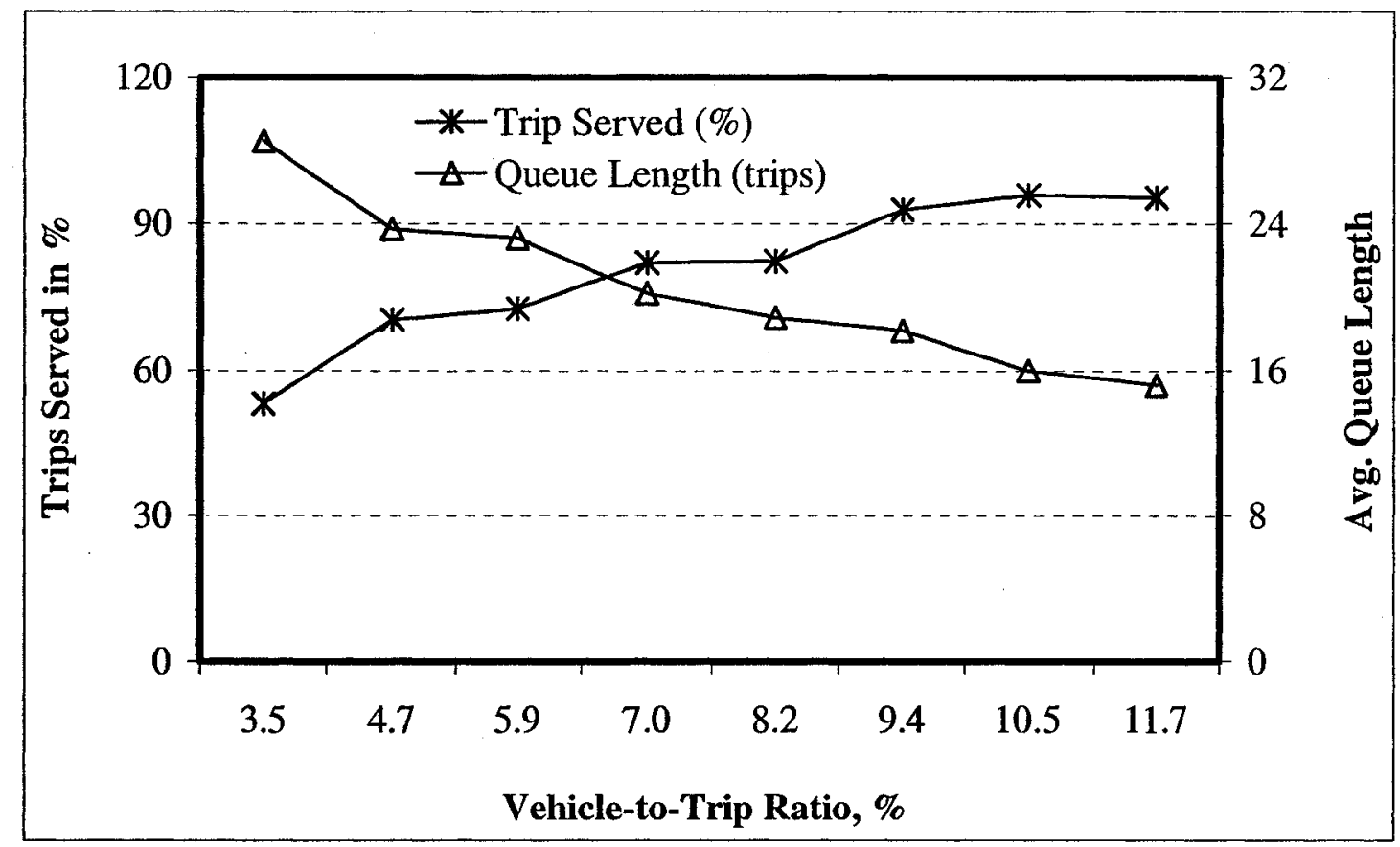

Figure 6.29 Trips served (\%) and queue length as a function of vehicle-to-trip ratio in scenario-3 
From Figures 6.28 and 6.29 , it is clear that the refinement gained in trip travel time estimation for a particular trip does not have a significant effect on the system's responses obtained in scenario-1. From Figure 6.28, a design vehicle-to-trip ratio value of 10.5 percent is found while keeping customer average wait time of about 11 minutes on average and number of vehicle relocations about at 30 per day. The number of trips served and queue length are observed to be $95 \%$ and 16 trips, respectively. These results are identical to those obtained in scenario-1. These results also crosscheck the accuracy of travel time sensitivity analysis done in scenario-1.

Despite lack of sensitivity of SVS system performance to trip travel times estimated using Bayesian technique, this method is found more realistic and convenient than the deterministic model employed by Barth and Todd (1999). The background rationale is that this way we could update the travel times. That is, without this method, we are limiting ourselves by using a database on roadway condition, traffic, and other factors that could be in need of updating. In the long run, this approach may have a significant effect on travel time values and consequently on the SVS system performance. It is also envisioned that this could be a robust or holistic approach to capture the effect of rare events, e.g., severe weather, traffic incident, etc, on calculated trip travel times and therefore SVS system performance.

\subsection{Comparison of Energy Consumption: Petroleum Fuel Saving}

In this research, it is of interest to compare energy consumption of trips made as a part of the shared vehicle systems (SVS) vs. conventional mode. In the previous sections, the specific performance measures are evaluated such as user average wait time, number 
of vehicle relocations, queue length, trips served, etc. with respect to a set of system input parameters. The comparison of energy consumption is assumed to be necessary to check the SVS as a sustainable urban public transportation system candidate from energy aspect of transportation systems.

As mentioned in the research methodology, in order to compute energy benefits of shared vehicle systems (SVS), this research focused on current vehicle trips that would be displaced by SVS trips in the CFB Ottawa case study. In this respect, it is possible to compare a "build" versus a "no-build" scenario by first estimating energy consumption associated with the "no-build" vehicle trips followed by an estimation of the energy consumption of SVS or "build" vehicle trips.

\subsubsection{Trip Estimation}

It was assumed in Miller (1982) study that 100 percent of the CFB Ottawa transportation demand, served by the then taxi system, should be met by the Miller's researched "self-drive taxi" system. Other literatures, such as Barth and Todd (1999) and Kyoto, Japan case studies, did not mention the percent of demand served. Cousins (1998) noted that a policy demand of $95 \%$, with a $5 \%$ give up or failure, could significantly reduce fleet size and the system capital cost. This finding is also supported in this research study. It was found that a 95 percent of total demand of the selected 5-station system could be served more economically than serving the total (100\%) demand. Therefore, to calculate the number of displaced vehicles, this study used the following steps: 
1. Set the degree of displacement or policy demand to be served

2. Determine the vehicle fleet and its composition (mix)

3. The energy or fuel efficiency/economy of vehicle fleet composition

According to the travel characteristics of CFB Ottawa personnel, it is observed that the demand is almost constant throughout the whole year. In cases with considerable variation in demand in different seasons of a year, the year may be divided into number of applicable periods/seasons. Analysis may be done for individual seasons and results can be accumulated to get the total energy consumption and savings that could be gained by comparing the SVS and "no-build" scenarios. The modified travel demand of CFB Ottawa, for a 5-station SVS system, is given in Table 6.2 in section 6.3.1.

Total number of daily demand, from Table $6.2=627$ trips

Party size distribution is

$80 \%$ of the trips are with party size $\leq 2$

$20 \%$ of the trips with party size $>2$ but $\leq 5$

The degree of displacement (i.e., trips that would be served by SVS system) $=95$ percent Fleet composition as obtained from model, on average, results $20 \%$ compact and $80 \%$ ultra compact

Total number of displaced trips $\quad=0.95 * 427$

$$
=406 \text { trips per day }
$$

Therefore, a total number of 406 trips per day would be displaced with the implementation of SVS for a 9-hour operation period. 


\subsubsection{Vehicle Fuel Economy}

From "Final Report, Phase 4, Honda R \& D North America, Inc.", prepared by CECERT University of California, Riverside, USA (1998), the fuel economy information on three different categories of vehicles was found (Table 6.18).

Table 6.18 Fuel consumption of three types of vehicles, Final Report, Honda (1997)

\begin{tabular}{||c|c|c|c||}
\hline & \multicolumn{3}{|c|}{ Vehicle Category } \\
\hline Fuel Consumption & Shuttle Van & Taxi & Renal Car \\
\hline miles/gal & 12 & 18 & 20 \\
\hline Liters/ 100 km (calculated) & 19.7 & 13.1 & 11.8 \\
\hline
\end{tabular}

In the above Table 6.18, Taxis and Rental Car could be assumed as standard internal combustion engine (ICE) vehicles.

Garcia, J. (2004), in his Ph.D. thesis entitled " Modeling Fuel Consumption of Advanced Technology Vehicles in Traffic Networks Using Artificial Neural Networks", noted the average fuel economy/efficiency of standard ICE vehicle under city and highway driving conditions as follows (Table 6.19). 
Table 6.19 Average fuel consumption of standard ICE vehicles, from Garcia (2004)

\begin{tabular}{|c|c|c|}
\hline & Average Speed, kph & $\begin{array}{c}\text { Fuel Economy of ICE, } \\
\text { Liters/ 100 km }\end{array}$ \\
\hline City Driving & 48.2 & 7.6 \\
\hline Highway Driving & 77 & 6.5 \\
\hline
\end{tabular}

Information is available from web sources on vehicle fuel consumption/economy in practical city and highway (Hwy) driving conditions. A set of web information on standard ICE vehicle fuel consumptions were acquired and from these, average values were found. These are presented in Table 6.20.

Table 6.20 Average fuel consumption of standard ICE vehicles from Internet sources

\begin{tabular}{|c|c|c|}
\hline & \multicolumn{2}{|c|}{ Standard ICE Vehicle Fuel Consumption } \\
\hline & Mile/gal & Liters/ $100 \mathrm{~km}$ \\
\hline City Driving & 26 & 9.1 \\
\hline Highway Driving & 34 & 6.9 \\
\hline
\end{tabular}

These data show that the information from web sources and Garcia's Ph.D. thesis are consistent, although there is a difference of 1.5 liter per $100 \mathrm{~km}$ in city driving condition. For the calculation of energy consumption of displaced vehicles in this study, average of these two sources of information on standard ICE vehicles fuel consumption is used and are as follows. 
$\begin{array}{ll}\text { Average fuel consumption in city driving } & =8.35 \text { liters } / 100 \mathrm{~km} \\ \text { Average fuel consumption in Hwy driving } & =6.70 \text { liters } / 100 \mathrm{~km}\end{array}$

\subsubsection{Fuel Consumption of Displaced Vehicles}

By knowing the number of displaced trips (NDT), the average trip length (ATL), and the average fuel consumption (FC) of displaced vehicles, the fuel consumption could be computed. Miller (1982) in his thesis came up with an average trip length of $7 \mathrm{~km}$. This research study used Miller's data with reduced number of stations. In this study, based on the nearness of the selected stations, an average trip length of $5.5 \mathrm{~km}$ was assumed. Therefore, the fuel consumption of the displaced vehicles per day under city driving condition is as follows:

Fuel consumption of displaced vehicle $=N D T \times A T L \times F C$

$$
\begin{aligned}
& =406 * 5.5 * 8.35 / 100 \\
& =186.5 \text { Liters per Day }
\end{aligned}
$$

Assuming 21 operation days per month, the total fuel consumption of the displaced vehicle trips in a year becomes $\left(186.5^{*} 21^{*} 12\right)=46,998$ or 47,000 liters per year.

\subsubsection{Shared Vehicle System's EV and Relocation Trip Energy Consumption}

Multiple station shared vehicle systems are designed to serve both one way and round trips in a particular market segment. Therefore, the demand among stations with time is asymmetric. This asymmetric demand has enough potential to produce imbalance in vehicle distribution and therefore need "relocation activity" to bring back the vehicle 
distribution balance. The relocation could be done using gasoline powered ICE truck or by electric towing truck. Since one objective of the shared vehicle system is to promote the use of electric vehicles, this study assumes that the system will use electric towing truck.

The energy consumption of an electric vehicle (EV) is typically given in terms of $\mathrm{kWh} / 100 \mathrm{~km}$. Various ranges of EV energy consumptions are found in the literature including "Final Report, Phase 4, Honda R\&D North America, Inc. (1998)"and web sources. These EV energy consumption rates ranges from about $12.5 \mathrm{kWh} / 100 \mathrm{~km}$ to $26.0 \mathrm{kWh} / 100 \mathrm{~km}$. This study uses an average energy consumption rate of $12.5 \mathrm{kWh} / 100$ $\mathrm{km}$ for the ultra-compact vehicles i.e., two seater EV (see Figure 4.5 in section 4.3.1) and $20.0 \mathrm{kWh} / 100 \mathrm{~km}$ for compact size EV with 5 seats (see Figure 4.5 in section 4.3.1).

\section{Computation of Shared Vehicle System's EV Energy Consumption}

The average shared vehicle system trip distance for CFB Ottawa is $5.5 \mathrm{~km}$. The total number of displaced trips was 406 trips. For $80 \%$ of these trips, party size is $\leq 2$ and made by ultra-compact $\mathrm{EV}$, and the rest 20 percent trips with party size $>2$ but $\leq 5$ are made by compact type EV. Therefore, the total energy consumption by the SVS's EV is as follows:

Energy consumption by ultra-compact EV $=$ NDT*ATL*FC*proportion in fleet

$$
\begin{aligned}
& =406 * 5.5 * \frac{12.5}{100} * 0.8 \mathrm{kWh} / \text { day } \\
& =223.3 \mathrm{kWh} / \text { day }
\end{aligned}
$$


Energy consumption by compact EV

Total energy consumption by EV

$$
\begin{aligned}
& =\mathrm{NDT} * \mathrm{ATL} * \mathrm{FC} * \text { proportion in fleet } \\
& =406 * 5.5 * \frac{20.0}{100} * 0.20 \mathrm{kWh} / \text { day } \\
& =89.3 \mathrm{kWh} / \text { day } \\
& =(223.3+89.3) \mathrm{kWh} / \text { day } \\
& =312.6 \mathrm{kWh} / \text { day }
\end{aligned}
$$

\section{Computation of Relocation Trip Energy Consumption}

The energy consumed, during relocation of vehicles, by the towing truck could be computed as follows:

Energy consumed by electric towing truck $\quad=\mathrm{NR}^{*} \mathrm{ARTL}{ }^{*} \mathrm{FC}$

The variables are defined as follows:

$\mathrm{NR}=$ Number of vehicle relocations

$\mathrm{ARTL}=$ Average relocation trip length

$\mathrm{FC}=$ Energy consumption of towing truck

In the case of vehicle relocation trips, the distribution of these trips, among stations, is important in determining the average relocation trip length (ARTL). The inter-station relocation trip distribution obtained from a set of simulation runs (i.e., 20 runs) for the 5station system is given in Table 6.21 . 
Table 6.21 Inter-station relocation trip distribution in percent

To Station

\begin{tabular}{|c|c|c|c|c|c|c|}
\hline \multirow{6}{*}{$\begin{array}{c}\text { From } \\
\text { Station }\end{array}$} & & 1 & 2 & 3 & 4 & 5 \\
\hline & 1 & 0 & 0 & 2.9 & 2.9 & 2.9 \\
\hline & 2 & 5.9 & 0 & 11.8 & 2.9 & 8.8 \\
\hline & 3 & 11.8 & 11.8 & 0 & 2.9 & 0 \\
\hline & 4 & 11.8 & 2.9 & 2.9 & 0 & 0 \\
\hline & 5 & 8.8 & 2.9 & 5.9 & 0 & 0 \\
\hline
\end{tabular}

Using this relocation trip distribution and the actual inter-station distance, the weighted average relocation trip length was measured. The resulting average relocation trip length was found as $4.5 \mathrm{kms}$. Furthermore, we need the energy consumption rate of the electric towing truck. The study assumes an energy consumption rate of 25.0 $\mathrm{kWh} / 100 \mathrm{~km}$ for the towing truck. This assumption is made based on the truck's characteristics. Therefore, we get,

Energy used in electric towing truck relocation $\quad=$ NR $*$ ARTL $*$ FC of electric truck

$$
\begin{aligned}
& =30 * 4.5 * \frac{25.0}{100} \mathrm{kWh} / \text { day } \\
& =33.75 \mathrm{kWh} / \text { day }
\end{aligned}
$$

Hence the total energy consumption of SVS

$$
\begin{aligned}
& =(312.6+33.75) \mathrm{kWh} / \text { day } \\
& =346.35 \mathrm{kWh} / \text { day } \\
& =21 * 12 * 346.35 \mathrm{kWh} / \text { year } \\
& =87,280.2 \mathrm{kWh} \text { per year }
\end{aligned}
$$

Note: 21 working days per month 
If a gasoline powered truck is used to relocate vehicles between stations, the fuel consumption could be calculated using the method described in the previous section with average fuel consumption of the relocated truck and may be assumed identical to the shuttle van described in the previous section.

\subsubsection{Petroleum Fuel Saving}

As stated in the previous section, this study assumed that the relocation is performed through an electric towing truck. Therefore, the total petroleum fuel saving is equal to the total fuel consumed by the standard ICE vehicles in displaced trips (section 6.4). The calculated fuel consumption was 186.51 liters/day and the yearly displacement of petroleum was found to be 47,000 liters, That is, 100 percent of the petroleum fuel consumed by the displaced trips could be saved.

If the system employed a gasoline powered truck to perform the relocation task, the petroleum fuel used for the relocation trip by the truck need to be quantified using the method described above. This amount should be subtracted from the petroleum fuel saved from the total displaced trips to get the net fuel savings that may be attributed to the SVS. A comparison of the energy consumption of the scenarios is shown is Table 6.22 . 
Table 6.22 Comparison of energy consumption

\begin{tabular}{|l|l|l|}
\hline Scenario & Energy consumed & Comments \\
\hline No-Build (without SVS) & 47,000 liters per year & Non renewable energy \\
\hline Build (with SVS) & $87,280 \mathrm{kWh}$ per year & Renewable energy \\
\hline
\end{tabular}

\subsection{Cost Analysis}

The economic feasibility of shared vehicle systems (SVS), a new innovative urban transportation paradigm, revolves around many factors or parameters. To study the economic feasibility of SVS, for real world implementation, this thesis research was motivated to perform a cost analysis. The costs are usually thought of as the initial investment or capital cost, a series of annual costs or variable costs, including the cost of operation and maintenance, and the revenue (Banks, 2002). The most significant cost that were included in the cost analysis are:

1. SVS system infrastructure setup/construction cost,

2. Degree of automation,

3. Vehicle cost (depreciation),

4. Operation control center (OCC) personnel cost,

5. Relocation cost,

6. Energy and maintenance cost, and

7. Customer usage rates 
The above cost items could be grouped into initial or capital cost, variable cost that includes operation and maintenance costs, and revenue items as mentioned in the previous section. The system setup/construction cost, vehicle depreciation, and system operation control center (OCC) personnel cost constitute the capital cost. Furthermore, it is obvious that an intelligent shared vehicle system's setup/construction cost is a function of degree of automation. The relocation, energy, and maintenance costs constitute the variable cost. Customer or user usage rate generates revenue. Therefore, at this level; the cost model of the shared vehicle system becomes:

$$
\mathrm{C}_{\mathrm{T}}=\mathrm{C}_{\mathrm{C}}+\mathrm{C}_{\mathrm{V}}
$$

where

$$
\begin{aligned}
& C_{T}=\text { Total Cost } \\
& C_{C}=\text { Capital Cost }, \text { cost items that relate to set-up/construction of the system } \\
& C_{V}=\text { Variable Costs; costs that are related to the operation and maintenance of SVS }
\end{aligned}
$$

These two cost items (i.e., capital and variable costs) are defined in detail below.

\section{Capital Cost Model}

The capital costs include all the items that are mentioned above and account for fixed costs. Therefore, the capital cost part of the cost model could be formulated as follows:

$$
\mathrm{C}_{\mathrm{C}}=\mathrm{C}_{1}+\mathrm{C}_{2}+\mathrm{C}_{3}+\mathrm{C}_{4}
$$

Different cost items in the capital cost model are defined as: 
$C_{1}$ - the SVS set-up/construction cost including registration kiosk, parking slots, and charging facility

$\mathrm{C}_{2}$ - represents automation cost, includes costs for ITS technologies, software, and hardware

$\mathrm{C}_{3}$ - denotes the annual vehicle depreciation

$\mathrm{C}_{4}$ - corresponds to annual operation control center (OCC) personnel, station managers and relocation truck operator costs (i.e., wages)

\section{Variable Costs Model}

The variable cost part of the shared vehicle system cost model could be formulated as follows:

$$
\mathrm{C}_{\mathrm{V}}=\mathrm{C}_{5}+\mathrm{C}_{6}+\mathrm{C}_{7}
$$

The three cost items of variable cost model part are defined as follows:

$\mathrm{C}_{5}$ - represents energy/fuel costs; in this case the cost of electric power,

$\mathrm{C}_{6}$ - the vehicle maintenance costs, and ITS technology usage cost, and

$\mathrm{C}_{7}$ - corresponds to spare parts and repair costs

Both the capital and variable cost items of the above cost model are described and quantified in the following sections.

\subsubsection{Cost Estimation}

\subsubsection{Capital Cost}

As formulated in the previous section, the capital cost of shared vehicle system comprises of system set-up/construction (i.e., registration kiosk, parking slots and 
charging facility) cost, vehicle depreciation, automation cost, and operation control center personnel cost. The capital cost part of the cost model is formulated as $C_{c}=C_{1}+C_{2}+C_{3}$ $+\mathrm{C}_{4}$.

The first element of capital cost part of the cost model, denoted by $C_{1}$, is the infrastructure set-up/construction cost that includes registration kiosk, parking slots, and charging facility costs. For the case study, a shared vehicle system with 5 stations is considered. Each station is assumed to be equipped with one registration kiosk. Based on the simulation results, it is found that each station requires 18 parking slots, for the given demand, at efficient system configuration. All parking slots are assumed to be equipped with charging facility.

A blanket cost of $\$ 10,000$ is used for each registration kiosk. This estimate is based on a telephone interview with Scotia Bank officer, at Gloucester Center, Ottawa. It was also informed by the officer that a 10-year lifetime is reasonable for the kiosk. Due to the unavailability of data about cost of installation of parking slots with charging facility, it is difficult to guess the cost at this stage. A cost of $\$ 1,000$ is assumed per parking slot including charging facility based on CarLink I, BART, California, USA experience (Shaheen and Uyeki, 2000). Based on information from Miller (1982) and Shaheen and Uyeki (2000), this study assumes a 10-year lifetime for the parking slots and its charging facility. It is assumed that the salvage value, at the end of lifetime (10 years), will be negligible/zero for both station registration kiosks and parking slots with charging equipments. 
Registration kiosks cost

Parking slots with charging facility cost

The infrastructure setup/construction cost

$$
=\$ 140,000
$$

Therefore, $\mathrm{C}_{1}=\$ 140,000$

The second item of capital cost part of the cost model is the automation cost, represented by $\mathrm{C}_{2}$. It includes cost of automation and/or ITS technologies. The smart shared vehicle system's ITS technology costs include hardware, software, and installation costs. A sum of $\$ 2,000$ is assigned as an initial investment for the equipments needed at operation control center (OCC), and vehicle tracking hardware and software (AVL technology) costs are assumed to be $\$ 300$ per vehicle (Shaheen and Uyeki, 2000). These items constitute a sub-total cost as:

Initial investment

ITS technology cost per vehicle

$$
=\$ 2,000
$$$$
=\$ 300
$$

The sub-total cost, $\mathrm{C}_{2}=\$(2,000+300 * \mathrm{n})$ where, $\mathrm{n}$ - is the number of vehicles in the fleet

The third element of the capital cost model is the vehicle depreciation. It is well established that the average lifetime of conventional ICE vehicle in Canada is 10 years. According to Miller's assumption, the use of vehicle from a vehicle pool, as in shared vehicle systems, by drivers of different levels of training would reduce the vehicle's 
average lifetime. Miller assumed a lifetime of 5 years for EV and he assigned an estimated price of each vehicle (2-seater ultra-compact) as $\$ 6,000$ (1982 cost level).

Today's EVs are much more developed and possess all features of ICE vehicles and are assumed to have lifetime comparable to as ICE vehicles. A research on the Internet revealed that the average manufacturer retail price of 2 -seater (ultra-compact) $\mathrm{EV}$ is $\$ 18,000$ and compact (5-seater) EV is $\$ 22,500$ in U.S. currency, which is equivalent to $\$ 23,000$ and $\$ 29,000$ Canadian, respectively. A currency conversion factor of 1.3 is used.

The simulation model results suggest a fleet of 45 vehicles, 36 of which are ultracompact and 9 compact EVs based on average vehicle mix. This research study is assuming vehicle lifetime to be the same as ICE vehicle with a salvage value of $\$ 1,500$ for ultra-compact and $\$ 3,000$ for compact $\mathrm{EV}$ at the end of 10 years period. Applying the straight-line depreciation method (Newman and Lavelle, 1998), the vehicle depreciation becomes:

Depreciation for ultra-compact vehicle per year $=\$((23,000-$ Sal_Value $\mathrm{UC}) / \mathrm{N}) * \mathrm{n}_{\mathrm{UC}}$ Depreciation for compact vehicle per year $\quad=\$\left(\left(29,000-\right.\right.$ Sal_Value $\left.\left._{C}\right) / \mathrm{N}\right) * \mathrm{n}_{\mathrm{C}}$ where, $\mathrm{N}$ - represent the vehicle lifetime or economic recovery period in year(s) Sal_Value $\mathrm{UC}$ - salvage value of ultra-compact vehicle at the end of period $\mathrm{N}$ years Sal_Value ${ }_{C}$ - salvage value of compact vehicle at the end of period $N$ years $\mathrm{n}_{\mathrm{UC}}$ - number of ultra-compact vehicles in the fleet $\mathrm{n}_{\mathrm{C}}$ - number of compact vehicles in the fleet 
Review of available literature indicates that one operator and a truck could relocate an average of 60-75 vehicles per day (Barth and Todd, 1999). The simulation results showed that the average number of relocations for the case study system was 30 for a 9 -hour operation period for the efficient system configuration. Therefore, it is reasonable to assume that one operator and an electric towing truck would be sufficient enough to perform the relocation task. An annual wage of $\$ 35,000$ for the truck operator and a vehicle (panel truck) price of $\$ 30,000$ were assumed. A salvage value of $\$ 4,000$ is assumed at the end of 10-year period for the truck.

Depreciation for towing truck per year

$$
=\$\left(\left(30,000-\text { Sal_Value }_{\text {truck }}\right) / \mathrm{N}\right)
$$

Note: the variables here denote similar meaning as in the previous section.

Therefore, the vehicle depreciation cost item becomes:

$$
\begin{aligned}
& \mathrm{C}_{3}=\$\left[\left(\left(23,000-\text { Sal_Value }_{\mathrm{UC}}\right) / \mathrm{N}\right) * \mathrm{n}_{\mathrm{UC}}+\$\left(\left(29,000-\mathrm{Sal} \_ \text {Value }\right) / \mathrm{N}\right) * \mathrm{n}_{\mathrm{C}}\right. \\
& \left.+\$\left(\left(30,000-\text { Sal_Value truck }_{\mathrm{t}}\right) / \mathrm{N}\right)\right]
\end{aligned}
$$

The last item of capital cost model is the operation control center personnel cost including station manager and relocation truck operator's wages and benefits. Based on recent modelling and experimental efforts, at an efficient level of operation it may be logical to assume that a single person, station manager, would be able to manage the operation of shared vehicle system for a service coverage not more than seven stations. Considering total operation hours, 9 hours in total, it was assumed that two managers would be needed indeed. These personnel are assumed to be at the operation control 
center (OCC) and communicate with users and system's dynamic database. An annual wage of $\$ 40,000$ is assumed for OCC manager. Therefore,

Annual OCC personnel (station manager and relocation truck operator) $\operatorname{cost}=\$(35,000$

$+2 * 40,000)=\$ 115,000$ per year

Hence, $\mathrm{C}_{4} \quad=\$ 115,000$ per year

Knowing the economic recovery period and an annual interest rate, the capital cost items, quantified above, could be easily converted to equivalent uniform annual cost (EUAC) or equivalent annual cost (EAC) using appropriate capital recovery model.

\subsubsection{Variable Costs}

The variable cost part of the cost model is formulated as $\mathrm{CV}_{\mathrm{V}}=\mathrm{C}_{5}+\mathrm{C}_{6}+\mathrm{C}_{7}$.

The independent variables are defined as:

$\mathrm{C}_{5}$ - represents energy/fuel costs

$\mathrm{C}_{6}$ - corresponds to vehicle maintenance costs, and ITS technology usage costs, and

$\mathrm{C}_{7}$ - stands for spare parts and repair costs

\section{Energy/Fuel Cost}

The first and major independent variable considered in variable cost part of the shared vehicle system cost model is the cost of energy/fuel. In this case, it is the cost of electric power used during vehicle recharging. The state-of-the-art of EV technology and analysis presented in "comparison of energy consumption" section of this research study suggests that the power required to travel a distance of $1 \mathrm{~km}$ by a compact size $\mathrm{EV}$ is $0.20 \mathrm{kWh}$ or 
$20 \mathrm{kWh}$ per $100 \mathrm{~km}$. At an assumed cost of $\$ 0.05$ per $\mathrm{kWh}$, based on Hydro Ottawa rate with use of up to $1000 \mathrm{kWh}$ per month, the cost of charging batteries for $1 \mathrm{~km}$ distance travel by $\mathrm{EV}$ is $\$ 0.01$ ( 1 cent). For an ultra-compact size $\mathrm{EV}$, the energy consumption is assumed as $12.5 \mathrm{kWh}$ per $100 \mathrm{kms}$. Therefore, the per km energy use is $0.125 \mathrm{kWh}$. This information constitutes a cost of travel of $1 \mathrm{~km}$ by an ultra-compact $\mathrm{EV}$ as $\$ 0.00625$ or 0.625 cent.

In the case study, for a total of 406 served trips, with an average trip length of 5.5 $\mathrm{kms}$, constitute a travel distance of $2233 \mathrm{kms}$ per day. Based on the simulation results, 80 percent of this distance is attributed to ultra-compact $\mathrm{EV}$ and the rest 20 percent to compact size EV. Assuming an average of 21 operation days per month, the yearly kms becomes $2233 * 21 * 12=562,716 \mathrm{kms}$. Hence, the energy consumption cost, by the vehicle fleet only, becomes:

Energy consumption cost $\quad=\$\left[(0.00625 * 0.8+0.01 * 0.2)^{*} 562,716\right]$

$=\$ 3,939$ per year.

In the "comparison of energy consumption" section of this research, it is observed that the energy consumption by the relocation towing truck is $33.75 \mathrm{kWh}$ per day or 9639 $\mathrm{kWh}$ per year. This item contributes to EV vehicle energy consumption cost of about $\$ 482$ per year. Therefore, the energy cost becomes,

$$
\begin{aligned}
C_{5} & =\$(3,939+482) \\
& =\$ 4,421 \text { per year. }
\end{aligned}
$$




\section{Maintenance and ITS Technology Usage Cost}

Based on Miller's (1982) study, it is assumed that each vehicle would be in the workshop once in every two-week period for routine preventive maintenance. To allow this preventive maintenance of vehicles, additional 6 vehicles, based on Miller's study, is assumed to be required for a fleet of 45 vehicles. Therefore, the resulting fleet size is 51 vehicles. Since the information on maintenance cost of EV is not well known, it was assumed that the monthly cost for routine maintenance is $\$ 45$ (about $\$ 35$ U.S.) per vehicle for both ultra-compact and compact model (Shaheen and Uyeki, 2000). This resulted in an annual maintenance cost of $\$ 27,540$ for vehicle fleet size of 51 .

ITS technologies are required for efficient operation, namely for automatic vehicle location (AVL), incidence management, and emergency communications with the station manager. These include the wireless communication systems i.e., cell phones, GPS, and AVL technologies. An average airtime cost of $\$ 35$ per vehicle per month is assumed (Shaheen and Uyeki, 2000). For a vehicle fleet size of 51, this cost item amounts to $\$ 21,420$ per year. Therefore, the vehicle maintenance and ITS technology usage cost becomes:

$$
\begin{aligned}
\mathrm{C}_{6} & =\$(27,540+21,420) \\
& =\$ 48,960 \text { per year }
\end{aligned}
$$

\section{Spare Parts and Repair Cost}

On the basis of Miller's (1982) research study and the cost analysis of smart carsharing experimental effort, CarLink I in San Francisco, California (Shaheen and 
Uyeki, 2000) an average cost of $\$ 500$ per vehicle per year is assumed for this cost item. For a vehicle fleet size of 51 , this results in a total of $\$ 25,500$ per year. Hence, the spare parts and repair cost portion of the variable cost part becomes:

$\mathrm{C}_{7}=\$ 25,500$ per year

\subsubsection{Cost Estimates}

The shared vehicle systems are new and hence limited information is available on cost of different items. Available literature is limited to studies by Barth and Todd (1999), and Shaheen et al (2000) on ICVS at University of California and CarLink I at BART, California, USA, respectively. Barth and Todd (1999) found that the extreme automation required a long economic recovery period. Based on their findings, this research study assumes, as mentioned in the methodology section, that the system is engineered with ITS technology to the extent that it is a balance of both manned and automated operation. The cost items and level of automation identified and quantified in the previous sections are assumed to be consistent with the balanced level of automation in shared vehicle systems operations. Using these cost items, the three cost analysis scenarios based on economic cost recovery periods of ten, five, and three years were analyzed.

All of the individual cost items are identified and quantified in the previous sections. Initially, the capital or fixed costs were transformed into equivalent annual cost (EAC) for an analysis period of ten years. The methodology was then used to compute the EAC for economic analysis periods of 5-year and 3-year. The analyses and the results for 
equivalent annual costs of all three cost recovery scenarios are shown below, respectively.

\section{Scenario 1: Economic Recovery Period of 10-year}

Under this scenario, it is assumed that the system's capital/fixed costs will be recovered within the first ten years of operations.

The total cost model was formulated, in section 6.7 , as:

$$
\mathrm{C}_{\mathrm{T}}=\mathrm{C}_{\mathrm{C}}+\mathrm{C}_{\mathrm{V}}
$$

Where the cost items are;

$\mathrm{C}_{\mathrm{C}}$ is the capital or fixed costs part of the cost model. This part of the cost model is defined as.

$$
\mathrm{C}_{\mathrm{C}}=\mathrm{C}_{1}+\mathrm{C}_{2}+\mathrm{C}_{3}+\mathrm{C}_{4}
$$

$\mathrm{C}_{\mathrm{V}}$ represents the variable costs part of the cost model. This part of the cost model is formulated as follows.

$$
\mathrm{C}_{\mathrm{V}}=\mathrm{C}_{5}+\mathrm{C}_{6}+\mathrm{C}_{7}
$$

\section{Equivalent Annual Cost (EAC) of Capital Cost Items:}

Now consider the scenario- 1 with economic recovery period of 10 years. The study assumes an annual interest rate of $3 \%$. This could be regarded as the real rate for constant dollar analysis. Also, it is low enough to be compatible with the inflation rate. Using the above information, the equivalent annual cost (EAC) of the fixed cost items were calculated as follows: 
Applying the interest rate of $3 \%$ and analysis period, economic recovery period, of 10 years with zero salvage value for the system set-up/construction cost, the EAC becomes:

$\mathrm{EAC}_{\mathrm{Cl}}=\$(140,000 *(\mathrm{~A} / \mathrm{P}, 3 \%, 10)) \quad$ [where $(\mathrm{A} / \mathrm{P}, 3 \%, 10)$ is capital recovery factor] $=(140,000 * 0.1172)$ $=\$ 16,408$

For a vehicle fleet size of 52 including the towing truck, the system automation cost:

$$
\begin{aligned}
C_{2} & =\$(2,000+52 * 300) \\
& =\$ 17,600
\end{aligned}
$$

Equivalent annual cost of $\mathrm{C}_{2}$, for 10 years period, becomes:

$$
\begin{aligned}
E A C_{C_{2}} & =\$(17,600 *(\mathrm{~A} / \mathrm{P}, 3 \%, 10)) \\
& =\$ 2,063
\end{aligned}
$$

Using the straight-line depreciation method (Newman and Lavelle, 1998), the annual depreciation of the vehicle fleet was calculated as:

Annual depreciation $\left(\mathrm{C}_{3}\right)=\$[((23,000-1,500) / 10) * 41+\$((29,000-3,000) / 10) * 10+$ $\$((30,000-4,000) / 10)]$

$C_{3}=\$ 116,750$ per year

Operation control center (OCC) personnel annual cost, $\mathrm{C} 4=\$ 115,000$

Therefore, the total EAC of the capital cost part of SVS cost model $=\mathrm{EAC}$ of $\mathrm{C}_{1}, \mathrm{C}_{2}, \mathrm{C}_{3}$, $\& \mathrm{C}_{4}$ and is equal to $(16,408+2,063+116,750+115,000)=\$ 250,221$

\section{Annual Cost of Variable Cost Items:}

The variable cost items are identified and estimated in the cost analysis section above. The individual variable cost items were estimated as follows: 


$$
\begin{aligned}
& \mathrm{C}_{5}=\text { Energy cost }=\$ 4,421 \text { per year } \\
& \mathrm{C}_{6}=\text { Vehicle maintenance and } \mathrm{ITS} \text { technology usage costs }=\$ 48,960 \\
& \mathrm{C}_{7}=\text { Parts and repair costs }=\$ 25,500
\end{aligned}
$$

Total annual cost for variable cost items $=\$(4,421+48,960+25,500)=\$ 78,881$

The total annual or EAC cost for scenario-1, with ten years analysis period, becomes:

$$
\begin{aligned}
C_{T} & =\text { Equivalent annual } C_{C}+\text { Annual } C_{V} \\
& =\$(250,221+78,881) \\
& =\$ 329,102
\end{aligned}
$$

Therefore, the equivalent annual cost under scenario-1, with ten years recovery period, is $\$ 329,102$. This cost results in an average cost of $\$ 0.59$ per $\mathrm{km}$, for a total travel of $562,716 \mathrm{kms}$ per year, and an average cost of $\$ 3.22$ per trip with an average length of

\section{$5.5 \mathrm{kms}$.}

\section{Scenario 2: Economic Recovery Period of 5-year}

Under scenario-2, it is assumed that the system's capital/fixed costs will be recovered within the first five years of operations.

The total cost model was formulated, in section 6.7 , as:

$$
\mathrm{C}_{\mathrm{T}}=\mathrm{C}_{\mathrm{C}}+\mathrm{C}_{\mathrm{V}}
$$

Where the cost items are;

$\mathrm{C}_{\mathrm{C}}$ is the capital or fixed costs part of the cost model. This part of the cost model is defined as.

$$
\mathrm{C}_{\mathrm{C}}=\mathrm{C}_{1}+\mathrm{C}_{2}+\mathrm{C}_{3}+\mathrm{C}_{4}
$$


$\mathrm{C}_{\mathrm{V}}$ represents the variable costs part of the cost model. This part of the cost model is formulated as follows.

$$
\mathrm{C}_{\mathrm{V}}=\mathrm{C}_{5}+\mathrm{C}_{6}+\mathrm{C}_{7}
$$

\section{Equivalent Annual Cost (EAC) of Capital Cost Items:}

In scenario-2, the economic recovery period is 5 years. The study assumes the same annual interest rate of $3 \%$. Thee equivalent annual costs (EAC) of the fixed cost items were calculated as follows:

Applying the annual interest of $3 \%$ and analysis period, economic recovery period, of 5 years with zero salvage value for the system set-up/construction cost, the EAC becomes:

$$
\begin{aligned}
\mathrm{EAC}_{\mathrm{C} 1} & =\$(140,000 *(\mathrm{~A} / \mathrm{P}, 3 \%, 5)) \quad \text { [where }(\mathrm{A} / \mathrm{P}, 3 \%, 5) \text { is capital recovery factor }] \\
& =(140,000 * 0.2184) \\
& =\$ 30,576
\end{aligned}
$$

For a vehicle fleet size of 52, including the towing truck, the system automation or ITS technology cost:

$$
\begin{aligned}
C_{2} & =\$(2,000+52 * 300) \\
& =\$ 17,600
\end{aligned}
$$

Equivalent annual cost of $\mathrm{C}_{2}$, for economic recovery period of 5 years and an annual interest rate of $3 \%$, becomes:

$$
\begin{aligned}
E A C_{C_{2}} & =\$\left(10,700^{*}(\mathrm{~A} / \mathrm{P}, 3 \%, 5)\right) \\
& =\$\left(17,600^{*} 0.2184\right) \\
& =\$ 3,844
\end{aligned}
$$


Under this scenario, with 5 years economic recovery period, the study assumes a salvage value of 40 percent for all types of EVs. Now using the straight-line depreciation method (Newnan and Lavelle, 1998), the annual depreciation of the vehicle fleet is calculated as:

Annual depreciation $\left(\mathrm{C}_{3}\right)=\$[((23,000-9,200) / 5) * 41+\$((29,000-11,600) / 5) * 10+$ $\$((30,000-12,000) / 5)]$

$\mathrm{C}_{3}=\$ 151,560$ per year

Operation control center (OCC) personnel, station manager and truck operator, annual cost, $\mathrm{C}_{4}=\$ 115,000$

Therefore, the total EAC of the capital cost part of SVS cost model $=E A C$ of $C_{1}, C_{2}, C_{3}$, $\& C_{4}$ and is equal to $(30,576+3,844+151,560+115,000)=\$ 300,980$

\section{Annual Cost of Variable Cost Items:}

It is obvious that annual cost from variable cost items will be same for any economic analysis period, since the total transportation demand per year is constant. Therefore, the variable cost items as computed in "cost estimation" are applicable here and are as:

$$
\begin{aligned}
& C_{5}=\text { Energy cost }=\$ 4,421 \text { per year } \\
& C_{6}=\text { Vehicle maintenance and ITS technology usage costs }=\$ 48,960 \\
& C_{7}=\text { Parts and repair costs }=\$ 25,500
\end{aligned}
$$

Total annual cost for variable cost items $=\$(4,421+48,960+25,500)=\$ 78,881$ The total annual or EAC cost for scenario-2, with five years analysis period, becomes: 


$$
\begin{aligned}
C_{T} & =\text { Equivalent annual } C_{C}+\text { Annual } C_{V} \\
& =\$(300,980+78,881) \\
& =\$ 379,861
\end{aligned}
$$

The resulting equivalent annual cost under scenario-2, with five years recovery period, is $\$ 379,861$. This cost results in an average cost of $\$ 0.68$ per $\mathrm{km}$, for a total vehicle travel of $562,716 \mathrm{kms}$ per year, and an average cost of $\$ 3.71$ per trip with an average trip length of $5.5 \mathrm{kms}$.

\section{Scenario 3: 3-Year Economic Recovery Period}

Under this scenario, it is assumed that the SVS system's capital/fixed costs will be recovered within the first three years of operations.

The total cost model of the SVS was formulated as:

$$
\mathrm{C}_{\mathrm{T}}=\mathrm{C}_{\mathrm{C}}+\mathrm{C}_{\mathrm{V}}
$$

The capital and variable cost items are defined as:

$\mathrm{C}_{\mathrm{C}}$ is the capital or fixed cost part of the cost model and is defined as.

$$
\mathrm{C}_{\mathrm{C}}=\mathrm{C}_{1}+\mathrm{C}_{2}+\mathrm{C}_{3}+\mathrm{C}_{4}
$$

$\mathrm{C}_{\mathrm{V}}$ represents the variable cost part of the SVS cost model and is formulated as.

$$
\mathrm{C}_{\mathrm{V}}=\mathrm{C}_{5}+\mathrm{C}_{6}+\mathrm{C}_{7}
$$




\section{EAC of Capital Cost Items:}

In scenario-3, the economic recovery period is 3 years. As before, the interest rate is $3 \%$. Using the above information, the equivalent annual cost (EAC) of the fixed cost items were calculated as follows:

Applying the annual interest rate of $3 \%$ and analysis period or economic recovery period of 3 years with zero salvage value for the system set-up/construction cost the EAC becomes:

$$
\begin{aligned}
\mathrm{EAC}_{\mathrm{C} 1} & \left.=\$\left(140,000^{*}(\mathrm{~A} / \mathrm{P}, 3 \%, 3)\right) \quad \text { [where }(\mathrm{A} / \mathrm{P}, 3 \%, 3) \text { is capital recovery factor }\right] \\
& =\left(140,000^{*} 0.3535\right) \\
& =\$ 49,490
\end{aligned}
$$

For a vehicle fleet size of 52 , including the towing truck, the system automation or ITS technology cost:

$$
\begin{aligned}
C_{2} & =\$(2,000+52 * 300) \\
& =\$ 17,600
\end{aligned}
$$

Equivalent annual cost of $\mathrm{C}_{2}$, for 3 years period, becomes:

$$
\begin{aligned}
E A C_{C_{2}} & =\$(17,600 *(\mathrm{~A} / \mathrm{P}, 3 \%, 3)) \\
& =\$(17,600 * 0.3535) \\
& =\$ 6,222
\end{aligned}
$$

Under this scenario, with 3 years economic recovery period, the study assumes a salvage value of 60 percent for all types of EVs. Using the straight-line depreciation method (Newnan and Lavelle, 1998), the annual depreciation of the vehicle fleet was calculated as: 
Annual depreciation $\left(C_{3}\right.$ per year $)=\$[((23,000-0.6 * 23,000) / 3) * 41+\$((29,000-$ $0.6 * 29,000) / 3) * 10+\$((30,000-0.6 * 30,000) / 3)]$

$=\$[((23,000-13,800) / 3) * 41+\$((29,000-17,400) / 3) * 10+\$((30,000-18,000) / 3)]$

$=\$ 168,400$

Hence, $C_{3}=\$ 168,400$ per year

Operation control center (OCC) personnel annual cost, $\mathrm{C}_{4}=\$ 115,000$

Therefore, the total EAC of the capital cost part of SVS cost model $=\mathrm{EAC}$ of $\mathrm{C}_{1}, \mathrm{C}_{2}, \mathrm{C}_{3}$, $\& \mathrm{C}_{4}$ and is equal to $(49,490+6,222+168,400+115,000)=\$ 339,112$

\section{Annual Cost of Variable Cost Items:}

As stated in the previous section, the annual cost from variable cost items will be same for any economic analysis period, since the total transportation demand per year is constant. Therefore, the variable cost items as computed in "cost estimation" are also applicable in this scenario and are as:

$$
\begin{aligned}
& C_{5}=\text { Energy cost }=\$ 4,421 \text { per year } \\
& C_{6}=\text { Vehicle maintenance and ITS technology usage costs }=\$ 48,900 \\
& C_{7}=\text { Parts and repair costs }=\$ 25,500
\end{aligned}
$$

Annual cost from variable cost items $=\$(4,421+48,900+25,500)=\$ 78,881$ per year The total annual or EAC cost for scenario-3, with 3 years analysis period, becomes: $\mathrm{C}_{\mathrm{T}}=$ Equivalent annual $\mathrm{C}_{\mathrm{C}}+$ Annual $\mathrm{C}_{\mathrm{V}}$

$$
\begin{aligned}
& =\$(339,112+78,881) \\
& =\$ 417,993
\end{aligned}
$$


Therefore, the equivalent annual cost under scenario-3 with 3 years recovery period is $\$ 417,993$. This cost results in an average cost of $\$ 0.74$ per $\mathrm{km}$, for an annual travel of $562,716 \mathrm{kms}$, and an average cost of $\$ 4.07$ per trip with an average trip length of $5.5 \mathrm{kms}$.

Costs items of all the above scenarios were tabulated and shown Table 6.23. A comparison of EAC and average trip cost under different analysis periods is shown in Figure 6.30. The average cost per trip under different analysis periods are showed on top of each stacked column.

Table 6.23 Estimated cost of scenarios with different analysis periods

\begin{tabular}{|c|c|c|c|c|}
\hline Cost Items & $\begin{array}{c}\text { Total } \\
\text { Estimated } \\
\text { Cost }(\$) \\
\end{array}$ & $\begin{array}{c}\text { EAC for } \\
\text { 10-Year Scenario (\$) }\end{array}$ & $\begin{array}{c}\text { EAC for } \\
\text { 5-Year Scenario (\$) }\end{array}$ & $\begin{array}{c}\text { EAC for } \\
\text { 3-Year Scenario (\$) }\end{array}$ \\
\hline \multicolumn{5}{|l|}{ Capital Costs } \\
\hline Setup Cost & 140,000 & 16,408 & 30,576 & 49,490 \\
\hline Automation Cost & 17,600 & 2,063 & 3,844 & 6,222 \\
\hline $\begin{array}{r}\text { Vehicle Cost } \\
\text { (depreciation) }\end{array}$ & $1,263,000$ & 116,750 & 151,560 & 168,400 \\
\hline $\begin{array}{r}\text { OCC } \\
\text { Personnel Wage }\end{array}$ & 115,000 & 115,000 & 115,000 & 115,000 \\
\hline \multicolumn{5}{|l|}{ Variable Costs/ year } \\
\hline Energy Cost & 4,421 & 4,421 & 4,421 & 4,421 \\
\hline $\begin{array}{r}\text { Maintenance and ITS } \\
\text { Usage Costs }\end{array}$ & 48,900 & 48,960 & 48,960 & 48,960 \\
\hline Parts and Repair Costs & 25,500 & 25,500 & 25,500 & 25,500 \\
\hline \multicolumn{2}{|l|}{ Total Cost } & 329,102 & 379,861 & 417,993 \\
\hline Average cost per km (\$) & & 0.59 & 0.68 & 0.74 \\
\hline Average cost per trip (\$) & & 3.22 & 3.71 & 4.07 \\
\hline
\end{tabular}




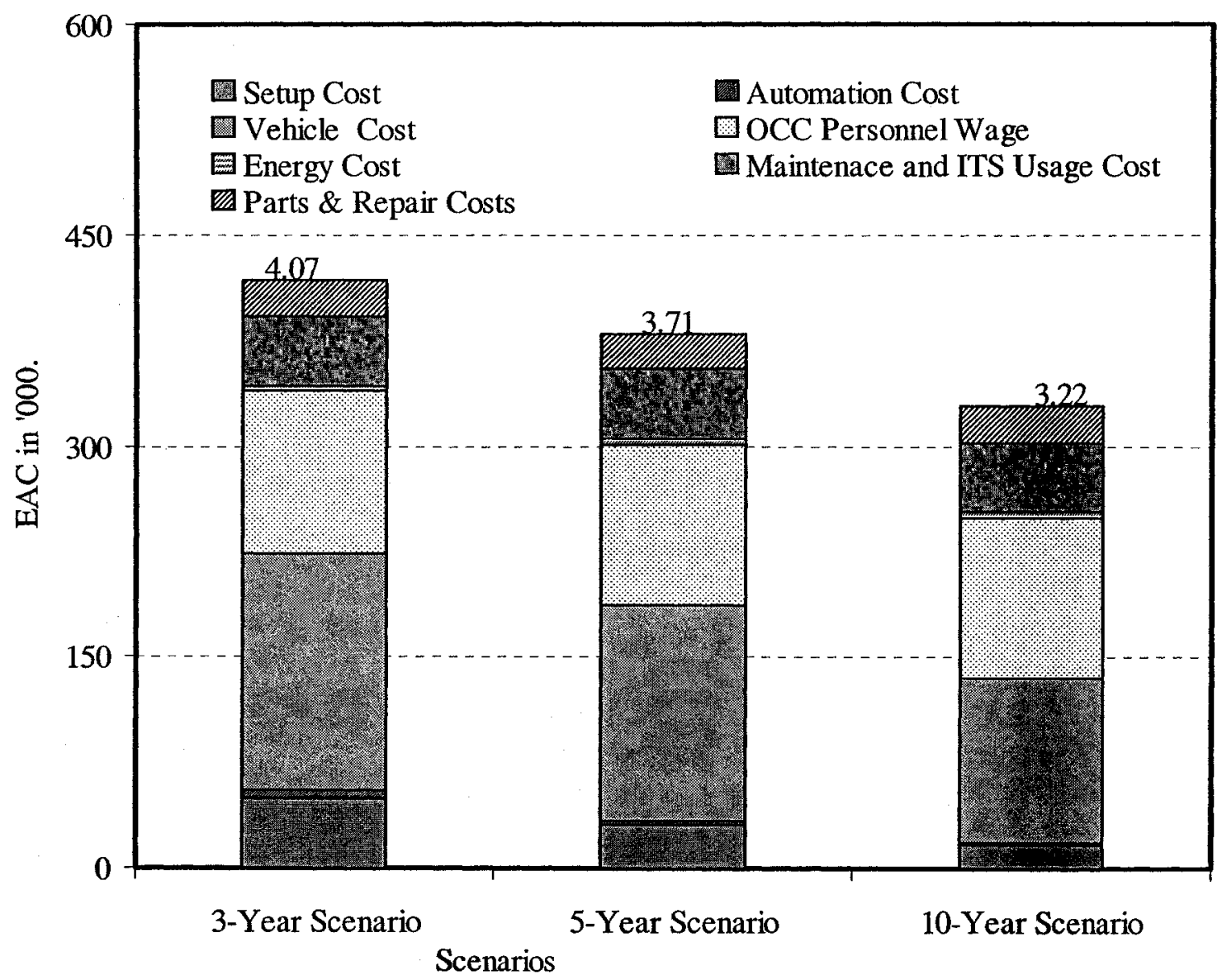

Figure 6.30 Estimated cost of scenarios with different analysis periods

Further, an analysis was performed on the share, in percent, of different cost items within the overall equivalent annual cost (EAC). Figures 6.31 and 6.32 showed the share of individual cost items within the EAC under analysis periods of 10-year and 3-year. 


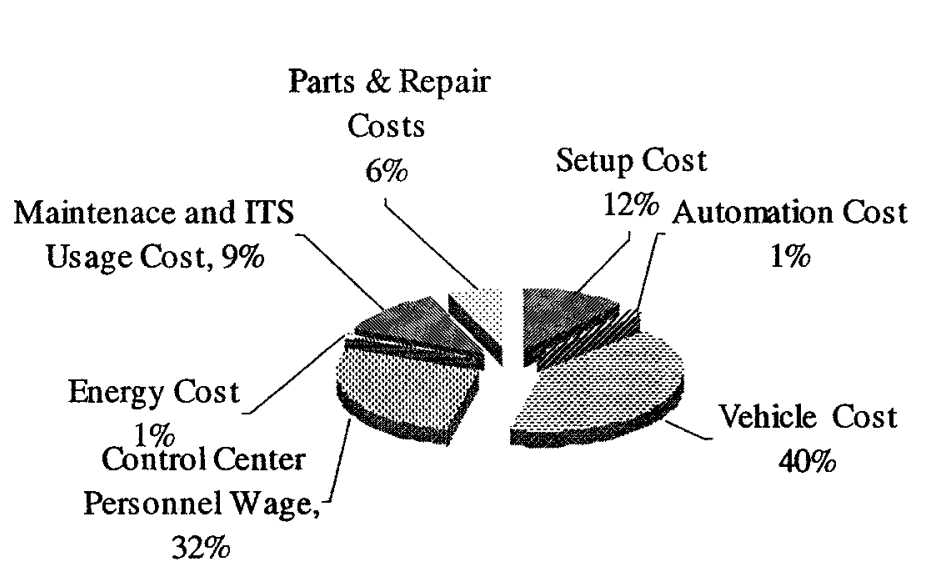

3-Year Scenario

arts \& Repair

Figure 6.31 Share (\%) of individual cost items in total cost for 3-year analysis period

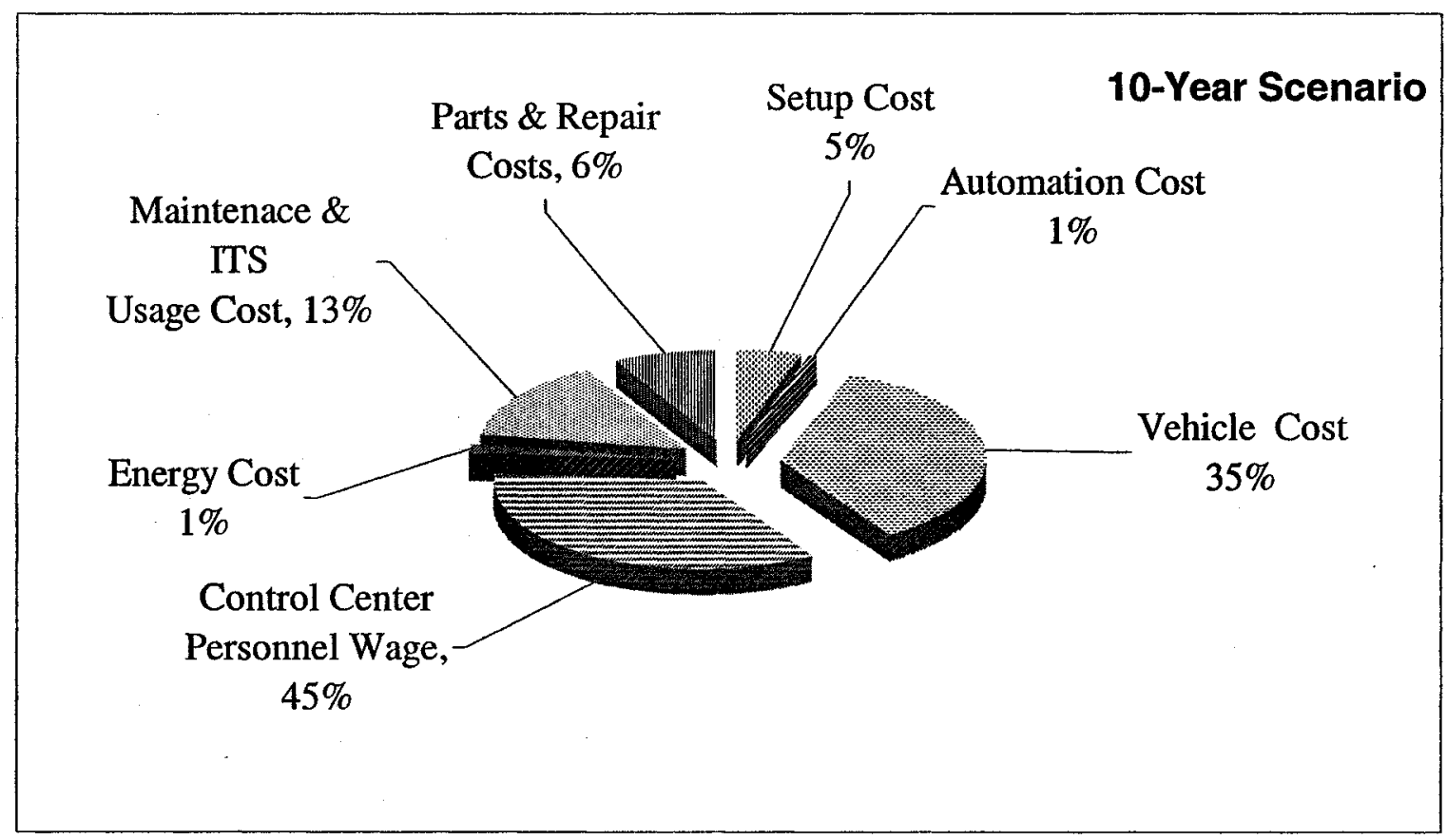

Figure 6.32 Share (\%) of individual cost items in total cost for 10-year analysis period 


\section{CHAPTER VII}

\section{CONCLUSIONS AND RECOMMENDATIONS}

\subsection{Conclusions}

Based on the results of this research, obtained with the case study data, the following conclusions can be reached.

1. The methodological framework based on discrete-event simulation technique and application of queuing theory to network that was implemented in Microsoft Visual $\mathrm{C}++$ environment in association with the event-oriented system simulation toolkit CSIM19 and Use Case modelling technique is found suitable for the shared vehicle system (SVS) design and operation research problem. Appropriate system measures of performance indicators were used to assess designs and operations. An iterative approach was employed to find the best design and efficient operation configuration of shared vehicle system.

2. A complete set of variables was taken into consideration to model the design and operations of SVS system in simulation. This set of variables was identified and selected through a comprehensive review of available literature, and the characteristics of the shared vehicle systems and the travel market they are intended to serve.

3. Ninety-five percent of the total demand service level was found to be efficient with respect to number of vehicle relocations, vehicle-to-trip ratio or the fleet size, and therefore the number of parking slots per station. This is also found to be 
economical to avoid costs incurred from excessive number of vehicles in the fleet and required number of parking slots to serve the 100 percent demand.

4. It was observed that shared vehicle systems performance is highly sensitive to vehicle-to-trip ratio as well as parking-to-vehicle ratio.

5. A vehicle-to-trip ratio of 10.5 percent was found to be the best/efficient for the case study travel demand, in satisfying an average user wait time of about 11 minutes, keeping number of vehicle relocations to about 30 per operation day. This value of the number of relocations is significantly lower than achieved by Barth and Todd (1999). They found that 150 relocations per 24-hour operation day were necessary for similar system (in terms of number of stations) and travel demand. This reduction in relocations may be attributed to the consideration of party size in customer/trip arrival.

6. A parking-to-vehicle ratio of 2:1 was found to be the best design value, for the case study travel demand, in satisfying an average user wait time of 11 minutes while keeping number of relocations to about 30 per operation day.

7. Another evidence of the suitability of the developed methodology can be seen from the study of extreme value. For example, excessive average waiting time, an average of 40 minutes was observed at lower vehicle to trip ratios i.e., 3.5 to 6.0 percent. On the other hand, the number relocations was observed to be fewer at lower vehicle-to-trip ratios (3.5 to 5.0 ). This result illustrates the insufficiency of vehicles in the system at low vehicle-to-trip ratio. In comparison, the customer wait time and the vehicle relocations are reasonable at the best value of vehicle-to-trip ratio of $10.5 \%$. 
8. In all case scenarios, the relationship of vehicle-to-trip ratio and customer average waiting time demonstrates the same pattern with an inflection point at 10.5 percent for the case study application.

9. The shape of the vehicle-to-trip ratio and number of relocations plots remain the same in all design scenarios for the case study SVS system.

10. A gradual decrease in queue length, in terms of number of trips, was observed with an increase in vehicle-to-trip ratio. An average queue length of 27 trips was observed at vehicle-to-trip ratio of 3.5 percent and 16 at the best/efficient design vehicle-to-trip ratio of 10.5 percent.

11. The simulation results revealed that the percent of demand served, which relates to the shared vehicle system (SVS) capacity, was found to increase with vehicle-to-trip ratio. At vehicle-to-trip ratio of 3.5 percent, only 55 percent of the total demand, on average, can be served. At the best design vehicle-to trip ratio of 10.5 percent, an average of 95 to 97 percent of the total demand can be served.

12. An analysis of percent of capacity gain to serve demand (in percent) with increasing vehicle-to-trip ratio showed that the gain in capacity at lower vehicle-to-trip ratio is higher and diminished at the value of 10.5 percent for the case study area. This result implies that it is important to find the efficient or best design vehicle-to-trip ratio and/or fleet size so as to obtain the benefits of sustainable and economic design and operations of multiple station shared vehicle systems.

13. Under scenario-2, normal Markov process was adopted to model the customer arrival process. The model results showed that the SVS performance is not significantly affected with respect to customer average wait time, number of 
relocations, and system capacity to serve the given demand. It was found that the modified Markov process is a realistic technique or method to model the customer "arrival process" for modelling shared vehicle system operations.

14. Under scenario-3, the Bayesian probabilistic technique was used in order to improve trip travel time estimates. The simulated system results showed that the SVS system is 'not sensitive' to the accuracy gain in travel time with respect to customer average waiting time and number of relocations. This observation applies to the present case study area. However, it is logical to suggest that this method is much more useful than the deterministic method employed by Barth and Todd (1999). This could be a holistic or robust approach in capturing the effects of rare events on trip travel time and thus improve system performance.

15. Sensitivity test results provide insights into the SVS characteristics. The travel time sensitivity results showed that the system performance was not significantly affected until trip travel times were 1.75 times, on average, longer than the base travel times.

16. Analysis with higher travel demand, specifically 1.5 and 2.0 times the original demand, in the same SVS system, resulted in a lower optimal vehicle-to-trip ratio of 8.5 and 6.2, respectively. This finding suggests that SVS systems with higher demand could be served with lower vehicle-to-trip ratio and hence more economically.

17. The simulation results showed that for a given travel demand level, with the best design vehicle-to-trip and parking-to-vehicle ratios, the number of relocations needed to keep the waiting time reasonable is increased linearly with number of 
stations in the SVS system. The implication is that the number of stations should be kept to a reasonable limit.

18. It was found that the mean vehicle state-of-charge was about 60.0 percent with a standard deviation of 6.6 , which constitutes a COV of 10.9 percent for the case study system. This result demonstrates the fact that the model EVs are suitable to serve the case study shared vehicle system travel demand even with the existing battery range characteristics.

19. As for petroleum fuel displacement, this research clearly demonstrates that an urban travel demand market niche can be served with vehicles that do not require petroleum fuels. In this research, electric vehicles (EV) are used.

20. A preliminary cost analysis was carried out with 3,5 , and 10 years of service periods. The average cost per trip under the three analysis periods was found to be very reasonable. For an average trip length of $5.5 \mathrm{kms}$, the cost per trip ranged from $\$ 4.07$ to $\$ 3.22$ in 2005 Canadian dollars. These results illustrate the fact that such a system could be very competitive with taxis and private automobiles in terms of cost.

\subsection{Recommendations}

1. This research focused on the development of an improved simulation model and its methodological framework for the design and operations studies of multiple station shared vehicle systems (SVS). The application of the model was demonstrated by using a modified database on the Canadian Base Force, Ottawa. Since the model and the broader methodology cover essential features of the multiple station SVS 
design and operations and also go beyond previous research on this subject, these can be used in their present form.

2. As reported in this thesis document, a modified database from previous research is used in this study to develop an application of the model and evaluate its performance. To go beyond this research, further research is recommended on the identification of market segments and estimation of travel demand for a potential shared vehicle system implementation at other sites. The use of stated preference (SP) approach, described in Appendix A, is recommended for demand studies.

3. Within an urban area, a number of locations can be considered for locating SVS stations, a combined travel demand of business companies and residential communities could be served efficiently with multiple station SVS. Therefore, the application of the developed model in a combined travel demand market is recommended.

4. The study focused on the application and evaluation of the simulation model performance of a multiple station shared vehicle system. Therefore, development of an application of the simulation model for a station car system is recommended.

5. Due to the unavailability of a real world multiple station shared vehicle system in Canada, it was not possible to validate the results obtained from the simulation model developed in this study. A research effort is recommended to validate research findings with an existing real world multiple station shared vehicle system operating elsewhere in the world.

6. It is acknowledged in the literature that human behaviour is complex and therefore, it is difficult to predict the acceptance of a new transportation system/service 
(Shaheen, 2000). Individuals from different communities and nations have different perspectives on mode choice and acceptance of new and innovative systems. Communities and nations with higher traffic related problems are more likely to use the SVS system than those who have not experienced traffic impacts. Therefore, research is recommended on exploring market niches for SVS systems in different geographical contexts.

7. The methodological framework used for the development of the SVS simulation model is very general in structure. Therefore, it could be used for modelling design and operations of other systems and services that are multiple stations in nature and there are movements of passengers or goods among them. For example, the developed methodology and model could be used for design and operations by airlines that transport passengers and goods among different airports with appropriate aircraft and fleet sizes.

In conclusion, this thesis research illustrated the methodology for the development of an improved shared vehicle system simulation model using discrete-event simulation technique and application of queuing theory to network while considering a complete set of design variables. A preliminary cost analysis is carried out to check the shared vehicle system's economic competitiveness with relevant other modes. Therefore, the results should be of interest to transportation and urban planners as well as transportation and environmental policy makers and researchers. 


\section{REFERENCES}

Alhir, Sinan (2000): Understanding Use Case Modeling, Methods \& Tools, 2000.

Arnaldi, Bruno, Cozot, Remi, Donikian, Stephene, and Parent, Michael (1998): Simulation Models for French Praxitele Project, Transportation Research Record, 1521.

Banks, James (2002): Introduction to Transportation Engineering, $2^{\text {nd }}$ Edition, McGraw Hill.

Barth, Matthew, and Shaheen, Susan (2002): Classification of Shared Vehicle Systems, Transportation Research Board, Proceedings, $79^{\text {th }}$ Annual Meeting, Washington, D.C.

Barth, Matthew and Todd, Michael (2001): User Behavior Evaluation of an Intelligent Shared Vehicle System, Transportation Research Board, Proceedings, $78^{\text {th }}$ Annual Meeting, Washington, D.C.

Barth, Matthew and Todd, Michael (2000): Intelligent Transportation System Architecture for a Multi-Station Shared Vehicle System, 2000 IEEE Intelligent Transportation Systems Conference Proceedings.

Barth, Matthew and Todd, Michael (1999): Simulation Model Performance Analysis of a Multiple Station Shared Vehicle System, Transportation Research Part C, Vol. 7.

Barth, Matthew, Todd, Michael, and Li, Jenny (1998): ICVS Research and Development, Phase 4, Final Report, Prepared for Honda R\&D North America, Inc.

Barth, Matthew, Todd, Michael, Anderson, Daniel, and Li, Jenny (1997): Evaluation of ICVS for the Palm Springs Area, CA. Phase 3, Final Report, Prepared for Honda R\&D North America, Inc. 
Bernard, Martin (1999): Charging, Smart, and Queuing Infrastructure Requirements for Station Cars, Prepared for 1999 North American EV Infrastructure Conference and Exposition, Atlanta, Georgia, USA.

Bernard, Martin, and Collins, Nancy (2001): Shared, Small, Battery Powered Electric Cars as a Component of Transportation System Sustainability, Transportation Research Record, No. 1750.

Bernard, Martin, and Collins, Nancy (1999): Shared EV in Denver: Extending the station car and Car Sharing Concepts, Q4 Associates, Oakland, CA, USA.

Bemard, Martin, and Collins, Nancy (1998): San Francisco Bay Area Station Car Demonstration Evaluation. Bay Area Rapid Transit District, Oakland, CA, USA.

Bernard, Martin and Nerenberg, V. (1998): Station Cars: Transit Based Smart Car Sharing Concept, National Station Car Association, Oakland, CA, USA.

Cousins, S. H., (1998): A Model of Car Availability in Car-Sharing Scheme of Different Sizes, Traffic Engineering \& Control, February 1998.

CSIM19 (2002): CSIM19 Simulation Engine (a general purpose simulation toolkit), Mesquite Software, Inc., Austin, TX, USA.

European Car Sharing (ECS) (1997): website www.carsharing.org.

Euronet and ICLEI (1996): StattAuto: Organization of Carsharing, website at www.iclei.org. 
Fastlane (1997): Volkswagen Pioneers Car Sharing Programs, website at www.carsharing.net.

Fishman, Robert (1999): The American Metropolis at the Century's End: Past and Future Influences, Housing Facts \& Findings, Vol.1, No. 4.

Garcia, Jaime (2004): Modelling Fuel Consumption of Advanced Technology Vehicles in Traffic Networks Using Artificial Neural Networks, Ph.D. Dissertation, Carleton University, Ottawa, ON, Canada.

Hole, Arne (2004): Forecasting the demand for an employee Park and Ride service using commuters' stated choices, Department of Economics, University of St Andrews, St. Andrews, Scotland, UK.

Katzev, Richard (1999): Carsharing Portland: Review and Analysis of Its First Year, Prepared for Oregon Department of Environmental Quality, Public Policy Research, Portland, Oregon, USA.

Katzev, Richard (1998): Car sharing: Breaking out of the transportation trap, World Transport Policy and Practice, Volume 3, No 4.

Lightfoot, George (1997): Pay As You Drive, Carsharing Final Report, EU-SAVE, Ireland

Liu, C., Sinha, Kumares, Fricker, Jon (1983): Simulation Analysis of a Mobility Enterprise System Operation, Journal of Advanced Transportation, Vol. 17, No. 2.

Martin, F. (1988): Computer Modeling and Simulation, New York: John Wiley and Sons.

Miller, John P. (1982): The Use of Electric Vehicles in CFB Ottawa's Base Taxi Fleet-A Comparative Cost Study, M.Eng. Thesis, Carleton University, Ottawa, ON, Canada. 
Munheim, P. (1998): Car Sharing Studies: An Investigation, Lucerne, Switzerland.

Nakayama, Shoichiro, Yamamoto, Toshiyuki, and Kitamura, Ryuichi (2001): A Simulation Analysis for the Management of an Electric-Vehicle Sharing System: The Case of the Kyoto Public-Car System, Transportation Research Board, Proceedings, $80^{\text {th }}$ Annual Meeting, Washington, D.C.

Newman, D., and Lavelle, J. (1998): Engineering Economic Analysis, Seventh Edition, Engineering Press, Austin Texas, USA.

Pooch, Udo and Wall, James (1993): Discrete Event Simulation: A Practical Approach, CRC Press, Florida, USA.

Reutter, Oscar and Bohler, Susanne (2000): Car Sharing for Business: The Aachen Region Pilot Project, World Transport Policy and Practice, Vol. 6, 2000.

Rifkin, Jeremy (2000): The Age of Access: The New Culture of Hypercapitalism, Where all of Life Is a Paid-For Experience, New York, USA, Tarchwe/Putnam Books.

Riley, Sarah (2002): Development of a Public Transit Information System Using GIS and ITS Technologies, M.A.Sc. Thesis, Carleton University, Ottawa, ON, Canada.

Salon, D., Sperling, D., Shaheen, S., and Sturges, D. (1999): New Mobility: Using Technology and Partnerships to Create More Sustainable Transportation, Institute of Transportation Studies, University of California, Davis, CA, USA. 
Schmeck, H. (1999): Mobility Services Made by Daimler Chrysler (DC). Presentation at Eco99: Workshop "Enhancing Eco-efficiency in Transportation”, Paris, France.

Shaheen, Susan (1999): Dynamics in Behavioral Adaptation to a Transportation Innovation: A Case Study of CarLink-A Smart Carsharing System, Ph.D. Dissertation, Institute of Transportation Studies, University of California at Davis, CA, USA.

Shaheen, Susan (2000): Commuter-Based Carsharing: Market Niche Potential, Transportation Research Record No. 1760.

Shaheen, Susan and Uyeki, Robert (2000): Carlink Economics: An Empirically-Based Scenario Analysis, University of California Davis, ITS Report no. 00-21.

Shaheen, Susan, Sperling, Daniel, and Wagner, Conrad (1998): Carsharing in Europe and North America: Past, Present, and Future, Transportation Quarterly, Vol. 52, No. 3.

Shaheen, Susan, Sperling, Daniel, and Wagner, Conrad (1999): Carsharing and Partnership Management: An International Perspective, Transportation Research Record No. 1666.

Shaheen, Susan, Sperling, Daniel, and Wagner, Conrad (2000): Carsharing and Mobility Services: An Updated Overview, San Francisco, CA, USA.

Shaheen, Susan, Write, J., and Sperling, Daniel (2002): California's Zero Emission Vehicle Mandate-Linking Clean Fuel Cars and Shared-Used Vehicles, TRB Paper 02-3587. 
Shaheen, Susan, Cohen, Adam, and Roberts, Darius (2005): Carsharing in North America: Market Growth, Current Developments, and Future Potential, Proceedings, ITS World Congress, San Francisco, CA, USA.

Shannon, Robert (1975): Simulation: A Survey with Research Suggestions, AIIE Transactions.

Sohmer, R., and Lang, R. (1999): Life at the Center: The Rise of Downtown Housing, Housing Facts \& Findings, Vol. 1, No. 1.

Tayyaran, Mohammad (2000): Impacts of Telecommuting, and Related Aspects of Intelligent Transportation Systems on Residential Location Choice: A Combined Revealed and Stated Preference Approach, Ph.D. Dissertation, Carleton University, Ottawa, ON, Canada.

Wagner, Conrad and Shaheen, Susan (1998): Car Sharing and Mobility Management: Facing New Challenges with Technology and Innovative Business Planning, World Transport Policy \& Practice, Vol. 4, No. 2.

Walb, Carol and London, William (1986): Evaluation of the Short-Term Auto Rental (STAR) Service in San Francisco, CA, Final Report, 1986.

Website_01: European Carsharing at www.carsharing.org

Website_02: Car-coop Singapore at www.carcoop.com.sg

Website_03: National Station Car Association at www.stncar.com 
Yamaguchi, Shinichi (2000): Evaluation results of Crayon (Toyota EV Commuter System) experiment, prepared for Environment affairs division, Toyota City, Japan.

Zegras, Christopher, and Gakenheimer, Ralph (1999): Car Sharing Organizations in Latin America: Examining Prospects for Santiago, Massachusetts Institute of Technology, Cooperative Mobility Program, Working Paper 99-4-1, MIT, MA, USA. 


\section{APPENDIX A \\ DEMAND ESTIMATION FOR NEW SITE: \\ STATED PREFERENCE APPROACH}

\section{A.1 Introduction}

In this research effort, a powerful discrete-event simulation model was developed to analyze shared vehicle systems (SVS) design and operations. Focus was on multiple station shared vehicle systems including station car systems. A travel database developed and used by Miller (1982) in his master's thesis was modified and used to implement the model. The database was also used to evaluate design and operational issues of multiple station shared vehicle systems under different case scenarios. A challenge of this research effort was to acquire travel demand data for an existing or hypothetical system to model the SVS and simulate, and evaluate the performance under different operating scenarios. The Canadian Force Base (CFB) Ottawa's Taxi system, studied by Miller (1982) was closed due to downsizing of the Federal Government. However, given useful attributes of the database, it was decided to project travel factors to the 2005 level. This approach worked well in this thesis research.

For other sites, existing databases may not be available. Therefore, there is a need to define methodology for obtaining travel related inputs required by the simulation model. Literature on travel demand forecasting for new transportation mode, service, or facility shows that Stated Preference (SP) or Stated Choice (SC) approach is an accepted technique for 
collecting data on potential users' preferences and choices. Such information can be used as inputs to simulation models and/or discrete choice models (Tayyaran, 2000 and Hole, 2004).

In the SP technique, the researcher can work with the factors that influence the choice or preference of respondents. This is mainly due to the flexibility of the SP approach to study new alternatives and attributes and to incorporate a wider range of attribute levels than what is observed in the market (Tayyaran, 2000 and Hole, 2004). However, literature indicates that the use of SP data has also been met with much skepticism or uncertainty because of the hypothetical nature of the data (Hole, 2004). The question is simply "how reliable are the data that are elicited/obtained from a hypothetical choice situation" (Hole, 2004). It is argued by several practitioners that SP data seem to be reliable given that the experiment is well designed and clearly explained to the respondents (Tayyaran, 2000 and Louviere et al, 2000). There is also a growing body of evidence of successful use of SP models in travel and other demand forecasting (Beaton et al, 1998, Fowkes and Tweddle, 1999: mentioned in Hope, 2004, and Tayyaran, 2000).

An SP survey can be designed for the purpose of travel demand forecasting for a planned SVS. In such a design, the following characteristics of the SP technique should be used to enhance the quality of information:

- SP surveys or experiments can be designed to reduce or eliminate interdependency among attributes,

- This method can provide respondents with broader ranges of choice attributes 
- The SP survey can include policies and alternatives that are completely new (Louviere et al, 1981: stated in Tayyaran, 2000, and Hole, 2004).

Three different types of stated preference (SP) techniques are in use for measuring individuals' utility (Tayyaran, 2000) and collecting stated preference data. These three techniques include:

1. Ranking Responses,

2. Rating Responses, and

3. Choice Responses or Stated Choices

Among the three, the choice responses or stated choices technique is believed to be the most reliable method in eliciting choice or preference data in travel demand forecasting.

\section{A.2 SP Survey Contents}

Survey methodology and questionnaire should be developed and tested prior to the actual implementation. The sample size should be established according to the principles of statistics. The questionnaire can be structured into the following parts:

\section{Part I: Socio-demographic and Travel Related Information}

1. Personal and demographic information,

2. Daily travel information, including trips for which a shared vehicle could be considered as an alternative to the private automobile or taxi, 
3. For selected trips, information on travel attributes (i.e., trip purpose, origin and destination (from which trip length can be estimated), party size, mode(s) used) will be required, and

4. Willingness to use SVS, and associated cost and service factors

\section{Part II: SP Questions Regarding Shared Vehicle System (SVS)}

1. Attributes and Their Levels: In the stated preference analysis, one would relate a series of independent variables (i.e., attributes) to some dependent variable such as mode choice, in our case the choice of SVS. Each of these attributes will have two or more levels, as designated by the SP survey designer (Kocur et al, 1982; mentioned in Tayyaran, 2000). Hole (2004) suggested, to increase the realism of an SP survey the attributes should be based around the individuals' actual travel related cost and its impacts when travelling by the usual mode. In our case, these are private automobile and taxi.

\section{A.3 The SP Experiment}

Having identified the attributes and their levels/magnitudes (qualitative or quantitative), the attribute levels are combined into an experiment (Tayyaran, 2000). The mix of attribute levels describes an alternative for a particular mode. The alternatives include the new mode i.e., the SVS. The potential user (i.e., the person who participates in the SP experiment) is given a number of options or choices. In a full factorial or orthogonal design, the number of options becomes very large and the experiment likely to cause fatigue in terms of respondents' capacity to participate in the experiment. It has been suggested in the literature that a partial 
factorial design is appropriate for the survey design (Tayyaran, 2000). The detailed design of the SP survey (including questionnaire and sample size) is beyond the scope of this thesis research. 


\section{APPENDIX B}

TRAVEL DEMAND AND TRAVEL TIME DATA 
Table B.1 Origin-Destination Matrix of CFB Ottawa Base Taxi for Selected Stations, October 1979

\begin{tabular}{|c|c|c|c|c|c|c|c|c|c|c|c|c|c|c|c|c|c|c|c|c|c|c|c|}
\hline & & & & & & & & & & OR & $\bar{G}$ & $\bar{N}$ & & & & & & & & & Sub- & Other & \\
\hline & & 3 & 5 & 8 & 10 & 12 & 13 & 20 & 23 & 26 & 27 & 29 & 30 & 31 & 32 & 33 & 41 & 42 & 43 & 44 & Total & DND & Total \\
\hline & 3 & 18 & 1 & 1 & 6 & & & & & 3 & 2 & 1 & & & & & 1 & & & 13 & 46 & 2 & 48 \\
\hline & 5 & & 2 & & & & & & & 4 & & & & & & & & & & & 6 & & 6 \\
\hline$n$ & 8 & 2 & & & 3 & & 8 & & 4 & 27 & & & & & & 2 & & & & 1 & 47 & & 47 \\
\hline$z$ & 10 & 12 & & 2 & 1 & 1 & & 1 & 1 & 7 & & & 1 & 3 & & & & & & & 29 & 1 & 30 \\
\hline 0 & 12 & & 1 & & & 1 & . & & 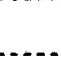 & - & 1 & & 1 & & 2 & & & 1 & 17 & & 24 & & 24 \\
\hline$\mapsto$ & 13 & & & 3 & & & 13 & & 1 & 5 & 1 & 18 & & & & 1 & & 1 & & 11 & 54 & 3 & 57 \\
\hline$E$ & 20 & & & & 1 & & & & 1 & 3 & & & & & & 1 & 2 & & & & 8 & & 8 \\
\hline$\varangle$ & 23 & & & & & & 1 & & 35 & 18 & & & & & & & 1 & & 3 & 1. & 59 & 1 & 60 \\
\hline Z & 26 & 4 & 3 & 21 & 2 & & & 3 & 9 & 97 & 4 & 1 & 28 & 7 & 4 & 8 & 21 & & 4 & 32 & 248 & 8 & 256 \\
\hline$\mapsto$ & 27 & 3 & & & & & 1 & 1 & 1 & 6 & 3 & & & & & & & 7 & & & 22 & & 22 \\
\hline$E$ & 29 & 1 & & & & & 20 & & & . & & & & & & & & & & & 21 & & 21 \\
\hline 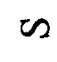 & 30 & & & & & 2 & 1 & 2 & & 40 & & & & & & 3 & & & & & 48 & 4 & 52 \\
\hline [I] & 31 & & & & & & & & & 5 & & & & 19 & & & & & & & 24 & 1 & 25 \\
\hline A & 32 & & & & & 4 & & & & 7 & & & & & & & & & & & 11 & & 11 \\
\hline & 33 & & & & & & & 2 & & 13 & & & 1 & & & 4 & & & & & 20 & 2 & 22 \\
\hline & 41 & 1 & & & & & 2 & & & 36 & 1 & & & 1 & & & 8 & & & & 49 & & 49 \\
\hline & 42 & & & & & 1. & 1 & & 2 & 1 & 1 & & & & & & & 1 & & & 7 & & 7 \\
\hline & 43 & & & & 1 & 17 & & & 4 & 7 & & & & & & & & & 1 & & 30 & 1 & 31 \\
\hline & 44 & 13 & & 1 & 1 & 1 & 19 & & 2 & 47 & & & & & & & & & 1 & 7 & 92 & 3 & 95 \\
\hline & $\begin{array}{l}\text { Sub- } \\
\text { Total }\end{array}$ & 54 & 7 & 28 & 15 & 27 & 66 & 9 & 60 & 326 & 13 & 20 & 31 & 30 & 6 & 19 & 33 & 10 & 26 & 66 & 846 & 26 & 872 \\
\hline & $\begin{array}{l}\text { Dther } \\
\text { DND }\end{array}$ & 6 & 2 & 4 & 4 & & 6 & & & 23 & & 4 & & 2 & & 4 & & 2 & & 1 & 58 & 7 & 65 \\
\hline & Total & 60 & 9 & 32 & 19 & 27 & 72 & 9 & 60 & 349 & 13 & 24 & 31 & 32 & 6 & 23 & 33 & 12 & 26 & 67 & 904 & 33 & 937 \\
\hline
\end{tabular}

Note: DND -Department of National Defense 
Table B.2 Candidate Station Selection Analysis

\begin{tabular}{|c|c|c|c|c|c|c|}
\hline \multirow{2}{*}{ Demand } & \multicolumn{7}{|c|}{ Stations Number } & \multirow{2}{*}{ Total } \\
\cline { 2 - 7 } & 3 & 13 & 23 & 26 & 44 & \\
Weekly demand & 40 & 25 & 24 & 133 & 35 & 240 \\
\hline Daily Demand & 8 & 5 & 5 & 27 & 7 & 48 \\
\hline $\begin{array}{c}\text { Projected Demand } \\
(2005)\end{array}$ & 98 & 75 & 74 & 99 & 81 & 100 \\
\hline
\end{tabular}

Note: All data are rounded to nearest integer values.

Two scenarios that satisfied minimum travel demand set by Barth \& Todd (1999)

\begin{tabular}{|c|c|c|c|c|}
\hline $\begin{array}{c}\text { No. of } \\
\text { Stations } \\
\text { in scenario }\end{array}$ & $\begin{array}{c}\text { Min. Demand } \\
\text { (Barth \& Todd) }\end{array}$ & $\begin{array}{c}\text { Projected Demand } \\
\text { (trips/day) }\end{array}$ & $\begin{array}{c}\text { Selected Stations } \\
\text { Number }\end{array}$ & $\begin{array}{c}\text { Min. } \\
\text { Demand } \\
\text { Fulfilled }\end{array}$ \\
\hline 3 & $40-60$ & 72 & $13,23,26$ & Yes \\
\hline 5 & $60-80$ & 95 & $3,13,23,26,44$ & Yes \\
\hline
\end{tabular}

Table B.3 Selected Candidate Stations

\begin{tabular}{|c|l|}
\hline $\begin{array}{c}\text { Selected Station No. } \\
\text { (in Miller study) }\end{array}$ & Station Description \\
\hline 3 & Berger Bldg - 100 Metcalfe \\
\hline 13 & Elggar Bldg - 200 Elgin \\
\hline 23 & L'Esplanade Laurier - 140 O'Connor \\
\hline 26 & National Defence HQ - 101 Col By \\
\hline 44 & CFB Ottawa - Rockcliffe Park \\
\hline
\end{tabular}

Day - normal working day with 9-hour duration

Station number and name source: M.Eng Thesis by Miller (1982) 
Table B.4 5-Station SVS System Travel Demand

\begin{tabular}{|c|c|c|c|c|c|c|c|c|c|c|}
\hline & $\begin{array}{c}8: 00- \\
9: 00\end{array}$ & $\begin{array}{c}9: 00- \\
10: 00\end{array}$ & $\begin{array}{c}10: 00-00 \\
11: 0\end{array}$ & $\begin{array}{c}11: 00-00 \\
12: 00\end{array}$ & $\begin{array}{c}12: 00 \\
1: 00\end{array}$ & $\begin{array}{c}1: 00- \\
2: 00\end{array}$ & $\begin{array}{c}2: 00- \\
3: 00\end{array}$ & $\begin{array}{c}3: 00- \\
4: 00\end{array}$ & $\begin{array}{c}4: 00- \\
5: 00\end{array}$ & Total \\
\hline $\begin{array}{c}\text { Station } \\
\# 1\end{array}$ & 10 & 11 & 12 & 11 & 10 & 10 & 12 & 10 & 12 & 98 \\
\hline $\begin{array}{c}\text { Station } \\
\# 2\end{array}$ & 7 & 10 & 9 & 12 & 7 & 10 & 11 & 7 & 2 & 75 \\
\hline $\begin{array}{c}\text { Station } \\
\# 3\end{array}$ & 11 & 2 & 3 & 15 & 11 & 2 & 8 & 11 & 11 & 74 \\
\hline $\begin{array}{c}\text { Station } \\
\# 4\end{array}$ & 12 & 3 & 14 & 10 & 12 & 11 & 15 & 12 & 10 & 99 \\
\hline $\begin{array}{c}\text { Station } \\
\text { \#5 }\end{array}$ & 8 & 15 & 2 & 13 & 8 & 15 & 9 & 8 & 3 & 81 \\
\hline Total & 48 & 41 & 40 & 61 & 48 & 48 & 55 & 48 & 38 & 427 \\
\hline
\end{tabular}

Table B.5 5-Station SVS System Travel Demand 1.5 times of Original

\begin{tabular}{|c|c|c|c|c|c|c|c|c|c|c|}
\hline & $\begin{array}{c}8: 00- \\
9: 00\end{array}$ & $\begin{array}{c}9: 00- \\
10: 00\end{array}$ & $\begin{array}{c}10: 00 \\
11: 00\end{array}$ & $\begin{array}{c}11: 00 \\
12: 00\end{array}$ & $\begin{array}{c}12: 00 \\
1: 00\end{array}$ & $\begin{array}{c}1: 00- \\
2: 00\end{array}$ & $\begin{array}{c}2: 00- \\
3: 00\end{array}$ & $\begin{array}{c}3: 00- \\
4: 00\end{array}$ & $\begin{array}{c}4: 00- \\
5: 00\end{array}$ & Total \\
\hline $\begin{array}{c}\text { Station } \\
\# 1\end{array}$ & 15 & 17 & 18 & 17 & 15 & 15 & 18 & 15 & 18 & 148 \\
\hline $\begin{array}{c}\text { Station } \\
\# 2\end{array}$ & 11 & 15 & 14 & 18 & 11 & 15 & 17 & 11 & 3 & 115 \\
\hline $\begin{array}{c}\text { Station } \\
\# 3\end{array}$ & 17 & 3 & 5 & 23 & 17 & 3 & 12 & 17 & 17 & 114 \\
\hline $\begin{array}{c}\text { Station } \\
\# 4\end{array}$ & 18 & 5 & 21 & 15 & 18 & 17 & 23 & 18 & 15 & 150 \\
\hline $\begin{array}{c}\text { Station } \\
\# 5\end{array}$ & 12 & 23 & 3 & 20 & 12 & 23 & 14 & 12 & 5 & 124 \\
\hline Total & 73 & 63 & 61 & 93 & 73 & 73 & 84 & 73 & 58 & 651 \\
\hline
\end{tabular}


Table B.6 Travel Time in Minute Data for 5-Station System

\begin{tabular}{|c|c|c|c|c|c|c|}
\hline & \multicolumn{7}{|c|}{ To Station } \\
\hline & & 1 & 2 & 3 & 4 & 5 \\
\hline & 1 & 11 & 9 & 12 & 17 & 10 \\
\hline From & 2 & 9 & 6 & 14 & 8 & 15 \\
\hline Station & 3 & 12 & 14 & 15 & 10 & 16 \\
\hline & 4 & 17 & 8 & 10 & 12 & 11 \\
\hline & 5 & 10 & 15 & 16 & 11 & 19 \\
\hline
\end{tabular}

Table B.7 Prior Probabilities of Three Travel Time States T1, T2, and T3 for 3-Station SVS

\begin{tabular}{|c|c|c|c|c|}
\hline Trip & $P^{\prime}(\mathrm{T} 1)$ & $P^{\prime}(\mathrm{T} 2)$ & $P^{\prime}(\mathrm{T} 3)$ & Sum \\
\hline $1-1$ & 0.240 & 0.645 & 0.115 & 1.000 \\
\hline $1-2$ & 0.325 & 0.560 & 0.115 & 1.000 \\
\hline $1-3$ & 0.265 & 0.595 & 0.140 & 1.000 \\
\hline
\end{tabular}

Table B.8 Conditional Probabilities

\begin{tabular}{|c|c|c|c|c|}
\hline State & $P(R 1)$ & $P(R 2)$ & $P(R 3)$ & Sum \\
\hline T1 & 0.700 & 0.250 & 0.050 & 1.000 \\
\hline T2 & 0.150 & 0.700 & 0.150 & 1.000 \\
\hline T3 & 0.050 & 0.250 & 0.700 & 1.000 \\
\hline
\end{tabular}


Table B.9 Original travel time in minute for a 3-station system

\begin{tabular}{|c|c|c|c|c|}
\hline & & To & & \\
\hline & & 1 & 2 & 3 \\
\hline From & 1 & 11 & 9 & 12 \\
\hline & 2 & 9 & 6 & 14 \\
\hline & 3 & 12 & 14 & 15 \\
\hline
\end{tabular}

Table B.10 Bayesian Estimated Travel Times with Advisory R1

\begin{tabular}{|c|c|c|c|c|}
\hline & & & & \\
\hline & & 1 & 2 & 3 \\
\hline From & 1 & 9 & 7 & 9 \\
\hline & 2 & 7 & 5 & 11 \\
\hline & 3 & 9 & 11 & 12 \\
\hline
\end{tabular}

Table B.11 Bayesian Estimated Travel Times with Advisory R3

\begin{tabular}{c|c|c|c|c|}
\multicolumn{1}{c|}{} & \multicolumn{4}{c|}{ To Station } \\
\cline { 2 - 5 } & & 1 & 2 & 3 \\
\hline \multirow{1}{*}{ From } & 1 & 14 & 12 & 15 \\
\cline { 2 - 5 } & 2 & 12 & 8 & 18 \\
\hline $\mathbf{3}$ & 15 & 18 & 19 \\
\hline
\end{tabular}




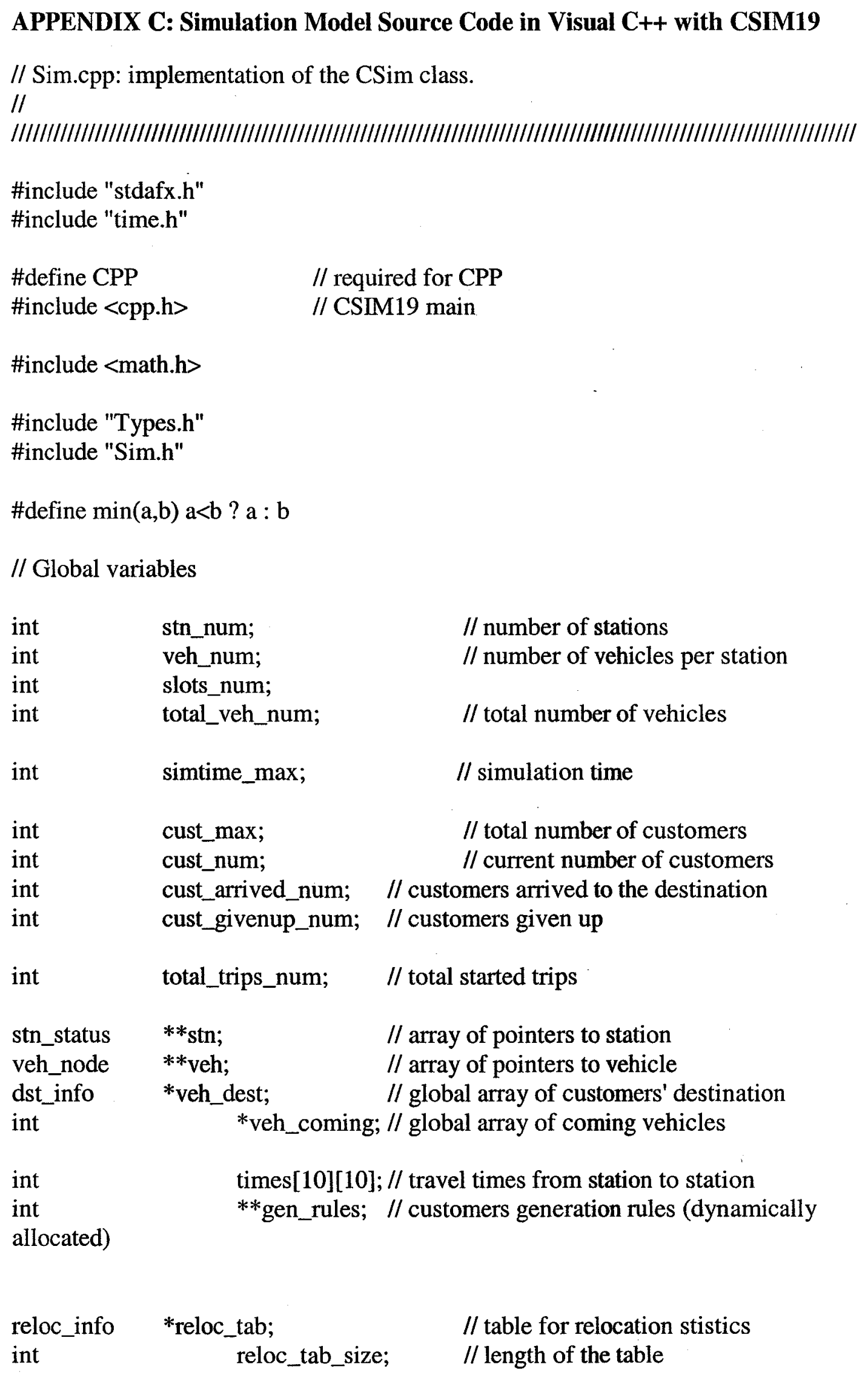


$\begin{array}{llll}\text { int } & \text { total_reloc_num; } & \text { // number of relocations; } \\ \text { wait_info } & \text { *wait_tab; } & / / \text { table for waiting statistics } & \\ & & \\ \text { const float CUSTOMER_GENERATION_MEAN }=1.0 ; \quad & / / \text { in minutes } \\ \text { const float CUSTOMER_GENERATION_STD } \quad=0.2 ; / / \text { in minutes }\end{array}$

//const int CHARGING_SLOTS_PER_STATION 1

IIIIIIIIIIIIIIIIIIIIIIIIIIIIIIIIIIIIIIIIIIIIIIIIIIIIIIIIIIIIIIIIII

// Construction/Destruction

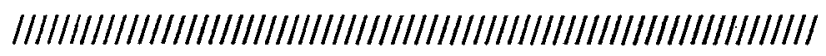

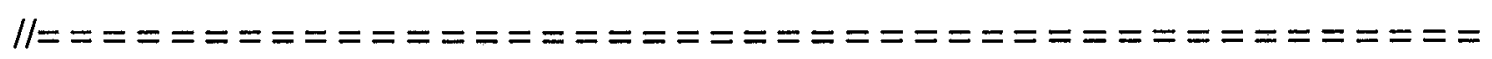

CSim::CSim( int_stn_num, int_veh_num, int_slots_num, int_simtime_max $)($

$\mathrm{m} \_\mathrm{pF}=\mathrm{NULL}$

$/ / \mathrm{m} \_\mathrm{pF}=$ fopen( "stdout.out", "wt" );

$/ / \mathrm{m} \_\mathrm{pF}=$ freopen( "!test.\$\$", "wt", stdout $)$;

//set_output_file( $\left.\mathrm{m} \_\mathrm{pF}\right)$;

srand( time( NULL ) );

stn = NULL;

veh = NULL;

veh_dest = NULL;

veh_coming = NULL;

gen_rules = NULL;

reloc_tab = NULL;

wait_tab = NULL;

reloc_tab_size $=0$;

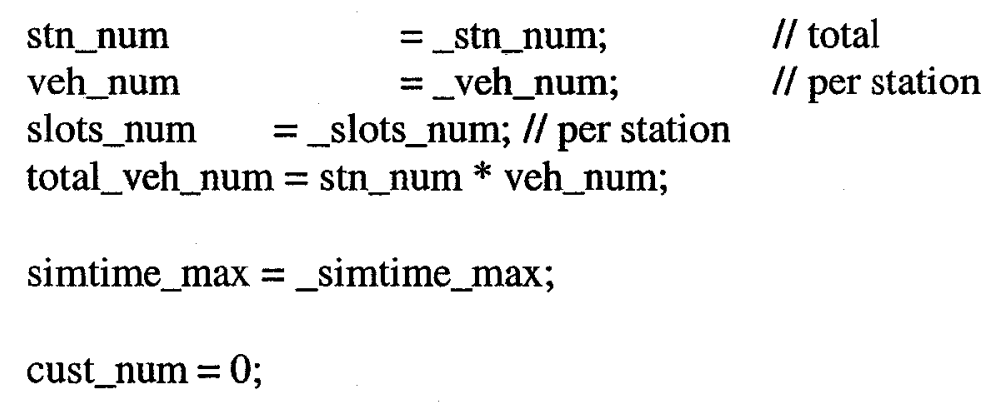




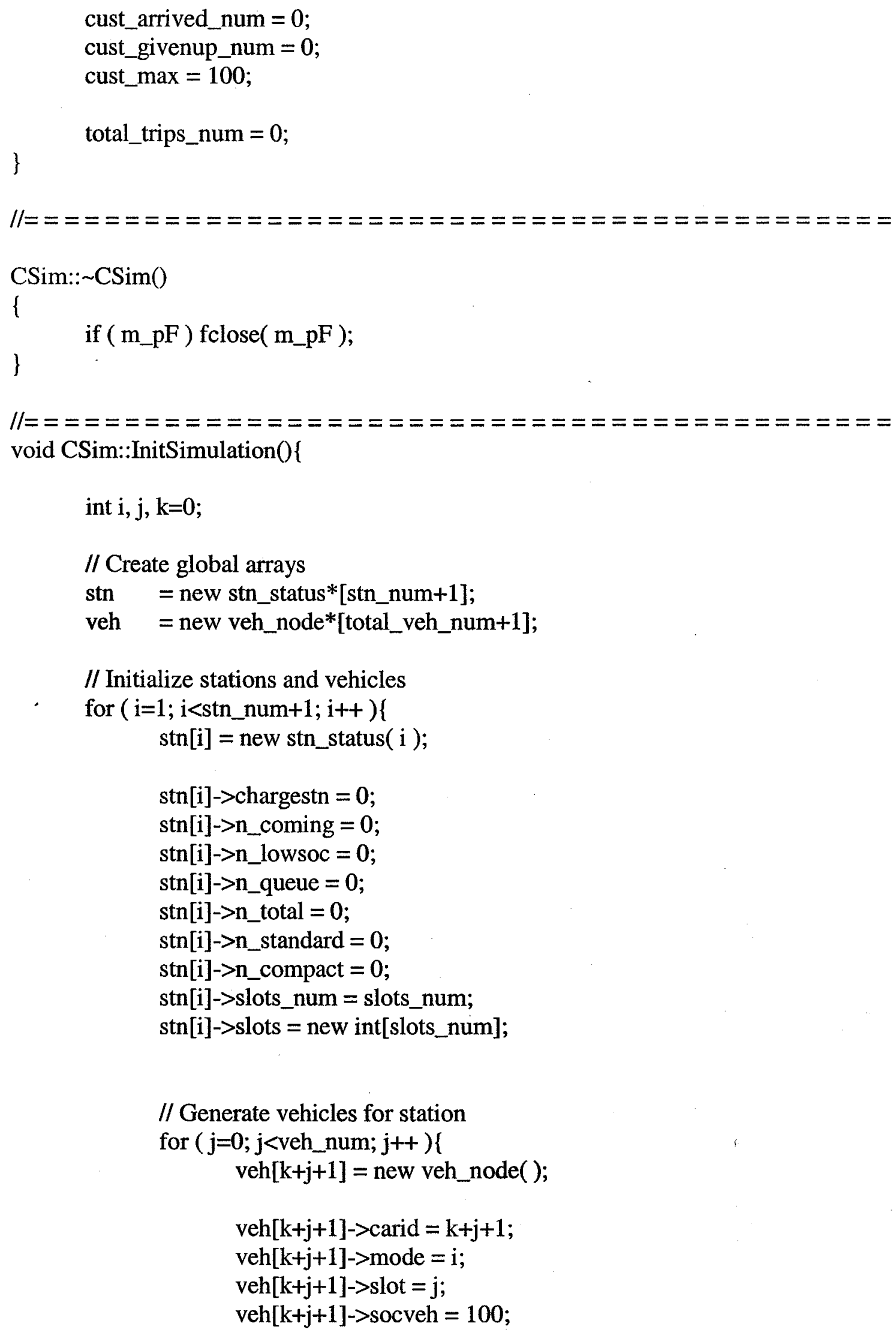




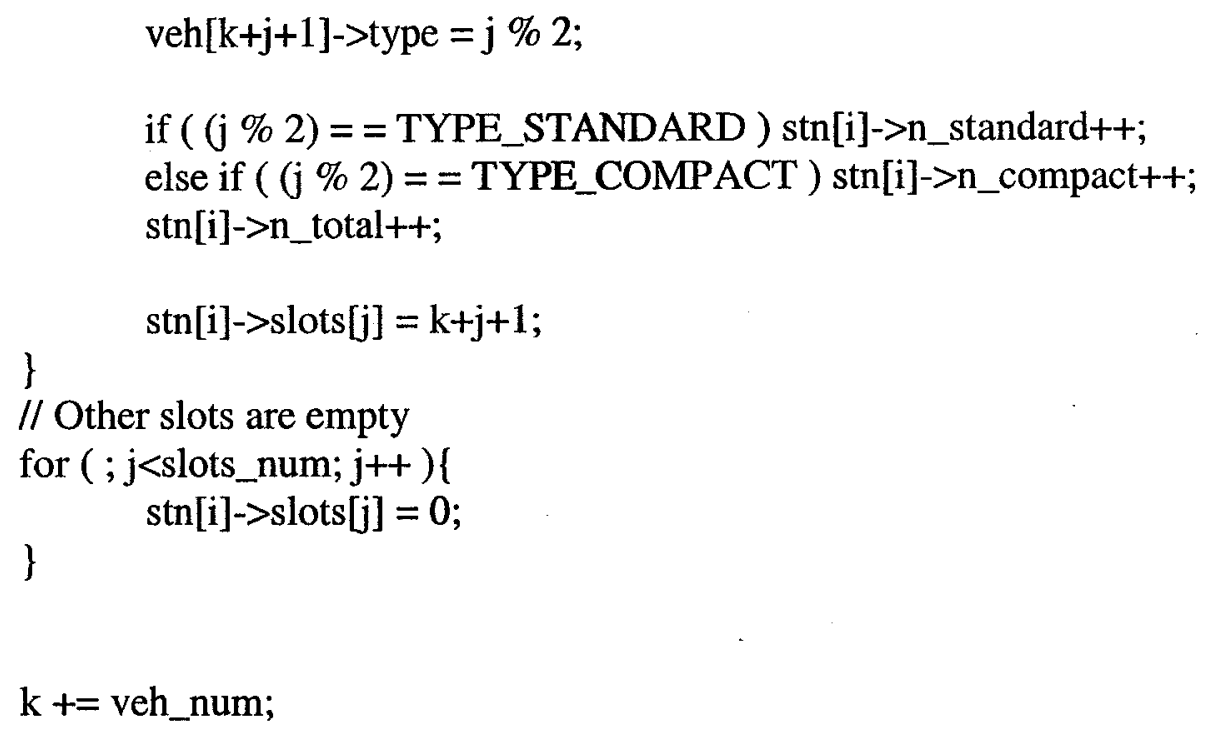




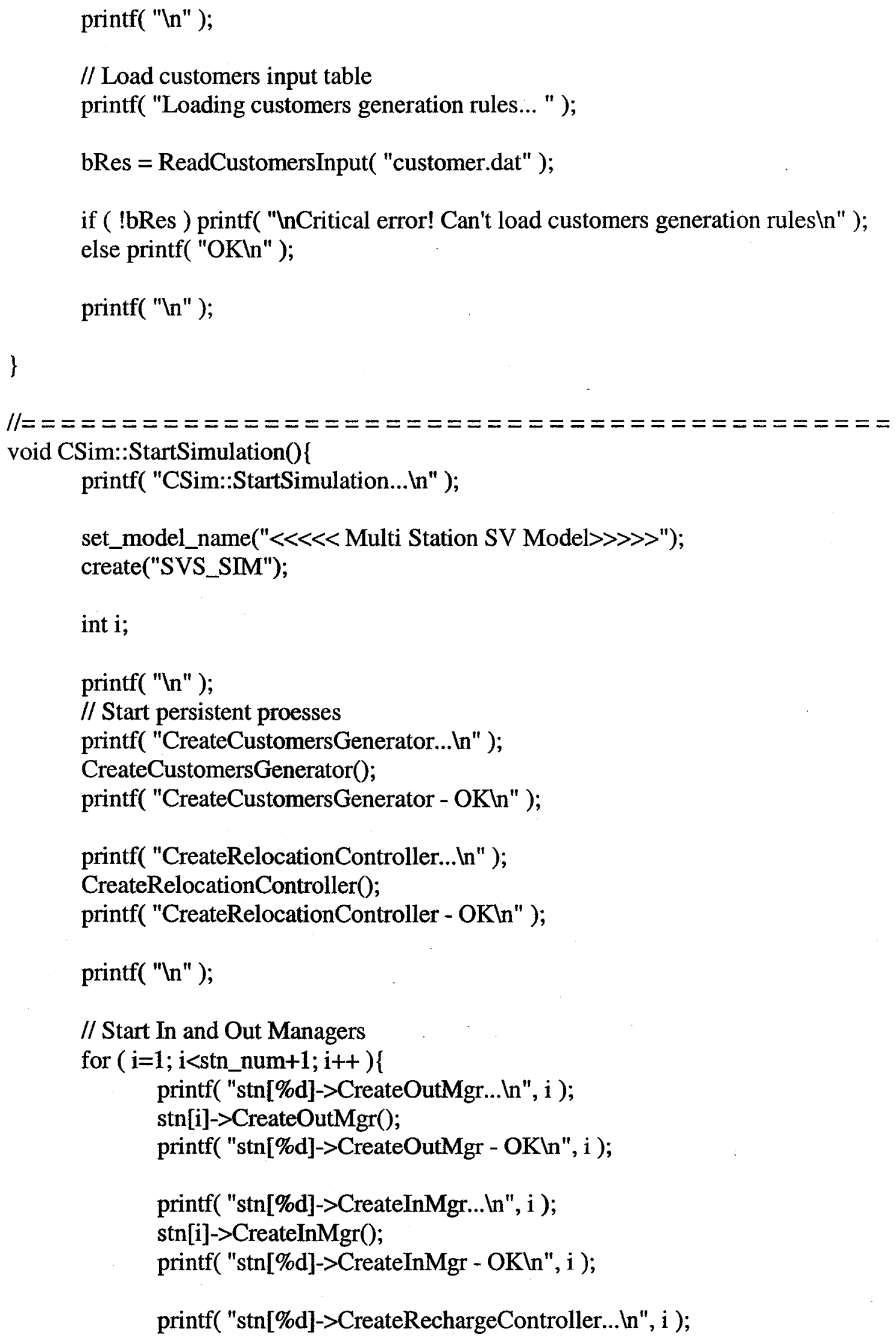




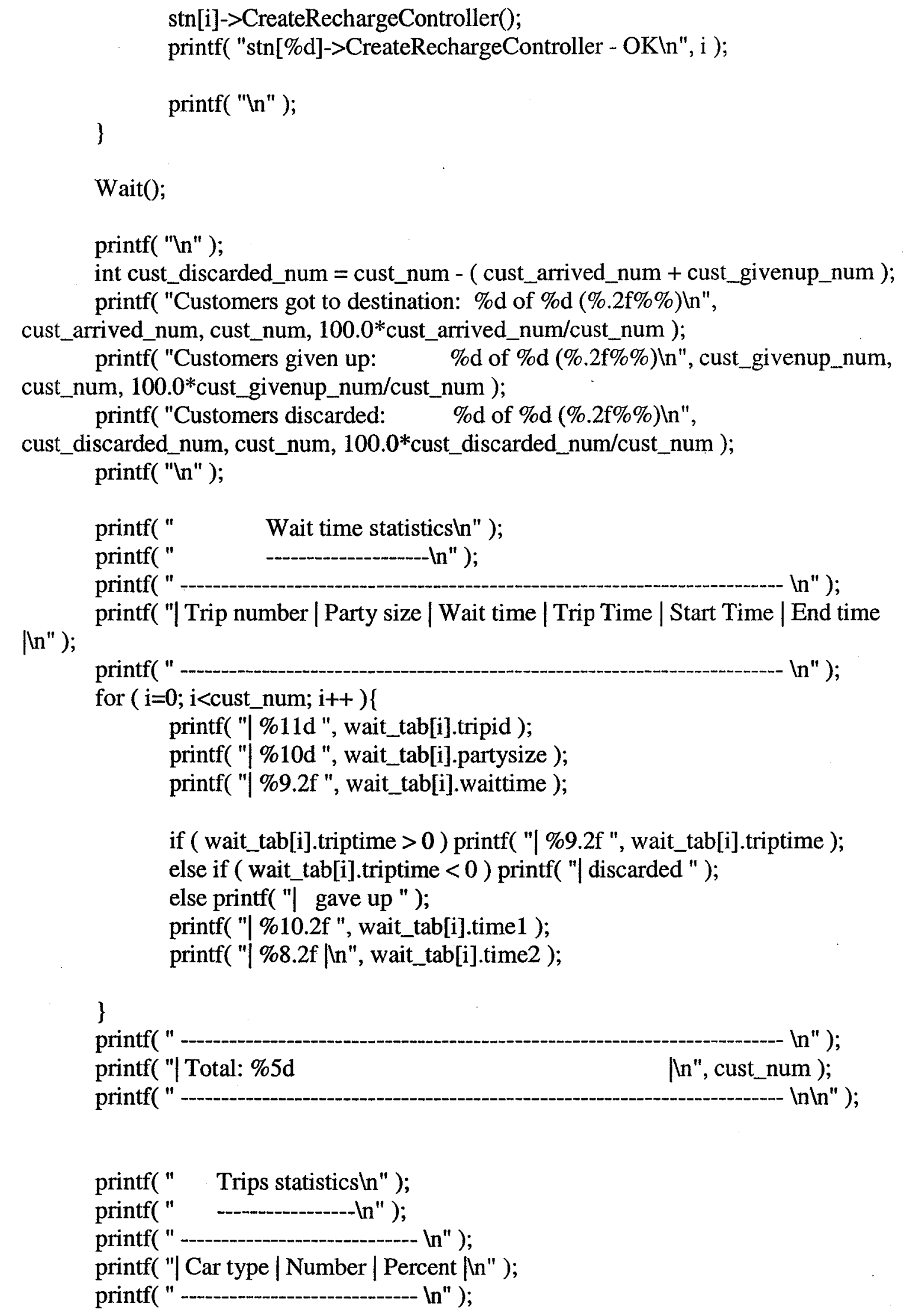




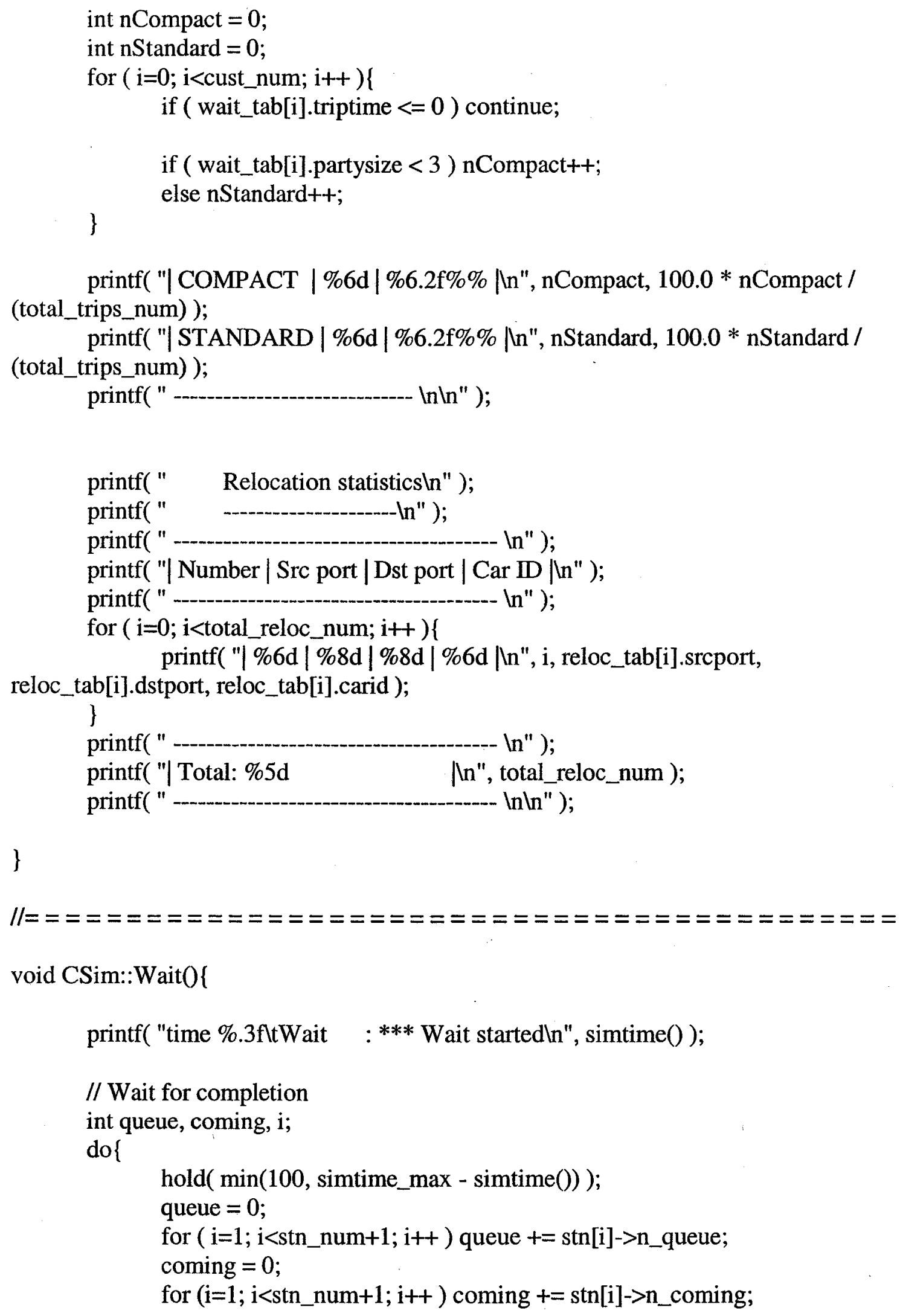


\} while $($ (simtime ()$<$ simtime_max) $\& \&$ (cust_num $<$ cust_max $\|$ queue $>0 \|$ coming >0) );

// If so, then simulation time finished before all the customers reached their destinations

float simtime_end $=$ simtime () ;

StopSimulation();

hold( simtime_max - simtime());

if ( simtime_max - simtime_end $<0.5)\{$

printf( "time \%.3fltWait : END: Simulation time is out. Some

customers were discaredln", simtime( $)$ );

\}

else\{ waiting.ln", simtime());

printf( "time \%.3fttWait : END: Work complete. No more customers

\}

// Update wait time statistics for discarded customers

for $(\mathrm{i}=0$; i<cust_num; $\mathrm{i}++)$ (

if ( wait_tab[i].triptime $<0)\{$

wait_tab[i].waittime = simtime() - wait_tab[i].waittime;

\}

wait_tab[i].time2 = simtime();

\}

printf( "time \%.3fttWait : $: * * *$ Wait finishedın", simtime() );

\}

//= = = = = = = = = = = = = = = = = = = = = = = = = = = = = = = = = =

void CSim::StopSimulation()\{

for ( int $\mathrm{i}=1 ; \mathrm{i}<$ stn_num $+1 ; \mathrm{i}++)\{$

$\operatorname{stn}[\mathrm{i}]->$ evDone- $>$ set();

(*stn[i]->esetTripReqAndDone)[1].set 0 ;

$\left({ }^{*} \operatorname{stn}[\mathrm{i}]->\operatorname{esetVehArrAndDone}\right)[1] . \operatorname{set}() ;$

\}

\} 


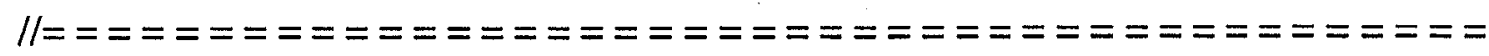

void CSim::ReleaseSimulation()\{

printf( "CSim::ReleaseSimulation... In" );

int $\mathrm{i}$;

for $\left(\mathrm{i}=1 ; \mathrm{i}<\mathrm{stn} \_\right.$num $\left.+1 ; \mathrm{i}++\right)$ (

delete [] (stn[i]->slots);

delete $\operatorname{stn}[\mathrm{i}]$

\}

if ( stn ) delete [] stn;

for $(\mathrm{i}=1 ;$ i<total_veh_num+1; i++ ) delete veh[i];

if ( veh ) delete [] veh;

if ( veh_dest ) delete [] veh_dest;

if ( veh_coming ) delete [] veh_coming;

if ( gen_rules ) \{

for $(i=1 ; i<10 ; i++)$ delete [] gen_rules[i];

\} delete gen_rules;

if ( wait_tab ) delete [] wait_tab;

if ( reloc_tab) delete [] reloc_tab;

printf( "CSim::ReleaseSimulation - OKIn" );

\}

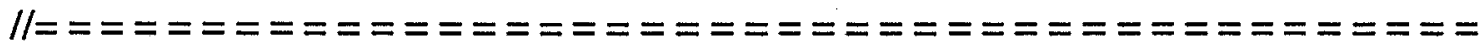

bool CSim::ReadRelocationTimes( char *lpszName )\{

FILE * pF = NULL;

$\mathrm{pF}=$ fopen ( lpszName, "rt" );

if $(\mathrm{pF})$ return false;

int nTime;

for ( int $\mathrm{i}=1 ; \mathrm{i}<10 ; \mathrm{i}++)$ \{

for $($ int $j=1 ; j<10 ; j++)\{$

fscanf( pF, "\%dlt", \&nTime ); 


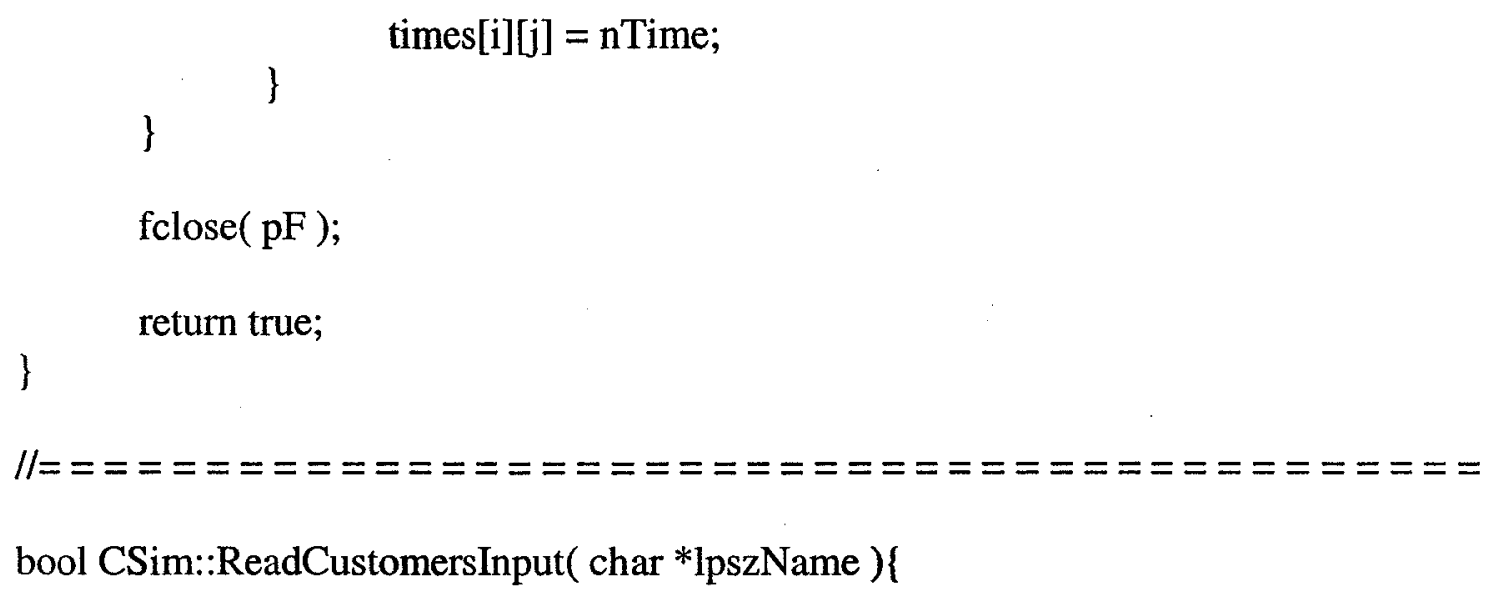

// Number of generation points (=hours) equals to total number of gen.points divied by number of stations

m_nGenPoints = nGensCounter $/ 9$; 
// Allocate memory for generation points information gen_rules = new int $*[10]$; for $(i=1 ; i<10 ; i++)$ gen_rules[i] = new int[m_nGenPoints];

// Load generation rules

int nAmount;

for $(\mathrm{i}=1 ; \mathrm{i}<10 ; \mathrm{i}++)\{$

for (int $\left.j=0 ; j<m \_n G e n P o i n t s ; j++\right)($ fscanf( $\mathrm{pF}$, "\%dlt", \&nAmount );

gen_rules $[i][j]=$ nAmount;

\}

\}

fclose ( $\mathrm{pF})$;

// Allocate waiting statistics table wait_tab = new wait_info[nCustCounter];

// Allocate relocation statistics table

NewRelocTable( 100 );

return true;

\}

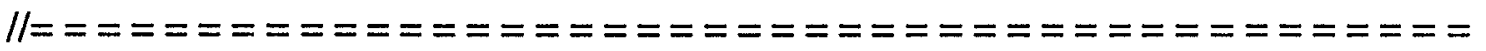

void CSim::CreateCustomersGenerator 0\{

create("CustomersGenerator");

printf( "time \%.3fttCustsGnrtr: *** CustomersGenerator startedln", simtime() );

int $\mathrm{i}$;

// Array of next customer generation times at each station

float $*$ gen_times = new float[stn_num+1];

int $n$ TotalGenPoints $=\min \left(\mathrm{m} \_n\right.$ GenPoints, simtime_max $\left./ 60.0\right)$;

int nCurGenPoint $=0 ; / /$ current generation point

do \{

// Initialize generation times array for the current hour for $\left(i=1 ; i<s t n \_\right.$num $\left.+1 ; i++\right)\{$ 


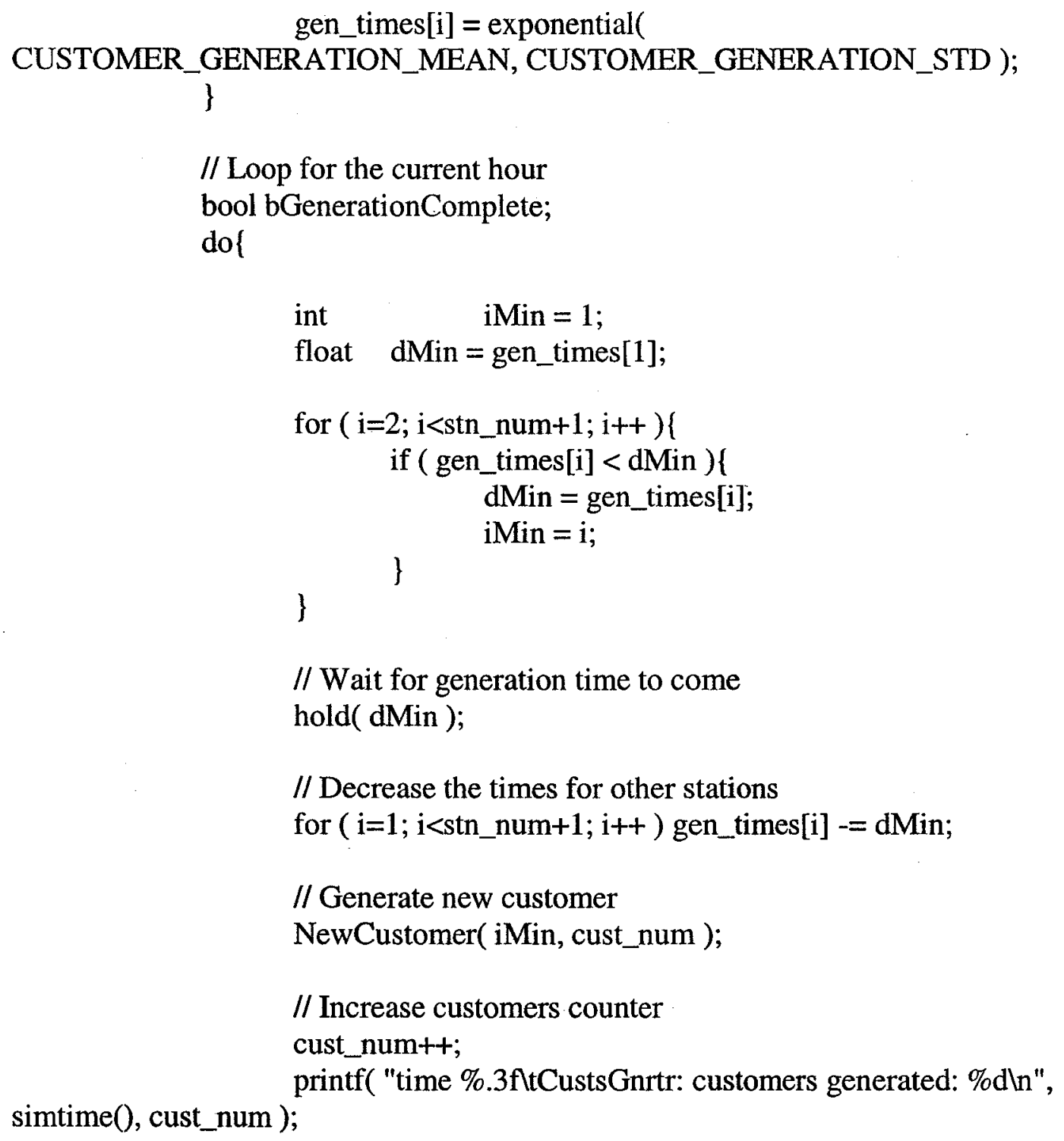

// Wait for generation time to come hold( dMin );

// Decrease the times for other stations for $\left(i=1 ; i<s t n \_n u m+1 ; i++\right)$ gen_times[i] $=d M i n$;

// Generate new customer

NewCustomer(iMin, cust_num );

// Increase customers counter cust_num++;

simtime(), cust_num );

printf( "time \%.3fttCustsGnrtr: customers generated: \%dln",

current hour

// Decrease the number of remaining Customers for this station and gen_rules[iMin][nCurGenPoint]--;

// If no more customers remaining for this station, then set generation time $=$ "infinite"

// Otherwise calculate new customer generation time for the station

Oxfffffff; if ( gen_rules[iMin][nCurGenPoint] $=0$ ) gen_times[iMin] =

CUSTOMER_GENERATION_MEAN, CUSTOMER_GENERATION_STD );

// Check for any customers remaining at any station bGenerationComplete $=$ true; 


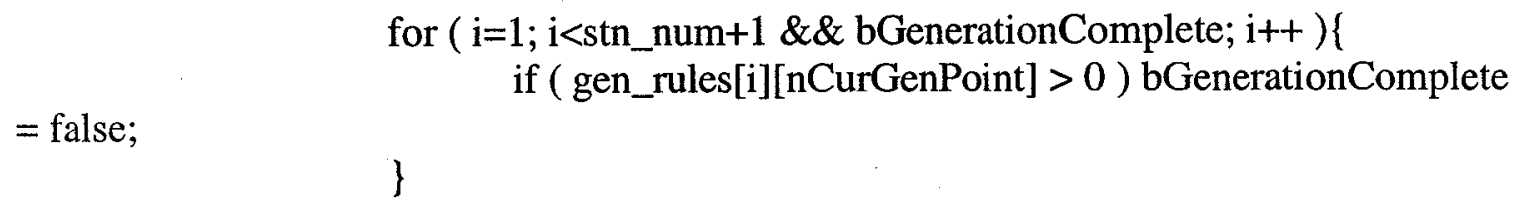

\} while ( !bGenerationComplete );

// Switch to the next generation point nCurGenPoint++;

if ( $\mathrm{nCurGenPoint} \mathrm{<} \mathrm{nTotalGenPoints} \mathrm{)}$

// Hold till the next hour printf( "time \%.3fltCustsGnrtr: hold... In", simtime() ); hold( nCurGenPoint*60.0 - simtime());

\} printf( "time \%.3fltCustsGnrtr: hold endln", simtime() );

\} while ( nCurGenPoint < nTotalGenPoints );

// Release array

delete [] gen_times;

\}

printf( "time \%.3fltCustsGnrtr: *** CustomersGenerator finishedln", simtime() );

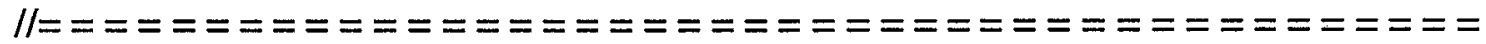

void CSim::NewCustomer( int srcport, int custid )\{

create("Customer");

// Select destination

int dstport $=$ rand ()$\%$ stn_num +1 ;

int $\quad$ partysize $=\operatorname{rand}() \% 5+1 ; / /$ party size

// Queue length increased

stn[srcport]->n_queue++;

printf( "time \%.3fltst \%d: Cust: queue length: \%dln", simtime(), srcport, $\operatorname{stn[srcport]->n\_ queue~);~}$

// Store statistics

//wait_tab[custid].tripid = -1 ;

wait_tab[custid].tripid = custid;

wait_tab[custid].partysize = partysize;

wait_tab[custid].triptime $=-1$; 
wait_tab[custid].waittime $=$ simtime () ;

wait_tab[custid].time1 = simtime () ;

wait_tab[custid].time2 $=0$;

// Kiosk facility is reserved until the customer is served $\operatorname{stn}[$ srcport]->fcKiosk->reserve();

veh_dest[srcport].stn = dstport; // destination station

veh_dest[srcport].size $=$ partysize; $\quad$ // party size

printf( "time \%.3fltst \%d: Cust: new customer \%d to \%d, party size \%dln", simtime(), srcport, custid, veh_dest[srcport].stn, veh_dest[srcport].size );

// Generate TripRequested event

(*stn[srcport]->esetTripReqAndDone)[0].set();

// Wait for TripGranted event

printf( "time \%.3fltst \%d: Cust: customer \%d TripGranted waitı", simtime(), srcport, custid );

$\operatorname{stn}[$ srcport]->evTripGranted->wait();

$\operatorname{stn}[$ srcport]->evTripGranted->clear();

printf( "time \%.3ftst \%d: Cust: customer \%d TripGranted occuredln", simtime(), srcport, custid );

// If customer gave up, then trip time $=0$

if ( veh_dest[srcport].stn $==0$ ) wait_tab[custid].triptime $=0$;

else wait_tab[custid].triptime $=$ times[srcport][dstport];

// Store wait time

wait_tab[custid].waittime $=$ simtime () - wait_tab[custid].waittime;

// Store arrive time

wait_tab[custid].time2 = simtime () ;

// Release Kiosk facility

stn[srcport]->fcKiosk->release();

printf( "time \%.3fltst \%d: Cust: queue length: \%dln", simtime(), srcport, $\operatorname{stn}[$ srcport] $>$ n_queue );

printf( "time \%.3fltst \%d: Cust: finishedln", simtime(), srcport );

\}

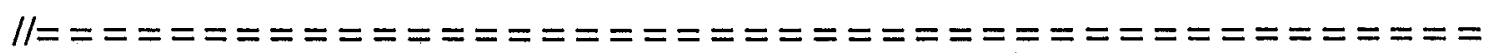
void CSim::CreateRelocationController()\{ 


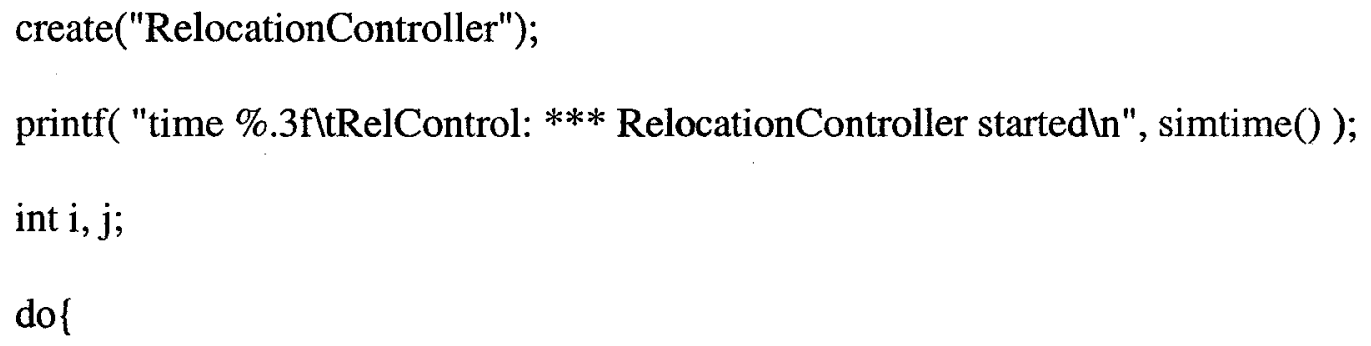

// Relocate standard vehicles for $(i=1 ; i<$ stn_num $+1 ; i++)\{$ 


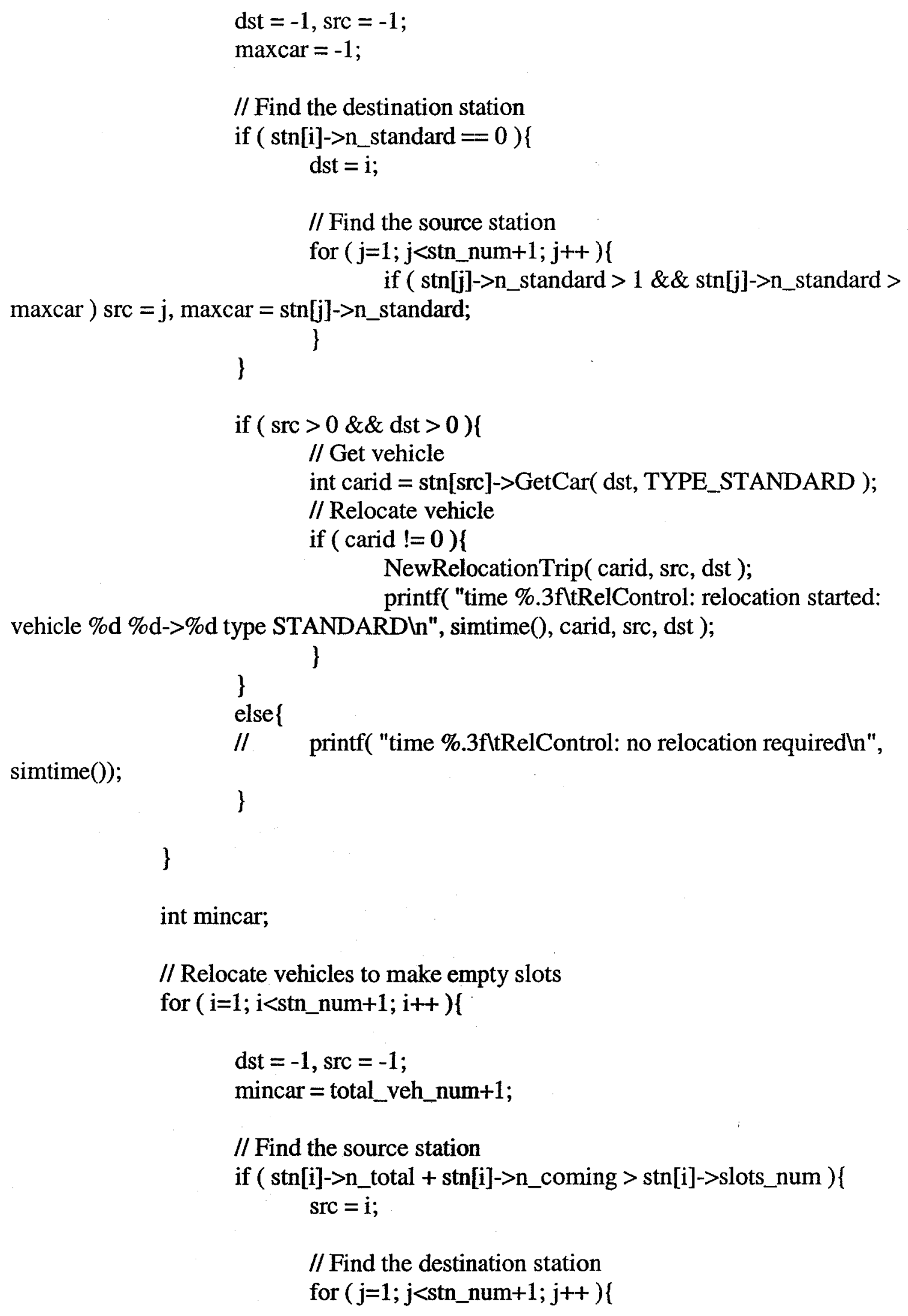


//printf( "time \%.3fltRelControl: hold endln", simtime() );

\}while ( true );

printf( "time \%.3ft: *** RelocationController finishedln", simtime() );

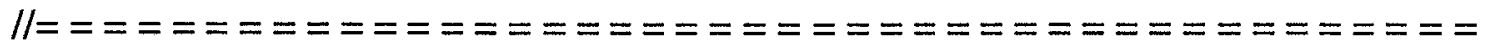
void CSim::NewRelocationTrip (int carid, int srcport, int dstport ) (

create("RelocationTrip");

// Store relocation statistics

reloc_tab[total_reloc_num].carid = carid;

reloc_tab[total_reloc_num].dstport $=$ dstport;

reloc_tab[total_reloc_num].srcport = srcport;

if ( total_reloc_num $+1>=$ reloc_tab_size ) NewRelocTable( $2 *$ reloc_tab_size ); total_reloc_num++;

float start_time $=$ simtime();

hold( times[srcport][dstport] ); // actual trip time

veh[carid]->socveh $=1 *$ times[srcport][dstport];// now just multiplied by 1

bool bParked;

do \{

bParked $=\operatorname{stn}[$ dstport] $->$ ParkCar ( carid );

if ( !bParked ) hold( $5.0 / 60.0)$; // hold for 5 seconds

\}while ( !bParked );

printf( "time \%.3fltRelocTrip : relocation complete: vehicle \%d \%d->\%dln", simtime(), carid, srcport, dstport );

printf( "time \%.3fltRelocTrip : relocation time: \%.0fln", simtime(), simtime() start_time );

printf( "time \%.3fltRelocTrip : st \%d vehicles parked: \%dln", simtime(), dstport, stn[dstport]->n_total );

\}

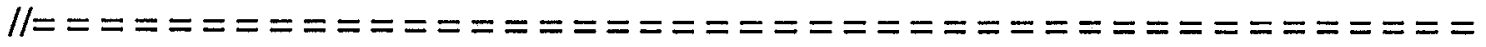
void CSim::NewRelocTable( int nLength ) \{ 


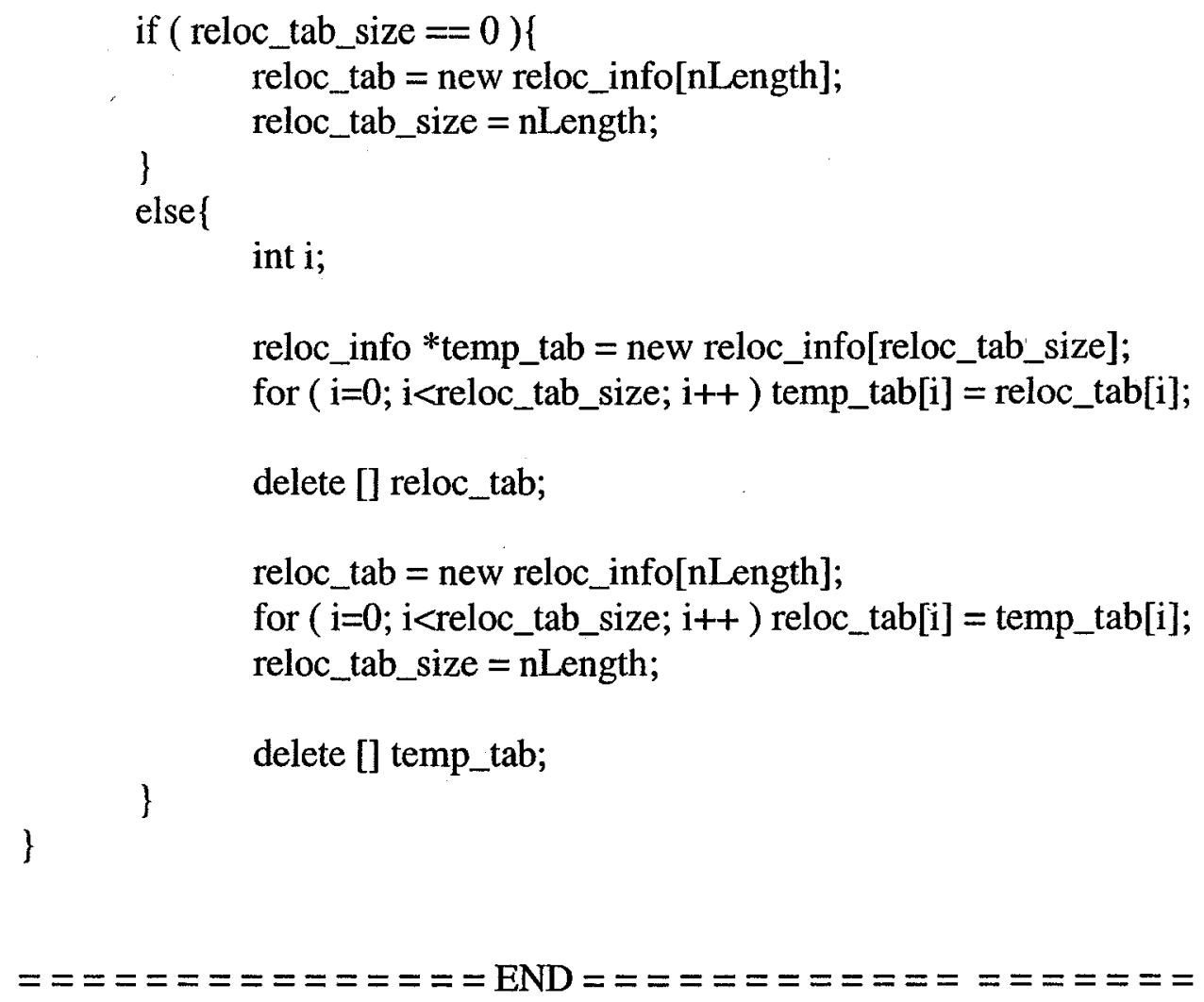




\section{APPENDIX D: SIMULATION MODEL OUTPUT}

Table D.1 SVS Simulation Model Initialization and System Simulation with

Implementation of Scenario-1

Starting SVS for

5 stations

9 vehicles per station

18 parking slots per station..

Simulation time: 540

$\max$ _classes $=5$

max_events $=100$

max_processes $=1000$

Loading travel times... OK

Loading customers generation rules... OK

CSim::StartSimulation...

CreateCustomersGenerator...

CreateCustomersGenerator - OK

CreateRelocationController..

CreateRelocationController - OK

$\operatorname{stn}[1]->$ CreateOutMgr...

$\operatorname{stn}[1]->$ CreateOutMgr - OK

$\operatorname{stn}[1]->$ CreateInMgr...

$\operatorname{stn}[1]->$ CreateInMgr - OK

$\operatorname{stn}[1]->$ CreateRechargeController...

$\operatorname{stn}[1]->$ CreateRechargeController - OK

$\operatorname{stn}[2]->$ CreateOutMgr...

$\operatorname{stn}[2]->$ CreateOutMgr - OK

$\operatorname{stn}[2]>>$ CreatelnMgr...

$\operatorname{stn}[2]->$ CreateInMgr - OK

$\operatorname{stn}[2]>>$ CreateRechargeController...

$\operatorname{stn}[2]->$ CreateRechargeController - OK 


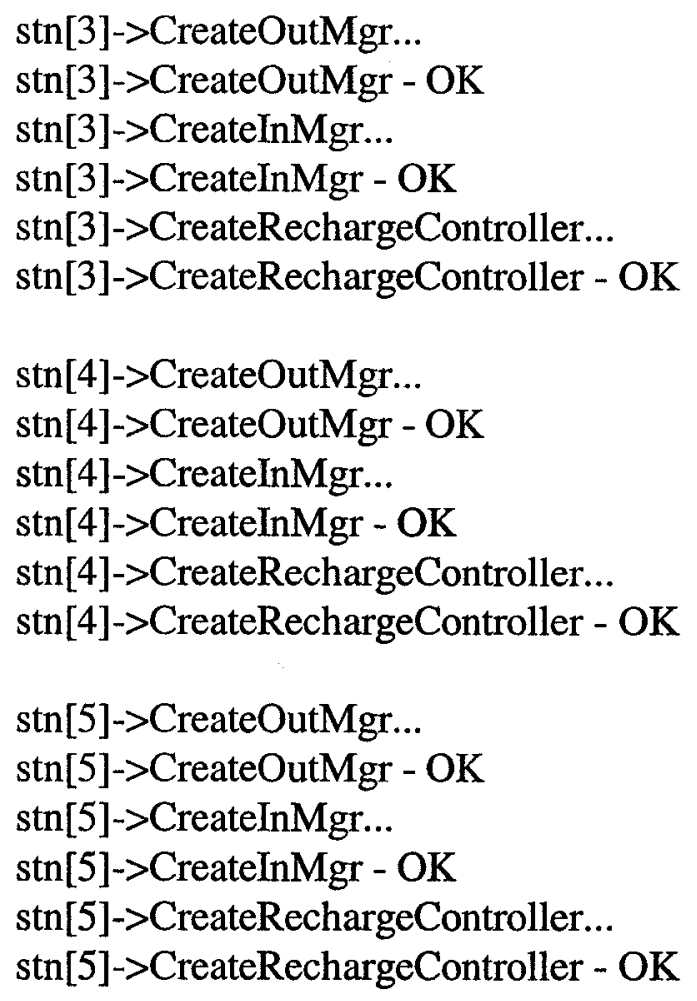

time 0.000 Wait : *** Wait started

time 0.000 CustsGnrtr: *** CustomersGenerator started

time 0.000 RelControl: *** RelocationController started

time 0.000 st 1: OutM: *** StationOutManager started

time 0.000 st 1: OutM: TripRequested wait

time 0.000 st $1: \operatorname{InM}:{ }^{* * *}$ StationInManager started

time 0.000 st $1: \operatorname{InM}$ : VehicleArrived wait

time 0.000 st 1: RecC: *** RechargeController started

time 0.000 st 2: OutM: *** StationOutManager started

time 0.000 st 2: OutM: TripRequested wait

time 0.000 st 2: InM : *** StationInManager started

time 0.000 st 2: InM : VehicleArrived wait

time 0.000 st 2: RecC: $* * *$ RechargeController started

time 0.000 st 3: OutM: *** StationOutManager started

time 0.000 st 3: OutM: TripRequested wait

time 0.000 st $3: \operatorname{InM}: * * *$ StationInManager started

time 0.000 st 3: InM : VehicleArrived wait

time 0.000 st 3: RecC: *** RechargeController started

time 0.000 st 4: OutM: *** StationOutManager started

time 0.000 st 4: OutM: TripRequested wait

time 0.000 st $4: \operatorname{InM}: * * *$ StationInManager started

time 0.000 st $4:$ InM : VehicleArrived wait 
time 0.000

time 0.000 time 0.000 time 0.000 time 0.000 time 0.000 time 0.735 time 0.735 time 0.735 time 0.735 time 0.735 time 0.735 time 0.735 time 0.735 time 0.962 time 0.962 time 0.962 time 0.962 time 0.962 time 0.962 time 0.962 time 0.962 time 1.015 time 1.015 time 1.015 time 1.015 time $\mathbf{1 . 0 1 5}$ time 1.015 time 1.015 time 1.015 time 1.208 time 1.208 time 1.208 time 1.208 time 1.208 time 1.208 time 1.452 time 1.452 time 1.452 time 1.452 time 1.452 time 1.452 time 1.452 st 4: RecC: *** RechargeController started st 5: OutM: *** StationOutManager started st 5: OutM: TripRequested wait st 5: InM : *** StationInManager started st 5: InM : VehicleArrived wait st 5: RecC: *** RechargeController started CustsGnrtr: customers generated: 1 st 1: Cust: queue length: 1 st 1 : Cust: new customer 0 to 4 , party size 1 st 1: Cust: customer 0 TripGranted wait st 1: OutM: TripRequested occured st 1: OutM: reserving DBLock... st 1: OutM: DBLock reserved st 1: OutM: hold CustsGnrtr: customers generated: 2 st 5: Cust: queue length: 1 st 5: Cust: new customer 1 to 2, party size 3 st 5: Cust: customer 1 TripGranted wait st 5: OutM: TripRequested occured st 5: OutM: reserving DBLock... st 5: OutM: DBLock reserved st 5: OutM: hold CustsGnrtr: customers generated: 3 st 4: Cust: queue length: 1 st 4: Cust: new customer 2 to 5, party size 3 st 4: Cust: customer 2 TripGranted wait st 4: OutM: TripRequested occured st 4: OutM: reserving DBLock... st 4: OutM: DBLock reserved st 4: OutM: hold CustsGnrtr: customers generated: 4 st 2: Cust: queue length: 1 st 2: Cust: new customer 3 to 4 , party size 3 st 2: Cust: customer 3 TripGranted wait st 2: OutM: TripRequested occured st 2: OutM: reserving DBLock... CustsGnrtr: customers generated: 5 st 3: Cust: queue length: 1 st 3: Cust: new customer 4 to 4 , party size 1 st 3: Cust: customer 4 TripGranted wait st 3: OutM: TripRequested occured st 3: OutM: reserving DBLock... st 3: OutM: DBLock reserved 
time 1.452

time 1.692

time 1.692

time 2.154

time 2.154

time 2.346

time 2.346

time 2.349

time 2.349

time 2.374

time 2.374

time 2.752

time 2.752

time 3.093

time 3.093

time 3.107

time 3.107

time 3.166

time 3.166

time 3.376

time 3.376

time 3.685

time 3.685

time 3.687

time 3.687

time 3.935

time 3.935

time 4.186

time 4.186

time 4.218

time 4.218

time 4.366

time 4.366

time 4.569

time 4.569

time 4.569

time 4.569

time 4.569

time 4.569

time 4.569

time 4.569

time 4.569

time 4.569 st 3: OutM: hold

CustsGnrtr: customers generated: 6

st 1: Cust: queue length: 2

CustsGnrtr: customers generated: 7

st 5: Cust: queue length: 2

CustsGnrtr: customers generated: 8

st 4: Cust: queue length: 2

CustsGnrtr: customers generated: 9

st 3: Cust: queue length: 2

CustsGnrtr: customers generated: 10

st 2: Cust: queue length: 2

CustsGnrtr: customers generated: 11

st 1: Cust: queue length: 3

CustsGnitr: customers generated: 12

st 5: Cust: queue length: 3

CustsGnrtr: customers generated: 13

st 4: Cust: queue length: 3

CustsGnrtr: customers generated: 14

st 2: Cust: queue length: 3

CustsGnrtr: customers generated: 15

st 1: Cust: queue length: 4

CustsGnrtr: customers generated: 16

st 4: Cust: queue length: 4

CustsGnrtr: customers generated: 17

st 3: Cust: queue length: 3

CustsGnrtr: customers generated: 18

st 2: Cust: queue length: 4

CustsGnrtr: customers generated: 19

st 1: Cust: queue length: 5

CustsGnrtr: customers generated: 20

st 3: Cust: queue length: 4

CustsGnrtr: customers generated: 21

st 5: Cust: queue length: 4

st 1: OutM: hold end

st 1: OutM: vehicle 1 departed to 4

st 1: OutM: vehicles parked: 13

st 1: OutM: DBLock released

st 1: OutM: n_queue: 4 , custnum: 21

st 1: OutM: TripRequested wait

st 1: Trip: (0 to 4$)$ new Trip

st 1: Trip: (0 to 4$)$ vehicle 1 started

st 1: Cust: customer 0 TripGranted occured

st 1: Cust: queue length: 4 
time 4.569

time 4.569

time 4.569

time 4.569

time 4.569

time 4.569

time 4.569

time 4.611 st 1: Cust: finished

st 1: Cust: new customer 5 to 4 , party size 1

st 1: Cust: customer 5 TripGranted wait

st 1: OutM: TripRequested occured

st 1: OutM: reserving DBLock...

st 1: OutM: DBLock reserved

st 1: OutM: hold

CustsGnrtr: customers generated: 22

$==\mathrm{=}=\mathrm{=}=\mathrm{=}=\mathrm{=}=\mathrm{=}$ break $=\mathrm{=}=\mathrm{=}=\mathrm{=}=\mathrm{=}=\mathrm{=}=\mathrm{=}$

\section{D.2 Sample CSIM19 Output Part in the Simulation Model of Scenario-1}

CSIM Simulation Report (Version 19.0 for MS Visual $\mathrm{C} / \mathrm{C}++$ )

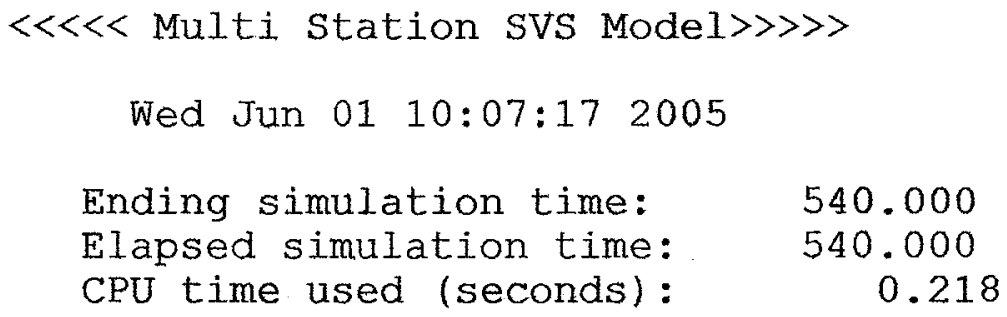

FACILITY SUMMARY

\begin{tabular}{lcrrrrr}
$\begin{array}{l}\text { facility } \\
\text { name }\end{array}$ & $\begin{array}{c}\text { service } \\
\text { disc }\end{array}$ & $\begin{array}{c}\text { service } \\
\text { time }\end{array}$ & util. & $\begin{array}{c}\text { through- } \\
\text { put }\end{array}$ & $\begin{array}{r}\text { queue } \\
\text { length }\end{array}$ & $\begin{array}{c}\text { response } \\
\text { time }\end{array}$ \\
\hline Kiosk1 & fcfs & 10.52721 & 0.933 & 0.08862 & 16.04954 & 31.61305 \\
DBLock1 & fcfs & 5.72804 & 0.933 & 0.16287 & 1.73630 & 10.66039 \\
Entrance1 & fcfs & 10.81934 & 0.803 & 0.07425 & 5.39781 & 11.69625 \\
Kiosk2 & fcfs & 10.17412 & 0.701 & 0.06886 & 18.87609 & 26.72239 \\
DBLock2 & fcfs & 5.43537 & 0.742 & 0.13653 & 1.37615 & 10.07969 \\
Entrance2 & fcfs & 9.98358 & 0.676 & 0.06766 & 2.69687 & 10.85644 \\
Kiosk3 & fcfs & 10.34964 & 0.768 & 0.07425 & 14.12417 & 18.70450 \\
DBLock3 & fcfs & 5.35199 & 0.811 & 0.15150 & 1.52046 & 10.03622 \\
Entrance3 & fcfs & 9.73494 & 0.752 & 0.07725 & 3.76099 & 11.68873 \\
Kiosk4 & fcfs & 10.73133 & 0.733 & 0.06826 & 13.28309 & 22.07689 \\
DBLock4 & fcfs & 5.54617 & 0.774 & 0.13952 & 1.46013 & 10.46532 \\
Entrance4 & fcfs & 10.21049 & 0.728 & 0.07126 & 2.48690 & 11.90025 \\
Kiosk5 & fcfs & 9.79412 & 0.880 & 0.08982 & 17.32450 & 19.07946 \\
DBLock5 & fcfs & 5.30377 & 0.892 & 0.16826 & 1.67270 & 9.94098 \\
Entrance5 & fcfs & 10.10914 & 0.793 & 0.07844 & 2.55270 & 11.54208
\end{tabular}

Model Status: csim_clock $=540.000$

STATUS OF PROCESSES 


\begin{tabular}{lccc} 
process & state & priority & class \\
\hline SVS SIM.1 & active & 1.0 & default \\
Relocationc. 3 & suspended & 1.0 & default
\end{tabular}

STATUS OF FACILITIES

$\begin{array}{lccc}\text { name.id } & \begin{array}{c}\text { busy } \\ \text { servers }\end{array} & \begin{array}{c}\text { queue } \\ \text { length }\end{array} & \text { processes } \\ \text { Kiosk1 } & 0 \text { of } 1 & 0 & \text { serv: idle } \\ \text { DBLock1 } & 0 \text { of } 1 & 0 & \text { serv: idle } \\ \text { Entrance1 } & 0 \text { of } 1 & 0 & \text { serv: idle } \\ \text { Kiosk2 } & 0 \text { of } 1 & 0 & \text { serv: idle } \\ \text { DBLock2 } & 0 \text { of } 1 & 0 & \text { serv: idle } \\ \text { Entrance2 } & 0 \text { of } 1 & 0 & \text { serv: idle } \\ \text { Kiosk3 } & 0 \text { of } 1 & 0 & \text { serv: idle } \\ \text { DBLock3 } & 0 \text { of } 1 & 0 & \text { serv: idle } \\ \text { Entrance3 } & 0 \text { of } 1 & 0 & \text { serv: idle } \\ \text { Kiosk4 } & 0 \text { of } 1 & 0 & \text { serv: idle } \\ \text { DBLock4 } & 0 \text { of } 1 & 0 & \text { serv: idle } \\ \text { Entrance4 } & 0 \text { of } 1 & 0 & \text { serv: idle } \\ \text { Kiosk5 } & 0 \text { of } 1 & 0 & \text { serv: idle } \\ \text { DBLock5 } & 0 \text { of } 1 & 0 & \text { serv: idle } \\ \text { Entrance5 } & 0 \text { of } 1 & 0 & \text { serv: idle }\end{array}$

STATUS OF STORAGES

$\begin{array}{lll} & \begin{array}{l}\text { queue } \\ \text { name.id available }\end{array} \text { processes }\end{array}$

STATUS OF BUFEERS

name.id size current qLength processes

STATUS OF GLOBAL EVENTS

\begin{tabular}{|c|c|c|c|}
\hline name.id & state & $\begin{array}{l}\text { counts } \\
\text { wait/queue }\end{array}$ & processes \\
\hline evnt 1 ist e. 1 & !occ & $0 / 0$ & wait: \\
\hline converged.2 & I OCC & $0 / 0$ & wait: \\
\hline end batch. 3 & $\operatorname{OCC}$ & $0 / 0$ & wait: \\
\hline sim term. 4 & $\operatorname{IOCC}$ & $0 / 0$ & wait: \\
\hline Done. 7 & occ & $0 / 0$ & wait: \\
\hline TripEnd. set. 8 & $10 \mathrm{Cc}$ & $0 / 0$ & wait: \\
\hline
\end{tabular}




\begin{tabular}{|c|c|c|c|}
\hline TripEnd [0].9 & $! \mathrm{OCC}$ & $0 / 0$ & wait \\
\hline TripEnd [1].10 & ! OCC & $0 / 0$ & wait \\
\hline TripEnd [2].11 & ! OCC & $0 / 0$ & wai \\
\hline TripEnd [3] .12 & $\operatorname{locc}$ & $0 / 0$ & wait \\
\hline TripEnd[4].13 & $! O C C$ & $0 / 0$ & wait \\
\hline TripEnd [5] . 14 & $! O C C$ & $0 / 0$ & wait \\
\hline TripRequest. 1 & $! \mathrm{OCC}$ & $0 / 0$ & wai \\
\hline TripRequest. 1 & ! OCC & $0 / 0$ & wai \\
\hline TripRequest. 1 & $! \mathrm{OCC}$ & $0 / 0$ & wai \\
\hline VehicleArri.1 & $! O C C$ & $0 / 0$ & wait \\
\hline VehicleArri.1 & $! \mathrm{OCC}$ & $0 / 0$ & wai \\
\hline VehicleArri. 2 & $10 \mathrm{OC}$ & $0 / 0$ & wai \\
\hline Tripgranted. 2 & ! OCC & $0 / 0$ & wai \\
\hline Done. 26 & $! \mathrm{OCC}$ & $0 / 0$ & wai \\
\hline TripEnd.set. 2 & $\operatorname{locC}$ & $0 / 0$ & wai \\
\hline TripEnd [0], 28 & ! OCC & $0 / 0$ & wai \\
\hline TripEnd [1].29 & $! \mathrm{OCC}$ & $0 / 0$ & wai \\
\hline TripEnd [2] .30 & $! \mathrm{OCC}$ & $0 / 0$ & wai \\
\hline TripEnd [3]. 31 & $! \mathrm{OCC}$ & $0 / 0$ & wai \\
\hline TripEnd [4].32 & $! O C C$ & $0 / 0$ & wai \\
\hline TripEnd [5].33 & ! OCC & $0 / 0$ & wai \\
\hline TripRequest. 3 & ! occ & $0 / 0$ & wait \\
\hline TripRequest. 3 & $! \mathrm{OCC}$ & $0 / 0$ & wai \\
\hline TripRequest. 3 & ! OCC & $0 / 0$ & wai \\
\hline VehicleArri.3 & ! OCC & $0 / 0$ & wai \\
\hline VehicleArri.3 & $\operatorname{locC}$ & $0 / 0$ & wai \\
\hline VehicleArri.3 & ! OCC & $0 / 0$ & wait \\
\hline TripGranted. 4 & $! \mathrm{OCC}$ & $0 / 0$ & wai \\
\hline Done. 45 & $! \mathrm{OCC}$ & $0 / 0$ & wai \\
\hline TripEnd. set . 4 & $! \mathrm{OCC}$ & $0 / 0$ & wa \\
\hline TripEnd [0].47 & $! \mathrm{OCC}$ & $0 / 0$ & wai \\
\hline TripEnd [1]. 48 & $! \mathrm{OCC}$ & $0 / 0$ & wai \\
\hline TripEnd [2] . 49 & ! occ & $0 / 0$ & wai \\
\hline TripEnd [3].50 & ! occ & $0 / 0$ & wai \\
\hline Trip End [4].51 & $\operatorname{locC}$ & $0 / 0$ & We \\
\hline TripEnd [5].52 & $! \mathrm{OCC}$ & $0 / 0$ & wa \\
\hline TripRequest. 5 & ! OCC & $0 / 0$ & wa: \\
\hline TripRequest. 5 & ! OCC & $0 / 0$ & wai \\
\hline TripRequest. 5 & $\operatorname{locc}$ & $0 / 0$ & wai \\
\hline VehicleArri. 5 & ! occ & $0 / 0$ & \\
\hline VehicleArri.5 & $! \mathrm{OCC}$ & $0 / 0$ & wa \\
\hline VehicleArri. 5 & !OCC & $0 / 0$ & waj \\
\hline TripGranted. 6 & $\operatorname{locc}$ & $0 / 0$ & wai \\
\hline Done. 64 & $!$ OCC & $0 / 0$ & \\
\hline TripEnd.set. 6 & $!$ occ & $0 / 0$ & \\
\hline TripEnd[0].66 & ! occ & $0 / 0$ & \\
\hline TripEnd[1].67 & ! occ & $0 / 0$ & waj \\
\hline TripEnd[2].68 & $\operatorname{locc}$ & $0 / 0$ & wa \\
\hline TripEnd [3].69 & $\operatorname{locc}$ & $0 / 0$ & wa \\
\hline TripEnd [4].70 & ! OCC & $0 / 0$ & \\
\hline TripEnd [5].71 & $! \mathrm{OCC}$ & $0 / 0$ & wa \\
\hline TripRequest. 7 & ! occ & $0 / 0$ & wa \\
\hline TripRequest. 7 & ! occ & $0 / 0$ & wa \\
\hline TripRequest. 7 & !OCC & $0 / 0$ & wa \\
\hline VehicleArri. 7 & ! occ & $0 / 0$ & \\
\hline VehicleArri. 7 & $\operatorname{locc}$ & $0 / 0$ & \\
\hline VehicleArri. 7 & ! OCC & $0 / 0$ & wa \\
\hline TripGranted. 8 & ! OCC & $0 / 0$ & \\
\hline
\end{tabular}




$\begin{array}{llll}\text { Done.83 } & \text { !occ } & 0 / 0 & \text { wait: } \\ \text { TripEnd.set.8 } & \text { !occ } & 0 / 0 & \text { wait: } \\ \text { TripEnd[0].85 } & \text { !occ } & 0 / 0 & \text { wait: } \\ \text { TripEnd[1].86 } & \text { !occ } & 0 / 0 & \text { wait: } \\ \text { TripEnd[2].87 } & \text { !occ } & 0 / 0 & \text { wait: } \\ \text { TripEnd[3].88 } & \text { !occ } & 0 / 0 & \text { wait: } \\ \text { TripEnd[4].89 } & \text { !occ } & 0 / 0 & \text { wait: }\end{array}$

STATUS OF GLOBAL MAILBOXES

$\begin{array}{ccc}\text { message } & \text { process } \\ \text { name.id count } & \text { count } & \text { processes }\end{array}$

STATUS OF EVENT IIST

$\begin{array}{lccc}\text { position } & \text { time } & \text { process } & \text { event type } \\ 0 & 540.000000 & \text { Relocationc. } 3 & \text { hold }\end{array}$

\section{VEHICLE COMPOSITION}

\begin{tabular}{|l|r|r|}
\hline Car type | Number | Percent | \\
\hline COMPACT | & $354 \mid$ & $77.12 \%$ | \\
\hline STANDARD | $105 \mid$ & $22.88 \%$ |
\end{tabular}

\section{RELOCATION STATISTICS}

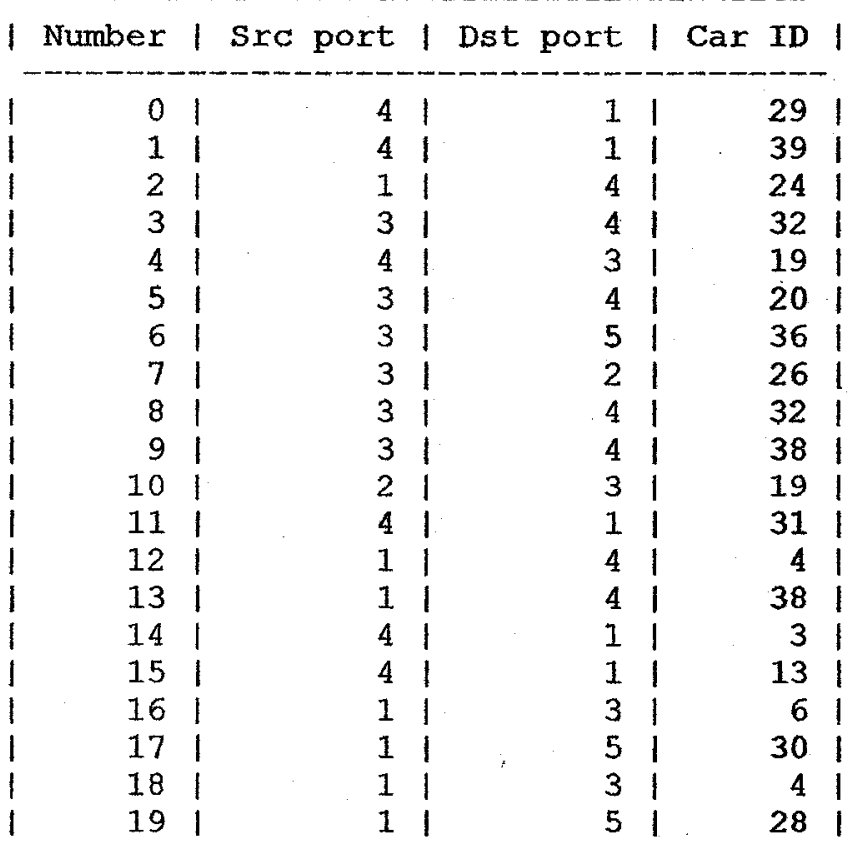




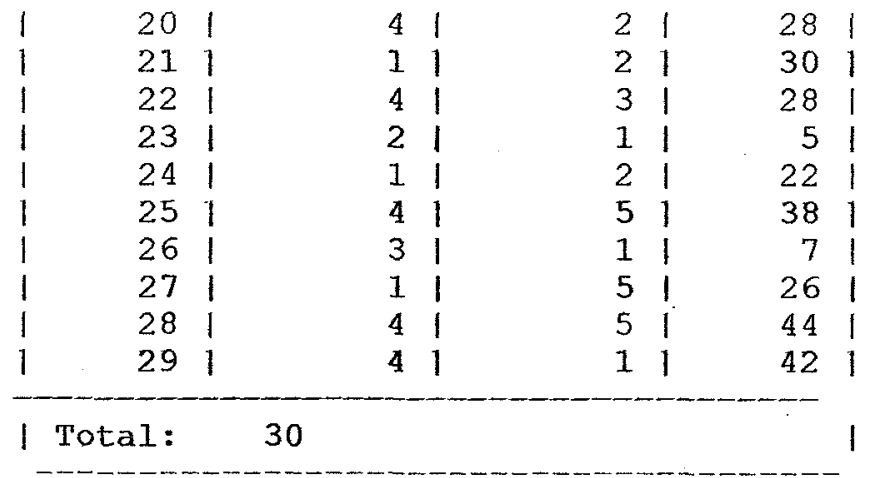

Note: Src - Source or origin, Dst - Destination 


\section{APPENDIX E: CASE STUDY RESULTS}

\section{E.1 Scenario-1 Results}

The SVS methodology was implemented for the case study site and a large number of results were produced. Highlights of results are presented in the main body of the thesis. In this section, detailed tables and figures from scenario-1 are shown.

Table E.1 Analysis for Vehicle-to-Trip Ratio for a 5-Station SVS System

\begin{tabular}{|c|c|c|c|c|c|c|c|c|}
\hline $\begin{array}{c}\text { Total } \\
\text { Demand } \\
\text { (Trips) }\end{array}$ & $\begin{array}{l}\text { Veh/Trip } \\
\text { Ratio (\%) }\end{array}$ & $\begin{array}{l}\text { Fleet Size } \\
\text { (Vehicle) }\end{array}$ & $\begin{array}{c}\text { Total } \\
\text { Served } \\
\text { (Trips) }\end{array}$ & $\begin{array}{c}\text { Trip } \\
\text { Served } \\
(\%)\end{array}$ & $\begin{array}{l}\text { Avg. } \\
\text { Service } \\
\text { Time } \\
\text { (min) }\end{array}$ & $\begin{array}{l}\text { Avg. Wait } \\
\text { Time } \\
\text { (min) }\end{array}$ & $\begin{array}{l}\text { Queue } \\
\text { Length } \\
\text { (trips) }\end{array}$ & $\begin{array}{l}\text { Number of } \\
\text { Relocations }\end{array}$ \\
\hline 427 & 3.5 & 15 & 227 & 53.2 & 14.0 & 37.8 & 27.1 & 33 \\
\hline 427 & 4.7 & 20 & 300 & 70.3 & 12.8 & 30.3 & 23.7 & 48 \\
\hline 427 & 5.9 & 25 & 310 & 72.6 & 12.3 & 27.7 & 22.0 & 42 \\
\hline 427 & 7.0 & 30 & 350 & 82.0 & 11.5 & 23.9 & 19.4 & 43 \\
\hline 427 & 8.2 & 35 & 352 & 82.4 & 11.5 & 18.5 & 18.9 & 45 \\
\hline 427 & 9.4 & 40 & 396 & 92.7 & 10.6 & 16.5 & 16.5 & 34 \\
\hline 427 & 10.5 & 45 & 406 & 95.1 & 10.4 & 11.3 & 15.9 & 29 \\
\hline 427 & 11.7 & 50 & 407 & 95.3 & 10.7 & 11.2 & 15.2 & 27 \\
\hline
\end{tabular}

Note: Bolded row indicates the best vehicle-to-trip ratio configuration with parking-to-vehicle ratio of $2: 1$. 
Table E.2 Analysis for Parking-to-Vehicle Ratio for a 5-Station SVS System

\begin{tabular}{|c|c|c|c|c|c|c|c|c|c|}
\hline $\begin{array}{c}\text { Number of } \\
\text { Stations } \\
\end{array}$ & $\begin{array}{c}\text { Total } \\
\text { Demand } \\
\text { (Trips) } \\
\end{array}$ & $\begin{array}{c}\begin{array}{c}\text { Parking/ } \\
\text { Veh }\end{array} \\
\text { Ratio } \\
\end{array}$ & $\begin{array}{l}\text { Parking/ } \\
\text { Station }\end{array}$ & $\begin{array}{c}\text { Total } \\
\text { Served } \\
\text { (Trips) } \\
\end{array}$ & $\begin{array}{c}\text { Trip Served } \\
(\%)\end{array}$ & \begin{tabular}{|c|} 
Avg. \\
Service \\
Time (min) \\
\end{tabular} & $\begin{array}{l}\text { Avg. Wait } \\
\text { Time (min) }\end{array}$ & $\begin{array}{c}\text { Queue } \\
\text { Length } \\
\text { (trips) } \\
\end{array}$ & $\begin{array}{l}\text { Number of } \\
\text { Relocations }\end{array}$ \\
\hline 5 & 427 & 1.0 & 9 & 387 & 90.6 & 10.8 & 41.8 & 17.1 & 79 \\
\hline 5 & 427 & 1.2 & 11 & 385 & 90.2 & 10.7 & 32.3 & 16.7 & 55 \\
\hline 5 & 427 & 1.4 & 13 & 391 & 91.6 & 10.5 & 25.7 & 16.1 & 45 \\
\hline 5 & 427 & 1.8 & 16 & 392 & 91.8 & 10.4 & 17.9 & 16.6 & 31 \\
\hline 5 & 427 & 2.0 & 18 & 406 & 95.1 & 10.4 & 11.5 & 15.9 & 29 \\
\hline 5 & 427 & 2.2 & 20 & 390 & 91.3 & 10.7 & 11.4 & 17.1 & 37 \\
\hline
\end{tabular}

Note: Vehicle-to-Trip ratio $=10.5: 100$ or 10.5 percent

Table E.3 Travel time sensitivity analysis results of shared vehicle system using KIOSK statistics

\begin{tabular}{|c|c|c|c|c|c|c|c|c|}
\hline $\begin{array}{c}\text { Number of } \\
\text { Stations }\end{array}$ & $\begin{array}{c}\text { Total } \\
\text { Demand }\end{array}$ & Travel Time & Trips Served & $\begin{array}{c}\text { Trip Served, } \\
\%\end{array}$ & $\begin{array}{c}\text { Avg. Service } \\
\text { Time, min }\end{array}$ & $\begin{array}{c}\text { Avg. Wait } \\
\text { Time, min }\end{array}$ & $\begin{array}{c}\text { Queue } \\
\text { Length } \\
\text { (trips) }\end{array}$ & $\begin{array}{c}\text { Number of } \\
\text { Relocations }\end{array}$ \\
\hline 5 & 427 & Original & 406 & 95.1 & 10.4 & 195.7 & 16.6 & 31 \\
\hline 5 & 427 & 1.9 times & 380 & 89.0 & 10.8 & 205.8 & 17.3 & 34 \\
\hline 5 & 427 & 4.0 times & 357 & 83.6 & 11.4 & 209.2 & 19.0 & 46 \\
\hline
\end{tabular}


Table E.4 Travel time sensitivity analysis results of shared vehicle system using ENTRANCE statistics

\begin{tabular}{|c|c|c|c|c|c|c|c|c|}
\hline $\begin{array}{c}\text { Number } \\
\text { of } \\
\text { Stations }\end{array}$ & $\begin{array}{l}\text { Veh/Trip } \\
\text { Ratio (\%) }\end{array}$ & $\begin{array}{l}\text { Travel } \\
\text { Time }\end{array}$ & $\begin{array}{c}\text { Total } \\
\text { Served } \\
\text { (Trips) } \\
\end{array}$ & $\begin{array}{c}\text { Trip } \\
\text { Served } \\
(\%) \\
\end{array}$ & $\begin{array}{c}\text { Avg. } \\
\text { Service } \\
\text { Time } \\
\text { (min) } \\
\end{array}$ & $\begin{array}{l}\text { Avg. } \\
\text { Wait } \\
\text { Time } \\
\text { (min) } \\
\end{array}$ & $\begin{array}{l}\text { Queue } \\
\text { Length } \\
\text { (trips) } \\
\end{array}$ & $\begin{array}{c}\text { Number of } \\
\text { Relocation } \\
\text { s } \\
\end{array}$ \\
\hline 5 & 10.5 & Original & 406 & 95.1 & 1.2 & 3.4 & 2.4 & 31 \\
\hline 5 & 10.5 & 1.9 times & 380 & 89.0 & 1.7 & 2.5 & 2.7 & 34 \\
\hline 5 & 10.5 & 4.0 times & 357 & 83.6 & 1.5 & 3.2 & 2.3 & 46 \\
\hline
\end{tabular}

Table E.5 Shared vehicle system capacity gain w.r.t. vehicle-to-trip ratio

\begin{tabular}{|c|c|c|}
\hline Vehicle/Trip Ratio, \% & $\begin{array}{c}\text { Estimated Number of Trip } \\
\text { Served }\end{array}$ & Capacity Gain in \% \\
\hline 1.0 & 130 & \\
\hline 1.5 & 154 & 18.1 \\
\hline 2.0 & 176 & 14.6 \\
\hline 2.5 & 198 & 12.2 \\
\hline 3.0 & 218 & 10.3 \\
\hline 3.5 & 238 & 8.9 \\
\hline 4.0 & 256 & 7.7 \\
\hline 4.5 & 273 & 6.8 \\
\hline 5.0 & 289 & 6.0 \\
\hline 5.5 & 305 & 5.3 \\
\hline 6.0 & 319 & 4.7 \\
\hline 6.5 & 332 & 4.1 \\
\hline 7.0 & 344 & 3.7 \\
\hline 7.5 & 356 & 3.2 \\
\hline 8.0 & 366 & 2.8 \\
\hline 8.5 & 375 & 2.5 \\
\hline 9.0 & 383 & 2.1 \\
\hline 9.5 & 390 & 1.8 \\
\hline 10.0 & 396 & 1.5 \\
\hline 10.5 & 401 & 1.3 \\
\hline 11.0 & 405 & 1.0 \\
\hline 11.5 & 408 & 0.7 \\
\hline 12.0 & 409 & 0.5 \\
\hline
\end{tabular}




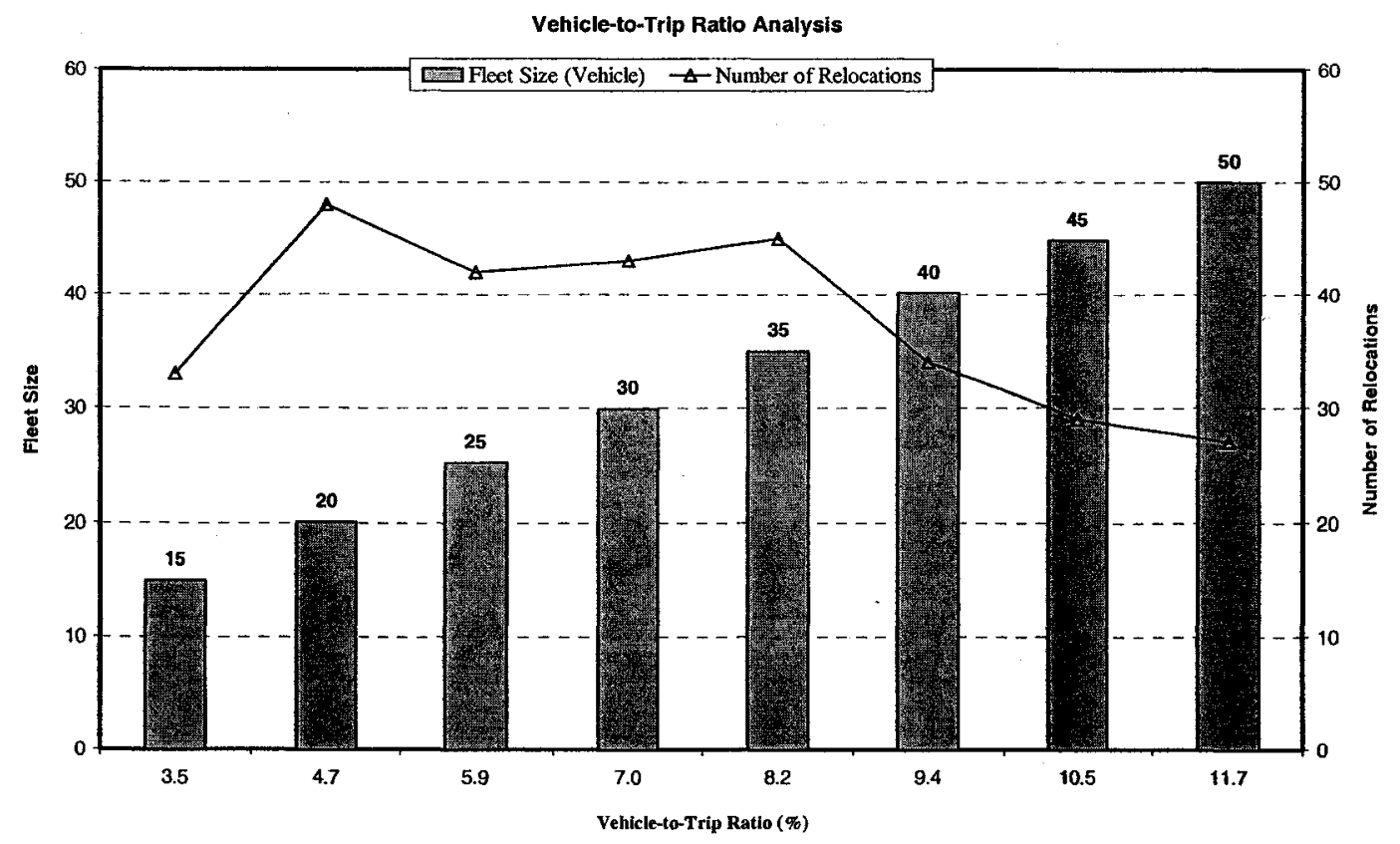

Figure E.1 Vehicle fleet size and number of relocations as a function of vehicle-to-trip ratio

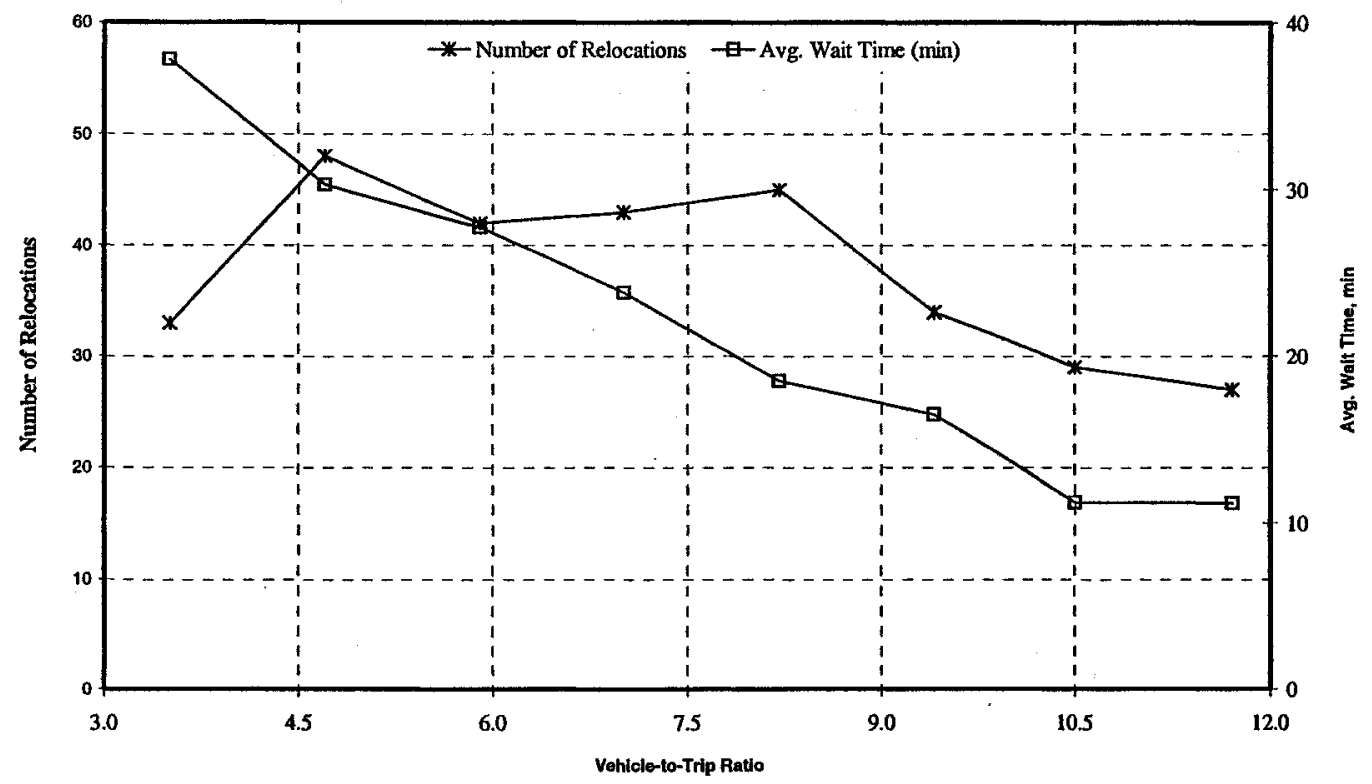

Figure E.2 Average customer wait time and number of relocations as a function of vehicle-to-trip ratio 


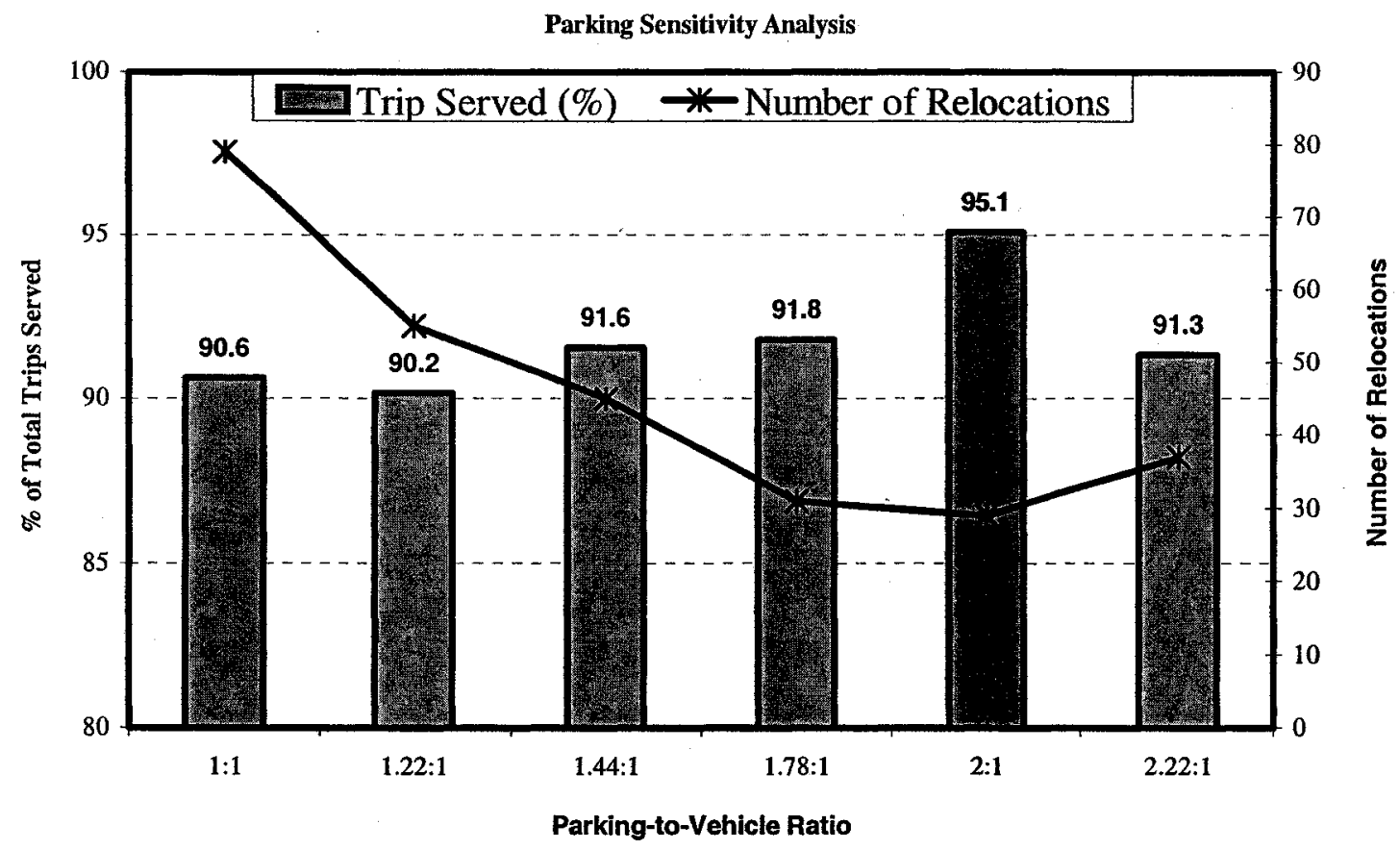

Figure E.3 Number of relocations and trips served in percent as a function of parkingto-vehicle ratio

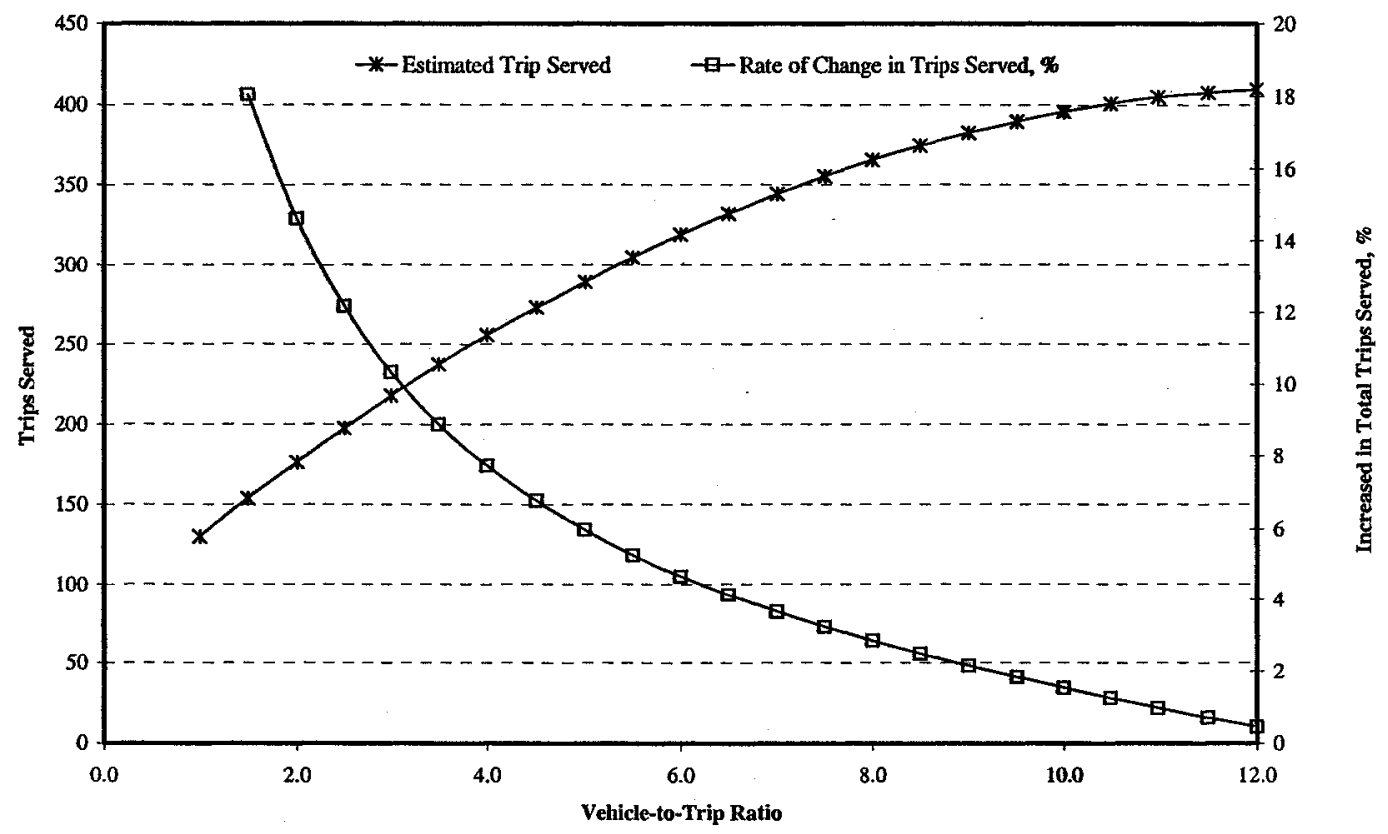

Figure E.4 Estimated trips served and SVS capacity gain as a function of vehicle-to-trip ratio 


\section{E.2 Analysis with Higher Travel Demand, 1.5 Times of Original}

Attempts were to evaluate the system performance under higher travel demand while keeping the number of stations in the system constant. Two travel demand scenarios with 1.5 and 2.0 times of the base demand were implemented. Results obtained from the model are shown here in detail.

Table E.6 Analysis for vehicle-to-trip ratio for a 5-station SVS system with travel demand 1.5 times of original

\begin{tabular}{|c|c|c|c|c|c|c|}
\hline $\begin{array}{c}\text { Veh/Trip } \\
\text { Ratio (\%) }\end{array}$ & $\begin{array}{c}\text { Total } \\
\text { Served } \\
(\text { Trips) }\end{array}$ & $\begin{array}{c}\text { Trip Served } \\
(\%)\end{array}$ & $\begin{array}{c}\text { Avg. } \\
\text { Service } \\
\text { Time (min) }\end{array}$ & $\begin{array}{c}\text { Avg. Wait } \\
\text { Time (min) }\end{array}$ & $\begin{array}{c}\text { Queue } \\
\text { Length } \\
\text { (trips) }\end{array}$ & $\begin{array}{c}\text { Number of } \\
\text { Relocations }\end{array}$ \\
\hline 3.5 & 462 & 71 & 12.6 & 19.1 & 44.4 & 65 \\
\hline 4.7 & 513 & 79 & 11.9 & 17.6 & 41.2 & 72 \\
\hline 5.9 & 571 & 88 & 11.1 & 15.1 & 36.8 & 67 \\
\hline 7.0 & 589 & 91 & 10.9 & 14.7 & 36.0 & 61 \\
\hline 8.2 & 618 & 95 & 10.5 & 13.9 & 34.0 & 40 \\
\hline 9.4 & 620 & 96 & 10.5 & 13.5 & 33.1 & 38 \\
\hline 10.5 & 627 & 96.3 & 10.5 & 10.3 & 32.0 & 32 \\
\hline 11.7 & 633 & 97.3 & 9.9 & 9.6 & 30.8 & 25 \\
\hline
\end{tabular}

Note: Bolded data items indicate the efficient system design, with respect to vehicle-to-trip ratio, for base and 1.5 times of base travel demand, respectively. 
Table E.7 Comparison of average wait time, number of relocations, and trip served (\%) between original, 1.5, and 2.0 times of original demand.

\begin{tabular}{|l|c|c|c|}
\hline \multicolumn{1}{|c|}{$\begin{array}{c}\text { Measure of } \\
\text { Performance }\end{array}$} & Original Demand & $\begin{array}{c}\text { Demand 1.5 Times } \\
\text { of Original }\end{array}$ & $\begin{array}{c}\text { Demand 2.0 Times } \\
\text { of Original }\end{array}$ \\
\hline $\begin{array}{l}\text { Optimum Vehicle-to- } \\
\text { trip ratio }\end{array}$ & 10.5 & 8.2 & 6.0 \\
\hline Avg. Wait Time, min & 11.3 & 13.9 & 17.2 \\
\hline Number of Relocations & 29.0 & 40.0 & 79.0 \\
\hline Trip Served in \% & 94.1 & 95.0 & 95.0 \\
\hline Avg. Vehicle SOC & 62.0 & 60.0 & 55.0 \\
\hline
\end{tabular}

Note: vehicle-to-trip ratio $=10.5$ and parking-to-vehicle ratio $=2: 1$ 


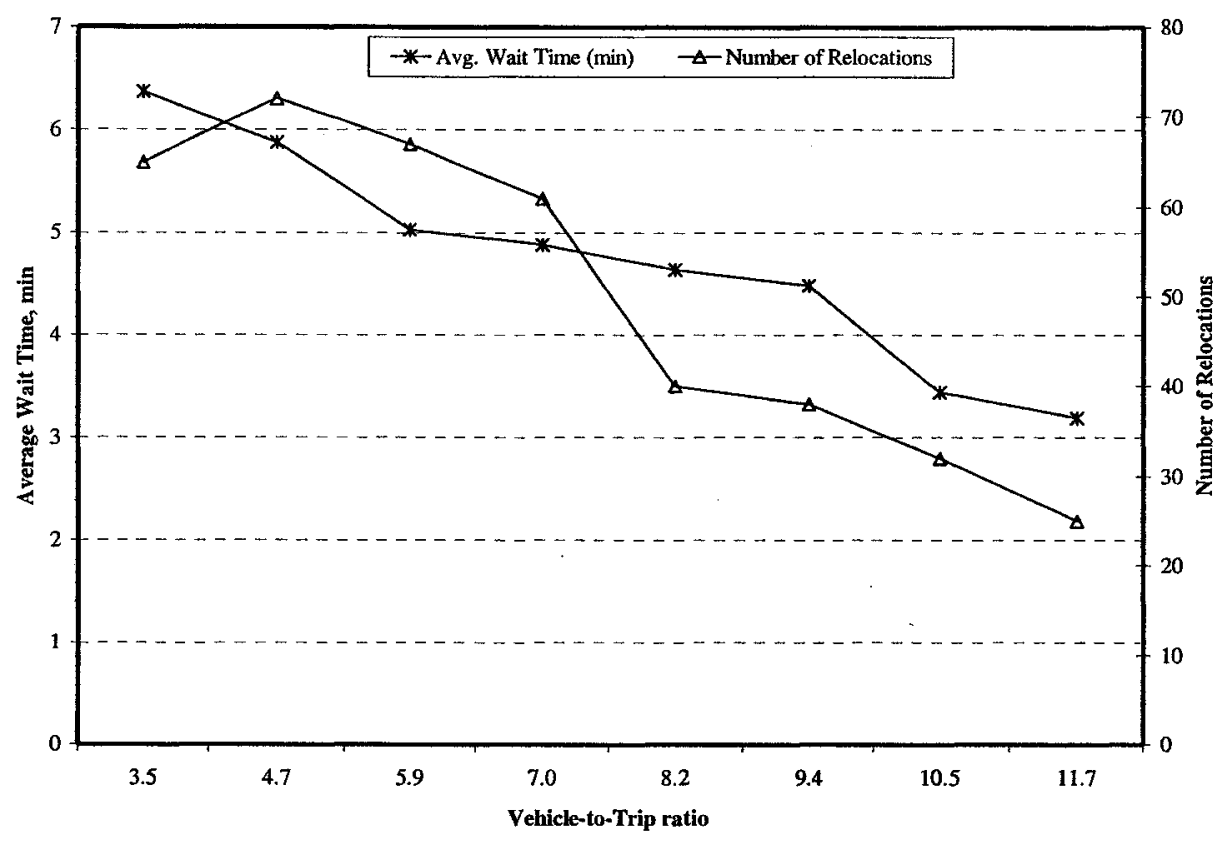

Figure E.5 Average customer wait time and number of relocations as a function of vehicle-to-trip ratio

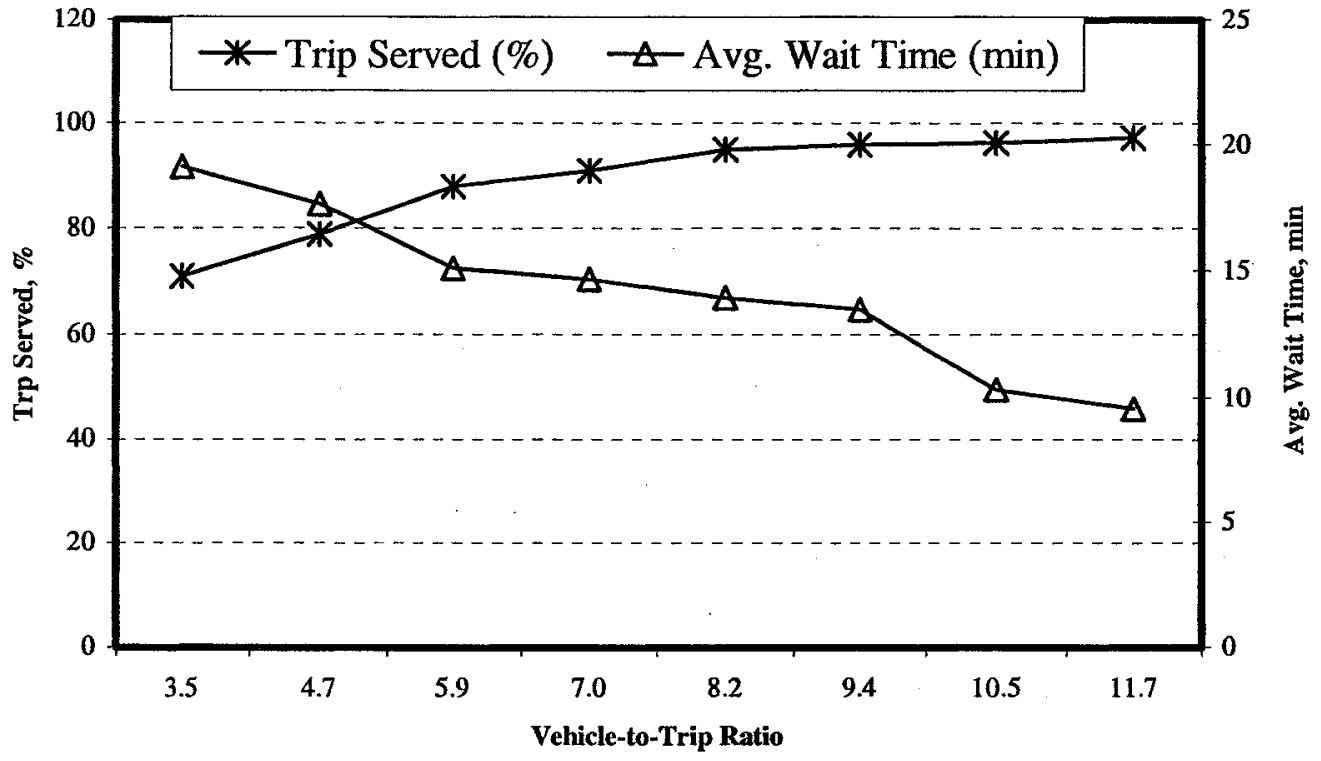

Figure E.6 Vehicle fleet size and customer average wait time as a function of vehicle-totrip ratio 


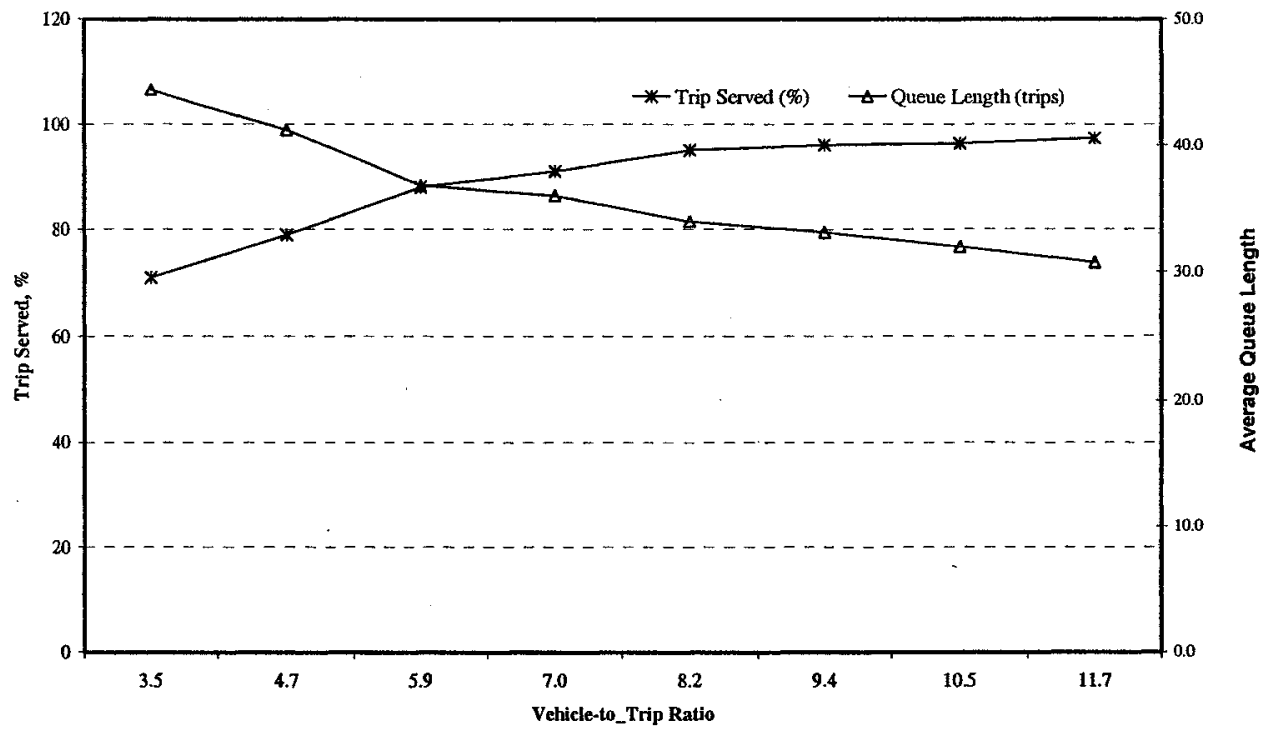

Figure E.7 Trips served in percent and average queue length (trips) as a function of vehicle-to-trip ratio

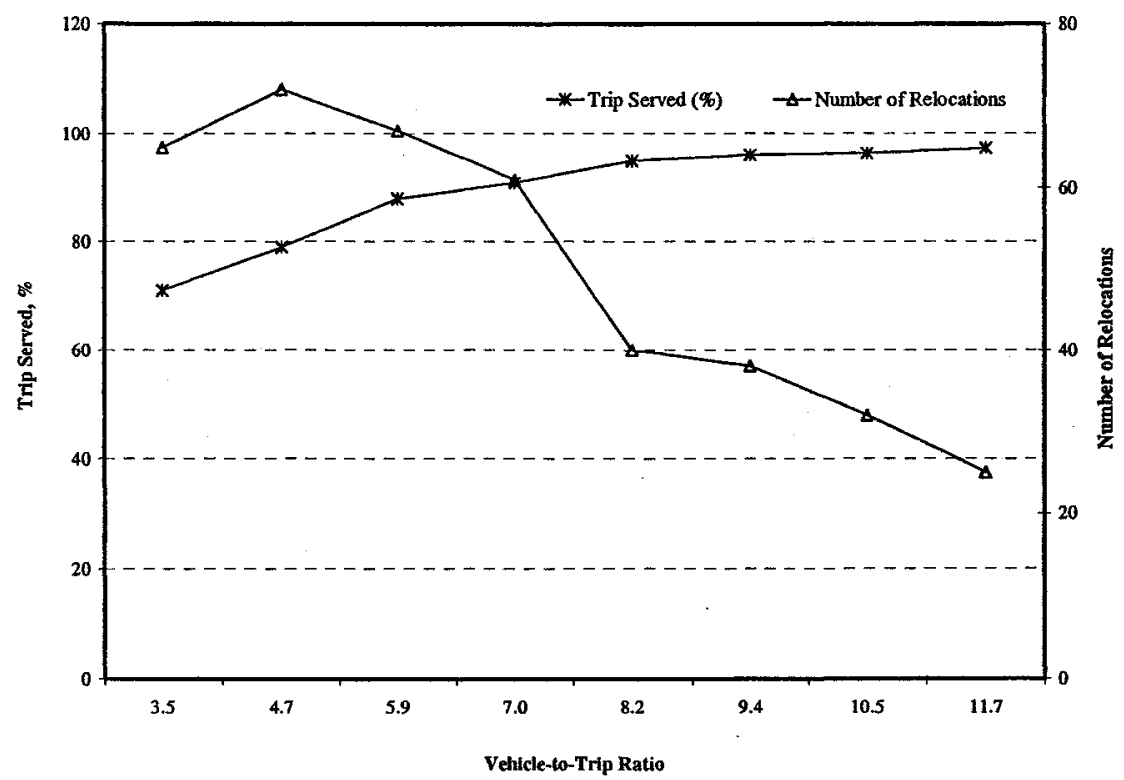

Figure E.8 Trips served in percent and average queue length (trips) as a function of vehicle-to-trip Ratio 


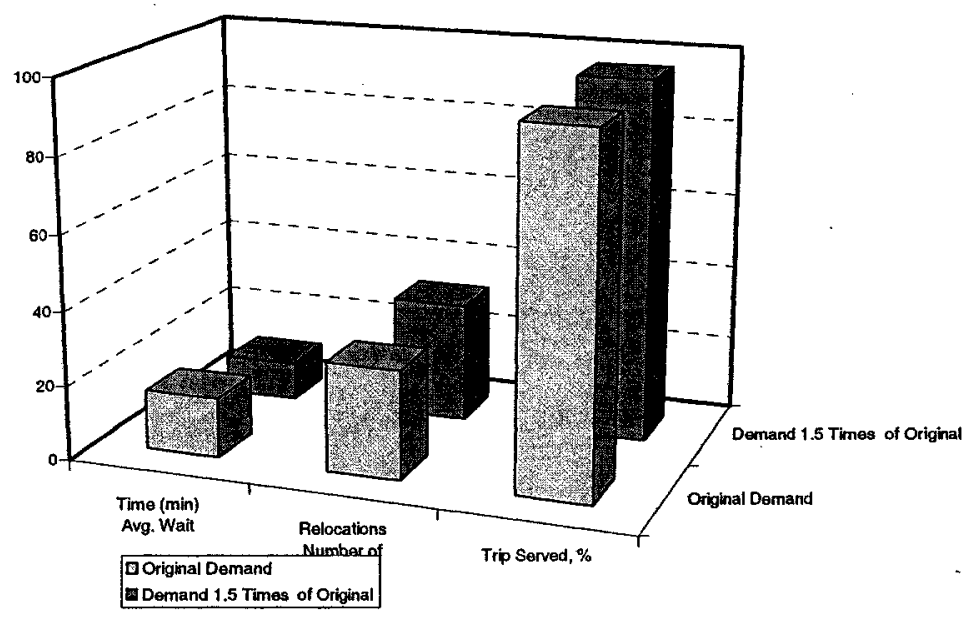

Figure E.9 Comparison of average wait time, number of relocations, and trip served (\%) between original and 1.5 times of original demand

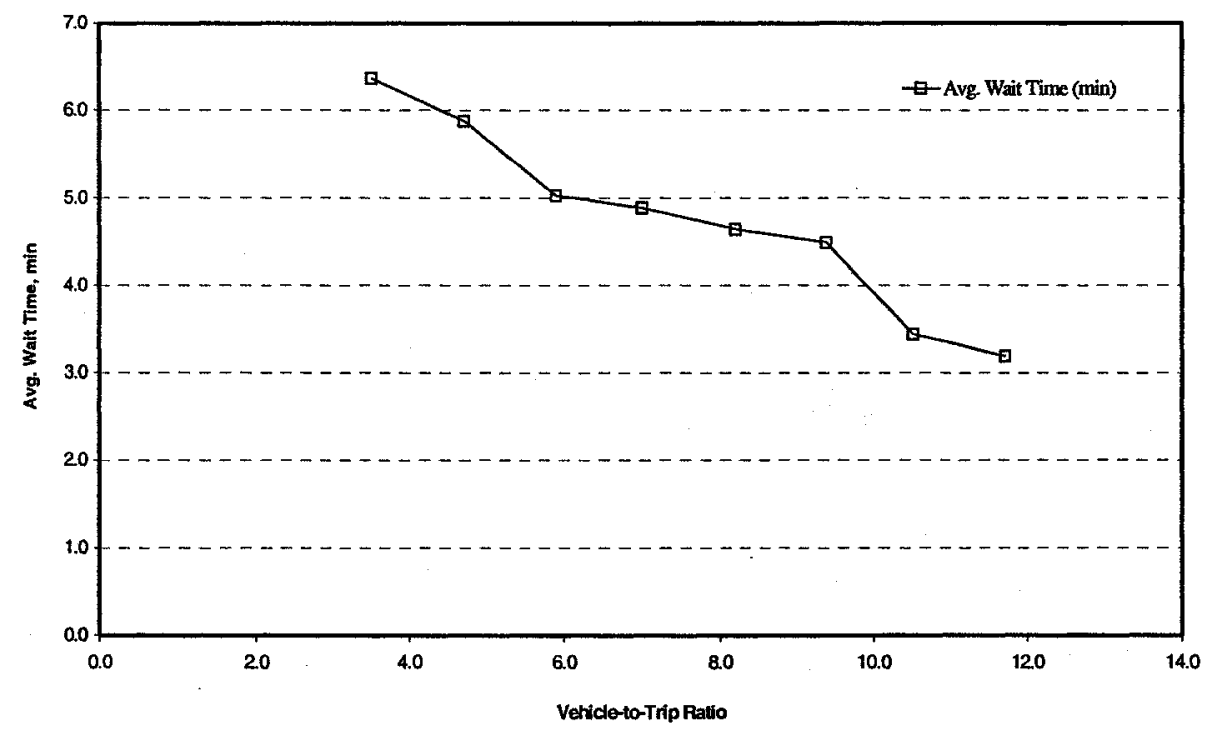

Figure E.10 Customer average wait time versus vehicle-to-trip ratio 


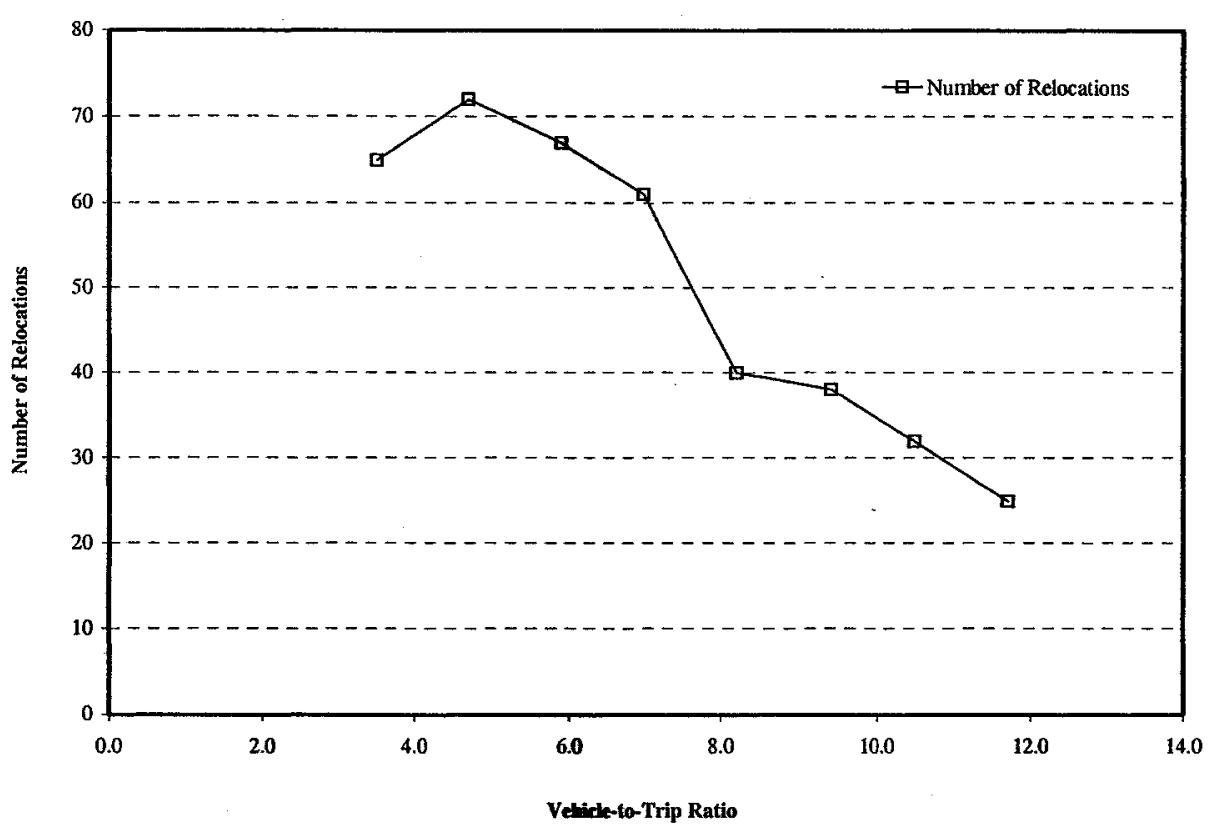

Figure E.11 Number of relocations versus vehicle-to-trip ratio plot

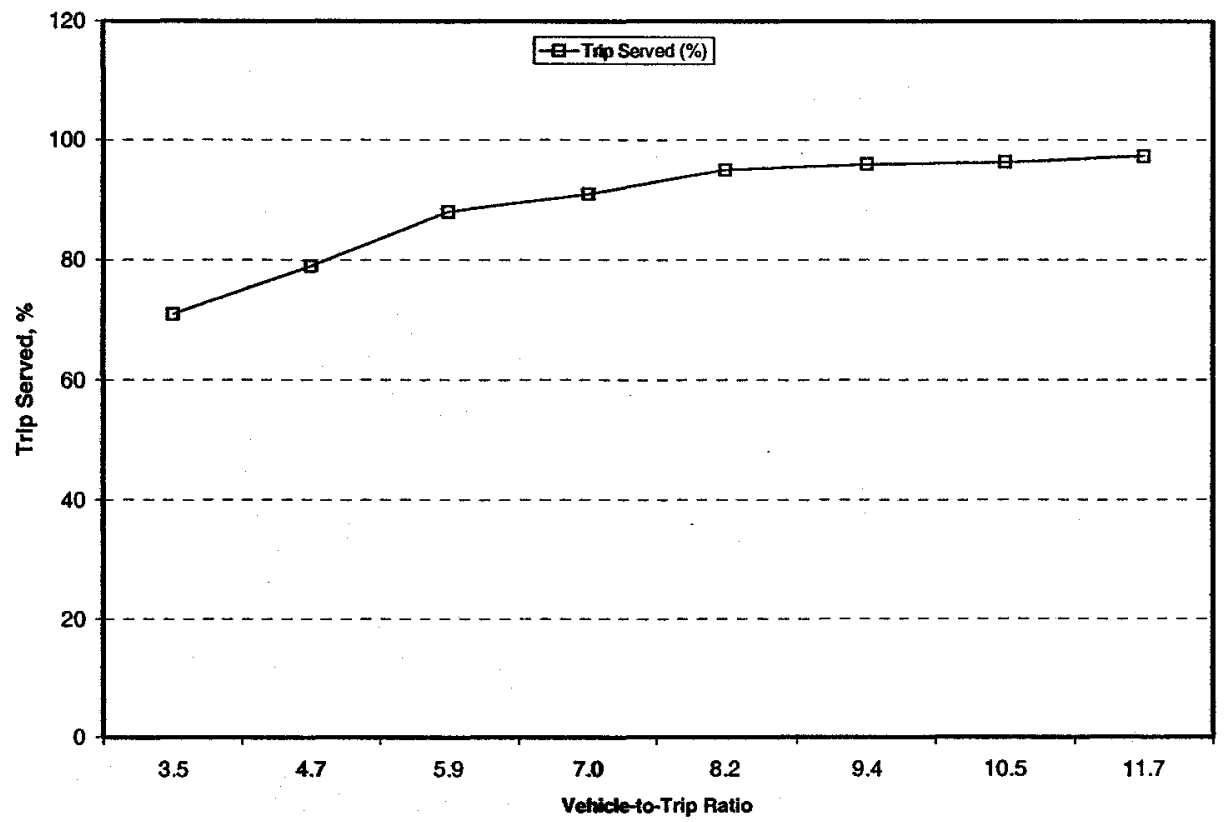

Figure E.12 Total trips served in percent versus vehicle-to-trip ratio relationship 


\section{E.3 Travel Time Sensitivity Analysis of SVS Performance Indicators}

To quantify the effect of longer travel time, three scenarios were tested. These are original or base travel times, 1.9 times the base, and 4.0 times the base travel times. Figures and tables are produced from the model results and given is this section.

Table E.8 Travel time sensitivity of different MOP of SVS

\begin{tabular}{|c|c|c|c|c|c|c|c|c|c|c|}
\hline $\begin{array}{c}\text { Travel } \\
\text { Time }\end{array}$ & $\begin{array}{c}\text { Total } \\
\text { Trips } \\
\text { Served }\end{array}$ & $\begin{array}{c}\% \\
\text { Change } \\
\text { w.r.t } \\
\text { original }\end{array}$ & $\begin{array}{c}\text { Avg. } \\
\text { Service } \\
\text { Time, } \\
\text { min }\end{array}$ & $\begin{array}{c}\% \\
\text { Change } \\
\text { w.r.t } \\
\text { original }\end{array}$ & $\begin{array}{c}\text { Avg. } \\
\text { Wait } \\
\text { Time, } \\
\text { min }\end{array}$ & $\begin{array}{c}\% \\
\text { Change } \\
\text { w.r.t } \\
\text { original }\end{array}$ & $\begin{array}{c}\text { Queue } \\
\text { Length }\end{array}$ & $\begin{array}{c}\% \\
\text { Change } \\
\text { w.r.t } \\
\text { original }\end{array}$ & $\begin{array}{c}\text { Number } \\
\text { of } \\
\text { Relocati } \\
\text { ons }\end{array}$ & $\begin{array}{c}\% \\
\text { Change } \\
\text { w.r.t } \\
\text { original }\end{array}$ \\
\hline Original & 406 & 0 & 10.4 & 0 & 11.3 .6 & 0 & 16.6 & 0 & 31 & 0 \\
\hline $\begin{array}{c}1.9 \\
\text { times }\end{array}$ & 380 & -6.4 & 10.8 & 3.8 & 15.2 & 34.5 & 17.3 & 4.1 & 34 & 9.7 \\
\hline $\begin{array}{c}4.0 \\
\text { times }\end{array}$ & 357 & -12.1 & 11.4 & 9.7 & 22.3 & 97.3 & 19.0 & 14.7 & 46 & 48.4 \\
\hline
\end{tabular}

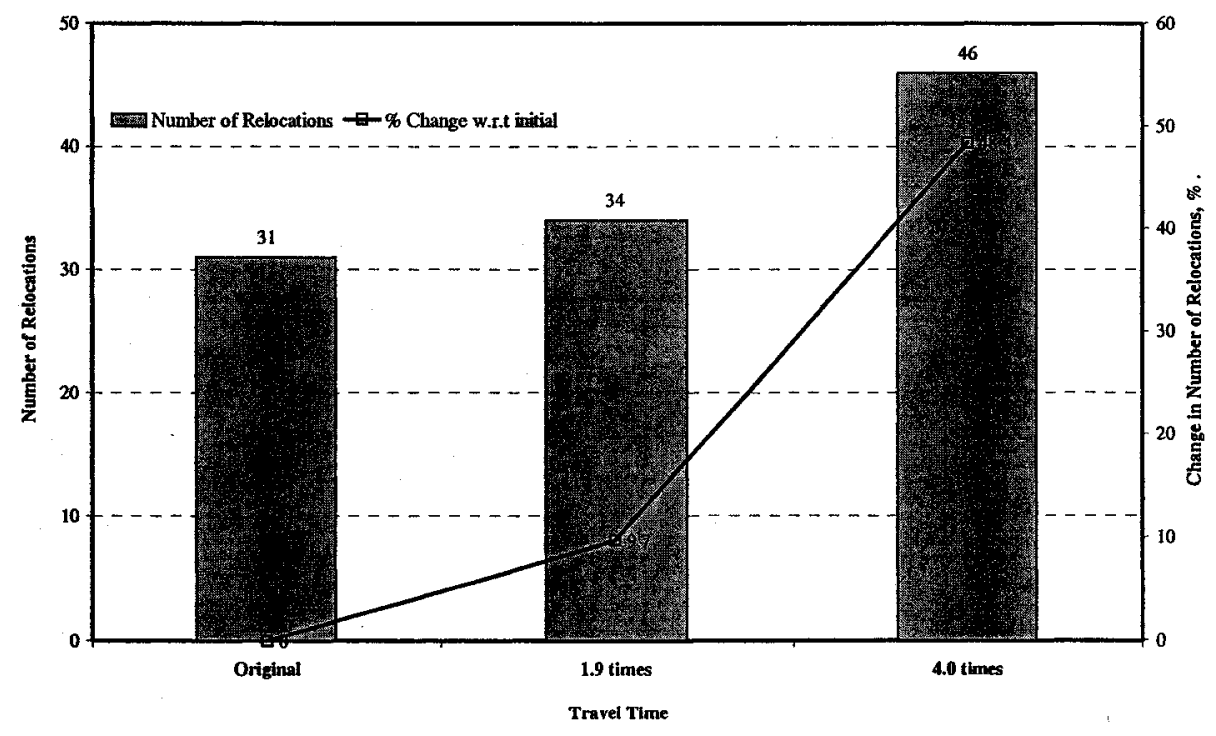

Figure E.13 Customer average wait time and percent of change under different travel time scenarios 


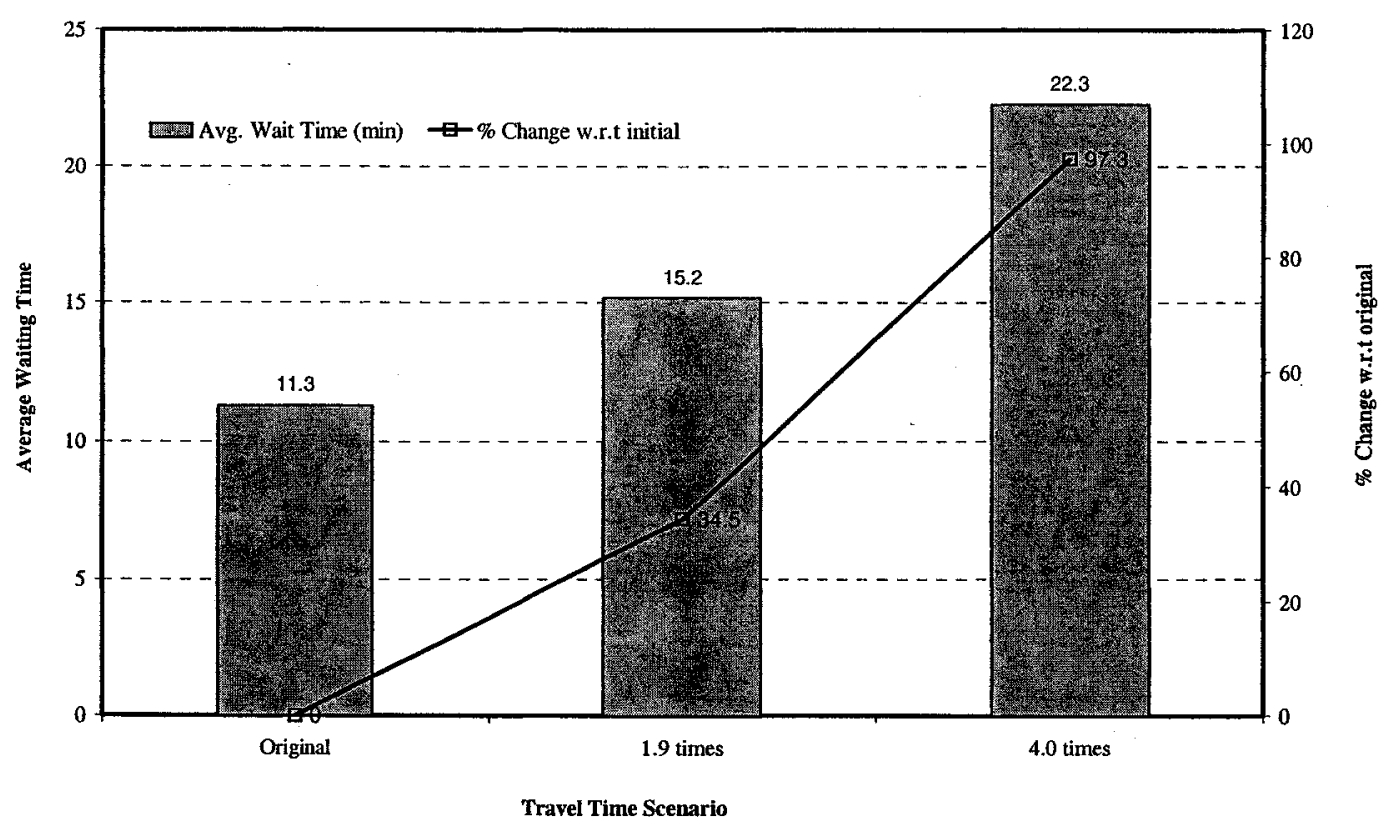

Figure E.14 Number of relocations and percent of change under different travel time scenarios 


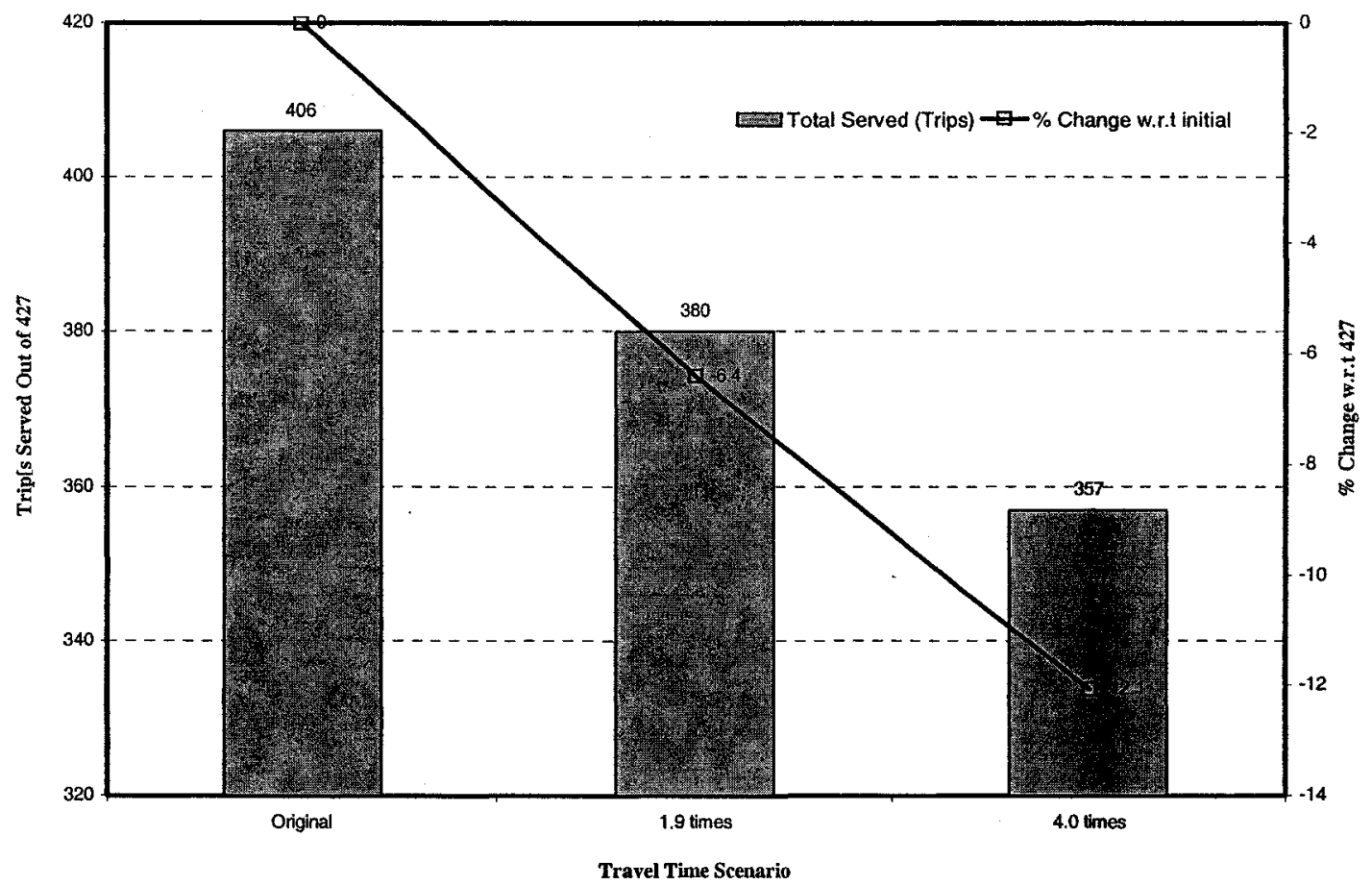

Figure E.15 Total trips served in \% and percent of change under different travel time scenarios

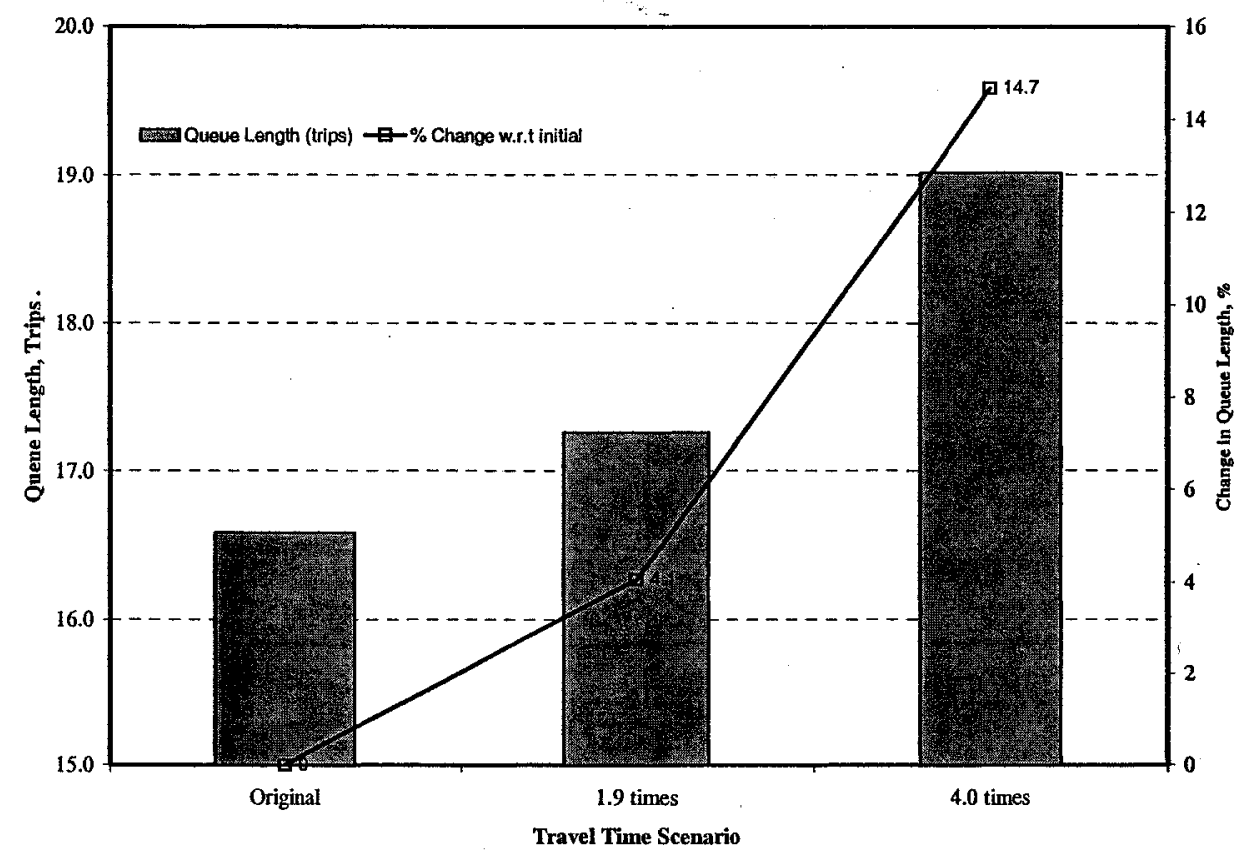

Figure E.16 Queue length and percent of change under different travel time scenarios 


\section{E.4 Variable Number of Stations Scenario}

An analysis was performed to quantify the effect of number of stations on number of relocations needed to keep the customer average wait time within limit and serving the policy demand. The system demand was linearly increased with number of stations within the shared vehicle system (SVS) network. The vehicle-to-trip ratio value of 10.5 percent and parking-tovehicle ratio of 2:1 were used in the system implementation.

Table E.9 Number of relocations as a function of number of stations in the shared vehicle system network

\begin{tabular}{|c|c|}
\hline $\begin{array}{c}\text { Number of Stations in the } \\
\text { SVS Network }\end{array}$ & $\begin{array}{c}\text { Required Number of } \\
\text { Relocations }\end{array}$ \\
\hline 2 & 11 \\
\hline 3 & 19 \\
\hline 4 & 27 \\
\hline 5 & 29 \\
\hline 6 & 39 \\
\hline 7 & 56 \\
\hline 8 & 63 \\
\hline 9 & 74 \\
\hline
\end{tabular}




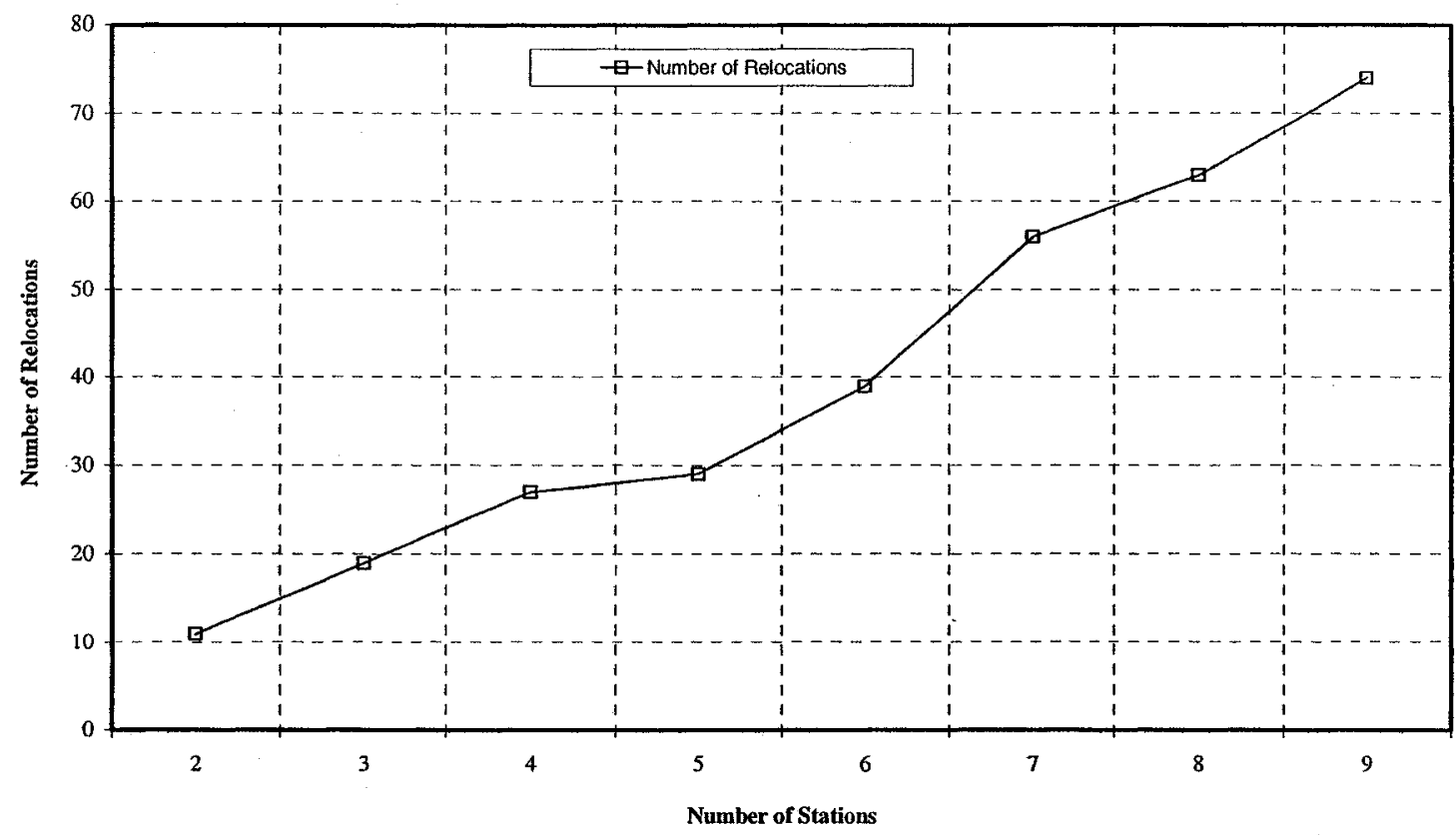

Figure E.17 Number of relocations as a function of number of station in SVS system with linearly increased number of stations and demand at vehicle-to-trip ratio 10.5 percent and parking-to-vehicle ratio 2:1 


\section{E.5 SVS Simulation Model Validation Results}

Validation is an important task in system modelling. Four approaches were used to validate the SVS simulation model. Under Internal Validity Test the system parameters were kept constant and a number of simulation runs were carried out. The results obtained from these runs were analyzed and shown in Figures E18 to E21. 


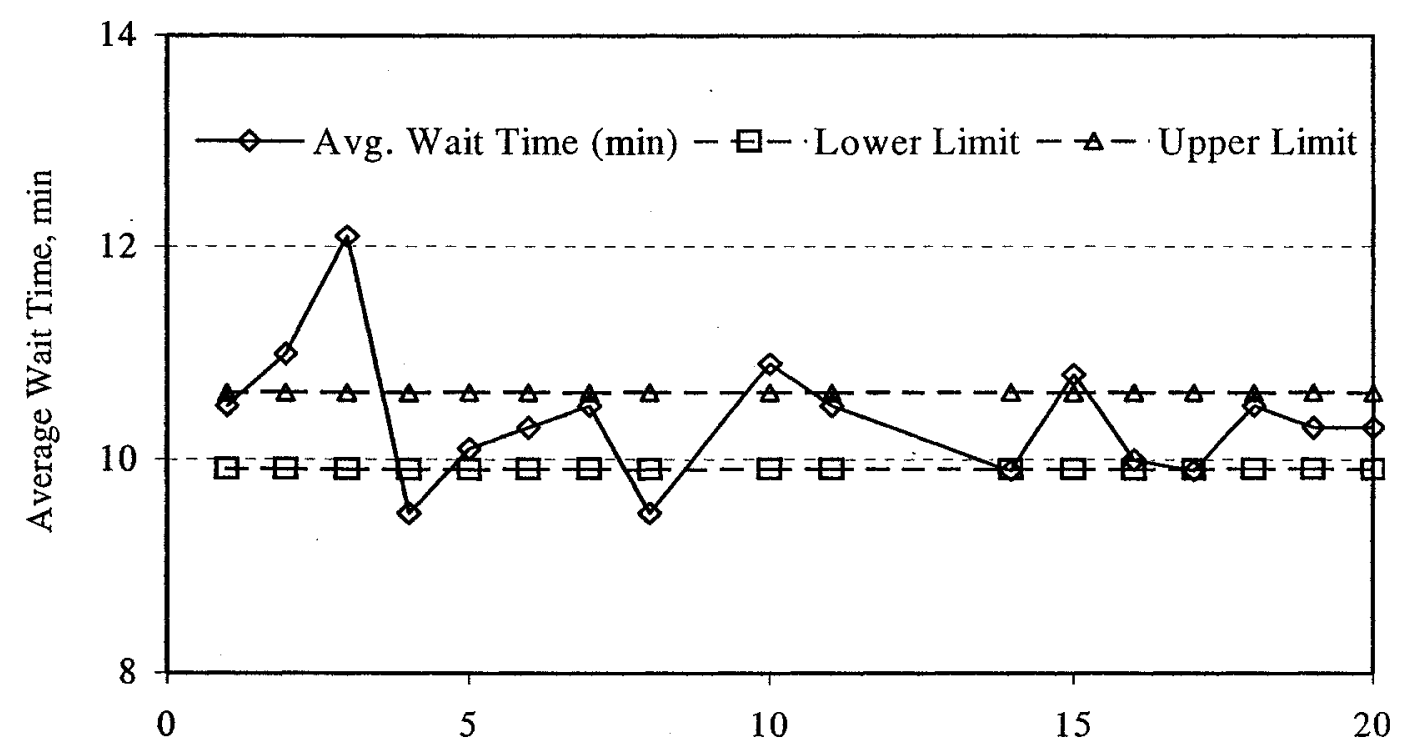

Simulation Run Number

Figure E.18 Customer average wait time and its $95 \%$ C.I. for 20 simulation runs

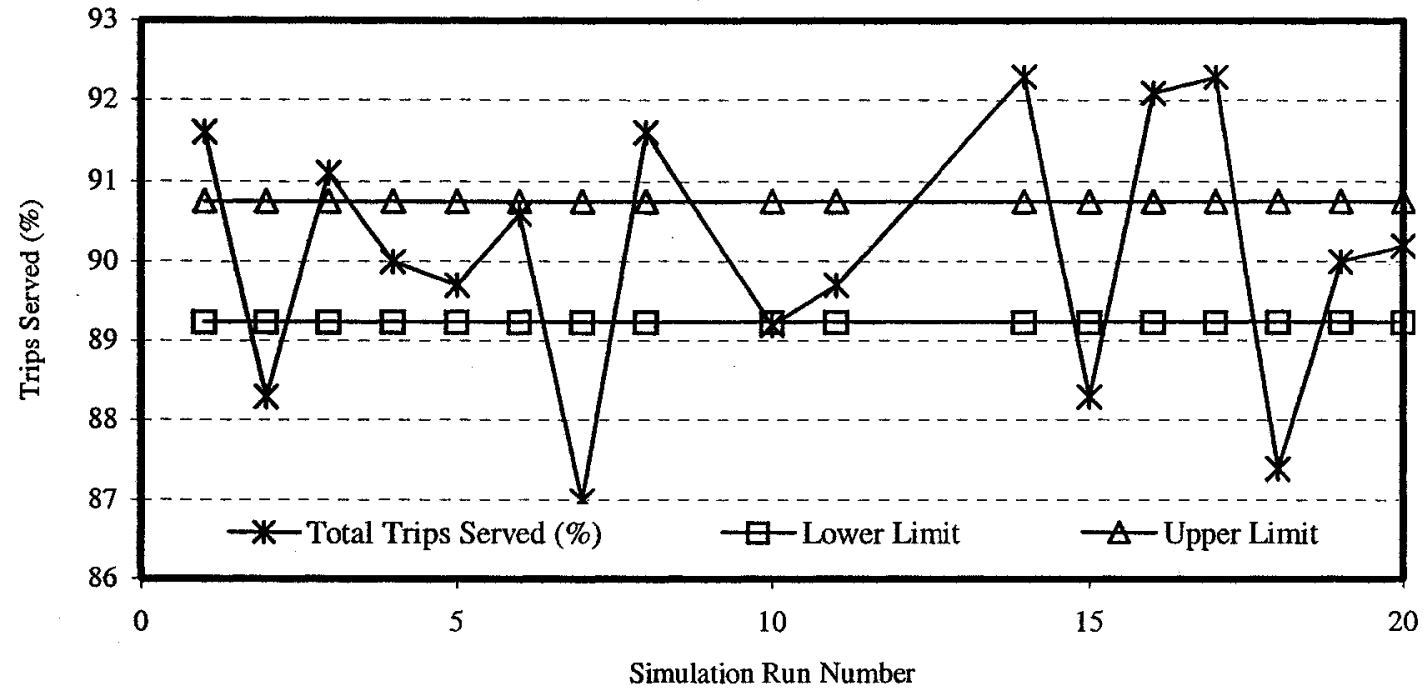

Figure E.19 Number of trips served in percent and its $95 \%$ C.I. for 20 simulation runs 


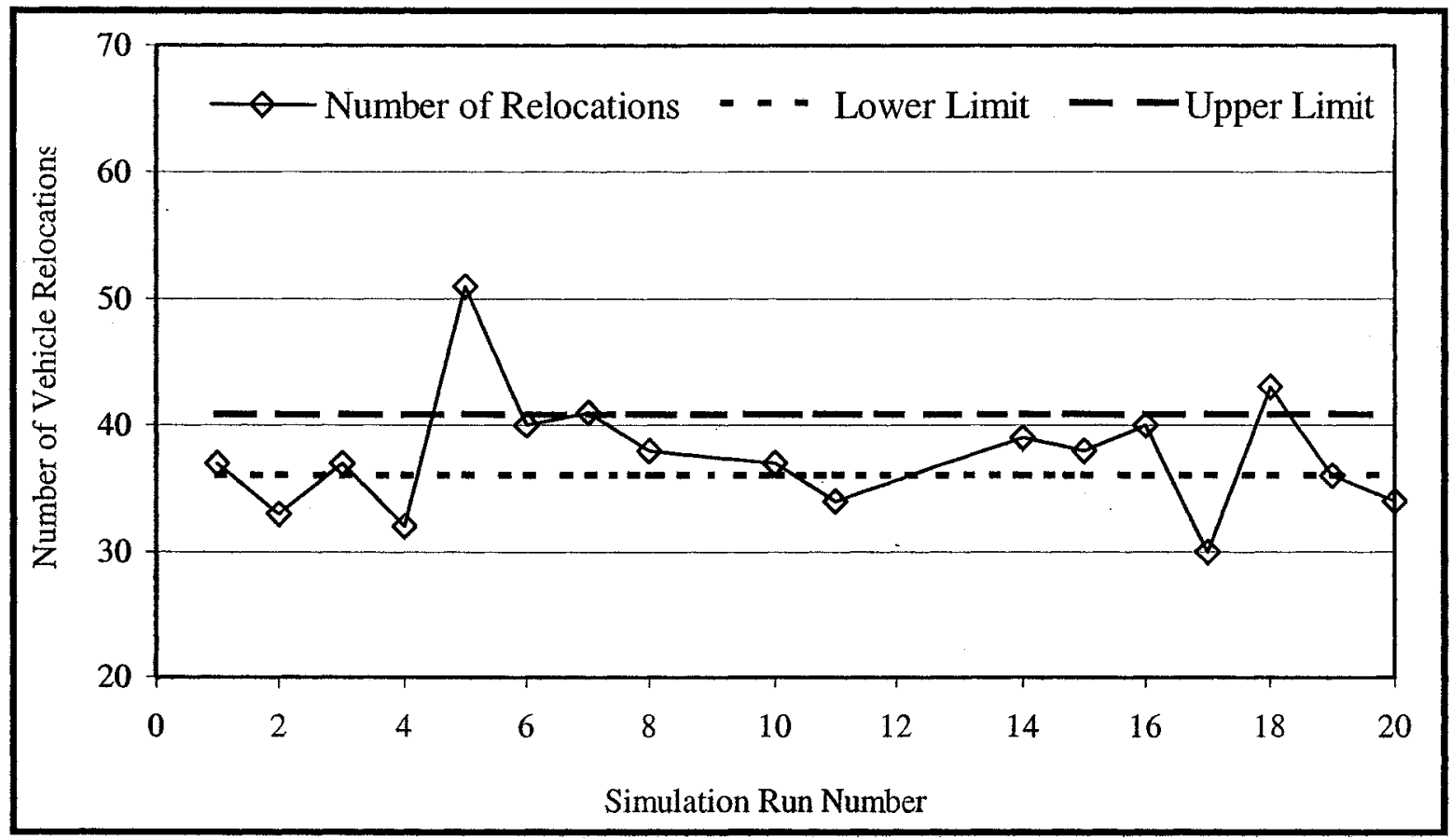

Figure E.20 Number of relocations and its $95 \%$ C.I. for 20 simulation runs

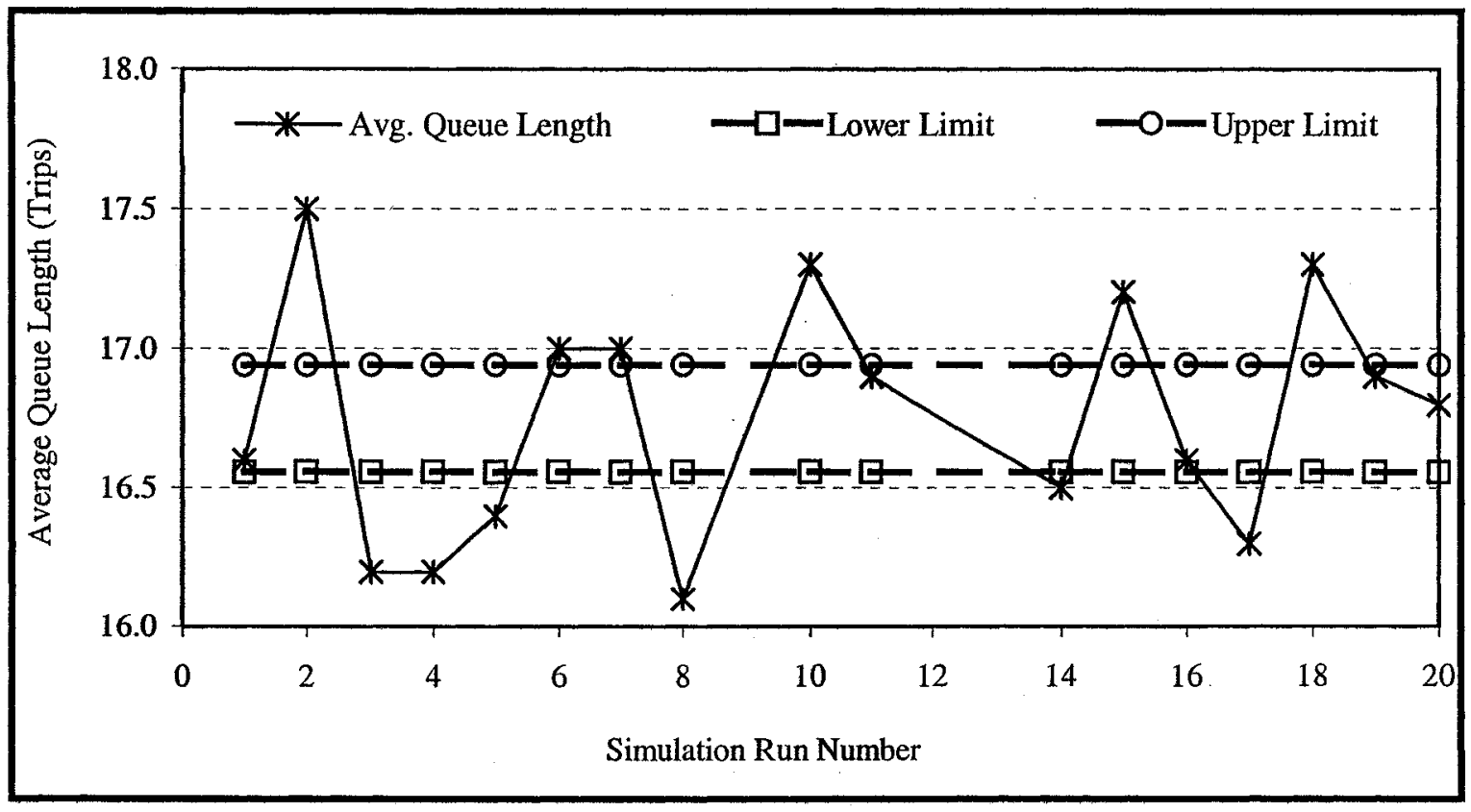

Figure E.21 Average queue length and its 95\% C.I. for 20 simulation runs 